Aus der

Klinik für Innere Medizin, SP Gastroenterologie, Endokrinologie und Stoffwechsel Direktor: Prof. Dr. Thomas M. Gress

des Fachbereichs Medizin der Philipps-Universität Marburg in Zusammenarbeit mit dem Universitätsklinikum Gießen und Marburg GmbH, Standort Marburg

\title{
Expression und Regulation von Typ II \\ transmembranären Serin \\ Proteasen (TTSP) auf humanen intestinalen \\ Epithelzellen
}

\author{
Inaugural-Dissertation \\ zur Erlangung des Doktorgrades der gesamten Humanmedizin \\ dem Fachbereich Medizin der Philipps-Universität Marburg \\ vorgelegt von
}

Marcus Rudi Siebert

aus Kassel

Marburg, 2009 
Angenommen vom Fachbereich Medizin der Philipps-Universität Marburg am 19.11.2009

Gedruckt mit Genehmigung des Fachbereichs

Dekan: Prof. Dr. Matthias Rothmund

Referent: PD Dr. med. Stephan Böhm

Korreferent: Prof. Dr. Achim Aigner 


\section{In Gedenken an Lars}

- September 2009 - 
1.1 Allgemeine Einteilung und Charakterisierung (Serin Proteasen).........................2

1.2 Spezielle Einteilung und Charakterisierung der TTSP........................................

1.3 Gewebeexpression, physiologische und pathophysiologische Funktion...............8

2 Materialien und Methoden ……………………...................................14

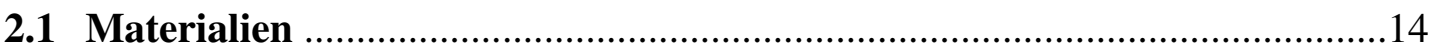

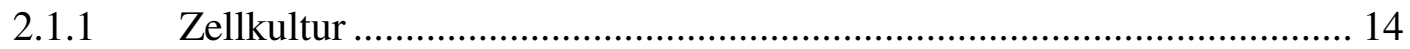

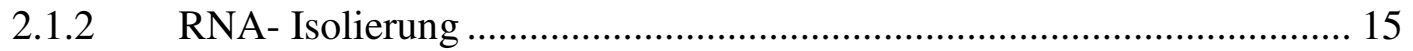

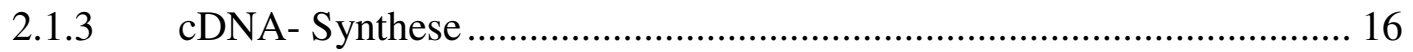

2.1.4 Real-time quantitative PCR (RT-PCR) ........................................... 17

2.1.5 Zytokin-, LPS- und Dexamethason-Experiment ................................. 18

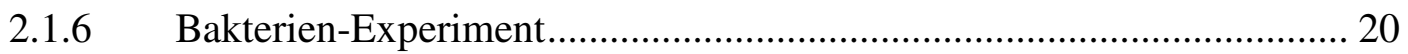

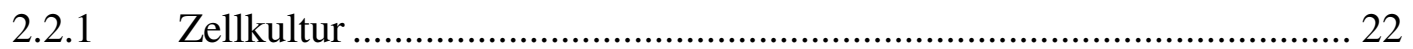

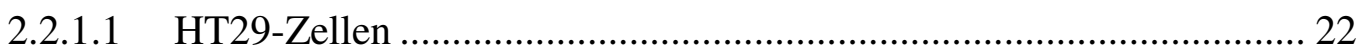

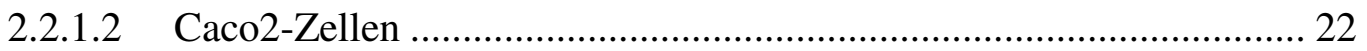

2.2.1.3 Kultivieren der Zellen.................................................................... 23

2.2.1.4 Splitten der Zellen .................................................................... 24

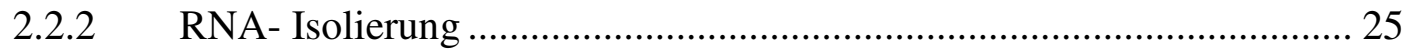

2.2.2.1 RNA - Isolierung aus intestinalen Epithelzellen (IEC) ....................... 25

2.2.2.2 RNA - Isolierung aus humanen gastrointestinalen Geweben ............... 27

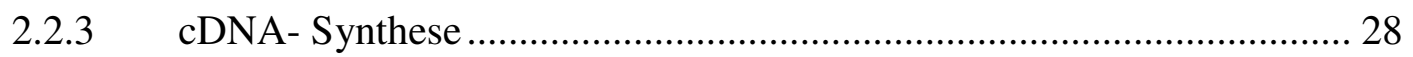

2.2.4 Real-time quantitative PCR (RT-PCR) …........................................ 29

2.2.5 Zytokin-, LPS-, Dexamethason-Experiment ....................................... 36

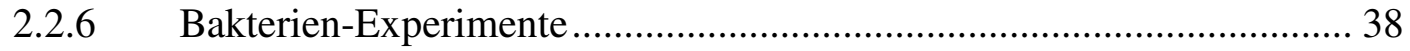

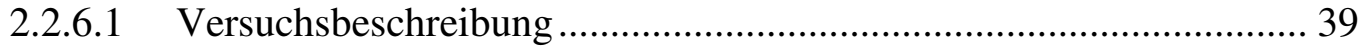




\subsection{Genexpression von Typ II transmembranären Serin Proteasen (TTSP) in} humanen gastrointestinalen Geweben

3.1.1 Statistische Auswertung der Expression der TTSP und PAR-2 nach Lokalisation im humanen GI-Trakt. .46

3.1.2 Textorische Zusammenfassung

3.2 Expression von TTSP in IEC in Abhängigkeit von proinflammatorischen

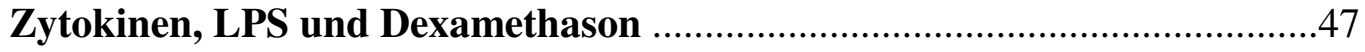

3.2.1 HT29- und Caco2-Zellen mit IFN-gamma......................................... 48

3.2.2 HT29- und Caco2-Zellen mit IL-1beta................................................ 50

3.2.3 HT29- und Caco2-Zellen mit TNF-alpha............................................ 52

3.2.4 HT29- und Caco2-Zellen mit LPS ..................................................... 54

3.2.5 HT29- und Caco2-Zellen mit Dexamethason....................................... 56

3.2.6 HT29- und Caco2-Zellen mit Dexamethason + IL-1beta...................... 58

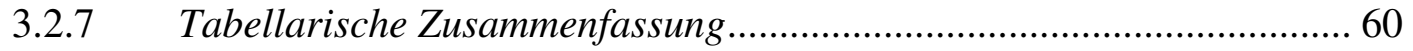

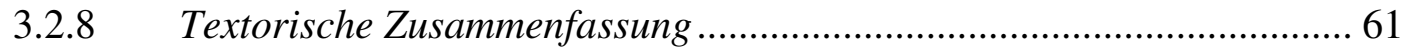

3.3 Expression von TTSP nach bakterieller Infektion intestinaler Epithelzellen

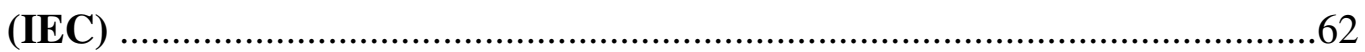

3.3.1 HT29- und Caco2-Zellen mit Enterococcus faecium ............................. 64

3.3.2 HT29- und Caco2-Zellen mit Escherichia coli...................................... 66

3.3.3 HT29- und Caco2-Zellen mit Listeria monocytogenes .......................... 68

3.3.4 HT29- und Caco2-Zellen mit Salmonella typhi ................................... 70

3.3.5 HT29- und Caco2-Zellen mit Yersinia enterocolitica .......................... 72

3.3.6 Tabellarische Zusammenfassung ........................................................ 74

3.3.7 Textorische Zusammenfassung ..................................................... 75

\subsection{Expression von TTSP nach bakterieller Infektion intestinaler Epithelzellen}

(IEC) mit verschiedenen E.coli - Stämmen.............................76

3.4.1 HT29-Zellen mit E. coli (vital, hitzeinaktiviert und Überstand).........79

3.4.2 Textorische Zusammenfassung E. coli mit HT29 .............................. 82

3.4.3 HT29-Zellen mit EHEC (vital, hitzeinaktiviert und Überstand) ............ 83 
3.4.4 Textorische Zusammenfassung EHEC mit HT29

3.4.5 HT29-Zellen mit E. coli Nissle (vital, hitzeinaktiviert und Überstand)

3.4.6 Textorische Zusammenfassung E. coli Nissle mit HT29 ....................... 90

3.4.7 Caco2-Zellen mit E. coli (vital, hitzeinaktiviert und Überstand) ........... 91

3.4.8 Textorische Zusammenfassung E. coli mit Caco2 ….............................. 94

3.4.9 Caco2-Zellen mit EHEC (vital, hitzeinaktiviert und Überstand) ........... 95

3.4.10 Textorische Zusammenfassung EHEC mit Caco2 ................................ 98

3.4.11 Caco2-Zellen mit E. coli Nissle (vital, hitzeinaktiviert und Überstand) 99

3.4.12 Textorische Zusammenfassung E. coli Nissle mit Caco2 .................... 102

3.4.13 Tabellarische Zusammenfassung......................................................103

3.4.14 Gesamtüberblick.......................................................................... 104

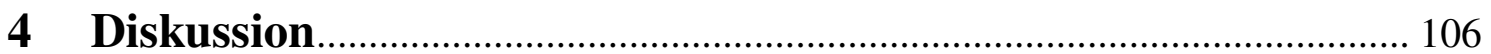

4.1 Genexpression von TTSP in humanen gastrointestinalen Geweben........106

4.2 Expression von TTSP in IEC in Abhängigkeit von proinflammatorischen Zytokinen, LPS und Dexamethason..................................114

\subsection{Expression von TTSP nach bakterieller Infektion intestinaler} Epithelzellen.

\subsection{Expression von TTSP nach bakterieller Infektion intestinaler}

Epithelzellen (IEC) mit verschiedenen E. coli - Stämmen.................127

4.4.1 HT29- und Caco2-Zellen mit E. coli ATCC 25922- Präparationen.....127

4.4.1.1 Zusammenfassung und Diskussion E. coli ATCC 25922 ................ 129

4.4.2 HT29- und Caco2-Zellen mit EHEC - Präparationen .......................... 130

4.4.2.1 Zusammenfassung und Diskussion EHEC .................................... 131

4.4.3 HT29- und Caco2-Zellen mit E. coli Nissle 1917 - Präparationen ...... 133

4.4.3.1 Zusammenfassung und Diskussion E. coli Nissle 1917 .................. 134 
5 Resümee

6 Literaturverzeichnis.

7 Abbildungsverzeichnis.

8 Tabellenverzeichnis .155

9 Verzeichnis der akademischen Lehrer .156

10 Danksagung 158

11 Ehrenwörtliche Erklärung 159 


\section{Einleitung}

Der humane Gastrointestinaltrakt mit seiner immensen Anzahl von Bakterien, Nahrungsbestandteilen, Wasser und Elektrolyten stellt ein komplexes Miniaturökosystem dar. Um dieses diffizile System in einem physiologischen Gleichgewicht $\mathrm{zu}$ halten, ist ein stetiges Interagieren von luminären mit zellulären Strukturen von großer Bedeutung. Dabei bilden intestinale Epithelzellen (IEC) eine erste funktionelle wie auch strukturelle Barriere. Über ihre apikale Membran stehen sie in ununterbrochenem Kontakt mit einer Vielzahl von mikrobiellen Antigenen. Um dieser täglichen Herausforderung gerecht zu werden, haben IEC diverse Mechanismen mit dem Ziel entwickelt, pathogene und apathogene Strukturen zu identifizieren und eine erste Immunantwort einzuleiten. Diese Vielfalt von Rezeptoren beinhalten neben Typ II transmembranäre Serin Proteasen (TTSP) viele andere auf der Oberfläche von IEC, wie Toll-like (TLR) und Nod Rezeptoren, aber auch Proteinase-aktivierter Rezeptor-2 (PAR-2).

TTSP sind eine relativ neue und stetig wachsende Familie von Proteasen, die in einer Vielzahl von humanen Geweben expremiert werden und deren physiologische wie auch pathophysiologische Funktion noch weitgehend ungeklärt ist. Mögliche physiologische Rollen bei diversen zellulären Aktivitäten, wie Hämostase, Wundheilung, Verdauung und Immunantwort werden beschrieben (Netzel-Arnett et al., 2003). Des Weiteren können einige Mitglieder der TTSP PAR-2 aktivieren, woraus sich die Frage nach der daraus möglicherweise folgende physiologische Funktion im Sinne einer Aktivierungskaskade verknüpft (Wilson et al., 2005).

Eine Vielzahl von Studien zeigt, dass TTSP eine eher restriktive Genexpression und Gewebeverteilung in normalen humanen Zellen aufweisen, während es bei Tumorwachstum und Metastasierung $\mathrm{zu}$ einer starken Dysregulation ihrer Genexpression kommt. So ist die proteolytische Aktivität an Zelloberflächen multizellulärer Organismen unter normalen Bedingungen ein wesentlicher Bestandteil biologisch aktiver Proteine. Diese wiederum können eine Vielzahl zellulärer Aktivitäten, wie Immunantwort, Zell-Zell-Interaktionen, Signaltransduktion, kontrolliertes Wachstum und Apoptose vermitteln. Wird dieses System zum Beispiel durch Mutationen, Toxine oder Alterungsprozesse gestört, benutzen insbesondere maligne Zellen das große Spektrum proteolytischer Aktivitäten um unkontrolliert Infiltration, Wachstum und Überleben des Tumors zu erreichen. 
Dies wird belegt dadurch, dass für einige Mitglieder der TTSP eine deutliche Überexpression in Kolorektalen-, Mamma-, Prostata- und Ovarialkarzinomen gefunden wurde (Szabo et al., 2003). Ihre ureigenste Funktion als Protease scheint dabei von grundlegender Bedeutung zu sein, denn dysregulierte perizelluläre Proteolyse ist ein wesentliches Kennzeichen von malignen Tumoren. Damit könnten die TTSP von großem Interesse in der weiteren Tumorforschung und Entwicklung von Tumormarkern sein, aber auch $\mathrm{zu}$ einem besseren Verständnis von physiologischen und pathophysiologischen Vorgängen beitragen.

In den letzten Jahren ist die Zahl der Veröffentlichungen über die Identifikation neuer Proteasen stark gestiegen. Dies begründet sich zum einen in der nun vollständigen Verfügbarkeit und damit noch intensiveren Nutzung der Genomsequenzen von Mensch und Maus, zum anderen in der kontinuierlichen Verbesserung der molekulargenetischen Materialien und Nachweismethoden. So werden immer mehr Mitglieder einer großen neuen Familie von membran-verankerten Serin Proteasen, den Typ II transmembranären Serin Proteasen (TTSP) beschrieben, von denen einige bedeutende Rollen sowohl in der physiologischen Organentwicklung als auch in der Tumorprogression zeigen.

Zurzeit sind 20 humane TTSP bekannt [Szabo, Bugge, 2008]. Ihre Funktion in physiologischen und pathophysiologischen Prozessen ist nach wie vor nur unzureichend erforscht und verstanden. Daraus ergeben sich zahlreiche offene Fragen, die durch intensive Forschung in den kommenden Jahren zu beantworten sein werden.

\subsection{Allgemeine Einteilung und Charakterisierung (Serin Proteasen)}

Als Mitglieder der Serin Protease-Familie sind die der Chymotrypsine (S1), der MatrixMetalloproteinasen (MMP), der ADAMS und ADAMTS zu nennen (Birkedal-Hansen, 1993; Hooper, 2001; Tang, 2001). Dabei sind die meisten der gut charakterisierten Mitglieder der S1 Familie (Chymotrypsine) sekretorische oder intrazellulär gespeicherte Enzyme, die nach Signalinduktion freigegeben werden. Gegenüber dieser klassischen Familie stellen die membran-verankerten Serin Proteasen (SP) nun eine völlig neue Gruppe dar. Sie sind mit einer transmembranären Domäne in der Plasmamembran verankert und weichen somit von der traditionellen Struktur und Funktion der S1 Familie deutlich ab.

Membran-verankerte Serin Proteasen bestehen aus einer intrazellulären (zytoplasmatischen), einer transmembranären oder membran-verankerten und einer 
extrazellulären Domäne. Diese extrazelluläre Domäne beinhaltet als wesentliche Struktur eine bei allen membran-verankerten Serin Proteasen sehr ähnlich aufgebaute Serin Protease Domäne (siehe auch Abb. 1.1). Neben dieser Protease Domäne enthält die extrazelluläre Domäne noch eine deutlich variablere Stammregion mit einer Vielzahl von weiteren Proteindomänen, deren Funktion sehr wahrscheinlich in multiplen regulatorischen Interaktionen mit extrazellulärer Matrix liegt (Szabo et al, 2003).

\section{Matriptase subfamily}

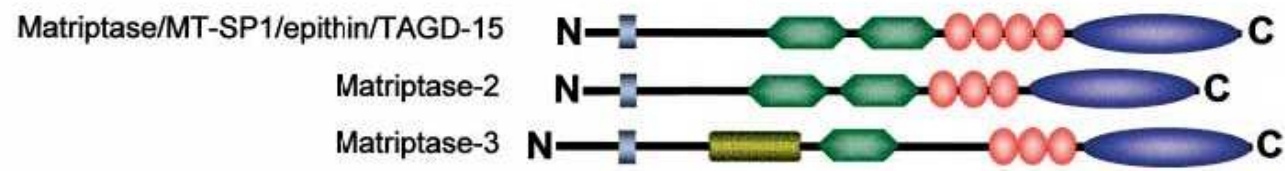

\section{Corin subfamily}

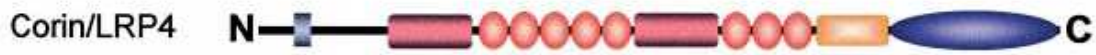

Abb. 1.1 Schematischer Aufbau der Matriptase- und Corin-Subfamilie (Szabo et al., 2003)

Um eine bessere Übersicht zu erhalten, kann man die membran-verankerten SP in zwei bzw. drei Klassen unterteilen. Die sog. Typ I-Serin Protease ist durch eine carboxyterminale transmembranäre Domäne definiert. Die zweite Klasse zeigt eine glycosylphosphatidylinositol Verbindung (sog. GPI-anchored) mit der Plasmamembran. Typ II transmembranäre Serin Proteasen (TTSP) besitzen dagegen eine amino-terminale transmembranäre Domäne, der eine zytoplasmatische Domäne variabler Aminosäurenlänge folgt (Netzel-Arnett, 2003).

In den weiteren Ausführungen möchte ich mich nun ausschließlich der Klasse der Typ II transmembranäre Serin Proteasen zuwenden. Wie bereits oben erwähnt, gibt es derzeit 20 in der Literatur beschriebene TTSP, von denen ich fünf in meiner Arbeit 
untersucht habe und hier eingehend beschreiben werde. Die Auswahl der nachfolgend genannten fünf TTSP begründet sich unter anderem in ihrem Expressionsmuster. So konnte in bisherigen Veröffentlichungen ihre Genexpression unter anderem in Geweben des humanen Gastrointestinaltrakts beschrieben werden. Folgende Typ II transmembranäre Serin Proteasen sind deshalb Gegenstand dieser Arbeit:

1. MTSP-1 (oder auch Matriptase)

2. Hepsin (oder auch TMPRSS-1)

3. TMPRSS-2

4. TMPRSS-4

5. Enterokinase (zu einem kleineren Anteil)

Die restlichen fünfzehn TTSP sind:

- Matriptase-2 und -3

- Corin

- TMPRSS-3, TMPRSS-5/Spinesin

- Polyserase-1

- DESC-1, -2, -3, -4

- HAT, HATL-3, $-4,-5$

- MSPL

\subsection{Spezielle Einteilung und Charakterisierung der TTSP}

Die 20 erwähnten Typ II transmembranären Serin Proteasen können für ein besseres Verständnis in vier Subfamilien unterteilt werden. Diese Unterteilung basiert auf phylogenetischen Analysen der Serin Proteasen Domäne, der Zusammensetzung der Stammregion und der chromosomalen Lokalisation der Gene (siehe folgende Abb. 1.2). 


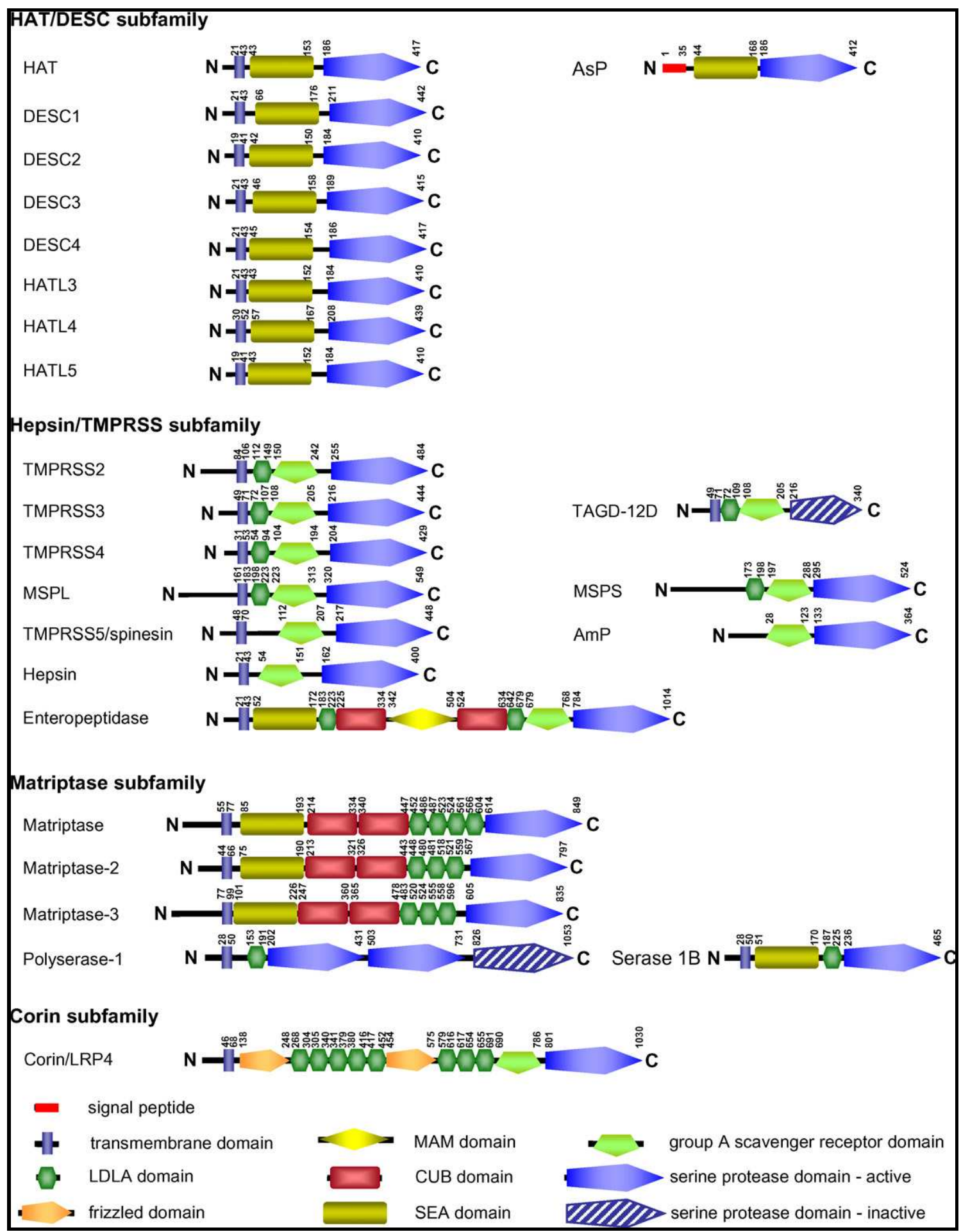

Abb. 1.2 Schematische Proteinstruktur der 20 bekannten humanen TTSP (Szabo, Bugge, 2008)

In der ersten Subfamilie gibt es acht Mitglieder: HAT, DESC-1, DESC-2, DESC-3, DESC-4 sowie HATL3, HATL4 und HATL5. Sie weisen starke Ähnlichkeiten in ihrer Serin Proteasen Domäne auf und besitzen bis auf DESC-3 alle eine SEA Domäne in 
ihrer Stammregion. Alle Mitglieder sind auf Chromosom 4 lokalisiert, was eine gemeinsame Herkunft wahrscheinlich macht (Szabo et al., 2003).

Zur zweiten (Hepsin/TMPRSS-Subfamilie) gehören: TMPRSS-2 und -4, Hepsin und Enterokinase (des weiteren TMPRSS-3, Spinesin(=TMPRSS-5) und MSPL).

TMPRSS-2 und TMPRSS-4 zeigen große Ähnlichkeit in ihrer Grundstruktur. Beide besitzen als extrazellulären Baustein eine Serin Protease Domäne, in ihrer Stammregion einen Gruppe A scavenger Rezeptorbereich und eine LDL Klasse A Rezeptor Domäne. Der transmembranäre Bereich ist bei beiden gleich. Sie unterscheiden sich lediglich in der Länge ihrer intrazellulären Aminosäuresequenz und damit auch gering in ihrer Gesamtgröße (TMPRSS-2: 43.8 kb, TMPRSS-4: $41.4 \mathrm{~kb}$ ). Erstaunlicherweise sind diese so ähnlichen Serin Proteasen auf zwei ganz unterschiedlichen Genen lokalisiert. TMPRSS-2 findet sich auf Chromosom 21q22.3 (Paoloni-Giacobino et al., 1997), dagegen TMPRSS-4 auf Chromosom 11q23.3 (Netzel-Arnett et al., 2003).

LDL-Rezeptor Klassse A Domänen sind die am zweithäufigsten zu findenden Domänen unter den TTSP (am häufigsten: SEA Domänen). Während TMPRSS-2 und -4 nur einen LDL-Bereich beinhalten, weist Corin nicht weniger als acht dieser Domänen auf. Der Gruppe A scavenger Rezeptorbereich befindet sich in acht TTSP. Seine Funktion liegt wahrscheinlich in der Modifizierung von Bindungen polyanionischer Moleküle wie modifizierten Lipoproteine, Lipiden der Zelloberflächen und einigen sulfatierten Polysacchariden (Hooper et al., 2001; Yun Kim et al., 2002).

Hepsin, als ein weiteres Mitglied der zweiten Subfamilie, zeigt sich im strukturellen Aufbau dem der beiden TMPRSS sehr ähnlich. So ist es ebenfalls extrazellulär aus einer Serin Protease Domäne und einem Gruppe A scavenger Rezeptorbereich aufgebaut. Ihm fehlt jedoch die LDL-Rezeptor Klassse A Domäne, während transmembranärer und intrazellulärer Bereich wieder Ähnlichkeiten zeigen. Hepsin ist mit einer Größe von $26.3 \mathrm{~kb}$ deutlich kleiner als die bereits beschriebenen TMPRSS. Hepsin ist auf Chromosom 19q13.1 lokalisiert (Tsuji et al., 1991).

Enterokinase (oder auch Enteropeptidase) gehört ebenfalls in die zweite Subfamilie. Diese Serin Protease zeigt, verglichen mit den anderen Proteasen dieser Subfamilie, einige Besonderheiten in Aufbau und Struktur. Die einzige Gemeinsamkeit besteht extrazellulär in einer Serin Protease Domäne und einem Gruppe A scavenger 
Rezeptorbereich. Die weitere Stammregion gliedert sich zusätzlich in zwei LDL-

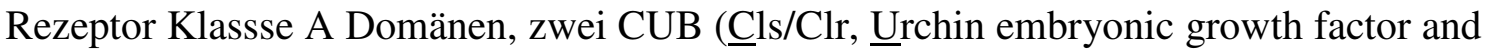

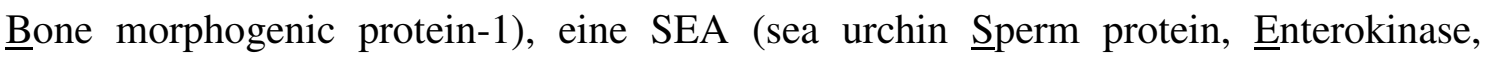
$\underline{\text { Agrin) }}$ sowie eine MAM (Memprin, $\underline{\mathrm{A} 5}$ antigen, and receptor protein phosphatase $\underline{\mu})$ Domäne. CUB Domänen findet man auch in Matriptase/MTSP-1, Matriptase-2 und -3. Diese Domänen sind in Subkomponenten von Komplementfaktoren sowie in vielen Proteinen, welche bedeutend für die Zellentwicklung sind, vohanden (Bork, Beckmann, 1993). SEA Domänen finden sich des Weiteren in HAT und DESC-2 und werden vor allem in kohlehydratreicher Umgebung nachgewiesen (Bork, Patthy, 1995). Eine MAM Domäne kommt bei den TTSP ausschließlich bei der Enterokinase vor und vermittelt wahrscheinlich Adhäsionsvorgänge mit verschiedensten Proteinen (Beckmann, Bork, 1993). Enterokinase ist mit einer Größe von $134.3 \mathrm{~kb}$ mit Abstand die zweitgrößte membranständige SP (hinter Corin mit einer Größe von $243.4 \mathrm{~kb}$ ). Sie ist auf Chromosom 21q21 lokalisiert und die am längsten bekannte und damit auch am Besten untersuchte TTSP, dies nicht zuletzt wegen ihrer fundamentalen Funktion im Verdauungstrakt (Louvard et al., 1975). Hier aktiviert sie pankreatisches Trypsinogen zu Trypsin. Enterokinase konnte 1994 als erste der TTSP in ihrer Struktur beschrieben und daraufhin molekulartechnisch geklont werden (Kitamoto et al., 1994, 1995).

Der dritten Subfamilie gehören die Matriptasen an. Matriptase/MTSP-1, Matriptase-2, Matriptase-3 und Polyserase-1 sind hier als Mitglieder zu nennen.

MTSP-1 besteht in seiner extrazellulären Struktur aus einer Serin Proteasen Domäne, vier LDL-Rezeptor Klasse A Domänen und zwei CUB Bereichen (siehe oben). Interessanterweise beinhaltet MTSP-1 von Mensch und Maus in der ersten CUB Domäne ein konserviertes RGD integrin-bindendes Motiv. Dieses Motiv dient vermutlich zur integrin-vermittelten Zelloberflächenbindung und konnte membrangebunden auf Nierenzellen der Affenzelllinie COS als eine verkürzte Form von humanem MTSP-1 nachgewiesen werden (Takeuchi et al., 2000).

MTSP-1 ist auf Chromosom 11q25 lokalisiert und besitzt eine Größe von 50.5 kb (Lin et al., 1999).

Als vierte und damit letzte Subfamilie der TTSP ist die der Corin Subfamilie mit Corin als alleinigem Mitglied zu nennen. Corin ist einzigartig unter den TTSP. Seine Serin Protease Domäne ist eher vergleichbar mit einigen sekretorischen Typ I 
transmembranären und glycosylphosphatidylinositol-verankerten Serin Proteasen der Chymotrypsin (S1) Gemeinde als mit denen der TTSP. Dies könnte bedeuten, dass die Familie der TTSP vermutlich aus zwei Urgenen mit konvergenter Evolution entstanden ist. Corin weist mit acht LDL-A Domänen die meisten unter den TTSP auf. Des Weiteren beinhaltet Corin als einzigste TTSP sogenannte „frizzled“ Domänen und ist mit einer Größe von $243.4 \mathrm{~kb}$ die mit Abstand größte TTSP. Sie ist auf Chromosom 4p12-13 lokalisiert (Netzel-Arnett et al., 2003).

\subsection{Gewebeexpression, physiologische und pathophysiologische Funktion}

TTSP sind eine relativ neue, stark expandierende Protease-Familie mit einem sehr breiten Verteilungsmuster in diversen menschlichen Geweben und einer Vielzahl von physiologischen und pathophysiologischen Funktionen, die zu einem Großteil noch unverstanden sind. Die folgende Zusammenfassung basiert auf der aktuellen wissenschaftlichen Datenlage und bezieht sich insbesondere auf die fünf membranständigen Serin Proteasen, deren Daten im Hauptteil zu sehen sind.

TMPRSS-2 ist in humanen Geweben vor allem in der Prostata, aber auch im Magen, in Nieren und Speicheldrüsen exprimiert (Lin, Ferguson et al., 1999). Des Weiteren kommt TMPRSS-2 in humanen Epithelzellen der Luftwege (Donaldson et al., 2002), in Mukosazellen im Kolon und in humanen Endothelzellen im mikrovaskulären Gefäßsystem vor (Aimes et al., 2003). Bei der Expression von TMPRSS-2 in Tumorzellen zeigt sich vor allem in Prostata-Karzinomgeweben eine signifikant erhöhte Genexpression verglichen mit benignen Prostatahyperplasie-Gewebeproben (Vaarala et al., 2001). Des Weiteren zeigen immunhistochemische Analysen von humanen Gewebeproben eine deutlich höhere Expression von TMPRSS-2 auf der apikalen Seite von normalen wie auch Karzinomgewebeproben sekretorischer Prostataepithelzellen (Afar et al., 2001). Androgene haben einen entscheidenden Einfluß auf die Genexpression von TMPRSS-2. So führt eine Androgen-Suppression zu einer signifikanten Erniedrigung der Expression von TMPRSS-2 in benignen Prostatageweben. In der gleichen Studie wird über eine Korrelation bei Inaktivierung der Serin Protease Domäne durch eine Mutation von TMPRSS-2 mit äußerst aggressivem Verhalten des Prostatakarzinoms berichtet (Vaarala et al., 2001). Weiterhin 
wird eine lösliche Form von TMPRSS-2 bei Prostata-Karzinomzellen beschrieben, welche durch einen autokatalytischen Prozess freigesetzt werden (Afar et al., 2001). Interessant ist hierzu die weitergehende Forschung bezüglich eines möglichen Serummarkers für das Prostatakarzinom. In einer aktuelleren Studie konnte gezeigt werden, dass TMPRSS-2 in malignen Prostatageweben den G Protein-gekoppelten Rezeptor PAR-2 aktiviert und vermutlich zu einer Metastasierung des Tumors beiträgt (Wilson et al., 2005).

Über die physiologische Funktion von TMPRSS-2 ist nur sehr wenig bekannt. So kann TMPRSS-2, wie auch TMPRSS-3/ und -4 sowie MTSP-1 (siehe unten), in vitro epitheliale Natriumkanäle $(\mathrm{ENaC})$ regulieren und somit vermutlich zur epithelialen Natriumhomöostase beitragen (Donaldson et al., 2002).

Die Datenlage für TMPRSS-4 ist äußerst spärlich. Zu seiner physiologischen Expression in humanen Geweben gibt es nur wenige Angaben. So konnte TMPRSS-4 insbesondere wegen seiner ausgeprägten Überexprimierung in Pankreastumoren nachgewiesen werden. In einem Pankreastumor-Modell zeigt sich jedoch weder in vitro noch in vivo durch rekombinantes TMPRSS-4 eine eindeutige Reaktion bezüglich der Invasivität und Tumorprogression (Wallrapp et al., 2000). Eine geringe Genexpression der transmembranären Serin Protease war in Geweben des Gastrointestinal- und Urogenitaltrakts nachzuweisen (Hooper et al., 2001). Des Weiteren kann TMPRSS-4 in malignen Schilddrüsenneoplasien nachgewiesen werden. So zeigt sich in dieser Studie die Erhöhung der Genexpression in malignen versus benignen Neoplasien signifikant erhöht und wird als unabhängiger Prediktor für maligne Schilddrüsenneoplasien postuliert (Kebebew et al., 2005). Auch hier stellt sich die Frage in der weiteren Forschung nach einer möglichen Rolle als effizienter Tumormarker bei durchgeführter Feinnadelbiopsie in Schilddrüsenneoplasien. Bezüglich der physiologischen Funktion von TMPRSS-4 finden sich lediglich mehrere Studien mit Hinweisen auf eine Beteiligung an der Aktivierung von epithelialen Natriumkanälen $(\mathrm{ENaC})$ in vitro und damit einer möglichen Rolle an der Regulierung des Blutdrucks (Adachi et al., 2001; Donaldson et al., 2002). Weitere physiologische Funktionen von TMPRSS-4 sind unbekannt.

$\mathrm{Zu}$ Hepsin gibt es über die normale Expression in humanen Geweben kaum Angaben. Ursprünglich wurde die Expression von Hepsin in Leberkarzinom-Zelllinien gefunden, 
später dann auch bei Nierentumoren (Leytus et al., 1988; Zacharski et al., 1998). Ebenso zeigt sich Hepsin stark exprimiert in fetalem wie auch adultem Lebergewebe (Leytus et al., 1988). Bei malignen Neoplasien wird eine deutlich erhöhte Genexpression in Ovarialtumoren (Tanimoto et al., 1997) und vor allem Prostatatumoren (Luo et al., 2001; Magee et al., 2001; Welsh et al., 2001) beschrieben. Neuere Veröffentlichungen berichten über eine mit der Überexpression von Hepsin in Prostatatumorzellen verbundenen Disorganisation der Basalmembran, was eine deutliche Tumorprogression und Metastasierung in Leber, Lunge und Knochen unterstützt (Klezovitch et al., 2004). In Analogie dazu zeigt sich in einer weiteren Studie, dass eine hohe Genexpression von Hepsin in Prostatakarzinomzellen mit einer deutlich schlechteren Patientenprognose korreliert (Dhanasekaran et al., 2001). Des Weiteren wird Hepsin mit drei anderen Biomarkern ein sehr effektiver Nutzen bezüglich der molekularen Diagnose von Prostatatumoren bescheinigt (Landers et al., 2005).

Die physiologische Funktion von Hepsin in vivo ist nach wie vor nur unzureichend beschrieben. So wird über eine mögliche Rolle in Wachstum und Entwicklung insbesondere bei Säugetierzellen berichtet (Torres-Rosado et al., 1993). In einer aktuellen Studie konnte in einem Mausmodel die Notwendigkeit für Hepsin bezüglich der Entwicklung und Funktion des Hörorgans beschrieben werden [Guipponi et al., 2007]. In vitro Experimente mit rekombinantem humanem Hepsin zeigen eine ausgeprägte Aktivierung des Gerinnungsfaktors VII (Kazama et al., 1995). Des Weiteren führt in Zellkulturstudien die Reduktion der Hepsin-Level durch Antikörper oder antisense Oligonukleotiden $\mathrm{zu}$ einer Veränderung der Morphologie von Lebertumorzellen und verminderten Proliferation. Das lässt für Hepsin eine direkte Beteiligung am Zellwachstum vermuten ( $\mathrm{Vu}$ et al., 1997). Interessanterweise veranschaulichen aber Ergebnisse von zwei verschiedenen Forschungsgruppen, dass Hepsin-defiziente Mäuse keinerlei Abnormalitäten aufweisen, sie zeigen weder Defekte in Hämostase, Leberfunktion noch in Leberregeneration. Sie sind lebensfähig und fruchtbar und besitzen ein normales Wachstum (Wu et al., 1998; Yu et al., 2000). Somit bleibt die Rolle von Hepsin in vivo unklar.

Für Enterokinase, als letztes Mitglied der Hepsin/TMPRSS Subfamilie, wird eine physiologische Genexpression in humanen Geweben lediglich für Darmepithelzellen im proximalen Dünndarm beschrieben (Rutgeerts, Eggermont, 1976). Dies korreliert auch mit den Ergebnissen dieser Arbeit (siehe unten). Enterokinase ist eine der 
bestuntersuchtesten TTSP. Es reguliert die enzymatische Verdauungskaskade im humanen Intestinuum durch Aktivierung von Trypsinogen zu Trypsin, das wiederum die Möglichkeit besitzt, weitere Enzyme wie Chymotrypsinogen, Proelastase, Prolipase und Procarboxypeptidase zu aktivieren (Kitamoto et al., 1995; Zamolodchikova et al., 2000). Interessant ist auch der Hinweis auf die Beteiligung von Enterokinase an einer trypsin-vermittelten Aktivierung von Proteinase-aktiviertem Rezeptor 2 (PAR-2) auf der Zelloberfläche von Darmepithelzellen (Böhm et al., 1996,1998). Ein angeborener Enterokinase-Mangel führt $\mathrm{zu}$ chronischer Diarrhoe, generalisierten Ödemen und Entwicklungsstörungen bei Kleinkindern (Szabo et al., 2003). Ein duodenopankreatischer Reflux von löslicher Enterokinase führt zur Aktivierung von Trypsinogen und damit zu einer Assoziation mit chronischer Pankreatitis (Mann, Mann, 1994). Dabei bleibt der genaue Mechanismus des Abtrennens der Enterokinase von der Zellmembran unklar (Fonseca, Light, 1983).

MTSP-1 ist die erste der aus insgesamt vier Mitgliedern bestehenden Matriptase Subfamilie. Sie ist neben Enterokinase eine der bestuntersuchtesten TTSP, was sich auch in einer größeren Anzahl von Veröffentlichungen wiederspiegelt. Die physiologische Expression von MTSP-1 findet sich im Gastrointestinaltrakt, Respirationstrakt, Urogenitaltrakt, in der Epidermis, im Thymus, in isolierten GewebeImmunzellen, ZNS-Purkinjezellen, Neuronen der Grauen und Weißen Substanz, Rückenmarkneuronen, Monozyten und Granulozyten (Satomi et al., 2001; Oberst et al., 2001). MTSP-1 zeigt auch in diversen epithelialen, aber nicht mesenchymalen Tumorgeweben eine weite Verbreitung. So konnte die starke Überexpression der Protease in folgenden Tumoren nachgewiesen werden: Mamma, Prostata, Ovar, Uterus, Colon, Kopf und Hals (Netzel-Arnett et al., 2003).

MTSP-1 wurde ursprünglich aus Thymusstromazellen der Maus isoliert (Kim et al., 1999). In humanen Thymusepithelzellen, insbesondere in den Hassal'schen Körperchen, konnte eine signifikante Erhöhung der Genexpression festgestellt werden (Szabo et al., 2003). Passend zur Expression von MTSP-1 in Thymusepithelzellen wurde eine drastische Steigerung der Rate von Apoptosen bei unreifen CD4+CD8+ doppelt positiven Thymozyten bei Mäusen festgestellt (List et al., 2002). Die Expression von Ratten-MTSP-1 in Caco2-Zellen zeigt eine fast ausschließliche Proteinexpression auf der basolateralen Seite der intestinalen Epithelzellen (Satomi et al., 2001). Neuere Daten belegen die ausschließliche Expression von MTSP-1 an der basolateralen Seite auch in 
normalen Enterozyten (Tsuzuki et al., 2005). Eine weitere Studie zeigt, dass Sphingosin 1-Phosphat die Aktivität von MTSP-1 auf Oberflächen von Epithelzellen regulieren kann (Benaud et al., 2002). Interessant ist ebenfalls eine Veröffentlichung, in der über die Aktivierung von MTSP-1 auf Zelloberflächen von humanen Tumorzelllinien durch Trypsin berichtet wird. Alle 24 in dieser Studie verwendeten humanen Tumorzelllinien exprimieren zudem MTSP-1 (Jin et al., 2005). Des Weiteren wird eine Co-Expression von MTSP-1 und hepatocyte growth factor activator inhibitor-1 (HAI-1) in normalen wie malignen Zellsystemen durch mehrere Veröffentlichungen belegt (Kang et al, 2003; Zeng et al., 2005; Vogel et al., 2006). So beschreibt eine Studie über Brustkrebs im Frühstadium ein deutlich erhöhtes Risiko für spätere Metastasierung und Tod, wenn initial MTSP-1 und HAI-1 exprimiert waren (Oberst et al., 2002).

Biochemische Studien zeigen, dass MTSP-1 in der Lage ist, den G Protein- gekoppelten Rezeptor PAR-2, den pleiotropen Wachstumsfaktor pro-hepatocyte growth factor (proHGF) und die pro-urokinase plasminogen activator (pro-uPA) Kaskade zu aktivieren. Dies lässt für MTSP-1 vermuten, an multiplen Signaltransduktionen und proteolytischen Abläufen beteiligt zu sein (Takeuchi et al., 2000; Lee, Dickson, Lin, 2000). Des Weiteren kann Trypsin in Versuchen mit humanen Tumorzelllinien MTSP-1 aktivieren (Jin et al., 2005). Eine Mutation im MTSP-1-Gen von Mäusen führt binnen $48 \mathrm{~h}$ nach Geburt zum Tod, bedingt durch unkontrollierbare Dehydratation und Hypothermie. Histologische Untersuchungen zeigen grundlegende Abnormalitäten in der Entwicklung des Stratum corneum sowie fehlerhafte Strukturen der epidermalen Lipide (Zeeuwen, 2004). Weitere Veröffentlichungen zeigen die bedeutende Rolle von MTSP-1 bei der Entwicklung der Epidermis und des Thymus. So bedingt der Verlust der epidermalen MTSP-1 abnormale Entwicklungen in Haarfollikeln, resultierend in generalisierter Follikelhypoplasie und follikulärer Dysgenesie (List et al., 2002; Bugge, List, Szabo, 2007). Damit sprechen die Daten für eine Schlüsselrolle von MTSP-1 bei der Entwicklung von follikulärer und interfollikulärer Epidermis. MTSP-1 ist die einzige TTSP, neben Enterokinase, für die ein endogener Inhibitor identifiziert werden konnte. Ursprünglich wurde er aus humaner Milch in einem Komplex isoliert und hepatocyte growth factor activator inhibitor (HAI)-1 benannt (Szabo et al., 2003). Neuere Untersuchungen haben eine eher multifunktionale Rolle von HAI-1 beschrieben. Demnach ist HAI-1 nicht nur MTSP-1-Inhibitor, sondern auch Aktivator und damit regulierend wirksam (Oberst et al., 2005). 
Unter Berücksichtigung und Reflektion der oben beschriebenen Ausführung der TTSP lassen sich zusammenfassend folgende Fragestellungen dieser Arbeit formulieren:

1. Wie ist die physiologische Expression von TTSP im humanen Gastrointestinaltrakt in Relation zur Expression von PAR-2?

2. Werden TTSP in IEC durch proinflammatorische Zytokine, LPS und Dexamethason induziert?

3. Was bewirkt eine Exposition von Bakterien unterschiedlicher Pathogenität in IEC für die Regulation der TTSP?

4. Welche Bakterienbestandteile und -Faktoren verursachen eine Induktion der TTSP in IEC?

5. Werden TTSP unter bestimmten Stimuli gleich- oder gegensinnig exprimiert und korreliert dies mit der Expression von PAR-2? 


\section{Materialien und Methoden}

\subsection{Materialien}

\subsubsection{Zellkultur}

\begin{tabular}{|c|c|c|}
\hline Produkt & Produktnummer & Firma \\
\hline L-Glutamin & Cat. K 0282 & Biochrome AG \\
\hline Bench LaminAir & HB2448 & Heraeus Instruments \\
\hline Disposable Cell Scraper & Cat. 541070 & greiner bio-one $\mathrm{GmbH}$ \\
\hline Gentamycin & Cat. P 11-004 & paa Laboratories $\mathrm{GmbH}$ \\
\hline Medium DMEM & Cat. 11966-025 & GIBCO Invitrogen Corp. \\
\hline Medium Mc Coy's 5A & Cat. 26600-023 & GIBCO Invitrogen Corp. \\
\hline Mikroskop & CK2 & Olympus \\
\hline Neubauer Zählkammer & Nr. 9161086 & Kobe \\
\hline Non Essential Aminoacids (100x) & Cat. $11140-035$ & GIBCO Invitrogen Corp. \\
\hline PBS- Puffer $0,1 \mathrm{M}$ & Nr. 6580/ 6346 & Merck \\
\hline Penicillin/ Streptomycin (100x) & Cat. P 11-010 & paa Laboratories GmbH \\
\hline Pipetboy acu & Nr. 155019 & IBS Integra Biosciences \\
\hline Pipette 606180 Cellstar $5 \mathrm{ml}$ & Cat. 101102 & greiner bio-one $\mathrm{GmbH}$ \\
\hline Pipette 607180 Cellstar $10 \mathrm{ml}$ & Cat. 260103 & greiner bio-one $\mathrm{GmbH}$ \\
\hline Pipette 710180 Cellstar $2 \mathrm{ml}$ & Cat. 310104 & greiner bio-one $\mathrm{GmbH}$ \\
\hline Pipette 760180 Cellstar $25 \mathrm{ml}$ & Cat. 050503 & greiner bio-one $\mathrm{GmbH}$ \\
\hline Pipette 768180 Cellstar $50 \mathrm{ml}$ & Cat. 190803 & greiner bio-one $\mathrm{GmbH}$ \\
\hline PP-Testtubes Cellstar $50 \mathrm{ml}$ & Cat. 227261 & greiner bio-one $\mathrm{GmbH}$ \\
\hline Sera Plus FBS & Cat. 3702 & PAN Biotech GmbH \\
\hline TC-plate Cellstar 6 Well & Cat. 657160 & greiner bio-one $\mathrm{GmbH}$ \\
\hline Tissue Culture Flasks $175 \mathrm{~cm}^{2}, 550 \mathrm{ml}$ & Cat. 660160 & greiner bio-one $\mathrm{GmbH}$ \\
\hline Tissue Culture Flasks $25 \mathrm{~cm}^{2}, 50 \mathrm{ml}$ & Cat. 690160 & greiner bio-one $\mathrm{GmbH}$ \\
\hline Tissue Culture Flasks $75 \mathrm{~cm}^{2}, 250 \mathrm{ml}$ & Cat. 658170 & greiner bio-one $\mathrm{GmbH}$ \\
\hline Trypsin/ EDTA (1x) & Cat. L 11-004 & paa Laboratories GmbH \\
\hline Einmalhandschuhe Norbaglove & Nr. 905443 & NORBA Verbandmittel \\
\hline Zentrifuge Labofuge 400e & Nr. 1980023 & Heraeus Instruments \\
\hline
\end{tabular}




\subsubsection{RNA- Isolierung}

\begin{tabular}{|c|c|c|}
\hline Produkt & Produktnummer & Firma \\
\hline 2-Mercaptoethanol $(50 \mathrm{ml})$ & ZA 1573506-541 & Merck \\
\hline Ampuwa, Dest. Wasser, 101 & Nr. PE 6062 & Fresenius Kabi GmbH \\
\hline Buffer RLT Lysis Buffer (45 ml) & Mat. 1015750 & Qiagen \\
\hline Buffer RPE Wash Buffer & Mat. 1017974 & Qiagen \\
\hline Buffer RW 1 Wash Buffer (45 ml) & Mat. 1014567 & Qiagen \\
\hline Collection tubes $(1,5 \mathrm{ml})(50)$ & Mat. 1017981 & Qiagen \\
\hline Collection tubes $(2 \mathrm{ml})(50)$ & Mat. 1016890 & Qiagen \\
\hline Ethanol absolut & Mat. 32205 & Riedel-de Haen \\
\hline Filtertips 1000E & Art.No. 771288 & greiner bio-one $\mathrm{GmbH}$ \\
\hline Filtertips $100 \mathrm{E}$ & Art.No. 772288 & greiner bio-one $\mathrm{GmbH}$ \\
\hline Filtertips 10E & Art.No. 765288 & greiner bio-one $\mathrm{GmbH}$ \\
\hline Gene Quant RNA/ DNA Calculator & No. 55873 & Pharmacia \\
\hline Laborwaage AE 163/9 & Nr. E 27478 & Mettler \\
\hline Mini-Vortex-Mixer REAX 1 DR & No. 54117 & Heidolph \\
\hline PBS- Puffer $0,1 \mathrm{M}$ & Nr. 6580/ 6346 & Merck \\
\hline Pipette Research variabel $0,5-10 \mu 1$ & Nr. 9283385 & Eppendorf \\
\hline Pipette Research variabel $100-1000 \mu 1$ & Nr. 9283381 & Eppendorf \\
\hline Pipette Research variabel $10-100 \mu 1$ & Nr. 9283383 & Eppendorf \\
\hline QIAshredder (50) & Cat. 79654 & Qiagen \\
\hline QIAshredder Mini Spin Column & Mat. 1011711 & Qiagen \\
\hline Reagiergefäße $1,5 \mathrm{ml}$ & No.Ref 72.690 & Sarstedt \\
\hline 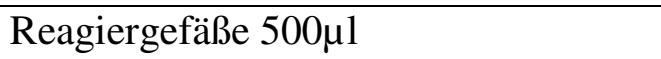 & No.Ref 72.699 & Sarstedt \\
\hline RNase Free DNase Set (50) & Cat. 79254 & Qiagen \\
\hline RNase Free Water $(10 \mathrm{ml})$ & Mat. 1017979 & Qiagen \\
\hline RNeasy Mini Column & Mat. 1011708 & Qiagen \\
\hline RNeasy Mini Kit (50) & Cat. 74104 & Qiagen \\
\hline Ultraschallsonde Labsonic U & No. G1188780 & B.Braun \\
\hline Einmalhandschuhe Norbaglove & Nr. 905443 & NORBA Verbandmittel \\
\hline Zentrifuge Haemofuge A & Nr. 1228 & Heraeus Christ GmbH \\
\hline
\end{tabular}




\subsection{3 cDNA- Synthese}

\begin{tabular}{|l|l|l|}
\hline Produkt & Produktnummer & Firma \\
\hline Mikro-Quarzküvette & Nr. 105.202-QS & Hellma \\
\hline $10 \mathrm{mM}$ dNTP Mix $250 \mu \mathrm{l}$ & Lot. 1012 & MBI Fermentas \\
\hline 5 x Reaction buffer $500 \mu \mathrm{l}$ & Lot. BG 044 & MBI Fermentas \\
\hline Ampuwa, Dest. Wasser, 101 & Nr. PE 6062 & Fresenius Kabi GmbH \\
\hline Control Primer (10 pmol/ $\mu \mathrm{l}), 40 \mu \mathrm{l}$ & Lot. 0912 & MBI Fermentas \\
\hline Deionized water,nuclease free, 1,5ml & Lot. 1411 & MBI Fermentas \\
\hline Filtertips 1000E & Art.No. 771288 & greiner bio-one GmbH \\
\hline Filtertips 100E & Art.No. 772288 & greiner bio-one GmbH \\
\hline Filtertips 10E & Art.No. 765288 & greiner bio-one GmbH \\
\hline Gene Quant RNA/ DNA Calculator & No. 55873 & Pharmacia \\
\hline Mini-Vortex-Mixer REAX 1 DR & No. 54117 & Heidolph \\
\hline M-MuLV Rev. Trans. $(20 \mathrm{u} / \mu \mathrm{l}), 240 \mu \mathrm{l}$ & Lot. 0842 & MBI Fermentas \\
\hline Oligo (dT)18 Primer $(0,5 \mu \mathrm{g} / \mu \mathrm{l}), 120 \mu \mathrm{l}$ & Lot. 1511 & MBI Fermentas \\
\hline Pipette Research variabel 0,5-10 $\mu 1$ & Nr. 9283385 & Eppendorf \\
\hline Pipette Research variabel 100-1000 $\mu \mathrm{l}$ & Nr. 9283381 & Eppendorf \\
\hline Pipette Research variabel 10-100 $\mu \mathrm{l}$ & Nr. 9283383 & Eppendorf \\
\hline Random Hex. Prim. $(0,2 \mu \mathrm{g} / \mu \mathrm{l}), 120 \mu \mathrm{l}$ & Lot. 1111 & MBI Fermentas \\
\hline Reagiergefäße 1,5ml & No.Ref 72.690 & Sarstedt \\
\hline Reagiergefäße 500 $\mu 1$ & No.Ref 72.699 & Sarstedt \\
\hline RevertAid 1st Strand cDNA Synth.Kit & \# K 1622 & MBI Fermentas \\
\hline Ribonuclease Inhibitor $(20 \mathrm{u} / \mu \mathrm{l}), 120 \mu \mathrm{l}$ & Lot. 9521 & MBI Fermentas \\
\hline Thermocycler & Varius V & Landgraf \\
\hline Einmalhandschuhe Norbaglove & Nr. 905443 & NORBA Verbandmittel \\
\hline Zentrifuge Haemofuge A & Nr. 1228 & Heraeus Christ GmbH \\
\hline
\end{tabular}




\subsubsection{Real-time quantitative PCR (RT-PCR)}

\begin{tabular}{|c|c|c|}
\hline Produkt & Produktnummer & Firma \\
\hline 96-Well Optical Reaction Plate & Part.No. 4306737 & PE Applied Biosystems \\
\hline Filtertips $1000 \mathrm{E}$ & Art.No. 771288 & greiner bio-one $\mathrm{GmbH}$ \\
\hline Filtertips $100 \mathrm{E}$ & Art.No. 772288 & greiner bio-one $\mathrm{GmbH}$ \\
\hline Filtertips $10 \mathrm{E}$ & Art.No. 765288 & greiner bio-one $\mathrm{GmbH}$ \\
\hline Human GAPDH (20x) & No. 4310884E & PE Applied Biosystems \\
\hline Human IL8 (20x) 0,125ml & No. $4327042 \mathrm{~F}$ & PE Applied Biosystems \\
\hline Micro Amp optical caps & No. N801-0935 & PE Applied Biosystems \\
\hline Micro Amp optical tubes $200 \mu 1$ & No. N801-0933 & PE Applied Biosystems \\
\hline Mini-Vortex-Mixer REAX 1 DR & No. 54117 & Heidolph \\
\hline Pipette Research variabel $0,5-10 \mu 1$ & Nr. 9283385 & Eppendorf \\
\hline Pipette Research variabel $100-1000 \mu 1$ & Nr. 9283381 & Eppendorf \\
\hline Pipette Research variabel $10-100 \mu 1$ & Nr. 9283383 & Eppendorf \\
\hline Primer Forward, custom made & Je Gen variabel & Applied Biosys./ Sigma \\
\hline Primer Reverse, custom made & Je Gen variabel & Applied Biosys./ Sigma \\
\hline Probe, custom made & Je Gen variabel & Applied Biosys./ Sigma \\
\hline Reagiergefäße $1,5 \mathrm{ml}$ & No.Ref 72.690 & Sarstedt \\
\hline 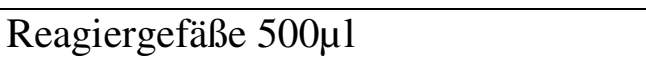 & No.Ref 72.699 & Sarstedt \\
\hline Ribosomal (20x) 18s & Part No. 4310875 & PE Applied Biosystems \\
\hline TaqMan Sequence Detection System & ABI Prism 7700 & PE Applied Biosystems \\
\hline TaqMan Universal PCR Mastermix & Part No. 4304437 & PE Applied Biosystems \\
\hline Einmalhandschuhe Norbaglove & Nr. 905443 & NORBA Verbandmittel \\
\hline Water, Molecular Biology Grade 11 & No. 0032006.159 & Eppendorf \\
\hline
\end{tabular}




\subsubsection{Zytokin-, LPS- und Dexamethason- Experiment}

\begin{tabular}{|c|c|c|}
\hline Produkt & Produktnummer & Firma \\
\hline 2-Mercaptoethanol (50 ml) & ZA 1573506-541 & Merck \\
\hline LPS (30 ng/ml) & No. F3665 & Sigma \\
\hline Ampuwa, Dest. Wasser, 101 & Nr. PE 6062 & Fresenius Kabi GmbH \\
\hline Bench LaminAir & HB2448 & Heraeus Instruments \\
\hline Buffer RLT Lysis Buffer $(45 \mathrm{ml})$ & Mat. 1015750 & Qiagen \\
\hline Buffer RPE Wash Buffer & Mat. 1017974 & Qiagen \\
\hline Buffer RW 1 Wash Buffer (45 ml) & Mat. 1014567 & Qiagen \\
\hline Collection tubes $(1,5 \mathrm{ml})(50)$ & Mat. 1017981 & Qiagen \\
\hline Collection tubes $(2 \mathrm{ml})(50)$ & Mat. 1016890 & Qiagen \\
\hline Disposable Cell Scraper & Cat. 541070 & greiner bio-one $\mathrm{GmbH}$ \\
\hline TNF- $\alpha(3 \mathrm{ng} / \mathrm{ml})$ & Cat.No. 1371843 & Roche \\
\hline $\mathrm{IL}-1 \beta(0,3 \mathrm{ng} / \mathrm{ml})$ & Cat.No. 1457756 & Roche \\
\hline $\mathrm{IFN}-\gamma(25 \mathrm{ng} / \mathrm{ml})$ & Cat.No. 1050494 & Roche \\
\hline Dexamethason $\left(1 * 10^{-7} \mathrm{M}\right)$ & No. D 4902 & Sigma \\
\hline Ethanol absolut & Mat. 32205 & Riedel-de Haen \\
\hline Filtertips $1000 \mathrm{E}$ & Art.No. 771288 & greiner bio-one $\mathrm{GmbH}$ \\
\hline Filtertips 100E & Art.No. 772288 & greiner bio-one $\mathrm{GmbH}$ \\
\hline Filtertips $10 \mathrm{E}$ & Art.No. 765288 & greiner bio-one $\mathrm{GmbH}$ \\
\hline Gene Quant RNA/ DNA Calculator & No. 55873 & Pharmacia \\
\hline Medium DMEM & Cat. 11966-025 & GIBCO Invitrogen Corp. \\
\hline Medium Mc Coy’s 5A & Cat. 26600-023 & GIBCO Invitrogen Corp. \\
\hline Mikroskop & CK2 & Olympus \\
\hline Mini-Vortex-Mixer REAX 1 DR & No. 54117 & Heidolph \\
\hline Neubauer Zählkammer & Nr. 9161086 & Kobe \\
\hline Non Essential Aminoacids (100x) & Cat. 11140-035 & GIBCO Invitrogen Corp. \\
\hline PBS- Puffer $0,1 \mathrm{M}$ & Nr. 6580/ 6346 & Merck \\
\hline Penicillin/ Streptomycin (100x) & Cat. P 11-010 & paa Laboratories GmbH \\
\hline Pipetboy acu & Nr. 155019 & IBS Integra Biosciences \\
\hline Pipette 607180 Cellstar $10 \mathrm{ml} / 5 \mathrm{ml}$ & Cat. 260103/1102 & greiner bio-one $\mathrm{GmbH}$ \\
\hline Pipette 710180 Cellstar $2 \mathrm{ml}$ & Cat. 310104 & greiner bio-one $\mathrm{GmbH}$ \\
\hline
\end{tabular}




\begin{tabular}{|c|c|c|}
\hline Pipette Research variabel $0,5-10 \mu 1$ & Nr. 9283385 & Eppendorf \\
\hline Pipette Research variabel $100-1000 \mu 1$ & Nr. 9283381 & Eppendorf \\
\hline Pipette Research variabel $10-100 \mu 1$ & Nr. 9283383 & Eppendorf \\
\hline QIAshredder (50) & Cat. 79654 & Qiagen \\
\hline QIAshredder Mini Spin Column & Mat. 1011711 & Qiagen \\
\hline Reagiergefäße $1,5 \mathrm{ml} / 0,5 \mathrm{ml}$ & No.72.690/72.699 & Sarstedt \\
\hline RNase Free DNase Set (50) & Cat. 79254 & Qiagen \\
\hline RNase Free Water $(10 \mathrm{ml})$ & Mat. 1017979 & Qiagen \\
\hline RNeasy Mini Column & Mat. 1011708 & Qiagen \\
\hline RNeasy Mini Kit (50) & Cat. 74104 & Qiagen \\
\hline Sera Plus FBS & Cat. 3702 & PAN Biotech GmbH \\
\hline TC-plate Cellstar 6 Well & Cat. 657160 & greiner bio-one $\mathrm{GmbH}$ \\
\hline Einmalhandschuhe Norbaglove & Nr. 905443 & NORBA Verbandmittel \\
\hline Zentrifuge Labofuge 400e & Nr. 1980023 & Heraeus Instruments \\
\hline
\end{tabular}




\subsubsection{Bakterien-Experiment}

\begin{tabular}{|c|c|c|}
\hline Produkt & Produktnummer & Firma \\
\hline L-Glutamin & Cat. K 0282 & Biochrome AG \\
\hline 2-Mercaptoethanol (50 ml) & ZA 1573506-541 & Merck \\
\hline Ampicillin & A5354 & Sigma \\
\hline Ampuwa, Dest. Wasser, 101 & Nr. PE 6062 & Fresenius Kabi GmbH \\
\hline Bench LaminAir & HB2448 & Heraeus Instruments \\
\hline BioPhotometer Eppendorf & Nr. 9776600 & Kobe/Eppendorf \\
\hline Buffer RPE Wash Buffer & Mat. 1017974 & Qiagen \\
\hline Buffer RW 1 Wash Buffer (45 ml) & Mat. 1014567 & Qiagen \\
\hline Collection tubes $1,5 \mathrm{ml} / 2 \mathrm{ml}$ & Mat.1017981/6890 & Qiagen \\
\hline Disposable Cell Scraper & Cat. 541070 & greiner bio-one $\mathrm{GmbH}$ \\
\hline Enterococcus faecium & ATCC 29212 & Mikrobio Uni Marburg \\
\hline Escherichia coli & ATCC 25922 & Mikrobio Uni Marburg \\
\hline Escherichia coli & $0157 \mathrm{EHEC}$ & Mikrobio Uni Marburg \\
\hline Escherichia coli & Nissle 1917 & Ardey Pharma \\
\hline Ethanol absolut & Mat. 32205 & Riedel-de Haen \\
\hline Filtertips 100E / 1000E & No. $77-2288 /-1288$ & greiner bio-one $\mathrm{GmbH}$ \\
\hline Filtertips $10 \mathrm{E}$ & No. 765288 & greiner bio-one $\mathrm{GmbH}$ \\
\hline Gene Quant RNA/ DNA Calc. & No. 55873 & Pharmacia \\
\hline Gentamycin & Cat. P 11-004 & paa Laboratories GmbH \\
\hline Laborwaage AE 163/9 & Nr. E 27478 & Mettler \\
\hline Listeria monocytogenes & Patienten-Isolat & Mikrobio Uni Marburg \\
\hline Medium DMEM & Cat. 11966-025 & GIBCO Invitrogen Corp. \\
\hline Medium Mc Coy’s 5A & Cat. 26600-023 & GIBCO Invitrogen Corp. \\
\hline Mikroskop & CK2 & Olympus \\
\hline Mini-Vortex-Mixer REAX 1 DR & No. 54117 & Heidolph \\
\hline Neubauer Zählkammer & Nr. 9161086 & Kobe \\
\hline Non Essential Aminoacids (100x) & Cat. 11140-035 & GIBCO Invitrogen Corp. \\
\hline PBS- Puffer $0,1 \mathrm{M}$ & Nr. 6580/ 6346 & Merck \\
\hline Penicillin/ Streptomycin (100x) & Cat. P 11-010 & paa Laboratories GmbH \\
\hline Pipetboy acu & Nr. 155019 & IBS Integra Biosciences \\
\hline
\end{tabular}




\begin{tabular}{|c|c|c|}
\hline Pipette 607180 Cellstar $10 \mathrm{ml} / 5 \mathrm{ml}$ & Cat. 260103/101102 & greiner bio-one $\mathrm{GmbH}$ \\
\hline Pipette 710180 Cellstar $2 \mathrm{ml}$ & Cat. 310104 & greiner bio-one $\mathrm{GmbH}$ \\
\hline Pipette Research variabel $0,5-10 \mu 1$ & Nr. 9283385 & Eppendorf \\
\hline Pipette Research var. $100-1000 \mu 1$ & Nr. 9283381 & Eppendorf \\
\hline Pipette Research var. $10-100 \mu 1$ & Nr. 9283383 & Eppendorf \\
\hline QIAshredder (50) & Cat. 79654 & Quagen \\
\hline QIAshredder Mini Spin Column & Mat. 1011711 & Qiagen \\
\hline Reagiergefäße 500 $\mu 1 / 1,5 \mathrm{ml}$ & No.Ref 72.699/690 & Sarstedt \\
\hline RNase Free DNase Set (50) & Cat. 79254 & Qiagen \\
\hline RNase Free Water $(10 \mathrm{ml})$ & Mat. 1017979 & Qiagen \\
\hline RNeasy Mini Column & Mat. 1011708 & Qiagen \\
\hline RNeasy Mini Kit (50) & Cat. 74104 & Qiagen \\
\hline Salmonella typhi & MCCM 01631 & Mikrobio Uni Marburg \\
\hline Sera Plus FBS & Cat. 3702 & PAN Biotech GmbH \\
\hline TC-plate Cellstar 6 Well & Cat. 657160 & greiner bio-one $\mathrm{GmbH}$ \\
\hline Einmalhandschuhe Norbaglove & Nr. 905443 & NORBA Verbandmittel \\
\hline Yersinia enterocolitica & MCCM 01839 & Mikrobio Uni Marburg \\
\hline Zentrifuge Labofuge 400e & Nr. 1980023 & Heraeus Instruments \\
\hline
\end{tabular}




\subsection{Methoden}

\subsubsection{Zellkultur}

Die Experimente in der Zellkultur wurden mit folgenden intestinalen Epithelzelllinien durchgeführt:

\subsubsection{HT29-Zellen}

Bei HT29 handelt es sich um eine humane Zelllinie, welche 1964 aus einem Adenokarzinom des Kolon einer 44-jährigen weißen Frau isoliert wurde. Bei dem Tumor handelte es sich um ein gut differenziertes (Grad I) Karzinom (Fogh et al., 1975, 1977; Rousset, 1986). Die Zelllinie wurde über die Deutsche Sammlung von Mikroorganismen und Zellkulturen GmbH (DSMZ), Depositor Dr. H. G. Drexler, Braunschweig, Deutschland bezogen.

Makroskopisch stellen sich HT29 als adhärent wachsende Epithelzellen dar, die als Monolayer große Kolonien ausbilden. Als Kulturmedium wurde McCoy's 5A Medium (GIBCO Invitrogen Corporation, Cat. 26600-023, Lot. 3072937) mit 10\% SERA Plus FBS (PAN Biotech GmbH, Cat. 3702 P 221107, Lot. P221107) verwendet. Die Zellen wurden alle 3 bis $6 \mathrm{~d}$ in einem Verhältnis von 1 Anteil Zellen zu 3 bis 5 Anteilen Kulturmedium gesplittet. Zur Passage wurde ein Gemisch aus Trypsin und EDTA (paa Laboratories GmbH, Cat. L 11-004) verwendet. Es sollten bei jeder Passage zwischen 1 x $10^{6}$ und $2 \times 10^{6}$ Zellen $/ \mathrm{cm}^{2}$ ausgesät werden. HT29 werden bei $37^{\circ} \mathrm{C}$ mit einem $\mathrm{CO}_{2}$-Anteil von $5 \%$ inkubiert. Für das Zellwachstum muß eine Verdopplungsrate von 40-60 h angesetzt werden. In den Experimenten wurden HT29-Zellen mit den PassageNummern $\mathrm{p}=118$ bis 132 verwendet.

\subsubsection{Caco2-Zellen}

Bei Caco2 handelt es sich ebenfalls um eine Adenokarzinom-Zelllinie des Kolon, die 1972 aus dem Adenokarzinom eines 72 Jahre alten weißen Mannes isoliert wurde (Fogh et al., 1975, 1977; Rousset, 1986). Die Zelllinie wurde über die Deutsche Sammlung von Mikroorganismen und Zellkulturen GmbH (DSMZ), Depositor Prof. A. Bacher, Braunschweig, Deutschland bezogen. 
Bei Caco2 handelt es sich um adhärent wachsende Darmepithelzellen, welche nach dem Splitten zunächst in kleinen Kolonien zu wachsen beginnen. Als Zellkulturmedium wurde DMEM (GIBCO Invitrogen Corporation, Cat. 11966-025, Lot. 1152137), 20\% SERA Plus FBS (PAN Biotech GmbH, Cat. 3702 P 221107, Lot. P221107) und NEAA MEM (100x) (Non-Essential Amino Acids, GIBCO Invitrogen Corporation, Cat. 11140-035, Lot. 3066694) verwendet. Die Zellen wachsen relativ langsam für eine Tumorzelllinie. Hat sich ein konfluenter Zellrasen ausgebildet, wurden die Zellen alle 5 bis $7 \mathrm{~d}$ in einem Verhältnis von 1 Anteil Zellen zu 6 bis 10 Anteilen Kulturmedium gesplittet. Da die Zellen stark an der Oberfläche der Kulturflasche haften, kann zum Splitten neben Trypsin und EDTA (paa Laboratories GmbH, Cat. L 11-004) ein ZellScraper erforderlich sein. Die Zellen sollten in einem Verhältnis von ca. $1 \times 10^{6}$ Zellen $/ 75 \mathrm{~cm}^{2}$ in $10 \mathrm{ml}$ Medium ausgesät und bei $37^{\circ} \mathrm{C}$ mit $5 \%$ igem $\mathrm{CO}_{2}$-Anteil inkubiert werden. Die Verdopplungsrate beträgt bei Caco2 ca. 80 h. Für die Experimente wurden Caco2-Zellen mit den Passage-Nummern $\mathrm{p}=86$ bis 97 verwendet.

Die nachfolgend aufgeführten Arbeiten in der Zellkultur wurden mit Hilfe der folgenden Pipetten und Pipettierhilfen durchgeführt:

- Pipette 710180 Cellstar 2ml, Cat. 310104; Pipette 606180 Cellstar 5ml, Cat. 101102; Pipette 607180 Cellstar 10 ml, alle Firma greiner bio-one GmbH.

- Pipetboy acu, Nr. 155019, IBS Integra Biosciences

Bei den gesamten Arbeitsabläufen wurden Untersuchungshandschuhe (NorbagloveLatex puderfrei, Nr. 905443, NORBA Verbandmittel Danz GmbH) getragen.

\subsubsection{Kultivieren der Zellen}

Nach dem Ausbringen der jeweiligen Zellsuspension in Kulturflaschen und einem regelrechten Wachstumverlauf wurde alle 2 bis 3 Tage das entsprechende Medium gewechselt (siehe oben). Zu erkennen ist die Notwendigkeit des Mediumwechsels makroskopisch am Farbumschlag des Mediums von normalerweise rot zu orange-gelb. Zum Mediumwechsel saugt man das alte, verfärbte Medium vorsichtig aus der Kulturflasche ab und ersetzt es durch $10 \mathrm{ml}$ (je nach Flaschengröße, hier bezogen auf eine $75 \mathrm{~cm}^{2}$ Flasche) frisches Medium. Dieses sollte vorher auf Raumtemperatur 
gebracht worden sein. Nach Wechsel des Mediums flammt man den Flaschenhals der Kulturflasche kurz ab, schraubt den Verschluss locker auf und deponiert die Zellen dann wieder im Inkubationsschrank.

\subsubsection{Splitten der Zellen}

Um den Zeitpunkt zu bestimmen, zu dem die Zellen passagiert werden müssen, kann zunächst die für die jeweilige Zelllinie bekannte Zeitangabe als grober Richtwert herangezogen werden. Für eine genauere Festlegung des Zeitpunkts wurden die Zellen makro- und mikroskopisch betrachten. Hat sich ein konfluentes Monolayer ausgebildet, werden die Zellen gesplittet. Wie bereits oben beschrieben, sollte man allen verwendeten Lösungen und Medien zuvor die Gelegenheit geben, sich vor der Verwendung der Raumtemperatur anzugleichen.

Zu Beginn wird der Zellrasen mit PBS (PBS- Puffer 0,1 M, Nr. 6580/ 6346, Merck) gewaschen. Dazu werden $5 \mathrm{ml}$ PBS auf die Zellen gegeben, die Zellkulturflasche wird mehrfach leicht geschwenkt und anschließend das PBS wieder abgesaugt. Nachfolgend werden $2 \mathrm{ml}$ eines Gemisches aus Trypsin und EDTA der Firma PAA Laboratories GmbH (Art. Nr.: L 11-004, Lot.Nr.: H 04123-031) hinzugefügt und für 3 min bis zum Ablösen der Zellen vom Untergrund auf dem Rasen belassen. Nach Zugabe von $8 \mathrm{ml}$ Kulturmedium wird die Zellsuspension anschließend in ein $50 \mathrm{ml}$ Falconröhrchen überführt und für $3 \mathrm{~min}$ bei $1200 \mathrm{U} / \mathrm{min}$ zentrifugiert (Zentrifuge Labofuge 400e, Nr. 1980023, Heraeus Instruments). Das foetale Kälberserum enthält die zur Inhibierung der Trypsinaktivität notwendigen Proteine. Der Überstand wird abgesaugt. Das Zellpellet wird nun mit $10 \mathrm{ml}$ Kulturmedium durch mehrmaliges vorsichtiges hin- und herpipettieren resuspendiert. Um die genaue Zellzahl $\mathrm{zu}$ ermitteln werden $10 \mu \mathrm{l}$ der entstandenen Suspension in einer Neubauer-Zählkammer durchgezählt. Entsprechend der ermittelten Zellzahl wird die jeweilige Menge der Suspension in die neuen Kulturflaschen pipettiert und auf ein Endvolumen von $10 \mathrm{ml}$ gebracht. Wieder erfolgt das Abflammen des Flaschenhalses und lockeres zuschrauben. Mikroskopisch verschafft man sich ein Bild von Qualität und Quantität der Zellen. Letztlich werden die Kulturflaschen im entsprechenden Milieu inkubiert. 


\subsubsection{RNA- Isolierung}

\subsubsection{RNA - Isolierung aus intestinalen Epithelzellen (IEC)}

Die Isolierung von RNA aus Zellen der Zellkultur wurde unter Verwendung des RNeasy Mini Kits (Cat. 74104) der Firma Qiagen durchgeführt. Die Methode basiert auf der von der Firma Qiagen speziell für das Kit beschriebenen Anleitung.

Es wurden bei der RNA-Isolierung folgende Pipetten, Filtertips, Eppendorf-Pipetten und Pipettierhilfen verwendet:

- Pipette 710180 Cellstar 2 ml, Cat. 310104; Pipette 606180 Cellstar 5 ml, Cat. 101102; Pipette 607180 Cellstar 10 ml, alle Firma greiner bio-one GmbH.

- Filtertips 10E, Art.No. 765288; Filtertips 100E, Art.No. 772288; Filtertips 1000E, Art.No. 771288, alle Firma greiner bio-one GmbH.

- Pipette Eppendorf Research variabel 0,5-10 $\mu$ 1, Nr. 9283385, Pipette Eppendorf Research variabel 10-100 $\mu 1$, Nr. 9283383, Pipette Eppendorf Research variabel 100-1000 $\mu 1$, Nr. 9283381, alle Firma Eppendorf.

- Pipetboy acu, Nr. 155019, IBS Integra Biosciences

Man beginnt die RNA-Isolierung mit dem Absaugen des Mediums aus der Zellkulturflasche (Cellstar Tissue Culture Flasks, 75 cm², $250 \mathrm{ml}$, Cat. 658170, greiner bio-one $\mathrm{GmbH}$ ) oder der 6 Well Platte (Cat. 657160, greiner bio-one $\mathrm{GmbH}$ ). Der Zellrasen wird mit $10 \mathrm{ml}$ PBS (PBS- Puffer 0,1 M, Nr. 6580/ 6346, Merck) unter vorsichtigen Schwenkbewegungen gewaschen. Die $10 \mathrm{ml}$ PBS werden wieder abgesaugt. Nach Vorlegen von $5 \mathrm{ml}$ PBS werden die Zellen mit einem Cell Scraper (Cat. 541070, greiner bio-one $\mathrm{GmbH}$ ) in die Lösung geschabt. Es sollte vom Flaschenende zum Flaschenhals geschabt und nicht wieder zurück gearbeitet werden. Dieses Zell/PBS-Gemisch wird in ein Testtube (Cellstar PP-Testtubes, $50 \mathrm{ml}$, Cat. 227261, greiner bio-one $\mathrm{GmbH}$ ) pipettiert und für $3 \mathrm{~min}$ bei $1200 \mathrm{U} / \mathrm{min}$ zentrifugiert (Zentrifuge Labofuge 400e, Nr. 1980023, Heraeus Instruments). Die folgenden Arbeitsschritte zur RNA-Isolierung wurden mittels RNeasy Mini Kit (50)(Cat. 74104) der Firma Qiagen durchgeführt.

Nach Ablauf der Zentrifugationszeit werden die Testtubes aus der Zentrifuge geholt und das entstandene Zellpellet begutachtet. Nun saugt man den Überstand ab und pipettiert 
$600 \mu 1$ RLT Buffer (Mat. 1015750, Qiagen) + $6 \mu$ l 2-Mercaptoethanol (ZA 1573506541, Merck) auf die Zellen. Dieses Gemisch sollte zu Beginn der Isolation frisch angesetzt werden um beste Ergebnisse zu erzielen. Mit einer Pipette wird solange aufund abpipettiert, bis eine relativ homogene und zähflüssige Lösung entsteht. Dieses Lysat gibt man nun auf eine Shredder-Säule (QIAshredder, Cat. 79654, Qiagen), und zentrifugiert bei $14000 \mathrm{U} / \mathrm{min}$ für 2 min (Haemofuge A, Nr. 1228, Heraeus Christ $\mathrm{GmbH})$. Der Einsatz des Shredders wird verworfen und das Gemisch danach mit $600 \mu 1$ 70\% Ethanol absolut (Mat. 32205, Riedel-de Haen) versetzt. Man pipettiert $700 \mu 1$ dieser Probe auf eine RNeasy Mini Column (Mat. 1011708, Quiagen) und zentrifugiert bei $8000 \mathrm{U} / \mathrm{min}$ für $15 \mathrm{sec}$. Die im Collection Tube (Mat. 1016890, Qiagen) befindliche Flüssigkeit muss entfernt werden. Jetzt gibt man den Rest des Ethanol-Gemisches auf die Säule und wiederholt den vorangegangenen Arbeitsschritt. Als nächstes werden 700 l RW1 Buffer (Mat. 1014567, Qiagen) in die Säule pipettiert und dann wieder für 15 sec bei 8000 U/min zentrifugiert. Das Zentrifugat wird verworfen.

Die im Nachfolgenden verwendeten Substanzen wurden im Verlauf der vorherigen Arbeitsschritte bereits auf Zimmertemperatur gebracht, um ein optimales Ergebnis zu gewährleisten. Dazu vermischt man $10 \mu 1$ DNase und $70 \mu 1$ RDD Buffer aus dem RNase Free DNase Set (Cat. 79254, Qiagen) und pipettiert sie auf die Säule. Die DNase wird mit einer Wirkzeit von 15 min bei $20-30^{\circ} \mathrm{C}$ auf der Säule belassen. Nach Ablauf der Zeit setzt man die Säule in einen neuen $2 \mathrm{ml}$ Collection Tube, pipettiert $500 \mu 1 \mathrm{RPE}$ Buffer (Mat. 1017974, Qiagen) hinein und zentrifugiert nochmals für $15 \mathrm{sec}$ bei 8000 U/min. Das Zentrifugat wird verworfen. Dieser Arbeitsschritt muss wiederholt und mit $500 \mu \mathrm{l}$ RPE Buffer für weitere $2 \mathrm{~min}$ bei $14000 \mathrm{U} / \mathrm{min}$ zentrifugiert werden. Um alle Pufferreste zu entfernen wird nochmals für 1 min auf einem neuen Collection Tube bei 14000 U/min zentrifugiert. Als letzten Arbeitsschritt gibt man den Säuleneinsatz auf ein Cup (Reaktionsgefäße, 1,5 ml, No./REF 72.690, Sarstedt) und pipettiert $50 \mu \mathrm{l}$ RNase Free Water (Mat. 1017979, Qiagen) hinzu. Es wird für $1 \mathrm{~min}$ bei $8000 \mathrm{U} / \mathrm{min}$ zentrifugiert. Hierbei wird die RNA aus dem Einsatz gewaschen. Dieses Procedere wird wiederholt. Ist eine geringe RNA-Konzentration zu erwarten, kann entsprechend auch mit 2 × $25 \mu$ l RNase Free Water gewaschen werden. Die im Cup befindliche RNA sollte bei $-20^{\circ} \mathrm{C}$ in einem dafür geeigneten Gefrierschrank gelagert werden. 


\subsubsection{RNA - Isolierung aus humanen gastrointestinalen Geweben}

Die Isolierung von RNA aus humanen gastrointestinalen Geweben wurde unter Verwendung des RNeasy Mini Kits (Cat. 74104) der Firma Qiagen durchgeführt. Die Methode basiert auf der von der Firma Qiagen speziell für das Kit beschriebenen Anleitung.

Folgende Filtertips und Eppendorf-Pipetten wurden verwendet:

- Filtertips 10E, Art.No. 765288; Filtertips 100E, Art.No. 772288; Filtertips 1000E, Art.No. 771288, alle Firma greiner bio-one GmbH.

- Pipette Eppendorf Research variabel 0,5-10 $\mu$ 1, Nr. 9283385, Pipette Eppendorf Research variabel 10-100 $\mu 1$, Nr. 9283383, Pipette Eppendorf Research variabel 100-1000 $\mu 1$, Nr. 9283381, alle Firma Eppendorf.

Bei dem gesamten Arbeitsablauf wurden Untersuchungshandschuhe (Norbaglove-Latex puderfrei, Nr. 905443, NORBA Verbandmittel Danz GmbH) getragen.

Die 1-3 mm³ großen Gewebebiopsiestücke wurden freundlicherweise von Prof. Dr. Dr. Rogler, Universitätsklinikum Regensburg, zur Verfügung gestellt. Die Biopsien wurden entlang der Longitudinalachse des humanen Gastrointestinaltraktes entnommen: Magen-Antrum, Magen-Korpus, Duodenum, terminales Ileum, Caecum, Colon ascendens, Colon transversum, Colon descendens, Sigma und Rektum.

Die Gewebebiopsien wurden auf Trockeneis tiefgefroren nach Marburg verschickt. Zu Beginnn der RNA-Isolation wurden die einzelnen Proben aufgetaut. Es erfolgte eine makroskopische Betrachtung und das Spülen mit PBS (PBS- Puffer 0,1 M, Nr. 6580/ 6346, Merck), um grobe Verunreinigungen zu entfernen. Die größeren Biopsiestücke wurden zunächst noch mechanisch zerkleinert. Wie bei der RNA-Isolierung aus Epithelzellen wurde auch hier ein frisches Gemisch aus $600 \mu$ l RLT Buffer (Mat. 1015750, Qiagen) und $6 \mu 1$ 2-Mercaptoethanol (ZA 1573506-541, Merck) in einem Cup (Reaktionsgefäße, 1,5 ml, No./REF 72.690, Sarstedt) für jede einzelne Biopsie angefertigt. In diesen Cup gibt man nun die Gewebeprobe und verwendet eine Ultraschallsonde (Ultraschallsonde Labsonic U, No. G1188780, B.Braun) zur weiteren, endgültigen Zerkleinerung. Es sollten ca. 4 Zyklen mit $6 \mathrm{sec}$ Dauer durchgeführt 
werden. Dabei ist darauf zu achten, dass in den Pausen das Cup auf Eis gelagert wird und kein Schaum entsteht. Ist unter makroskopischer Begutachtung eine homogene Lösung ohne größere Gewebestücke entstanden, kann der Ultraschall beendet werden.

Die weitere RNA-Isolation aus den Gewebeproben erfolgt analog der unter 2.2.2.1 beschriebenen Prozedur.

\subsection{3 cDNA- Synthese}

Für das Umschreiben von isolierter RNA in cDNA wurde das Kit der Firma MBI Fermentas (Revert Aid First Strand cDNA Synthesis Kit (\#K 1622)) verwendet. Die Methode folgt der von der Firma MBI Fermentas für das Kit geschriebenen Anleitung.

Folgende Filtertips und Eppendorf-Pipetten wurden verwendet:

- Filtertips 10E, Art.No. 765288; Filtertips 100E, Art.No. 772288; Filtertips 1000E, Art.No. 771288, alle Firma greiner bio-one GmbH.

- Pipette Eppendorf Research variabel 0,5-10 $\mu 1$, Nr. 9283385, Pipette Eppendorf Research variabel 10-100 $\mu 1$, Nr. 9283383, Pipette Eppendorf Research variabel 100-1000 $\mu 1$, Nr. 9283381, alle Firma Eppendorf.

Bei dem gesamten Arbeitsablauf wurden Untersuchungshandschuhe (Norbaglove-Latex puderfrei, Nr. 905443, NORBA Verbandmittel Danz GmbH) getragen.

$\mathrm{Zu}$ Beginn wird die isolierte RNA (Cups mit jeweils 50 oder $100 \mu \mathrm{l}$ Inhalt, tiefgefroren bei $-20^{\circ} \mathrm{C}$ ) langsam aufgetaut. Der Inhalt wird vorsichtig durchmischt. Nachfolgend wird die genaue RNA-Konzentration mittels Photometrie bestimmt. Dazu werden $8 \mu 1$ der zuvor gewonnenen RNA und $72 \mu 1$ destilliertes Wasser (Ampuwa, Nr. PE 6062) in eine $10 \mathrm{~mm}$ Mikro-Quarzküvette der Firma Hellma (Best.Nr. 105.202-QS) pipettiert. Unter Verwendung eines Photometers der Firma Pharmacia (Gene Quant RNA/ DNA Calculator, No. 55873) wird die Extinktion bei $260 \mathrm{~nm}$ gemessen. Die RNA Konzentration ergibt sich nun aus dem Produkt der Extinktion bei $260 \mathrm{~nm}$ und dem Faktor 0,4. Für jede cDNA- Synthese werden jeweils $2 \mu \mathrm{g}$ RNA eingesetzt. 
Für die nachfolgend beschriebene PCR wurde ein Thermocycler der Marke Landgraf, Varius V, benutzt. Die Arbeitsschritte, welche außerhalb des Thermocyclers stattfinden, sollten auf Eis durchgeführt werden.

Für die eigentliche reverse Transkription pipettiert man nun das Volumen, welches $2 \mu \mathrm{g}$ RNA enthält, in ein Eppendorf Cup (500 Reaktionsgefäße, $500 \mu 1$, No./REF 72.690, Sarstedt), mit deionisiertem Wasser wird auf ein Gesamtvolumen von $11 \mu$ l aufgefüllt. Im nächsten Schritt wird $1 \mu$ l Random Hexamer Primer hinzugefügt. Nach kurzem Durchmischen der Substanzen wird im Thermocycler für 5 min bei $70^{\circ} \mathrm{C}$ inkubiert. Daraufhin erfolgt, wiederum außerhalb des Thermocyclers, die Zugabe von $4 \mu 1$ Reaction Buffer, $1 \mu 1$ RNase-Inhibitor und $2 \mu 1$ dNTP-Mix. Im anschließenden Schritt verbleibt das Cup für $15 \mathrm{~min}$ bei $25{ }^{\circ} \mathrm{C}$ im Thermocycler. Der letzte Arbeitsschritt beinhaltet die Zugabe von $1 \mu \mathrm{l}$ M-MuL Reverse Transcriptase (200 U/ $\mu \mathrm{l}$ ) und eine 10 minütige Inkubation bei $25^{\circ} \mathrm{C}$. Die Hauptreaktion erfolgt nun für $60 \mathrm{~min}$ bei $42^{\circ} \mathrm{C}$. Beendet wird die reverse Transkription durch Erhitzen für 10 min auf $70^{\circ} \mathrm{C}$ und anschließendem Kühlen auf $4^{\circ} \mathrm{C}$.

In weiteren Arbeitsschritten wurde die neu entstandene cDNA dann mit Wasser (Water, Molecular Biology Grade, 1 1, Order.No. 0032006.159, Eppendorf) seriell in einem Verdünnungsverhältnis von 1 zu 5 bis 1 zu 3125 verdünnt. Die sorgfältig beschrifteten Cups mit der verdünnten cDNA wurden bei $-20^{\circ} \mathrm{C}$ gelagert.

\subsubsection{Real-time quantitative PCR (RT-PCR)}

Im Folgenden wird die real-time quantitative Polymerase Chain Reaction (RT- PCR) beschrieben. Ein hierfür von der Fa. PE Applied Biosystems entwickelter Kit heißt TaqMan® Assay. Generell gibt es zwei Arten von quantitativer RT-PCR: TaqMan® und SYBR green. SYBR green benutzt eine fluoreszierende Färbung, die an jegliche neusynthetisierte Doppelstrang-DNA binden kann. Dagegen basiert die TaqMan®Methode auf einer doppelt-fluoreszierenden Probe, welche ein EinzelstrangOligonukleotid von ca. 20-26 Nukleotiden darstellt. Dieser Einzelstrang bindet ausschließlich an eine spezifische DNA-Sequenz. Die Probe besteht aus einem fluoreszierenden Reporter (wir verwendeten 6-Carboxyfluorescein (FAM)) und fluoreszierendem Quencher (wir verwendeten Tetramethylrhodamin (TAMRA)), welche kovalent an die 5 und $3^{`}$-Enden synthetisiert werden. Im Vergleich zu SYBR 
green ist der TaqMan ${ }^{\circledR}$ die präzisere und zuverlässigere Methode, jedoch auch die kostenintensivere.

Die PCR wurde unter Verwendung des Gerätes ABI Prism 7700 Sequence Detection Systems der Firma PE Applied Biosystems durchgeführt. Als Reaktionsgefäße wurden 96-Well Optical Reaction Plates (Part. No. 4306737) und Micro Amp Optical Caps (Part. No. 4323032) derselben Firma verwendet.

Pipettiert wurde mit folgenden Pipetten der Firma Eppendorf:

- Pipette Research variabel 0,5-10 $\mu 1$, Nr. 9283385

- Pipette Research variabel 10-100 $\mu 1$, Nr. 9283383

- Pipette Research variabel 100-1000 $\mu 1$, Nr. 9283381

Um Kontaminationen oder Verunreinigungen $\mathrm{zu}$ verhindern, wurden spezielle Filterpipettenspitzen der Firma Greiner-Bio-One zum Arbeiten benutzt:

- Filtertips 10E, Art.No. 765288

- Filtertips 100E, Art.No. 772288

- $\quad$ Filtertips 1000E, Art.No. 771288

Bei dem gesamten Arbeitsablauf wurden Untersuchungshandschuhe (Norbaglove-Latex puderfrei, Nr. 905443, NORBA Verbandmittel Danz GmbH) getragen.

Bei dieser quantitativen RT-PCR bestand das Gesamtreaktionsvolumen eines Wells der 96-Well Optical Reaction Plate aus jeweils $25 \mu$ l. Dieses Volumen setzt sich aus cDNA, TaqMan Mastermix, den jeweiligen Forward- und Reverse-Primern, der Probe und speziellem Wasser zusammen. Die eingesetzten Primer und doppelt-fluoreszierenden Gensonden (Probes) wurden zuvor individuell nach unseren Vorgaben von den Firmen Sigma oder PE Applied Biosystems (je nach Gen, siehe nachfolgend) synthetisiert. Der TaqMan Universal PCR Master Mix (Part.No. 4304437, PE Applied Biosystems) enthält in exaktem Mengenverhältnis die folgenden Grundsubstanzen der PCR: AmpliTaq Gold DNA Polymerase, AMPErase UNG, dNTPs (desoxyNucleotidtrisphosphate) und dUNPs sowie optimierte Puffer. 
$\mathrm{Zu}$ Beginn wird die cDNA der entsprechenden Verdünnungsstufe (siehe auch Methode cDNA-Synthese) aufgetaut und gevortext. In die RT-PCR wurden $5 \mu 1$ Volumina in die dafür vorgesehenen Wells eingesetzt. Um Irrtümer beim Pipettieren vorzubeugen und die Auswertung zu erleichtern wurde zuvor ein Pipettierschema erstellt (siehe auch Abbildungen 2.2 und 2.3). Wegen der Lichtempfindlichkeit der doppelt fluoreszierendmarkierten Probes sollten diese so kurz wie möglich lichtexponiert sein. Um die Lichtexposition während der Lagerung zu minimieren wurden sie in lichtdichten Cups gelagert. Zur Beschleunigung des Pipettiervorgangs wurde ein Mastermix erstellt. Dieser bestand aus folgenden Einzelkomponenten:

12,5 $\mu \mathrm{l}$ TaqMan Universal PCR Mastermix (Part.No. 4304437, PE Applied Biosystems), 2,5 $\mu$ l Forward-Primer, 2,5 $\mu$ l Reverse-Primer (custom made), $1 \mu 1$ Probe (custom made) und 1,5 $\mu \mathrm{l}$ Wasser (Water, Molecular Biology Grade 1 1, Order.No. 0032006.159, Eppendorf). Der entstandene Mastermix wurde gevortext und in Volumina zu 20 $\mu 1$ auf die entsprechenden $5 \mu \mathrm{l}$ cDNA in die Wells gegeben. Bevor die fertig pipettierte 96-Well Optical Reaction Plate in den Real Time PCR Thermal Cycler eingebracht wurde, verschloß man die Wells mittels Micro Amp Optical Caps (Part. No. 4323032, PE Applied Biosystems).

Am ABI Prism 7700 Sequence Detection System wurden vor dem Start der quantitativen PCR folgende Thermal Cycler Einstellungen vorgenommen:

Initial wurde das Reaktionsgmisch für 2 min auf $50^{\circ} \mathrm{C}$ erhitzt. Dies ermöglichte der AmpErase UNG eine optimale Enzymaktivität. Danach erfolgte zur Aktivierung der AmpliTaq Gold DNA Polymerase eine Phase von 10 min bei $95^{\circ} \mathrm{C}$. Diese Phase diente auch dazu eine unspezifische Bindung von Primern zu vermeiden. Dann folgten eine two-step PCR mit 40 bis 50 Zyklen von $15 \mathrm{sec}$ bei $95^{\circ} \mathrm{C}$ und $1 \mathrm{~min}$ bei $60^{\circ} \mathrm{C}$. Die Zahl der Zyklen war abhängig von der Genkonzentration der gesuchten cDNA. Nach 2 bis 2,5 h war die PCR beendet und die Daten konnten auf einer zip-disc zur weiteren Bearbeitung gespeichert werden. Abb. 2.1 zeigt nachfolgend ein exemplarisches Ergebnisprotokoll einer RT-PCR.

Die unter 2.2.2.2 gezeigten Daten (humane intestinale Gewebeproben) wurden für weiterführende statistische Berechnungen aufgearbeitet. Gerechnet wurde mit SPSS Version 17.0. Es handelt sich um nonparametrische Paarvergleiche mit Hilfe von Wilcoxon-Tests. 


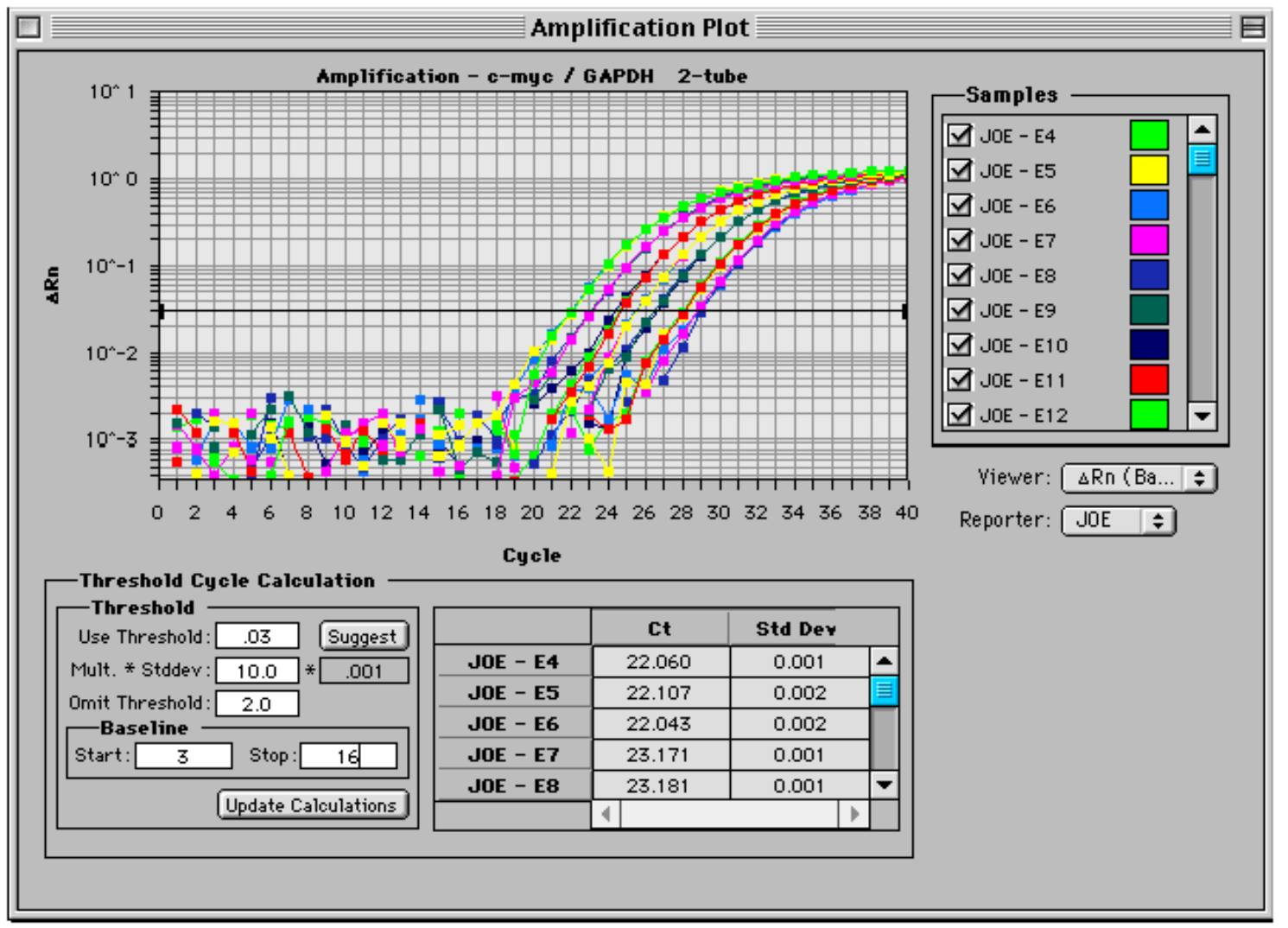

Abb. 2.1 Exemplarisches Ergebnisprotokoll einer real-time quantitativen PCR mit 40 Zyklen 
Gensequenzen und Verdünnungsstufen der verwendeten Primers und Probes:

\section{TMPRSS-2}

Name: $\quad$ hsTMPRSS2-18Forward primer

Sequenz: $\quad$ GCGGAGGCTCCATCATCA

Name: $\quad$ hsTMPRSS2-111Reverse primer

Sequenz: $\quad$ GCAAATGCCGTCCAATGC

Name: $\quad$ hsTMPRSS2-60TaqMan Probe

Sequenz: CCCACTGCGTGGAAAAACCTCTTAACAA

Verdünnung: 1:625

\section{TMPRSS-4}

Name: $\quad$ hsTMPRSS4-188Forward primer

Sequenz: GCCCTCATGAAGCTGCAGTT

Name: $\quad$ hsTMPRSS4-262Reverse primer

Sequenz: CTCATCAAAGAAGGGCAGACAG

Name: $\quad$ hsTMPRSS4-214TaqMan probe

Sequenz: CACTTTCTCAGGCACAGTCAGGCCCAT

Verdünnung: 1:625

\section{MTSP-1}

Name: $\quad$ hsMT-SP1-180Forward primer

Sequenz: TCAATGACTTCACCTTCGACTATGA

Name: $\quad$ hsMT-SP1-314Reverse primer

Sequenz: TGACCCAGATGGCCTTGC

Name: $\quad$ hsMT-SP1-221TaqMan probe

Sequenz: CTGGAGAAACCGGCAGAGTACAGCTCC

Verdünnung: 1:3125

\section{Hepsin}

Name: $\quad$ hsHepsin-197Forward primer

Sequenz: GCGAGGAGAACAGCAACGA

Name: hsHepsin-279Reverse primer

Sequenz: $\quad$ GAGGCACACAGGCTGGATGT

Name: $\quad$ hsHepsin-217TaqMan probe

Sequenz: ATTGCCCTGGTCCACCTCTCCAGTC

Verdünnung: 1:3125 
Alle Primers und Probes wurden nach Verdünnung in entsprechende Volumina (meist $100 \mu \mathrm{l})$ in lichtundurchlässigen Cups alliquotiert und bei $-20^{\circ} \mathrm{C}$ gelagert.

Für jedes zu messende Gen wurde zunächst immer eine so genannte Primer-ProbeMatrix und eine Verdünnungsreihe pipettiert und gemessen. Die Matrix dient der Bestimmung des effizientesten Konzentrationsverhältnisses von Forward- zu ReversePrimer mit der entsprechenden Probe. 50, 300 und $900 \mu$ mol von Forward/- ReversePrimer wurden in den möglichen $3^{2}=9$ Konzentrationsverhältnissen gemessen. Dasjenige Primerverhältnis mit dem höchsten quantitativen Output an umgeschriebenen Genprodukt und gleichzeitig geringster Primer-Konzentration wurde ermittelt, notiert und für alle weiteren Messungen verwendet.

\begin{tabular}{|c|c|c|c|c|c|c|c|c|c|c|c|c|}
\hline $\begin{array}{l}\text { 96well } \\
\text { plate }\end{array}$ & 1 & 2 & 3 & 4 & 5 & 6 & 7 & 8 & 9 & 10 & 11 & 12 \\
\hline $\mathbf{A}$ & $\mathrm{H} 2 \mathrm{O}$ & $\mathrm{H} 2 \mathrm{O}$ & & & & & & & & & & \\
\hline B & $\begin{array}{c}\text { F50 } \\
\text { R900 }\end{array}$ & $\begin{array}{c}\text { F50 } \\
\text { R900 }\end{array}$ & $\begin{array}{l}\text { F300 } \\
\text { R900 }\end{array}$ & $\begin{array}{l}\text { F300 } \\
\text { R900 }\end{array}$ & \begin{tabular}{l|} 
F900 \\
R900
\end{tabular} & $\begin{array}{l}\text { F900 } \\
\text { R900 }\end{array}$ & & & & & & \\
\hline$C$ & $\begin{array}{c}\text { F50 } \\
\text { R300 }\end{array}$ & $\begin{array}{c}\text { F50 } \\
\text { R300 }\end{array}$ & $\begin{array}{l}\text { F300 } \\
\text { R300 }\end{array}$ & $\begin{array}{l}\text { F300 } \\
\text { R300 }\end{array}$ & \begin{tabular}{l|} 
F900 \\
R300
\end{tabular} & $\begin{array}{l}\text { F900 } \\
\text { R300 }\end{array}$ & & & & & & \\
\hline D & $\begin{array}{l}\text { F50 } \\
\text { R50 }\end{array}$ & $\begin{array}{l}\text { F50 } \\
\text { R50 }\end{array}$ & $\begin{array}{l}\text { F300 } \\
\text { R50 }\end{array}$ & $\begin{array}{c}\text { F300 } \\
\text { R50 }\end{array}$ & \begin{tabular}{|c|} 
F900 \\
R50
\end{tabular} & $\begin{array}{c}\text { F900 } \\
\text { R50 }\end{array}$ & & & & & & \\
\hline $\mathbf{E}$ & & & & & & & & & & & & \\
\hline$F$ & & & & & & & & & & & & \\
\hline $\mathbf{G}$ & & & & & & & & & & & & \\
\hline $\mathrm{H}$ & & & & & Hepsin & & & & & & & \\
\hline
\end{tabular}

Abb. 2.2 Exemplarisches Beispiel eines Pipettierschemas mit Primer-Probe-Matrix

Die Verdünnungsreihe ist Voraussetzung für die Quantifizierung der einzelnen Gene. Nur wenn die Amplifikation des Gens über mindestens 5 Konzentrations-log-Stufen stabil bleibt, ist eine Quantifizierung sinnvoll. Hierfür wurden die Konzentrationen 1:5, $1: 25,1: 125,1: 625,1: 3125$ und 1:15625 eingesetzt. In einem Diagramm, in dem auf der Abszisse logarithmisch die cDNA-Konzentration/ -Verdünnung gegen die Anzahl der Zyklen aufgetragen wird, nach der das Amplifikationssignal erstmals positiv wird, muß sich über diese 3 log-Stufen eine Gerade ergeben (siehe auch Abb. 2.4). Nur so kann 
zuverlässig die Konzentration eines Gens in einer unbekannten Probe ermittelt werden. Ein Housekeeping-Gen (meistens Ribosomal 18s RNA) wurde ebenfalls mitverdünnt und gemessen. Damit wurde kontrolliert und belegt, dass sich die verschiedenen Gene in unterschiedlichen Konzentrationen gleich verhalten.

Nachdem man diese Grundabstimmungen bezüglich der Amplifikation festgelegt hatte, d.h. dass die Kurven in Abb. 2.4 parallel verlaufen, konnten die eigentlichen Messungen der verschiedenen Gene durchgeführt werden. Ein PCR-Run oder Lauf besteht wie oben bereits beschrieben aus 40 bis 50 Zyklen und dauert 2 bis 2,5 h. Die aus einem solchen Lauf ermittelten Daten werden Ct-Werte genannt. Diese geben den Zyklus wieder, in dem sich das entsprechende Gen und damit auch sein Genprodukt quantitativ verändert. Diese Veränderung wird registriert über die Messung der Fluoreszenzintensität, die somit die Quantität des Genproduktes wiederspiegelt. Zur weiteren Auswertungen der Daten muß der Ct-Wert eines Gens von dem Wert des entsprechenden HouskeepingGens subtrahiert werden. Diese Differenz wird nun von einem Normwert, zum Beispiel einer unstimulierten Zelle, subtrahiert und das Ergebnis als Potenz zur Basis 2 gestellt. Dieses Ergebnis kann eine Erhöhung oder Verringerung der Genexpression beschreiben und dann im Kontext von weiteren Messungen gesehen und interpretiert werden.

\begin{tabular}{|c|c|c|c|c|c|c|c|c|c|c|c|c|}
\hline $\begin{array}{l}\text { 96well } \\
\text { plate }\end{array}$ & 1 & 2 & 3 & 4 & 5 & 6 & 7 & 8 & 9 & 10 & 11 & 12 \\
\hline A & $\mathrm{H} 2 \mathrm{O}$ & $\mathrm{H} 2 \mathrm{O}$ & $\overline{\mathrm{H} 2 \mathrm{O}}$ & $\mathrm{H} 2 \mathrm{O}$ & & & & & & & & \\
\hline B & $1 / 25$ & $1 / 25$ & $1 / 25$ & $1 / 25$ & & & & & & & & \\
\hline C & $1 / 125$ & $1 / 125$ & $1 / 125$ & $1 / 125$ & & & & & & & & \\
\hline D & $1 / 625$ & $1 / 625$ & $1 / 625$ & $1 / 625$ & & & & & & & & \\
\hline $\mathbf{E}$ & $\begin{array}{c}1 / \\
3125\end{array}$ & $\begin{array}{c}1 / \\
3125\end{array}$ & $\begin{array}{c}1 / \\
3125\end{array}$ & $\begin{array}{c}1 / \\
3125\end{array}$ & & & & & & & & \\
\hline $\mathbf{F}$ & $\begin{array}{c}1 / \\
15625\end{array}$ & $\begin{array}{c}1 / \\
15625\end{array}$ & $\begin{array}{c}1 / \\
15625\end{array}$ & $\begin{array}{c}1 / \\
15625\end{array}$ & & & & & & & & \\
\hline $\mathbf{G}$ & & & & & & & & & & & & \\
\hline $\mathbf{H}$ & epsin & & $18 s$ & & & & & & & & & \\
\hline
\end{tabular}

Abb. 2.3 Exemplarisches Beispiel eines Pipettierschemas mit Verdünnungsreihe von Hepsin und Housekeeping-Gen $18 \mathrm{~s}$ 


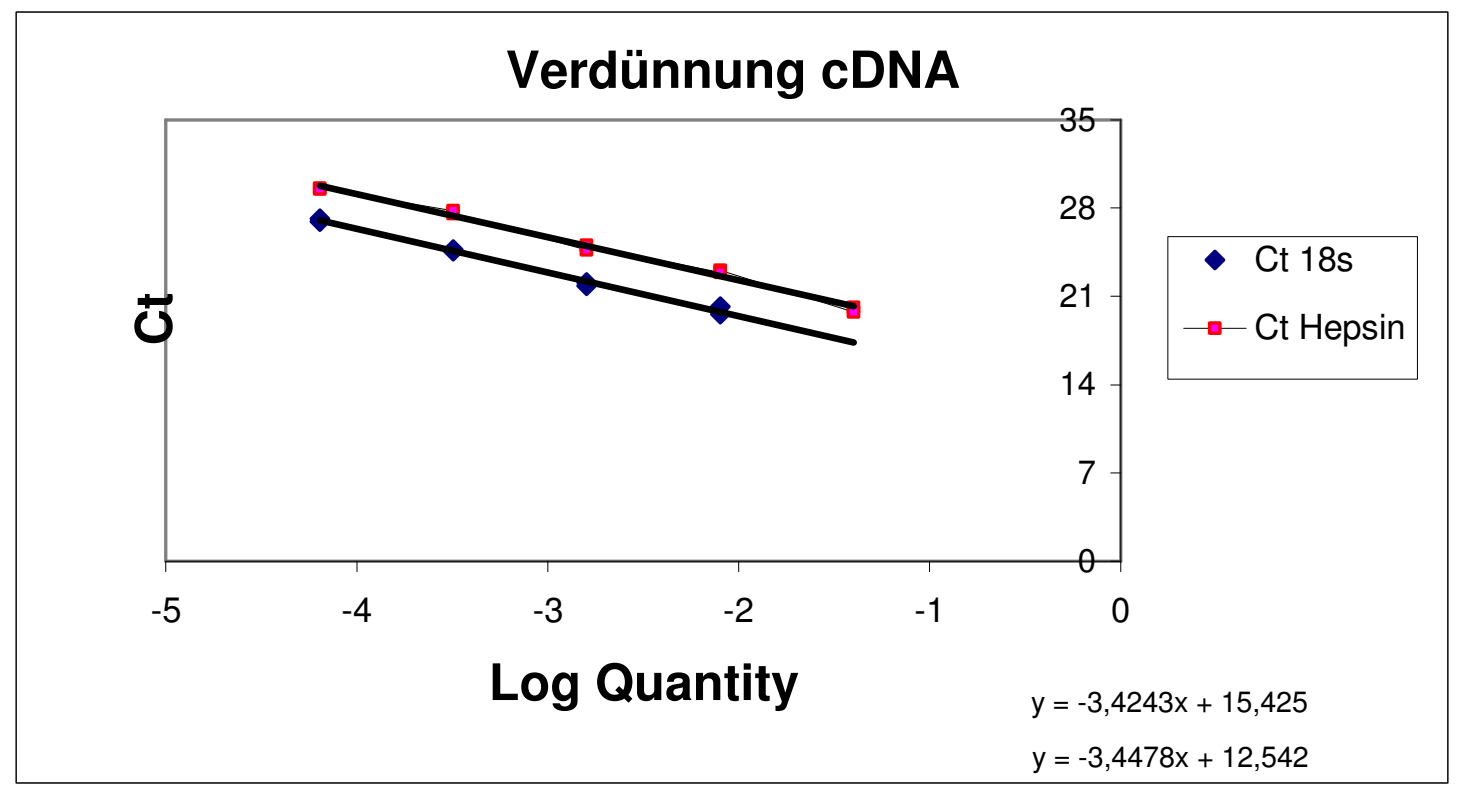

Abb. 2.4 Exemplarisches Beispiel einer Verdünnungsreihe

\subsubsection{Zytokin-, LPS-, Dexamethason-Experiment}

Bei diesem Experiment wurden Monolayers der beiden intestinalen Epithelzelllinien HT29 und Caco2 mit proinflammatorischen Zytokinen, LPS und Dexamethason stimuliert und die Expression der TTSP über $72 \mathrm{~h}$ monitoriert.

Während des gesamten Arbeitsablaufs wurden Untersuchungshandschuhe (NorbagloveLatex puderfrei, Nr. 905443, NORBA Verbandmittel Danz GmbH) getragen.

Folgende Pipetten, Filtertips, Eppendorf-Pipetten und Pipettierhilfen wurden verwendet:

- Pipette 710180 Cellstar 2 ml, Cat. 310104; Pipette 606180 Cellstar 5 ml, Cat. 101102; Pipette 607180 Cellstar 10 ml, alle Firma greiner bio-one GmbH.

- Filtertips 10E, Art.No. 765288; Filtertips 100E, Art.No. 772288; Filtertips 1000E, Art.No. 771288, alle Firma greiner bio-one GmbH.

- Pipette Eppendorf Research variabel 0,5-10 $\mu 1$, Nr. 9283385, Pipette Eppendorf Research variabel 10-100 $\mu 1$, Nr. 9283383, Pipette Eppendorf Research variabel 100-1000 $\mu 1$, Nr. 9283381, alle Firma Eppendorf.

- Pipetboy acu, Nr. 155019, IBS Integra Biosciences 
Wie bereits oben beschrieben, wurden die bekannten intestinalen Epithelzelllinien (IEC) HT29 und Caco2 verwendet. Für weitere Informationen zu diesen Zelllinien wird auf den Abschnitt „Methoden“ 2.2.1 Zellkultur verwiesen.

$\mathrm{Zu}$ Beginn wurden unter Verwendung einer Neubauer-Zählkammer HT29 mit ca. 160.000 und Caco2 mit ca. 180.000 Zellen pro Well einer 6-Well-Platte (TC-plate Cellstar 6 Well, Cat. 657160, greiner bio-one $\mathrm{GmbH}$ ) ausgesät. Die Zellen wurden in idealem Milieu für $4 \mathrm{~d}$ inkubiert. War unter mikroskopischer Betrachtung ein subkonfluenter Monolayer erreicht, konnte das Stimulationsexperiment beginnen.

Man beginnt mit dem Absaugen des alten Mediums. Das neue, für jede Zelllinie spezifische Medium, wurde zuvor mit den entsprechend berechneten vier Zytokinen sowie Dexamethason und Dexamethason + IL-1 $\beta$ (nach einer Stunde) versetzt. $2 \mathrm{ml}$ des neuen Mediums wurden pro Well pipettiert. Jedes Well beinhaltete jetzt $2 \mathrm{ml}$ Medium mit folgenden Konzentrationen:

- IFN- $\gamma, 25$ ng/ml, (Cat.No. 050494, Roche)

- $\quad$ IL-1 $\beta, 0,3$ ng/ml, (Cat.No. 1457756, Roche)

- $\quad$ TNF- $\alpha, 3$ ng/ml, (Cat.No. 1371843, Roche)

- $\quad$ LPS, 30 ng/ml, (No. F3665, Sigma)

- Dexamethason, 1x $10^{-7}$ M, (No. D4902, Sigma)

Zur gleichen Zeit wurden die 0 h-Werte (einer pro 6-Well-Platte) isoliert. Dies ist der eigentliche Start und zugleich Nullpunkt des Experiments. Die Isolation der RNA wurde analog der schon in Material und Methoden unter 2.2.2.1 beschriebenen Vorgehensweise mit dem RNA-Isolierungs-Kit RNeasy Mini Kit (Cat. 74104) der Firma Qiagen durchgeführt.

Das Medium mit den Stimulationszusätzen verblieb während des gesamten Zeitverlaufs auf den Zellen. Eine Ausnahme bildet dabei Dexamethason + IL-1 $\beta$. Hierbei wurde zunächst Dexamethason in der oben genannten Konzentration auf die Wells pipettiert und nach einer Stunde IL-1 $\beta$, ebenfalls in der oben beschriebenen Konzentration, hinzugegeben. Die weiteren Zeitpunkte zum Isolieren der RNA wurden bei 2, 4, 8, 12 und 24 h sowie im Dexamethason-Experiment nach weiteren 48 und 72 h durchgeführt. Nach der Isolation des letzten Zeitpunktes, also nach 24 bzw. 72 h, endete das Experiment. In weiteren Arbeitsschritten wurde die gewonnene RNA analog dem unter 2.2.3 beschriebenen Vorgehen in cDNA umgeschrieben. 


\subsubsection{Bakterien-Experimente}

Bei diesen Versuchen wurden Monolayers von intestinalen Epithelzellen (IEC) mit unterschiedlichen Bakterien infiziert. Als Zelllinien fanden die bereits zuvor schon beschriebenen HT29 und Caco2 Verwendung. Die IEC wurden mit folgenden Bakterien infiziert:

- Escherichia coli (nicht invasiv, gramnegativ), ATCC 25922, Mikrobiologie Universität Marburg

- Escherichia coli (nicht invasiv, gramnegativ), 0157 EHEC, Mikrobiologie Universität Marburg

- Escherichia coli (nicht invasiv, gramnegativ), Nissle 1917, Ardey Pharma

- Enterococcus faecium (nicht invasiv, gramnegativ), ATCC 29212, Mikrobiologie Universität Marburg

- Listeria monocytogenes (invasiv, grampositiv), Patienten-Isolat, Mikrobiologie Uni Marburg

- Salmonella typhi (invasiv, gramnegativ), MCCM 01631, Mikrobiologie Universität Marburg

- Yersinia enterocolitica (invasiv, gramnegativ), MCCM 01839, Mikrobiologie Universität Marburg

Diese Bakterien wurden mit freundlicher Unterstützung von Dr. Zimmermann, Institut für Mikrobiologie, Universitätsklinikum Marburg, bereitgestellt.

Bei dem gesamten Arbeitsablauf wurden Untersuchungshandschuhe (Norbaglove-Latex puderfrei, Nr. 905443, NORBA Verbandmittel Danz GmbH) getragen.

Folgende Pipetten, Filtertips, Eppendorf-Pipetten und Pipettierhilfen wurden verwendet:

- Pipette 710180 Cellstar 2 ml, Cat. 310104; Pipette 606180 Cellstar 5 ml, Cat. 101102; Pipette 607180 Cellstar 10 ml, alle Firma greiner bio-one GmbH.

- Filtertips 10E, Art.No. 765288; Filtertips 100E, Art.No. 772288; Filtertips 1000E, Art.No. 771288, alle Firma greiner bio-one GmbH.

- Pipette Eppendorf Research variabel 0,5-10 $\mu 1$, Nr. 9283385, Pipette Eppendorf Research variabel 10-100 $\mu 1$, Nr. 9283383, Pipette Eppendorf Research variabel 100-1000 $\mu 1$, Nr. 9283381, alle Firma Eppendorf. 
- Pipetboy acu, Nr. 155019, IBS Integra Biosciences

\subsubsection{Versuchsbeschreibung}

In diesem Bakterien-Versuch wurden dieselben Medien und Zusätze, welche schon im Abschnitt „Methoden“ 2.2.1 Zellkultur für die jeweilige Zelllinie beschrieben wurden, benutzt. $\mathrm{Zu}$ Beginn wurden unter Verwendung einer Neubauer-Zählkammer (Nr. 9161086, Kobe) HT29 mit ca. 160.000 und Caco2 mit ca. 180.000 Zellen pro Well einer 6-Well-Platte (TC-plate Cellstar 6 Well, Cat. 657160, greiner bio-one GmbH) ausgesät. Die Wells wurden weiter inkubiert. Nach 4 Tagen war Subkonfluenz erreicht und somit der eigentliche Start des Bakterien-Experiments möglich. In der Zwischenzeit wurden die Bakterien im Mikrobiologischen Institut kultiviert. Für den Versuchsansatz der 3 verschiedenen E. coli- Stämme (ATCC 25922, EHEC 0157 und Nissle 1917) wurden diese Bakterien noch weiter in Bakterien, Bakterienkulturüberstand und hitzeinaktivierte Bakterien differenziert. Bei der Bakterien-Versuchsreihe mussten diese zunächst mit einer sterilen Öse vom Nähragar ihrer Kulturschale abgeschabt und in Zellkulturmedium aufgelöst werden. In der zweiten Versuchsreihe wurden Bakterien in antibiotikafreiem, flüssigem Zellmedium kultiviert. Die benötigte Menge wurde durch einen sterilen Mikrofilter gepresst. Dieser Überstand enthielt somit keine Bakterien mehr. Die dritte Versuchsreihe wurde mit hitzeinaktivierten Bakterien durchgeführt. Dazu wurden die in Medium kultivierten Bakterien für 15 min bei $80^{\circ} \mathrm{C}$ erhitzt, abgekühlt und auf die Zellen gegeben.

Die genaue Bestimmung der Bakterienzahl erfolgte mittels photometrischer Trübungsmessung nach McFarland. Im Durchschnitt wurde ein Wert von 4.0 McFarland ermittelt. Anschließend wurde durch Ausplattierung in Verdünnungsschritten von $10^{-2}, 10^{-3}$ und $10^{-4}$ und Zählung der Kolonien nach $24 \mathrm{~h}$ die im Experiment verwandte Bakterienzahl nachgewiesen, diese betrug im Durchschnitt 3 x $10^{8}$. Nach McFarland-Bestimmung und Verdünnen der Bakterien in dem jeweiligen Medium (ohne Antibiotika-Zusatz) der entsprechenden Zelllinie wurden $2 \mathrm{ml}$ dieser Substanz in die dafür bestimmten Wells pipettiert. Zur gleichen Zeit erfolgte die RNAIsolation der 0 h-Werte. Die Isolation der RNA wurde analog der schon in „Methoden“ 2.2.2.1 RNA-Isolierung aus IEC beschriebenen Vorgehensweise mit dem RNAIsolierung-Kit RNeasy Mini Kit (Cat. 74104) der Firma Qiagen durchgeführt. 
Die Bakterien-Medium-Suspension wurde für eine Stunde auf den Zellmonolayern belassen. Dann wurde diese Lösung abgesaugt, der Zellrasen mit PBS (PBS- Puffer 0,1 M, Nr. 6580/ 6346, Merck) gewaschen, wiederum abgesaugt, und durch $3 \mathrm{ml}$ neues, diesmal mit Antibiotika (10 mg/ml Penicillin/ Streptomycin, Cat. P 11-010, paa Laboratories $\mathrm{GmbH}$ und $16 \mu \mathrm{g} / \mathrm{ml}$ Ampicillin, Cat.No. A5354, Sigma) versehenes Medium ersetzt. Nach 2 h wurde die nächste RNA-Isolierung, wieder mittels RNAIsolierung-Kit RNeasy Mini Kit (Cat. 74104) der Firma Qiagen, durchgeführt. Analog erfolgten die RNA-Isolierungen nach 4, 8, 12 und $24 \mathrm{~h}$. Die gewonnene RNA wurde im weiteren Ablauf in cDNA umgeschrieben (siehe auch unter 2.2.3). 


\section{Hauptteil}

\subsection{Genexpression von Typ II transmembranären Serin Proteasen (TTSP) in humanen gastrointestinalen Geweben}

Die mRNA-Expression der TTSP und PAR-2 wurde entlang der longitudinalen Achse des humanen Gastrointestinaltraktes untersucht. Hepsin wurde in keinem Gewebe exprimiert, Enterokinase ließ sich lediglich in humanem Duodenum nachweisen. Die Expression von TMPRSS-2, TMPRSS-4, MTSP-1 und PAR-2 ist in den Abbildungen

3.1 bis 3.4 dargestellt sowie in Tabelle 3.1 zusammengefasst.

\begin{tabular}{|l|c|c|c|c|}
\hline \multicolumn{1}{|c|}{ Gen } & TMPRSS-2 & TMPRSS-4 & MTSP-1 & PAR-2 \\
\hline Lokalisation & & & & \\
\hline Korpus & ++ & -- & + & + \\
\hline Antrum & - & - & - & + \\
\hline Duodenum & -- & - & + & + \\
\hline Term. Ileum & + & + & + & $0 /-$ \\
\hline Caecum & ++ & + & +++ & ++ \\
\hline Colon asc. & +++ & + & ++ & + \\
\hline Colon trans. & - & + & + & - \\
\hline Colon desc. & + & + & + & + \\
\hline Sigma & 0 & $0 /-$ & 0 & + \\
\hline Rectum & 0 & 0 & 0 & 0 \\
\hline
\end{tabular}

Tab. 3.1: Übersicht der Genexpression von TTSP im Verlauf des humanen GI-Trakts

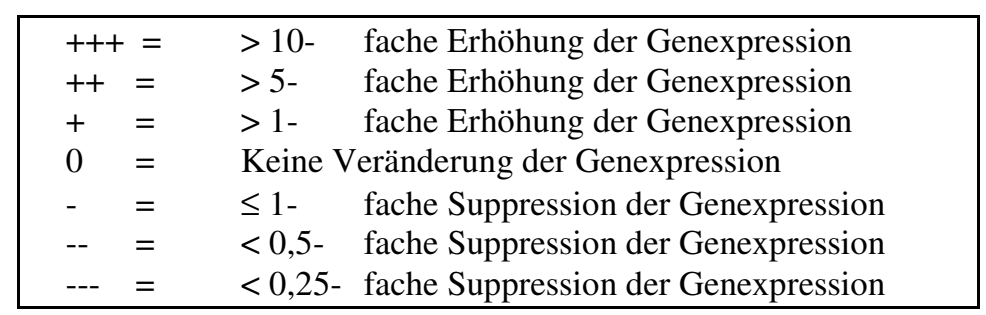

Anmerkung: Rectum wurde als Referenzwert verwendet 
TMPRSS-2: Als Referenzwert wurde das Rectum festgelegt. TMRSS-2 wird entlang des humanen Gastrointestinaltrakts bei 5 von 9 Lokalisationen deutlich erhöht exprimiert. Im Magenkorpus findet sich eine knapp 8-fache, im terminalen Ileum eine 2,7-fache Erhöhung der Genexpression. Die maximale Induktion zeigt sich im Caecum mit einer 8,3-fachen Erhöhung. Auch im Colon ascendens und Colon descendens findet sich eine 4,3- bzw. 4,2-fache Erhöhung der TMPRSS-2- Genexpression. Magenantrum und Duodenum zeigen eine deutliche Suppression der Genexpression (0,6- und 0,5fach). Dagegen weisen Colon transversum und Sigma keine wesentlichen Veränderungen auf. (Abb. 3.1)

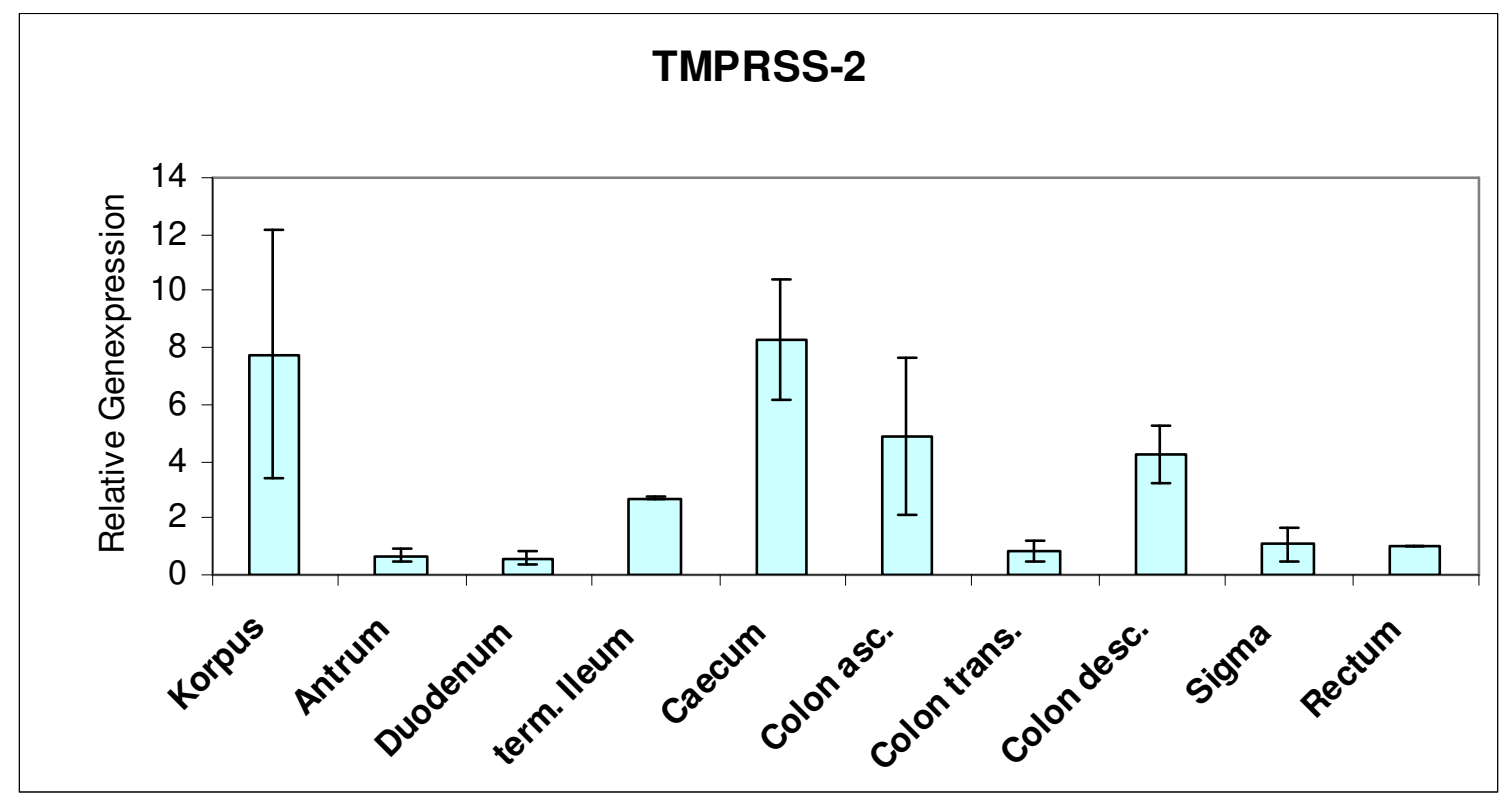

Abb. 3.1: Die RNA-Isolation erfolgte aus Gewebe, das während elektiver ÖsophagoGastro-Duodenoskopie und Koloskopie aus gesundem, nicht entzündlichem Gewebe an den oben genannten zehn Lokalisationen des humanen Gastrointestinaltrakts bioptisch gewonnen wurde. Die Messung der relativen Genexpression erfolgte mittels quantitativer RT-PCR und Normalisierung der Werte zu 18sRNA. Die Anzahl der Proben betrug bei jeder Lokalisation $n \geq 3$. Der Rectum-Wert dient als Bezugsgröße und wurde zur Berechnung gleich 1 gesetzt. Es ist der Standardfehler des Mittelwertes (SEM) abgebildet. 
TMPRSS-4: Rectum wurde analog zu TMPRSS-2 als Referenzwert festgelegt. TMPRSS-4 wird entlang der longitudinalen Achse des menschlichen Verdauungstrakts vor allem im Bereich des Colons erhöht exprimiert. Dagegen weisen Magenkorpus und Magenantrum mit einer 0,2-fachen und 0,5-fachen sowie Duodenum mit einer 0,4fachen Genexpression eine deutliche Suppression auf. Im terminalen Ileum zeigt sich eine 2,3-fache, im Caecum eine 3-fache Erhöhung der Genexpression. Auch im weiteren Verlauf nach caudal bleibt die Genexpression für TMPRSS-4 erhöht. So weisen die Proben des Colon ascendens eine 2,5-fache, die des Colon transversum noch eine 1,6-fache Erhöhung auf. Im Colon descendens zeigt TMPRSS-4 sein absolutes Maximum mit einer 3,7-fachen Erhöhung der Genexpression. Im Sigmabereich zeigt sich ähnlich wie bei TMPRSS-2 keine ausgeprägte Veränderung. (Abb. 3.2)

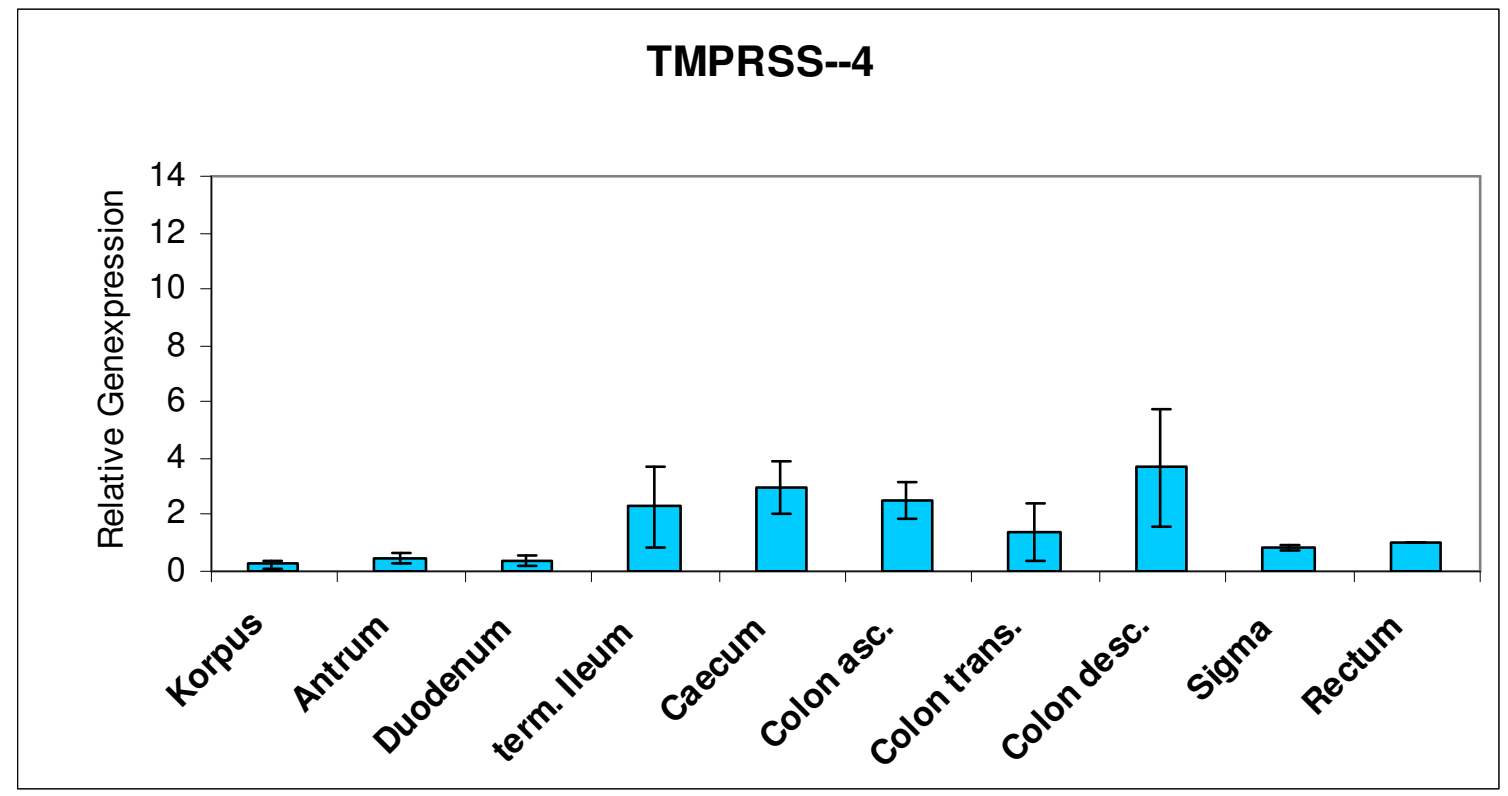

Abb. 3.2: Die RNA-Isolation erfolgte aus Gewebe, das während elektiver ÖsophagoGastro-Duodenoskopie und Koloskopie aus gesundem, nicht entzündlichem Gewebe an den oben genannten zehn Lokalisationen des humanen Gastrointestinaltrakts bioptisch gewonnen wurde. Die Messung der relativen Genexpression erfolgte mittels quantitativer RT-PCR und Normalisierung der Werte zu 18sRNA. Die Anzahl der Proben betrug bei jeder Lokalisation $\mathrm{n} \geq 3$. Der Rectum-Wert dient als Bezugsgröße und wurde zur Berechnung gleich 1 gesetzt. Es ist der Standardfehler des Mittelwertes (SEM) abgebildet. 
MTSP-1: MTSP-1 zeigt unter den gemessenen TTSP innerhalb der Gewebeproben des GI-Trakts die stärkste Induktion. Magenkorpus und Magenantrum zeigen keine ausgeprägte Veränderung. Im Duodenum und terminalen Ileum erhöht sich die Genexpression auf das 3,2- und 2,6-fache. Das absolute Maximum wird im Bereich des Caecums mit einer gut 11-fachen Erhöhung der Genexpression gemessen. Im Colon ascendens und descendens zeigt sich die Genexpression von MTSP-1 ebenfalls ausgeprägt erhöht mit einer 5,3- und 3,4-fachen Induktion. Colon transversum und Sigma weisen keine wesentlichen Veränderungen auf. (Abb. 3.3)

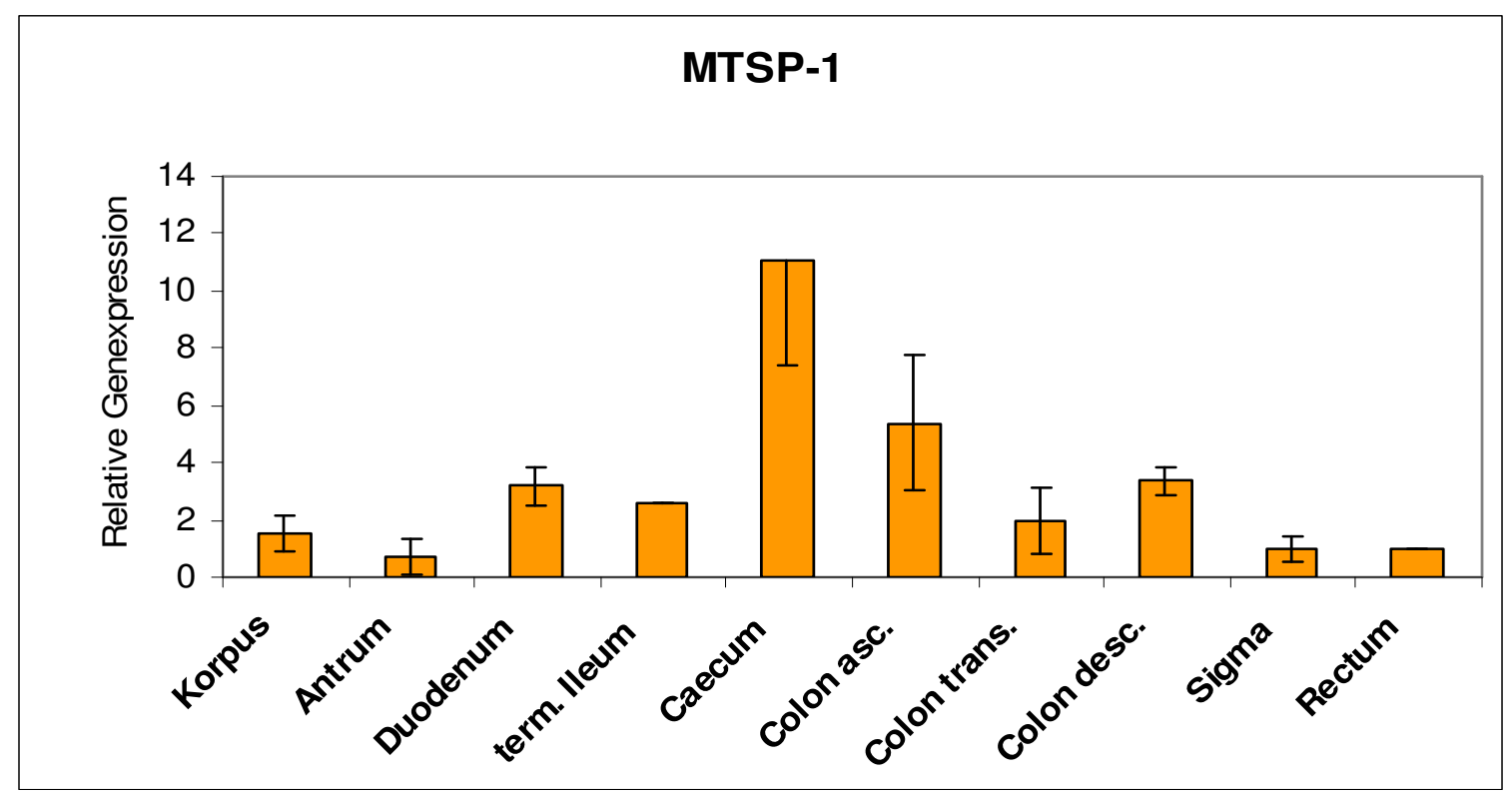

Abb. 3.3: Die RNA-Isolation erfolgte aus Gewebe, das während elektiver ÖsophagoGastro-Duodenoskopie und Koloskopie aus gesundem, nicht entzündlichem Gewebe an den oben genannten zehn Lokalisationen des humanen Gastrointestinaltrakts bioptisch gewonnen wurde. Die Messung der relativen Genexpression erfolgte mittels quantitativer RT-PCR und Normalisierung der Werte zu 18sRNA. Die Anzahl der Proben betrug bei jeder Lokalisation $\mathrm{n} \geq 3$. Der Rectum-Wert dient als Bezugsgröße und wurde zur Berechnung gleich 1 gesetzt. Es ist der Standardfehler des Mittelwertes (SEM) abgebildet. 
PAR-2: Im Vergleich mit den TTSP zeigt PAR-2 ein sehr ähnliches Expressionsmuster entlang der longitudinalen Achse des humanen GI-Trakts. Im Magenantrum und -korpus zeigen sich mit 1,7- und 1,8-facher Induktion nur geringe Erhöhungen der Genexpression. Der Bereich des Duodenums zeigt eine 3,8-fache Erhöhung. Dagegen unterliegt das terminale Ileum keiner wesentlichen Veränderung (0,9-fach). Das Caecum weist das absolute Maximum mit einer 7,8-fachen Induktion auf. Im Colon ascendens zeigt sich die relative Genexpression noch um das 3,8-fache erhöht. Im weiteren Verlauf wird PAR-2 im Colon transversum mit 0,6-fach deutlich supprimiert. Im Colon descendens mit einer 1,9-fachen Induktion und im Sigma mit einer 2,5-fachen Induktion zeigt sich dagegen wieder eine Erhöhung der Genexpression. Zur Berechnung und Darstellung wurde wiederum Rectum als Referenzwert festgelegt. (Abb. 3.4)

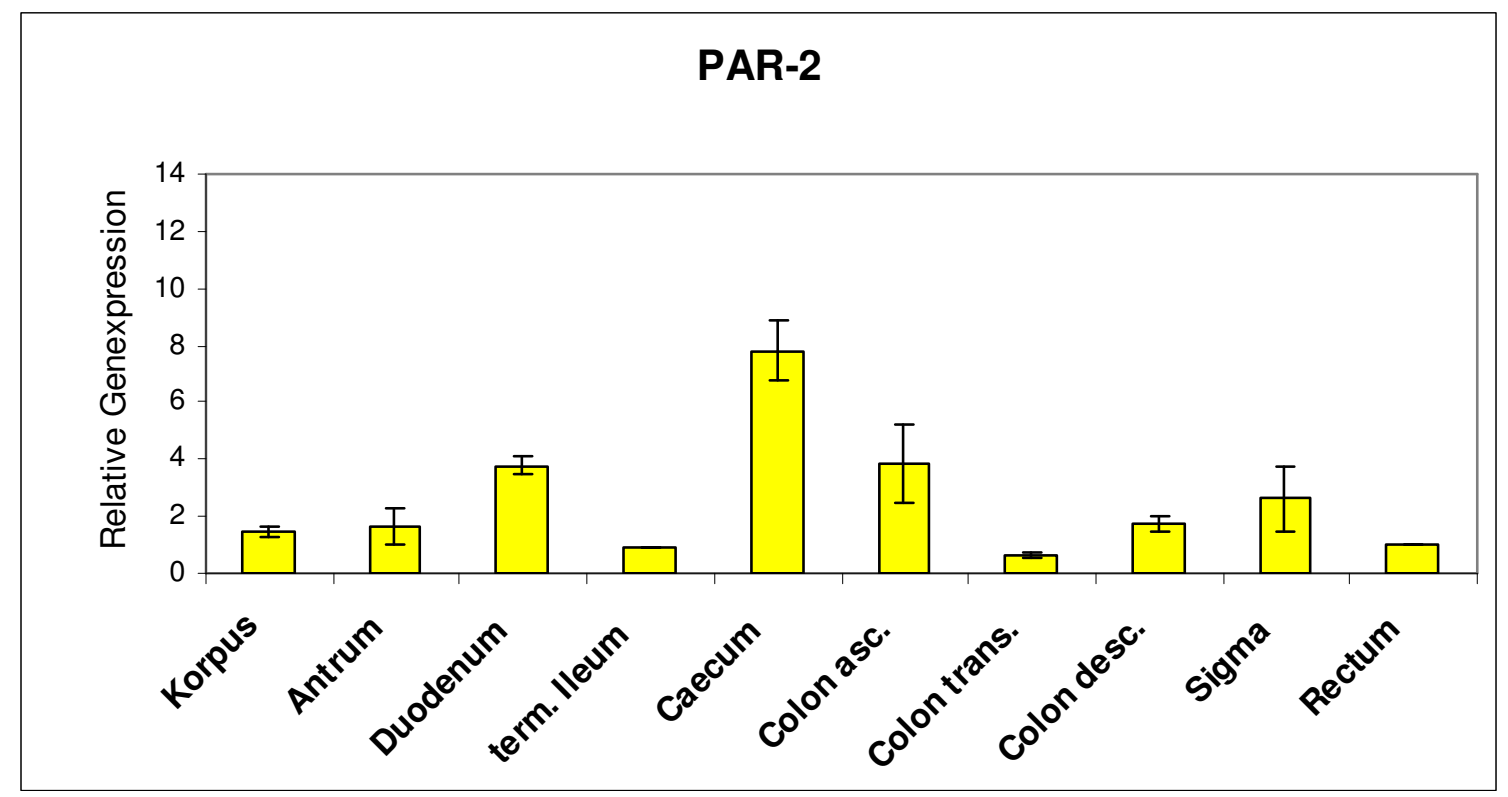

Abb. 3.4: Die RNA-Isolation erfolgte aus Gewebe, das während elektiver ÖsophagoGastro-Duodenoskopie und Koloskopie aus gesundem, nicht entzündlichem Gewebe an den oben genannten zehn Lokalisationen des humanen Gastrointestinaltrakts bioptisch gewonnen wurde. Die Messung der relativen Genexpression erfolgte mittels quantitativer RT-PCR und Normalisierung der Werte zu 18sRNA. Die Anzahl der Proben betrug bei jeder Lokalisation $\mathrm{n} \geq 3$. Der Rectum-Wert dient als Bezugsgröße und wurde zur Berechnung gleich 1 gesetzt. Es ist der Standardfehler des Mittelwertes (SEM) abgebildet. 


\subsubsection{Statistische Auswertung der Expression der TTSP und PAR-2 nach Lokalisation im humanen GI-Trakt}

\begin{tabular}{|c|c|c|c|c|}
\hline Gen & \multicolumn{2}{|c|}{ TMPRSS-2 } & \multicolumn{2}{|c|}{ TMPRSS-4 } \\
\hline Statistik & Wilcoxon-Z & Signifikanz [p] & Wilcoxon-Z & Signifikanz [p] \\
\hline Lokalisation & & & & \\
\hline Korpus & $-1,069$ & 0,285 & $-1,604$ & 0,109 \\
\hline Antrum & $-1,069$ & 0,285 & $-1,604$ & 0,109 \\
\hline Duodenum & $-2,023$ & 0,043 & $-2,023$ & 0,043 \\
\hline Term. Ileum & $-1,342$ & 0,180 & $-1,069$ & 0,285 \\
\hline Caecum & $-1,604$ & 0,109 & $-1,604$ & 0,109 \\
\hline Colon asc. & $-1,604$ & 0,109 & $-1,604$ & 0,109 \\
\hline Colon trans. & $-0,535$ & 0,593 & 0,000 & 1,000 \\
\hline Colon desc. & $-1,604$ & 0,109 & $-1,069$ & 0,285 \\
\hline Sigma & $-0,535$ & 0,593 & $-0,535$ & 0,593 \\
\hline Gen & \multicolumn{2}{|c|}{ MTSP-1 } & \multicolumn{2}{|c|}{ PAR-2 } \\
\hline Statistik & Wilcoxon-Z & Signifikanz [p] & Wilcoxon-Z & Signifikanz [p] \\
\hline $\begin{array}{l}\text { Lokalisation } \\
\text { Korpus }\end{array}$ & $-1,069$ & 0,285 & $-1,604$ & 0,109 \\
\hline Antrum & 0,000 & 1,000 & $-1,069$ & 0,285 \\
\hline Duodenum & $-2,201$ & 0,028 & $-2,201$ & 0,028 \\
\hline Term. Ileum & $-1,342$ & 0,180 & $-0,447$ & 0,655 \\
\hline Caecum & $-1,604$ & 0,109 & $-1,604$ & 0,109 \\
\hline Colon asc. & $-1,069$ & 0,285 & $-1,604$ & 0,109 \\
\hline Colon trans. & $-0,535$ & 0,593 & $-1,633$ & 0,102 \\
\hline Colon desc. & $-1,604$ & 0,109 & $-1,604$ & 0,109 \\
\hline Sigma & $-0,535$ & 0,593 & $-1,604$ & 0,109 \\
\hline
\end{tabular}

Tab. 3.2: Ergebnisse der nonparametrischen Paarvergleiche mittels Wilcoxon-Tests

Anmerkung: Rectum wurde als Referenzwert verwendet und gleich 1 gesetzt 


\subsubsection{Textorische Zusammenfassung der Genexpression von TTSP und PAR-2 in humanen gastrointestinalen Geweben}

1. Das augenfälligste Ergebnis ist die starke Induktion von MTSP-1, TMPRSS-2, PAR-2 und TMPRSS-4 vor allem im Bereich des Caecums und Colon ascendens.

2. Quantitativ die ausgeprägteste Geninduktion zeigen MTSP-1 und TMPRSS-2 mit einer 11-fachen und 8,3-fachen Erhöhung im Caecum.

3. TMPRSS-4 unterliegt im oberen GI-Trakt einer Suppression. Dagegen zeigt TMPRSS-2 im Bereich des Magenantrums eine deutliche Induktion.

4. MTSP-1 und PAR-2 zeigen im Duodenum eine sehr ähnliche, statistisch signifikant $(\mathrm{p}<=0,05)$ Induktion mit 3,2-facher und 3,8-facher Erhöhung der Genexpression.

5. Dagegen werden TMPRSS-2 und TMPRSS-4 im Duodenum signifikant supprimiert $(\mathrm{p}<=0,05)$.

6. Hepsin wurde in keinem Gewebe exprimiert.

7. Enterokinase ließ sich lediglich im Duodenum nachweisen.

8. Insgesamt zeigt sich für MTSP-1, TMPRSS-2, TMPRSS-4 und PAR-2 ein immer gleiches Muster der Genexpression mit stärkster Induktion (++) im Caecum, robuster Induktion (+) im Colon ascendens, keiner wesentlichen Induktion (o) im Colon transversum sowie einer deutlichen Induktion (+) im Colon descendens.

\subsection{Expression von TTSP in IEC in Abhängigkeit von proinflammatorischen Zytokinen, LPS und Dexamethason}

Monolayers der Zelllinien HT29 und Caco2 wurden mit IFN- $\gamma$ (25 ng/ml), IL-1 $\beta$ (0,3 $\mathrm{ng} / \mathrm{ml}), \mathrm{TNF}-\alpha(3 \mathrm{ng} / \mathrm{ml})$, LPS $(30 \mathrm{ng} / \mathrm{ml})$ sowie Dexamethason $\left(1 \times 10^{-7} \mathrm{M}\right)$ und Dexamethason + IL-1 $\beta$ stimuliert und die Expression der TTSP über 72h monitoriert. 


\subsubsection{HT29- und Caco2-Zellen mit IFN-gamma}

IFN-gamma bei HT29-Zellen: Nach einer 3-fachen Erhöhung nach 2 h steigt Hepsin bis zum Endpunkt der Messung bei $72 \mathrm{~h}$ auf eine 21,9-fache Erhöhung an. MTSP-1 zeigt keine deutliche Induktion seiner Genexpression und liegt bei allen Stundenwerten minimal ober- und unterhalb der Baseline. IFN- $\gamma$ induziert bei TMPRSS- 2 und -4 eine deutliche Suppression der relativen Genexpression. Beide Kurven verlaufen ähnlich und zeigen den niedrigsten Wert jeweils bei $12 \mathrm{~h}$ (0,2- und 0,4-fach). (Abb. 3.5)

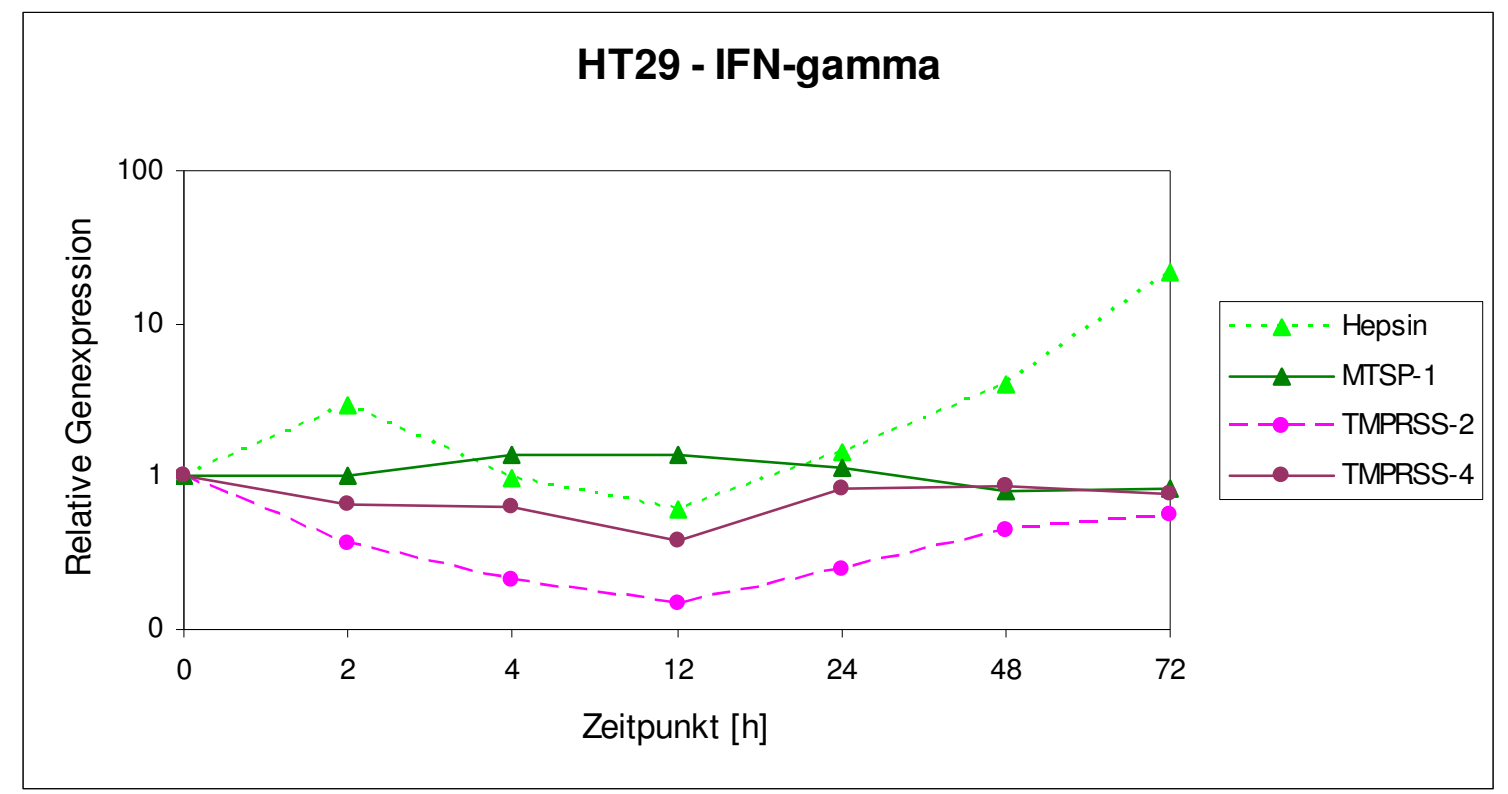

Abb. 3.5: Monolayers der Zelllinie HT29 wurden bei Subkonfluenz mit dem Zytokin IFN- $\gamma(25 \mathrm{ng} / \mathrm{ml})$ stimuliert. Die RNA wurde nach 0, 2, 4, 12, 24, 48 und $72 \mathrm{~h}$ isoliert. Unter Verwendung eines Transkriptionskits wurde cDNA hergestellt und die Genexpression mittels real time quantitative PCR bestimmt. Die Werte wurden gegen 18sRNS normalisiert. 
IFN-gamma bei Caco2-Zellen: IFN- $\gamma$ induziert bei Hepsin eine Erhöhung der Genexpression mit einem Maximum (2,1-fach) nach 4 h. MTSP-1 wird kontinuierlich ansteigend bis einschließlich 24 h nur schwach erhöht exprimiert (Maximum 1,5-fach), um danach zum $72 \mathrm{~h}$-Wert hin abzufallen.

TMPRSS-2 und TMPRSS-4 zeigen weder eine ausgeprägte Erhöhung noch Erniedrigung der Genexpression im gesamten Zeitverlauf und schwanken beide um

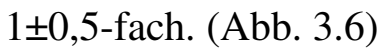

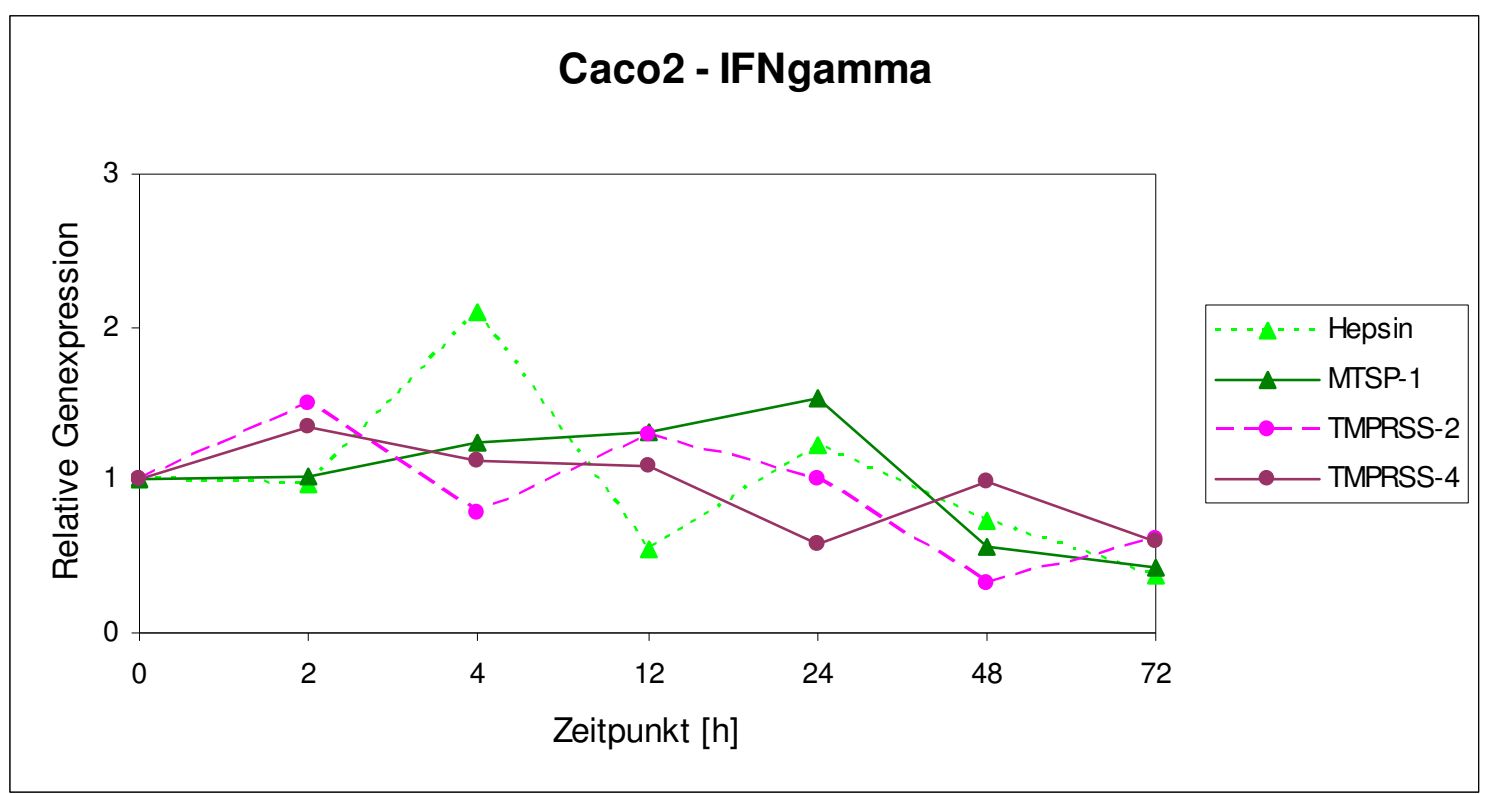

Abb. 3.6: Monolayers der Zelllinie Caco 2 wurden bei Subkonfluenz mit dem Zytokin IFN- $\gamma(25 \mathrm{ng} / \mathrm{ml})$ stimuliert. Die RNA wurde nach 0, 2, 4, 12, 24, 48 und $72 \mathrm{~h}$ isoliert. Unter Verwendung eines Transkriptionskits wurde cDNA hergestellt und im abschließenden Arbeitsschritt die Genexpression mittels real time quantitative PCR bestimmt. Die Werte wurden gegen 18sRNS normalisiert. 


\subsubsection{HT29- und Caco2-Zellen mit IL-1beta}

IL-1beta bei HT29-Zellen: IL-1 $\beta$ induziert eine Suppression der Genexpression von Hepsin bis einschließlich $24 \mathrm{~h}$, danach erfolgt eine Induktion der Genexpression bis auf das 9,7-fache bei 72 h. MTSP-1 wird über den gesamten Zeitverlauf supprimiert bei Werten von 0,3- bis 0,6-fach bis einschließlich $72 \mathrm{~h}$.

Die transmembranären Serinproteasen TMPRSS-2 und -4 erfahren durch die Stimulation mit IL-1ß eine Suppression. Der Kurvenverlauf beider Proteasen ist bis einschließlich des $12 \mathrm{~h}$-Wertes mit einer 0,25- und 0,2-fachen Suppression vergleichbar. Danach steigt TMPRSS-2 wieder leicht an (0,67-fach), während TMPRSS-4 deutlich erniedrigt bleibt. (Abb. 3.7)

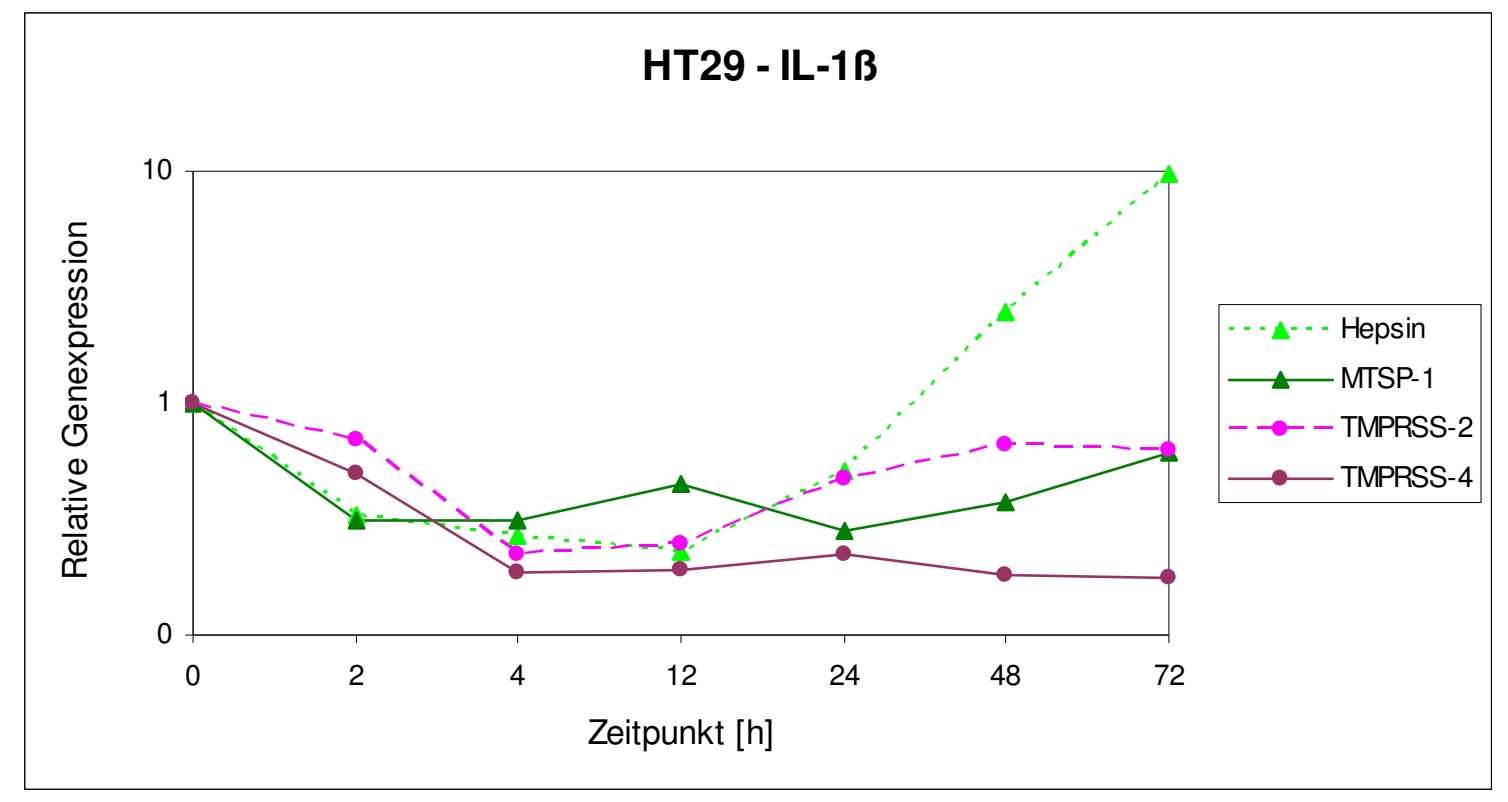

Abb. 3.7: Monolayers der Zelllinie HT29 wurden bei Subkonfluenz mit dem Zytokin IL-1 $\beta(0,3 \mathrm{ng} / \mathrm{ml})$ stimuliert. Die RNA wurde nach $0,2,4,12,24,48$ und $72 \mathrm{~h}$ isoliert. Unter Verwendung eines Transkriptionskits wurde cDNA hergestellt und im abschließenden Arbeitsschritt die Genexpression mittels real time quantitative PCR bestimmt. Die Werte wurden gegen 18sRNS normalisiert. 
IL-1beta bei Caco2-Zellen: Hepsin erfährt eine schwache Induktion seiner Genexpression mit drei Peaks, wobei die höchste Expression nach $24 \mathrm{~h}$ mit einer 2,4fachen Induktion erreicht wird. MTSP-1 zeigt ebenfalls eine Induktion mit einem Peak nach $4 \mathrm{~h}$ und einer 1,9-fachen Erhöhung. Danach wird MTSP-1 supprimiert bis zu einem Tiefstwert bei $72 \mathrm{~h}(0,48$-fach).

Die Stimulation mit IL-1 $\beta$ führt bei TMPRSS-2 zu einer fast über die gesamte Dauer anhaltenden Suppression der Genexpression (nur 24 h-Wert 1,1-fach, sonst zwischen 0,3- und 0,9-fach). TMPRSS-4 zeigt ein leichtes Expressions-Maximum nach $4 \mathrm{~h}$ (1,5fach) um danach mit wenigen Abweichungen um den Ausgangspunkt zu schwanken. (Abb. 3.8)

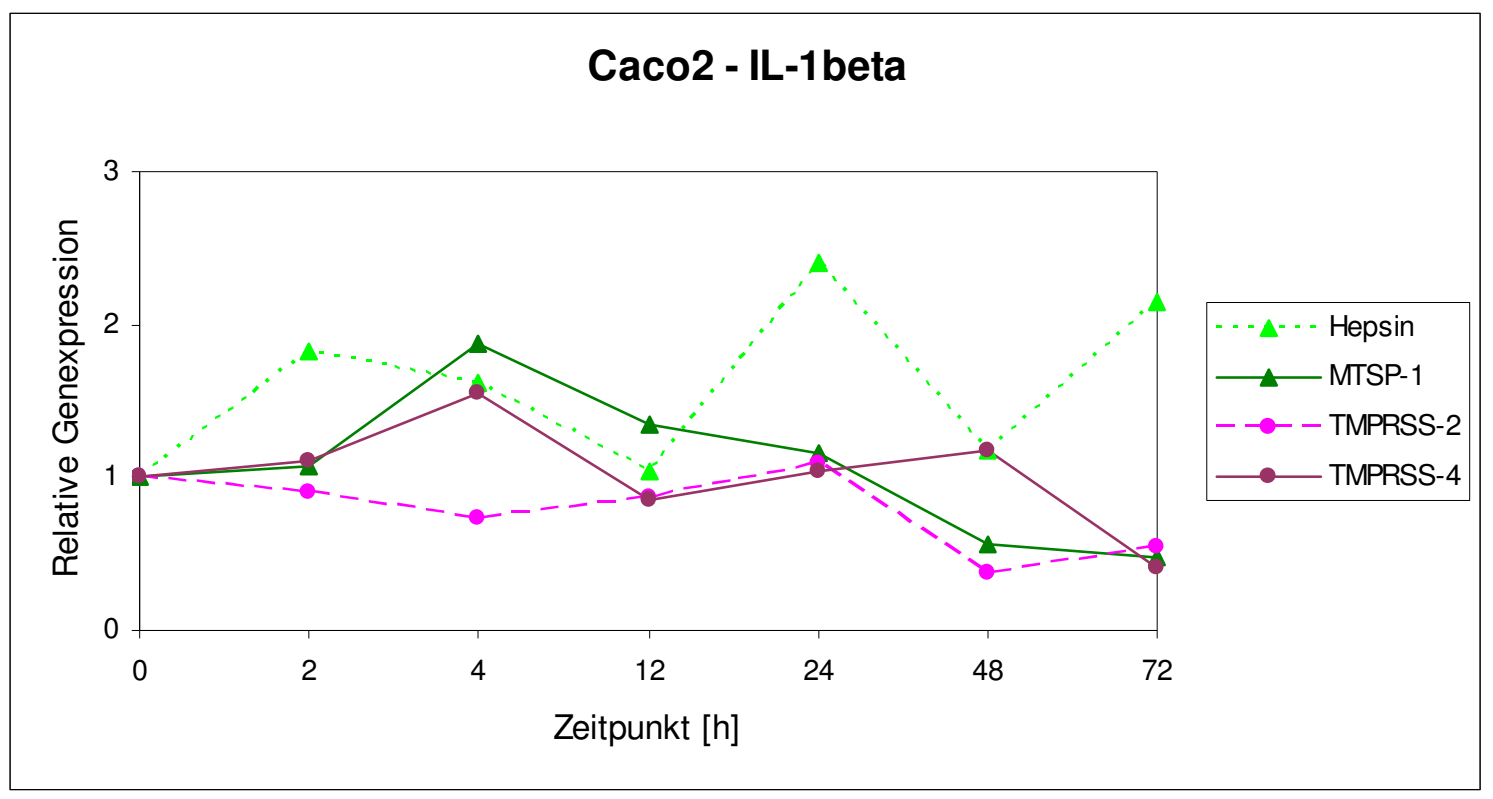

Abb. 3.8: Monolayers der Zelllinie Caco2 wurden bei Subkonfluenz mit dem Zytokin IL-1 $\beta(0,3 \mathrm{ng} / \mathrm{ml})$ stimuliert. Die RNA wurde nach $0,2,4,12,24,48$ und $72 \mathrm{~h}$ isoliert. Unter Verwendung eines Transkriptionskits wurde cDNA hergestellt und im abschließenden Arbeitsschritt die Genexpression mittels real time quantitative PCR bestimmt. Die Werte wurden gegen 18sRNS normalisiert. 


\subsubsection{HT29- und Caco2-Zellen mit TNF-alpha}

TNF-alpha bei HT29-Zellen: Nach Stimulation mit diesem klassischen proinflammatorischen Zytokin wird die Hepsin-Expression $\mathrm{zu}$ frühen Zeitpunkten erniedrigt gemessen (0,31-fach bei $12 \mathrm{~h})$, um danach bis zu einem Höchstwert von 2,7fach bei 72-h anzusteigen. MTSP-1 hat seinen Peak schon bei $4 \mathrm{~h}$ mit der 4-fachen Erhöhung der Genexpression um sich danach bei Werten um 2,5 -fach einzupendeln.

Die Stimulation mit TNF- $\alpha$ führt bei TMPRSS-2 und TMPRSS-4 zu identischen Kurvenverläufen, welche sich lediglich durch die Höhe der relativen Genexpression unterscheiden. Beide weisen einen ersten Peak bei $4 \mathrm{~h}$ auf (TMPRSS-4: 2,2-fach, TMPRSS-2: 1,8-fach). Bei 12 und $24 \mathrm{~h}$ sinken beide auf Tiefstwerte ab, um sich dann wieder auf das 4 h-Niveau zu bewegen (2,2-fach und 1,7-fach bei 72 h). (Abb. 3.9)

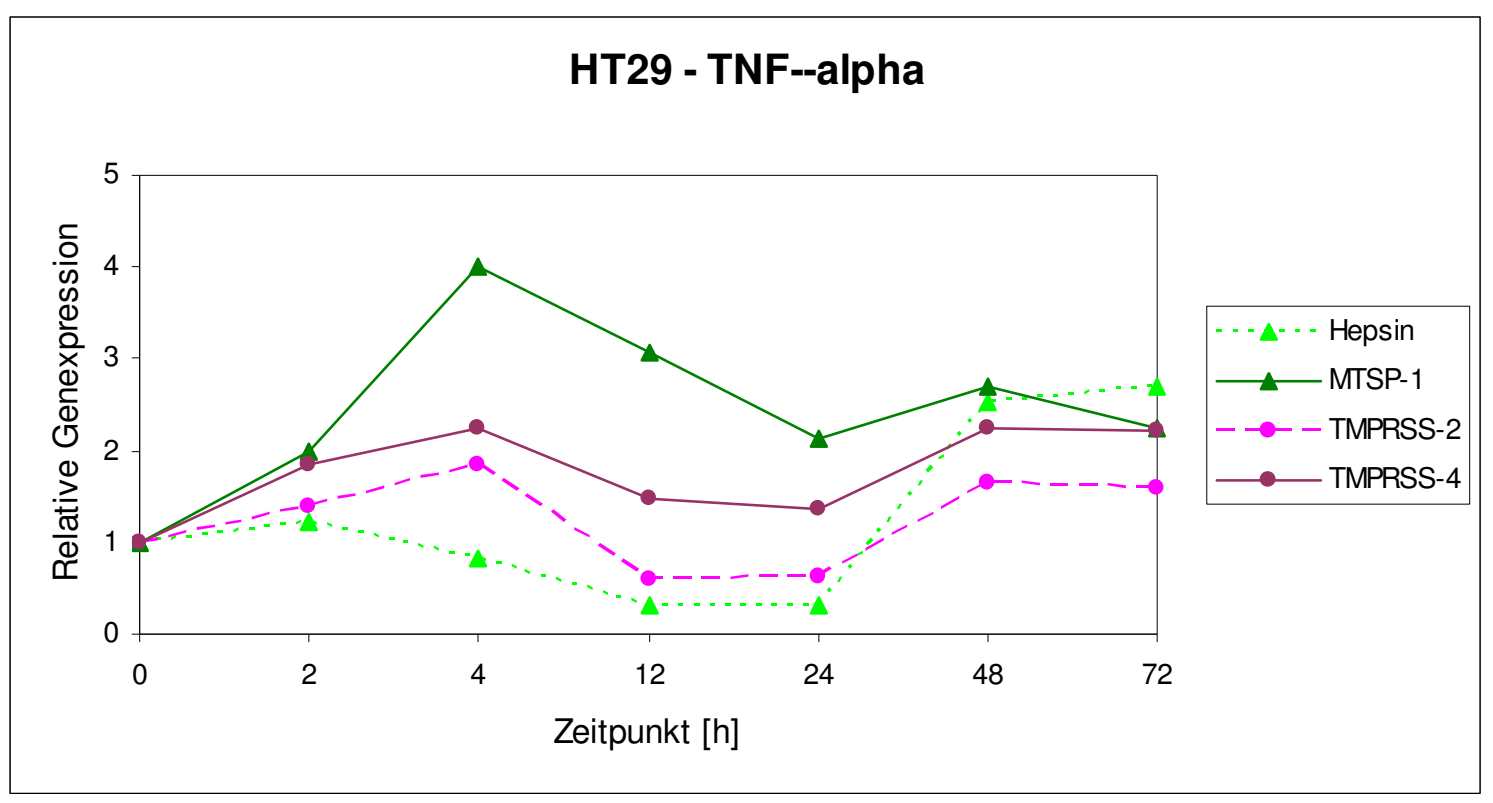

Abb. 3.9: Monolayers der Zelllinie HT29 wurden bei Subkonfluenz mit dem Zytokin TNF- $\alpha$ (3 ng/ml) stimuliert. Die RNA wurde nach 0, 2, 4, 12, 24, 48 und $72 \mathrm{~h}$ isoliert. Unter Verwendung eines Transkriptionskits wurde cDNA hergestellt und im abschließenden Arbeitsschritt die Genexpression mittels real time quantitative PCR bestimmt. Die Werte wurden gegen 18sRNS normalisiert. 
TNF-alpha bei Caco2-Zellen: Hepsin reagiert auf die Stimulation durch TNF- $\alpha$ mit einer ausgeprägten und anhaltenden Induktion der Genexpression. Der bogenförmige Kurvenverlauf hat mit einer 5,1-fachen Erhöhung bei $12 \mathrm{~h}$ sein Maximum und fällt daraufhin zum 72 h-Wert (1,1-fach) ab. Auch MTSP-1 hat sein Maximum bei $12 \mathrm{~h}$ erreicht (4,2-fach), hier fällt die Kurve allerdings deutlich spitzgipfliger aus.

TMPRSS-2 zeigt eine deutliche Induktion der relativen Genexpression mit einem Peak nach $2 \mathrm{~h}$ (5,1-fach) um danach bis auf 0,7-fach abzusinken. Die Stimulation mit TNF- $\alpha$ führt bei TMPRSS-4 zu keiner wesentlichen Erhöhung der Genexpression (maximal 1,6-fach). (Abb. 3.10)

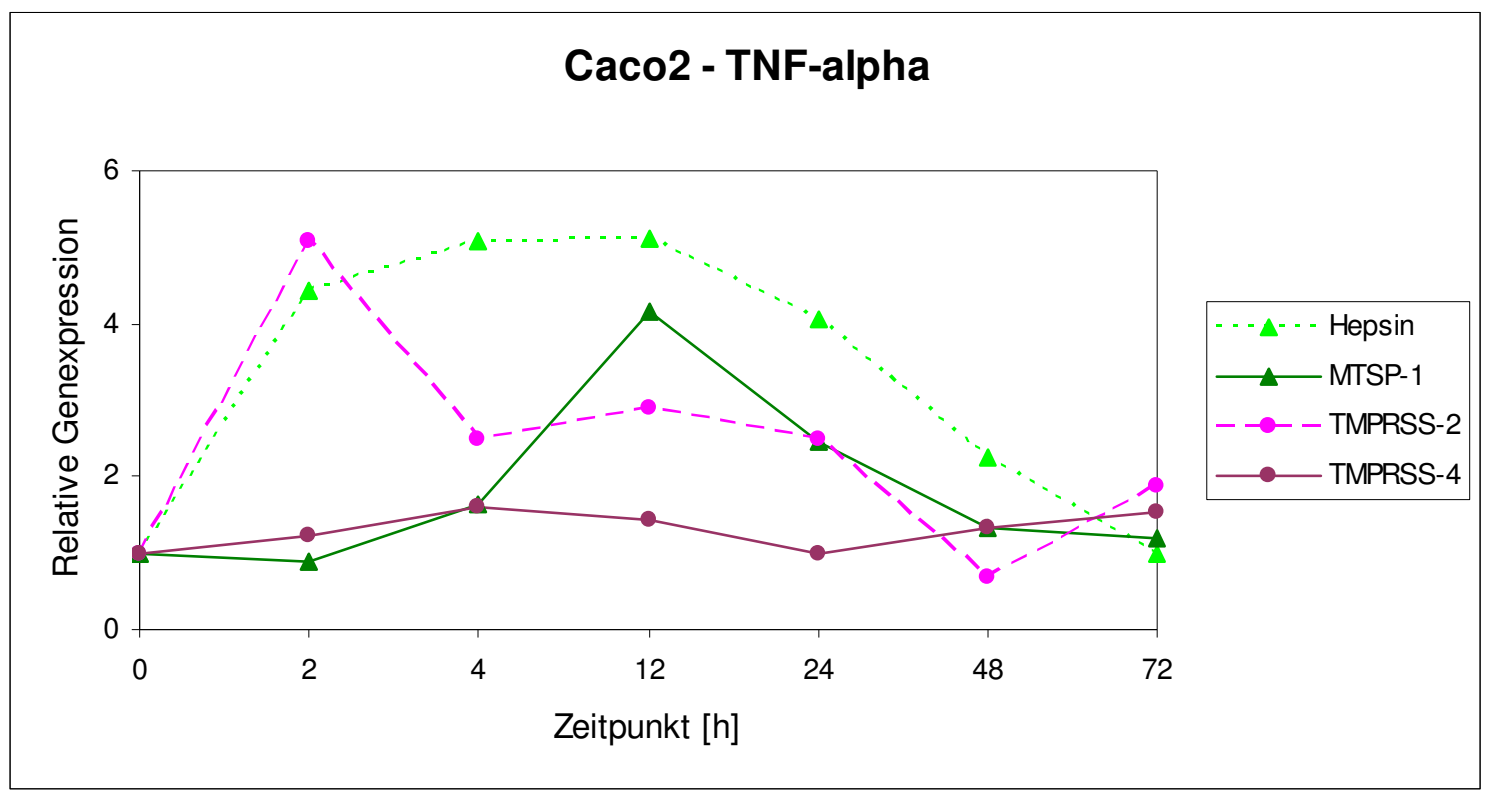

Abb. 3.10: Monolayers der Zelllinie Caco 2 wurden bei Subkonfluenz mit dem Zytokin TNF- $\alpha$ (3 ng/ml) stimuliert. Die RNA wurde nach 0, 2, 4, 12, 24, 48 und 72 h isoliert. Unter Verwendung eines Transkriptionskits wurde cDNA hergestellt und im abschließenden Arbeitsschritt die Genexpression mittels real time quantitative PCR bestimmt. Die Werte wurden gegen 18sRNS normalisiert. 


\subsubsection{HT29- und Caco2-Zellen mit LPS}

LPS bei HT29-Zellen: Der proinflammatorisch wirkende Wandbestandteil gramnegativer Bakterien Lipopolysaccharid (LPS) führt bei allen vier TTSP nur zu einer ganz geringen Regulation. Hepsin wird zunächst bei 2 und $4 \mathrm{~h}$ schwach erhöht exprimiert (1,3-fach), fällt danach aber bis auf das 0,34-fache bei $24 \mathrm{~h}$ ab. MTSP-1 zeigt einen schwachen aber kontinuierlichen Anstieg der Erhöhung der relativen Genexpression bis auf das 1,9-fache nach $24 \mathrm{~h}$.

Der Kurvenverlauf der beiden membranständigen Proteasen TMPRSS-2 /-4 ist ähnlich mit einem kleinen Peak bei $2 \mathrm{~h}$, einem leichten Abfall bei $4 \mathrm{~h}$ und einem wiederum leichten Anstieg zum 24 h-Zeitpunkt hin. TMPRSS-4 zeigt dabei die größere relative Erhöhung der Genexpression (1,6-fach zu 1,4-fach bei 2 h sowie 1,8- zu 1,3-fach nach 24 h). (Abb. 3.11)

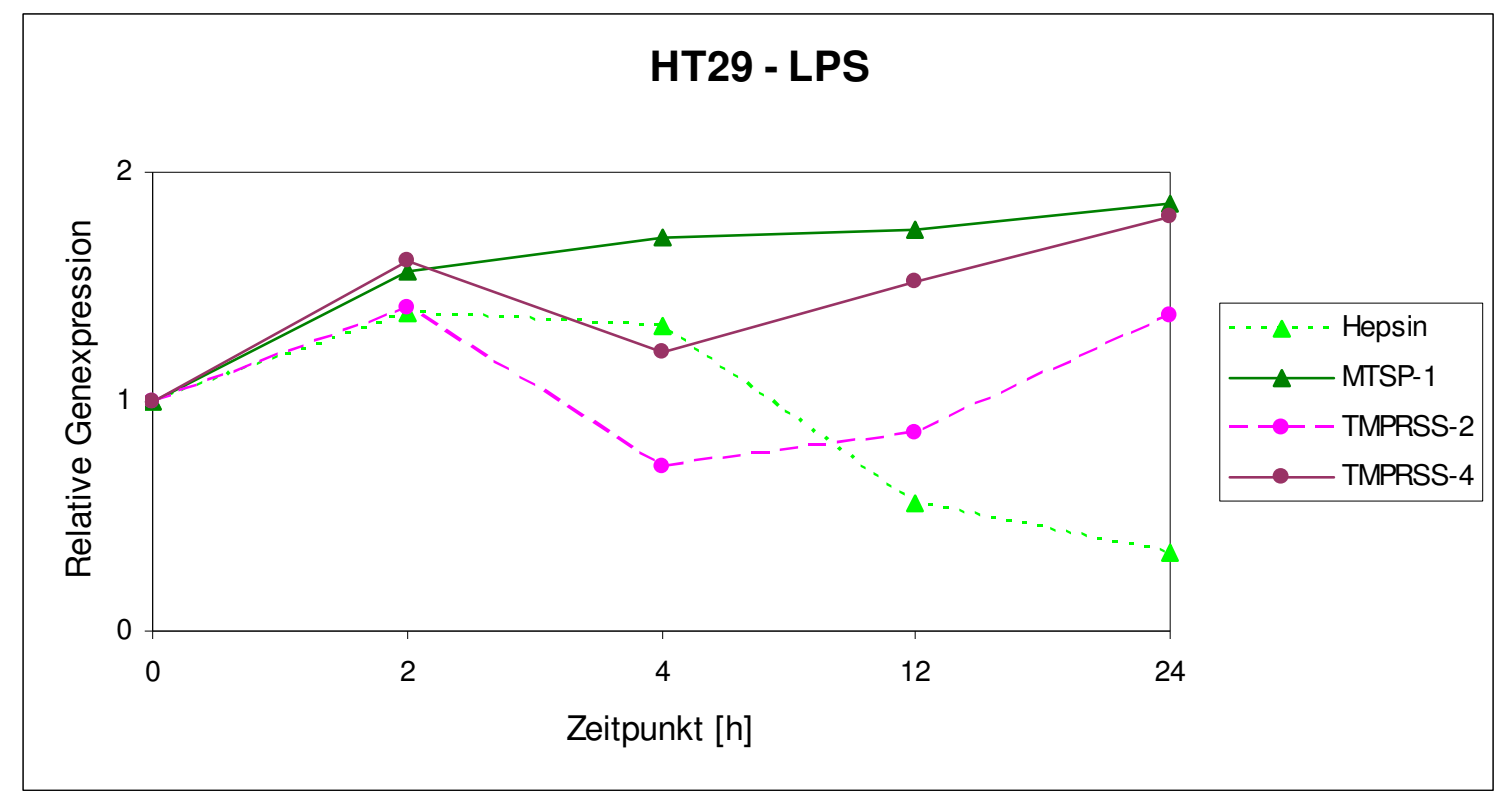

Abb. 3.11: Monolayers der Zelllinie HT29 wurden bei Subkonfluenz mit LPS (30 $\mathrm{ng} / \mathrm{ml}$ ) stimuliert. Die RNA wurde nach $0,2,4,12$ und bei $24 \mathrm{~h}$ isoliert, da sich im weiteren Zeitverlauf die Zellen vom Untergrund ablösten. Unter Verwendung eines Transkriptionskits wurde cDNA hergestellt und im abschließenden Arbeitsschritt die Genexpression mittels real time quantitative PCR bestimmt. Die Werte wurden gegen 18sRNS normalisiert. 
LPS bei Caco2-Zellen: LPS induziert eine mäßige relative Erhöhung der Genexpression bei Hepsin. Das Maximum liegt bei $4 \mathrm{~h}$ mit 1,9-facher Erhöhung. MTSP-1 zeigt einen allmählichen Anstieg auf einen Höchstwert nach 24 h (2-fach), um danach steil abzufallen (0,4-fach nach $72 \mathrm{~h})$.

TMPRSS-2 weist nach 2 und 4 h zwei identische Höchstwerte auf (beide 1,7-fach), um dann abzusinken und nach $24 \mathrm{~h}$ einen erneuten, leicht geringeren Peak (1,4-fach) zu erreichen. Danach fällt auch TMPRSS-4 steil ab. TMPRSS-4 wird supprimiert (um 0,7fach) und zeigt nur bei 48 h eine geringe Erhöhung der Genexpression (1,2-fach). (Abb. 3.12)

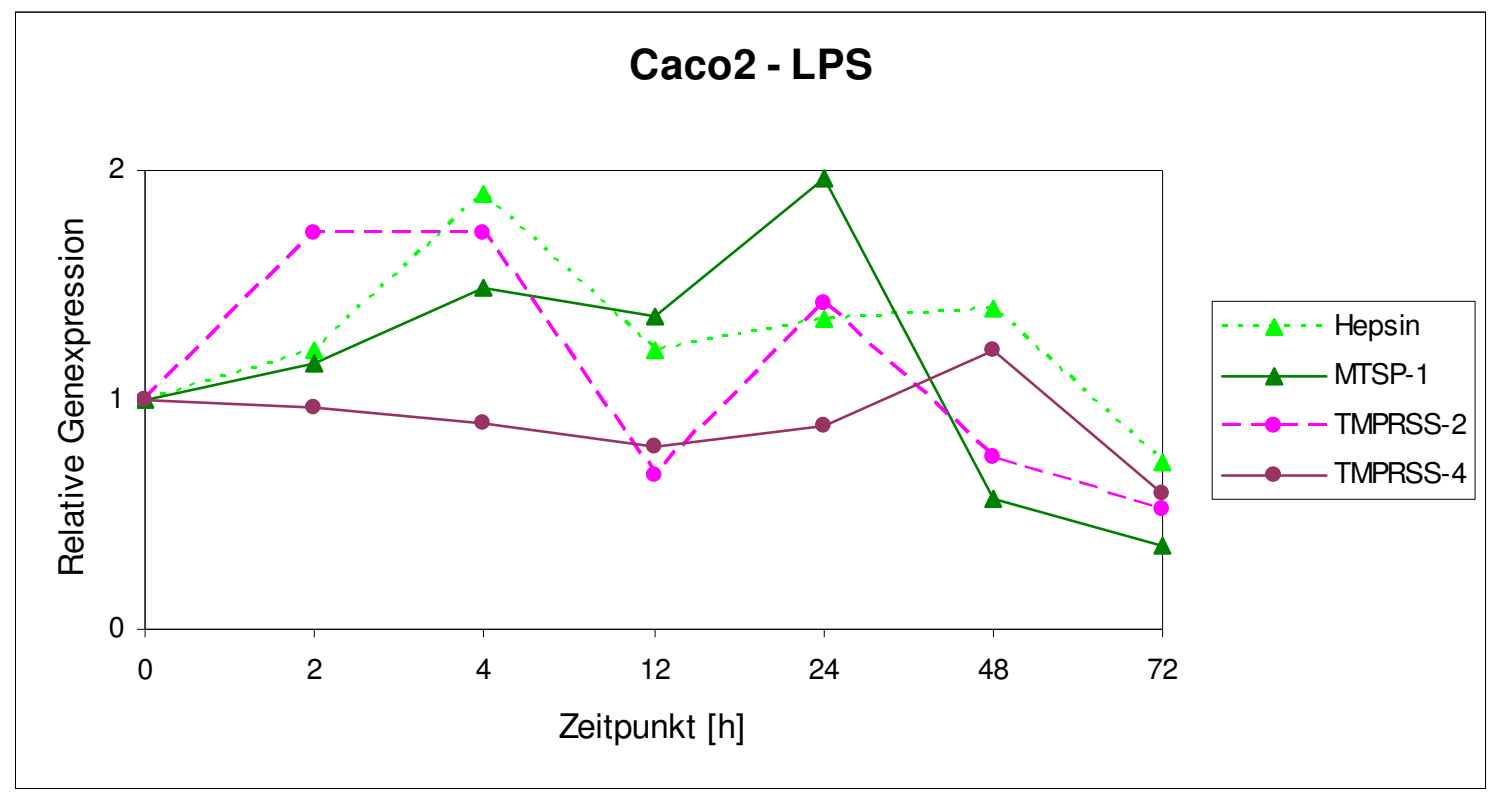

Abb. 3.12: Monolayers der Zelllinie Caco2 wurden bei Subkonfluenz mit LPS (30 $\mathrm{ng} / \mathrm{ml}$ ) stimuliert. Die RNA wurde nach 0, 2, 4, 12, 24, 48 und $72 \mathrm{~h}$ isoliert. Unter Verwendung eines Transkriptionskits wurde cDNA hergestellt und im abschließenden Arbeitsschritt die Genexpression mittels real time quantitative PCR bestimmt. Die Werte wurden gegen 18sRNS normalisiert. 


\subsubsection{HT29- und Caco2-Zellen mit Dexamethason}

Dexamethason bei HT29-Zellen: Hepsin erfährt eine deutliche Erhöhung der relativen Genexpression mit Maximalwerten bei 48 und 72 h (14,1- und 12,8-fach). MTSP-1 dagegen zeigt keine ausgeprägte Regulation.

TMPRSS-2 und TMPRSS-4 werden gleichsinnig bis einschließlich des $24 \mathrm{~h}$-Wertes supprimiert, TMPRSS-2 dabei deutlicher (0,4-fach zu 0,9-fach bei $24 \mathrm{~h}$ ). Die Genexpression von TMPRSS-4 gipfelt in einem Peak bei 48 h (2,2-fach) um danach abzufallen. (Abb. 3.13)

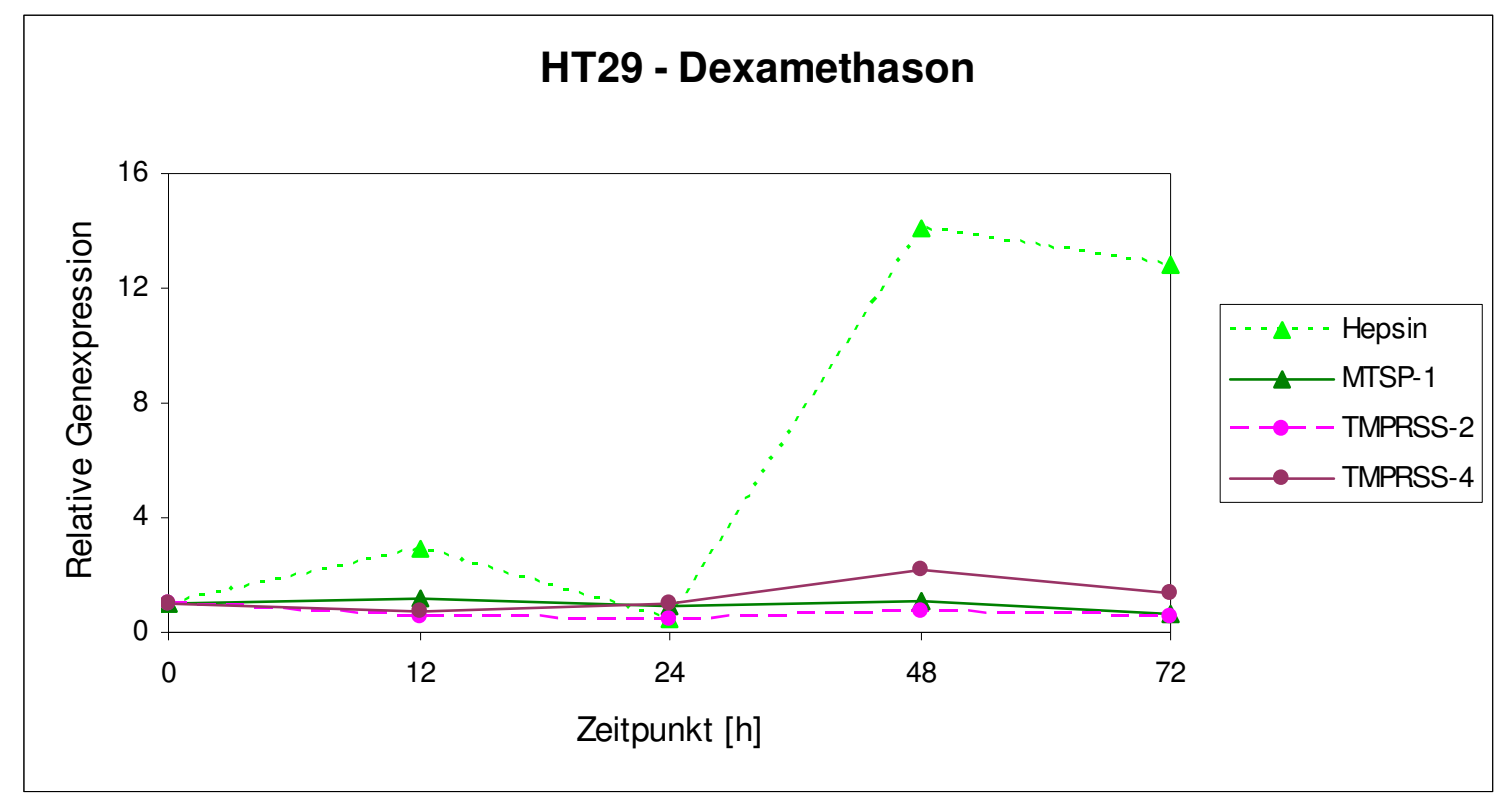

Abb. 3.13: Monolayers der Zelllinie HT29 wurden bei Subkonfluenz mit Dexamethason $\left(1 \times 10^{-7} \mathrm{M}\right)$ stimuliert. Die RNA wurde nach 0, 12, 24, 48 und $72 \mathrm{~h}$ isoliert. Unter Verwendung eines Transkriptionskits wurde cDNA hergestellt und im abschließenden Arbeitsschritt die Genexpression mittels real time quantitative PCR bestimmt. Die Werte wurden gegen 18sRNS normalisiert. 
Dexamethason bei Caco2-Zellen: Dexamethason führt bei Hepsin und TMPRSS-4 zu einer Suppression auf das 0,5-fache des Ausgangswertes, MTSP-1 und TMPRSS-2 unterliegen keiner ausgeprägten Regulation der Genexpression. Im weiteren Verlauf steigen Hepsin und TMPRSS-2 nach $48 \mathrm{~h}$ auf das 1,9-fache bzw. 2,6-fache des Ausgangswertes an. MTSP-1 und TMPRSS-4 zeigen auch im weiteren Zeitverlauf kaum eine Regulation der Genexpression. (Abb. 3.14)

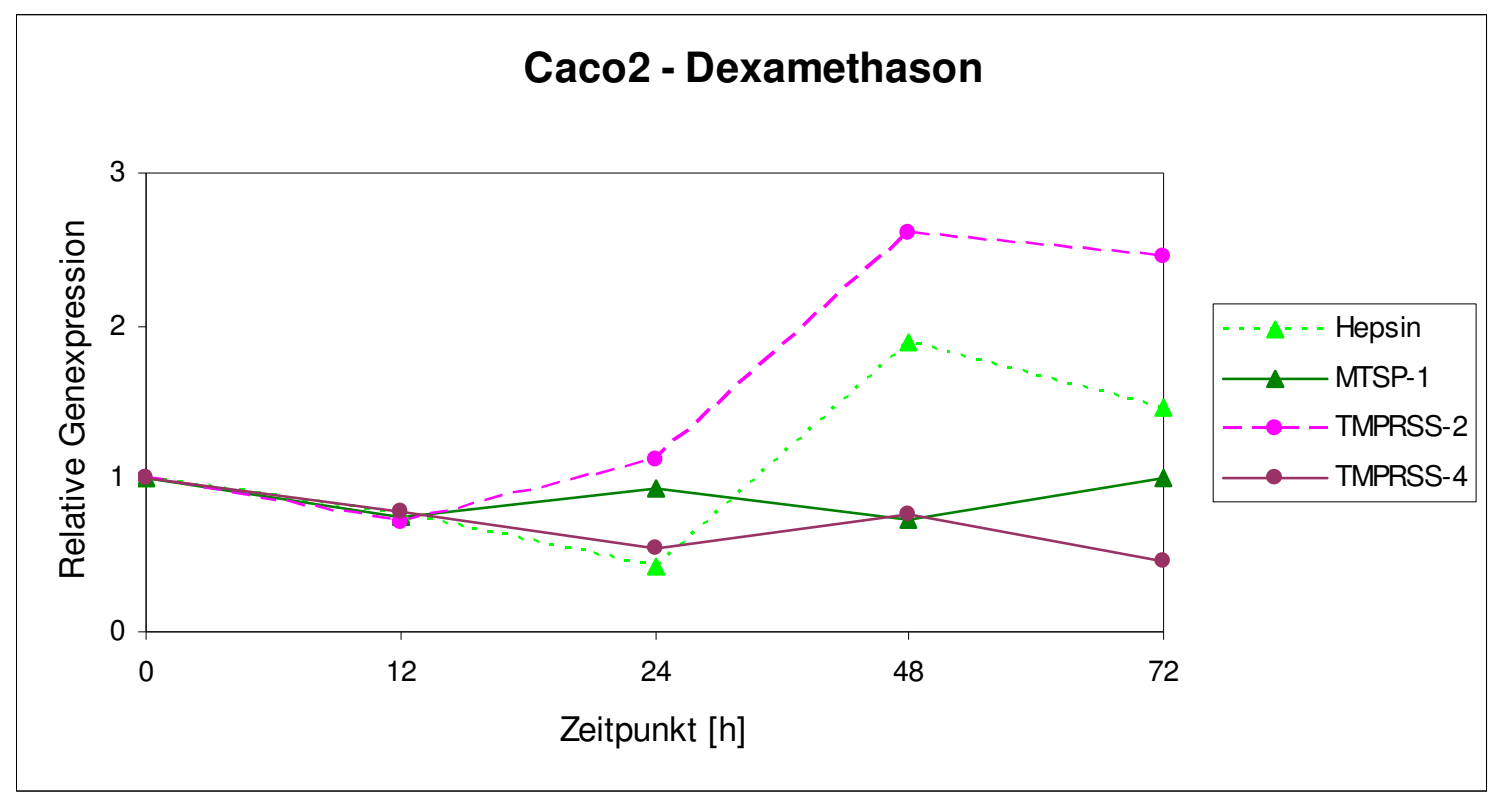

Abb. 3.14: Monolayers der Zelllinie Caco2 wurden bei Subkonfluenz mit Dexamethason $\left(1 \times 10^{-7} \mathrm{M}\right)$ stimuliert. Die RNA wurde nach $0,12,24,48$ und $72 \mathrm{~h}$ isoliert. Unter Verwendung eines Transkriptionskits wurde cDNA hergestellt und im abschließenden Arbeitsschritt die Genexpression mittels real time quantitative PCR bestimmt. Die Werte wurden gegen 18sRNS normalisiert. 


\subsubsection{HT29- und Caco2-Zellen mit Dexamethason + IL-1beta}

Dexamethason + IL-1beta bei HT29-Zellen: Hepsin wird zunächst bei $12 \mathrm{~h}$ deutlich supprimiert gemessen (0,3-fach). Der weitere Verlauf zeigt dann eine Induktion der Expression mit einem Maximalwert bei 72 h mit 8,6-facher Erhöhung. MTSP-1 zeigt keine ausgeprägte Induktion seiner Genexpression mit Werten von 1 bis maximal 1,8fach bei $72 \mathrm{~h}$.

TMPRSS-4 erfährt eine stärkere Induktion seiner Genexpression als TMPRSS-2. So steigt TMPRSS-4 auf ein Maximum von 2,6-fach bei $72 \mathrm{~h}$. TMPRSS-2 dagegen bleibt erniedrigt (0,5- bis 0,9-fach). (Abb. 3.15)

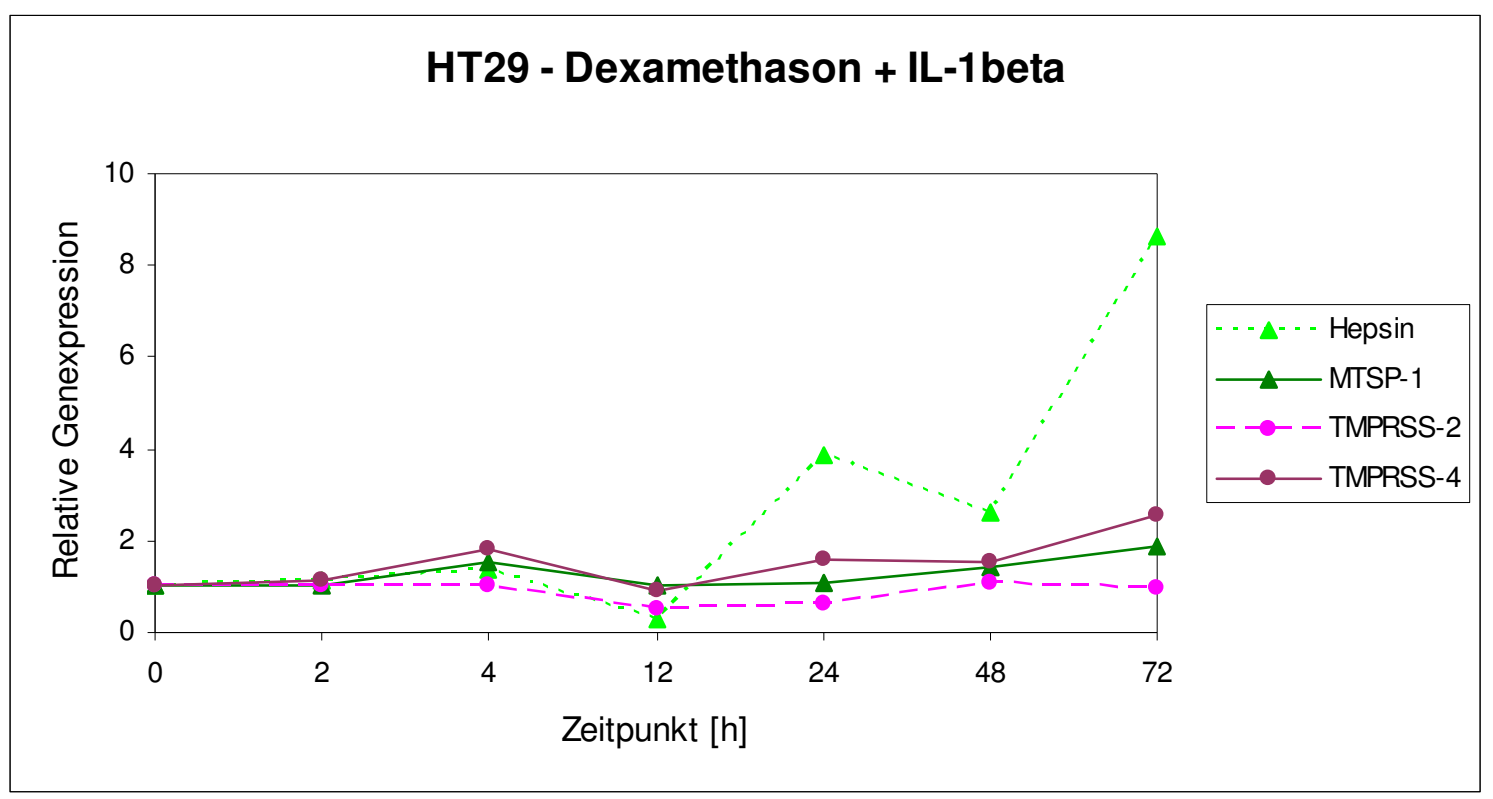

Abb. 3.15: Monolayers der Zelllinie HT29 wurden bei Subkonfluenz mit Dexamethason $\left(1 \times 10^{-7} \mathrm{M}\right)$ und zusätzlich nach einer Stunde mit IL-1 $\beta(0,3 \mathrm{ng} / \mathrm{ml})$ stimuliert. Die RNA wurde nach 0, 2, 4, 12, 24, 48 und $72 \mathrm{~h}$ isoliert. Unter Verwendung eines Transkriptionskits wurde cDNA hergestellt und im abschließenden Arbeitsschritt die Genexpression mittels real time quantitative PCR bestimmt. Die Werte wurden gegen 18 sRNS normalisiert. 
Dexamethason + IL-1beta bei Caco2-Zellen: Hepsin wird zunächst deutlich supprimiert (0,4-fach bei 24 h). Im weiteren Verlauf steigt die Kurve aber kontinuierlich bis auf einen Maximalwert bei 72 h (2,7-fach). MTSP-1 zeigt bei $24 \mathrm{~h}$ einen geringen Peak (1,6-fach) und bei $72 \mathrm{~h}$ ein Maximum mit einer 2-fachen Erhöhung der Genexpression.

Die Stimulation mit Dexamethason und IL-1 $\beta$ führt bei TMPRSS-2 zu keiner wesentlichen Erhöhung der relativen Genexpression (Werte bis 1,5-fach). TMPRSS-4 ist ebenfalls nur diskret erhöht (1,2-fach bei 4 h). (Abb. 3.16)

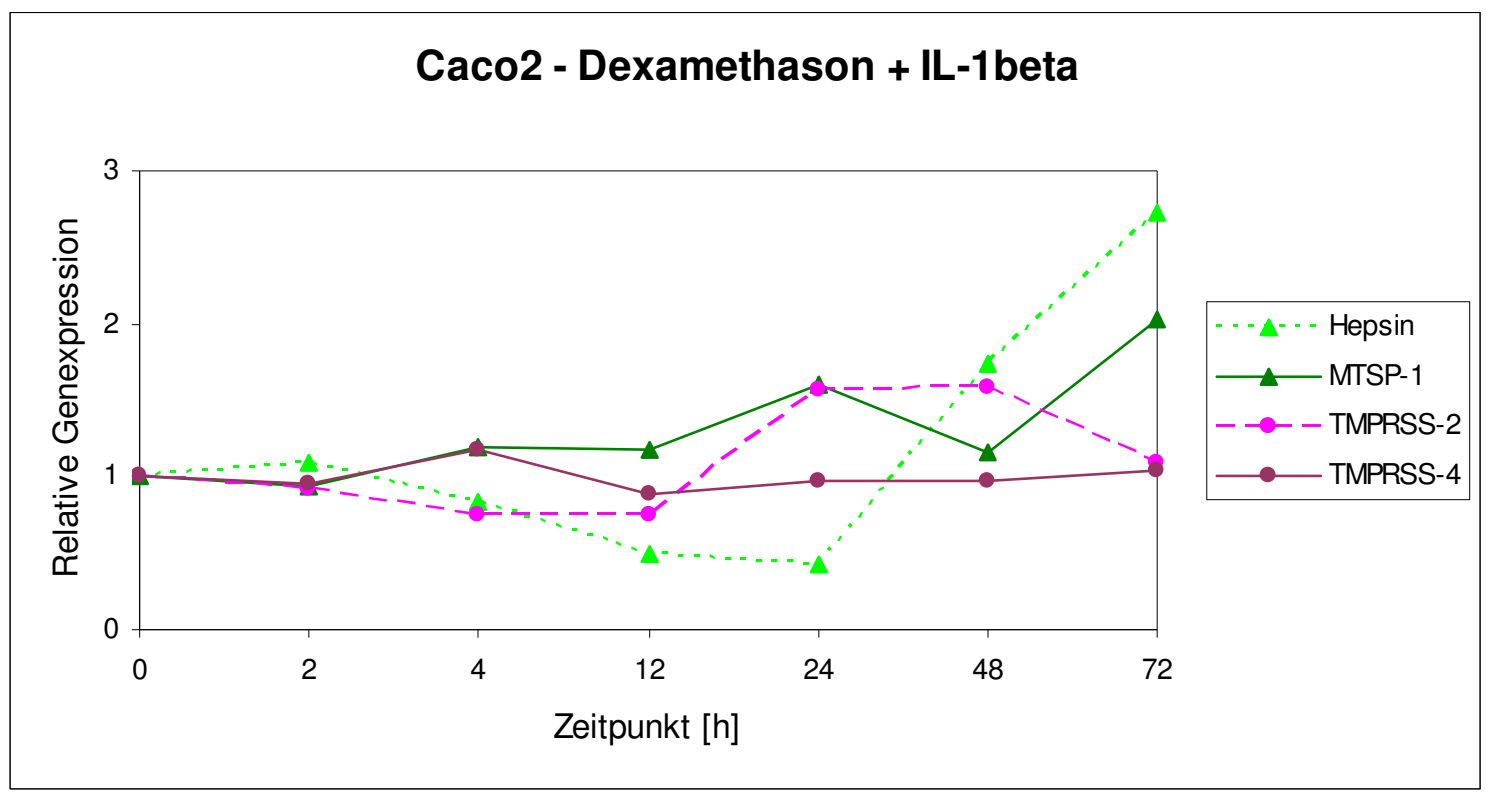

Abb. 3.16: Monolayers der Zelllinie Caco2 wurden bei Subkonfluenz mit Dexamethason $\left(1 \times 10^{-7} \mathrm{M}\right)$ und zusätzlich nach einer Stunde mit IL-1 $\beta(0,3 \mathrm{ng} / \mathrm{ml})$ stimuliert. Die RNA wurde nach 0, 2, 4, 12, 24, 48 und $72 \mathrm{~h}$ isoliert. Unter Verwendung eines Transkriptionskits wurde cDNA hergestellt und im abschließenden Arbeitsschritt die Genexpression mittels real time quantitative PCR bestimmt. Die Werte wurden gegen 18sRNS normalisiert. 


\subsubsection{Tabellarische Zusammenfassung}

\begin{tabular}{|c|c|c|c|c|c|c|c|c|c|c|c|c|}
\hline НТ29 & \multicolumn{2}{|c|}{ IFN- $\gamma$} & \multicolumn{2}{|c|}{ 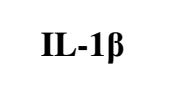 } & \multicolumn{2}{|c|}{ TNF- $\alpha$} & \multicolumn{2}{|c|}{ LPS } & \multicolumn{2}{|c|}{ Dexameth. } & \multicolumn{2}{|c|}{$\begin{array}{l}\text { Dexameth. } \\
\text { + IL-1 }\end{array}$} \\
\hline IL-8 & + & $72 \mathrm{~h}$ & +++ & $2 \mathrm{~h}$ & +++ & $2 \mathrm{~h}$ & ++ & $2 \mathrm{~h}$ & + & $72 \mathrm{~h}$ & ++ & $4 \mathrm{~h}$ \\
\hline PAR-2 & + & $2 \mathrm{~h}$ & ++ & $2 \mathrm{~h}$ & + & $72 \mathrm{~h}$ & + & $4 \mathrm{~h}$ & + & $48 \mathrm{~h}$ & 0 & $4 \mathrm{~h}$ \\
\hline Hepsin & ++ & $72 \mathrm{~h}$ & + & $72 \mathrm{~h}$ & + & $72 \mathrm{~h}$ & + & $2 \mathrm{~h}$ & ++ & $48 \mathrm{~h}$ & + & $72 \mathrm{~h}$ \\
\hline MTSP-1 & + & $12 \mathrm{~h}$ & - & $72 \mathrm{~h}$ & + & $4 \mathrm{~h}$ & + & $24 \mathrm{~h}$ & 0 & $12 \mathrm{~h}$ & + & $72 \mathrm{~h}$ \\
\hline TMPRSS-2 & - & $72 \mathrm{~h}$ & - & $2 \mathrm{~h}$ & + & $4 \mathrm{~h}$ & + & $24 \mathrm{~h}$ & - & $48 \mathrm{~h}$ & 0 & $48 \mathrm{~h}$ \\
\hline TMPRSS-4 & 0 & $48 \mathrm{~h}$ & - & $2 \mathrm{~h}$ & + & $4 \mathrm{~h}$ & + & $24 \mathrm{~h}$ & + & $48 \mathrm{~h}$ & + & $72 \mathrm{~h}$ \\
\hline
\end{tabular}

Tab. 3.3.1: Übersicht der Stimulationsexperimente mit Angabe der maximalen Höhe der Genexpression und dem korrespondierenden Zeitpunkt bei HT29-Zellen

\begin{tabular}{|c|c|c|c|c|c|c|c|c|c|c|c|c|}
\hline Caco2 & \multicolumn{2}{|c|}{ IFN- $\gamma$} & \multicolumn{2}{|c|}{ IL-1及 } & \multicolumn{2}{|c|}{ TNF- $\alpha$} & \multicolumn{2}{|c|}{ LPS } & \multicolumn{2}{|c|}{ Dexameth. } & \multicolumn{2}{|c|}{$\begin{array}{l}\text { Dexameth. } \\
+ \text { IL-1 }\end{array}$} \\
\hline IL-8 & ++ & $48 \mathrm{~h}$ & +++ & $2 \mathrm{~h}$ & + & $48 \mathrm{~h}$ & ++ & $2 \mathrm{~h}$ & +++ & $72 \mathrm{~h}$ & +++ & $4 \mathrm{~h}$ \\
\hline \begin{tabular}{|l|} 
PAR-2 \\
\end{tabular} & + & $4 \mathrm{~h}$ & + & $2 \mathrm{~h}$ & + & $24 \mathrm{~h}$ & + & $4 \mathrm{~h}$ & 0 & $48 \mathrm{~h}$ & + & $4 \mathrm{~h}$ \\
\hline Hepsin & + & $4 \mathrm{~h}$ & + & $24 \mathrm{~h}$ & + & $12 \mathrm{~h}$ & + & $4 \mathrm{~h}$ & + & $48 \mathrm{~h}$ & + & $72 \mathrm{~h}$ \\
\hline MTSP-1 & + & $2 \mathrm{~h}$ & + & $4 \mathrm{~h}$ & + & $12 \mathrm{~h}$ & + & $24 \mathrm{~h}$ & 0 & $48 \mathrm{~h}$ & + & $72 \mathrm{~h}$ \\
\hline TMPRSS-2 & + & $2 \mathrm{~h}$ & 0 & $24 \mathrm{~h}$ & + & $2 \mathrm{~h}$ & + & $4 \mathrm{~h}$ & + & $48 \mathrm{~h}$ & + & $48 \mathrm{~h}$ \\
\hline TMPRSS-4 & + & $2 \mathrm{~h}$ & + & $4 \mathrm{~h}$ & + & $4 \mathrm{~h}$ & 0 & $48 \mathrm{~h}$ & 0 & $12 \mathrm{~h}$ & 0 & $4 \mathrm{~h}$ \\
\hline
\end{tabular}

Tab. 3.3.2: Übersicht der Stimulationsexperimente mit Angabe der maximalen Höhe der Genexpression und dem korrespondierenden Zeitpunkt bei Caco2-Zellen

Tab. 3.3.1 und 3.3.2 fassen die vorangegangenen Daten für HT29- und Caco2-Zellen zusammen. Für die obige Darstellung der Daten wurden die jeweiligen absoluten Maximalwerte, unabhängig vom Zeitpunkt, verwendet.

\begin{tabular}{|llll|}
\hline++ & $=$ & $>100-$ & fache Erhöhung der Genexpression \\
++ & $=$ & $>10-$ & fache Erhöhung der Genexpression \\
+ & $=$ & $>1,25-$ fache Erhöhung der Genexpression \\
0 & $=$ & Keine Veränderung der Genexpression \\
- & $=$ & $<0,75-$ fache Suppression der Genexpression \\
-- & $=$ & $<0,5-$ fache Suppression der Genexpression \\
-- & $=$ & $<0,25-$ fache Suppression der Genexpression
\end{tabular}




\subsubsection{Textorische Zusammenfassung}

1. Ein auffälliges Ergebnis für die Protease Hepsin ist eine durch alle Substanzen vorhandene robuste bis starke Erhöhung der Genexpression bei HT29- und Caco2-Zellen

2. Quantitativ die ausgeprägteste Geninduktion ist durch IFN- $\gamma$, IL-1ß und Dexamethason für Hepsin mit einer 21,9-fachen, 10-fachen sowie 14,1-fachen Erhöhung zu beobachten.

3. Dagegen zeigen sich TMPRSS-2 und TMPRSS-4 unter der Stimulation mit IFN- $\gamma$, IL-1ß und Dexamethason insgesamt supprimiert.

4. IL-8 zeigt als Positiv-Kontrolle bei allen Substanzen und in beiden Zelllinien eine deutliche Induktion (in 5 der 12 Kategorien eine mehr als 100-fache Erhöhung) und belegt damit die Funktionalität der Substanzen und des in vitro Modells.

5. In beiden Zelllinien erfährt PAR-2 eine robuste Geninduktion, wenngleich diese bei HT29 diskret stärker ausfällt.

6. Der proinflammatorisch wirkende Wandbestandteil gramnegativer Bakterien Lipopolysaccharid (LPS) führt bei allen vier TTSP nur zu einer ganz geringen Regulation.

7. MTSP-1 wird durch alle Substanzen mit Ausnahme von Dexamethason bei Caco2-Zellen und IL-1ß bei HT29-Zellen leicht moduliert.

8. Dexamethason und IL-1ß scheinen bei HT29-Zellen für die Regulation von Hepsin einen additiven Effekt zu haben. Bei Caco2-Zellen zeigt sich dieser Effekt dagegen nicht.

\section{Anmerkungen:}

1. IL-8 und PAR-2 sind zwecks eines besseren Verständnisses und möglichen Zusammenhängen zu den TTSP hier aufgeführt. Vor allem dient IL-8 auch als Positiv-Kontrolle für die Funktion der Substanzen und des Zellmodells. Die Daten sind der Arbeit von Hr. M. Himpel entnommen und erscheinen mit dessen freundlicher Genehmigung.

2. Die Experimente wurden 2-3-mal wiederholt, es wurde für alle Substanzen ein repräsentatives Ergebnis gezeigt. 


\subsection{Expression von TTSP nach bakterieller Infektion intestinaler Epithelzellen (IEC)}

Monolayers der Zelllinien HT29 und Caco2 wurden über einen Zeitraum von $24 \mathrm{~h}$ mit fünf verschiedenen Bakterien beimpft. Folgende Bakterienstämme wurden ausgewählt:

1. Enterococcus faecium (= Ecfc) ATCC 29212: Ecfc ist ein grampositives, kokkenförmiges, nicht invasives, fakultativ aerobes Bakterium. Es gehört zur Gattung der Enterokokken (ca. 25 Spezies), diese wiederum gehören zur Normalflora des Gastrointestinaltrakts. Nosokomiale Infektionen durch Ecfc können bei immunsupprimierten Patienten vorkommen. Im GI-Trakt besitzt das Bakterium eine wichtige Rolle in der Regulation und Aufrechterhaltung der Verdauungsprozesse. Ecfc wird neben vielen anderen Stämmen u.a. in probiotischen Lebensmitteln verwendet. Ecfc sollte in diesem Experiment den apathogenen, womöglich protektiven Stimulus repräsentieren (Brock, 2003).

2. Escherichia coli (= Esco) ATCC 25922: Escherichia coli (E. coli) ist ein säurebildendes (Laktose-positiv), gramnegatives, fakultativ anaerobes, stäbchenförmiges, Oxidase-negatives und peritrich begeißeltes Bakterium, das in großer Anzahl als Kommensale im menschlichen und tierischen Intestinum vorkommt. Es gehört zur Familie der Enterobacteriaceae. Für E. coli werden drei Gruppen von Serotypen unterschieden: „O“ für die Lipopolysaccharide, „H“ für

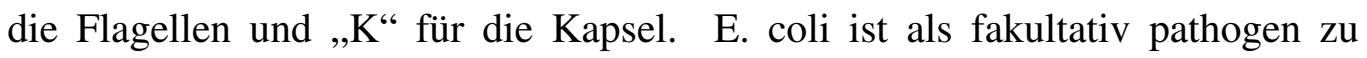
bezeichnen, da es außerhalb des Darms Infektionen (z.B. Harnwegsinfekte, Peritonitis, Neugeborenenmeningitis etc.) hervorrufen kann. Daraus resultierend wurde E. coli als gramnegativer kommensaler fakultativ pathogener Keim ausgewählt (Brock, 2003).

3. Listeria monocytogenes (= Limo) [Patienten-Isolat]: Bei Limo handelt es sich um grampositive, fakultativ anaerobe und begeißelte Stäbchenbakterien. Es zeigt ein ubiquitäres Vorkommen bei einer relativ großen Widerstandsfähigkeit. Bei ca. 10\% gesunder Menschen kann Limo im Darm nachgewiesen werden. Für zahlreiche Tierarten ist es ein pathogener Erreger. Beim Menschen gibt es dagegen kein spezifisches Krankheitsbild. Limo sind klassische Opportunisten. 
Bei immunkompetenten Patienten verläuft die Infektion zumeist inapparent oder mit leichten grippeähnlichen Prodromi. Dagegen können die Erreger bei immunsupprimierten Patienten schwere Infektionen verursachen. Das von den Bakterien produzierte Toxin Listeriolysin O (LLO) spielt hinsichtlich der Pathogenität eine wesentliche Rolle. Die Listeriose während der Schwangerschaft kann zum Abort oder konnataler Listeriose führen. Limo wurde als nicht-residentes, fakultativ pathogenes, grampositives Stäbchen für dieses Experiment ausgewählt (Schlegel, 2006).

4. Salmonella typhi (= Saty) MCCM 01631: Saty gehören zu den gramnegativen stäbchenförmigen Bakterien. Sie sind peritrich begeißelt, fakultativ anaerob sowie nicht Sporen bildend. Man unterscheidet bei den Salmonellosen zwischen den typhösen und den enteritischen Erkrankungen. Dabei ist die SalmonellaNomenklatur sehr komplex, es werden mehr als 2500 Serovare beschrieben. Saty kommt nur im Menschen vor. Eine Infektion erfolgt über fäkal kontaminiertes Wasser oder Lebensmittel, wobei eine nur sehr geringe Infektionsdosis notwendig ist. Das Vollbild der Infektion als Typhus abdominalis zeigt einen stadienhaften Verlauf und ist durch ein schwerwiegendes Krankheitsbild gekennzeichnet. Die Salmonellose ist eine meldepflichtige Erkrankung. Saty wurde als pathogenes, invasives gramnegatives Stäbchen ausgesucht (Brock, 2003).

5. Yersinia enterocolitica (= Yeen) MCCM 01839: Yersinien sind gramnegative, begeißelte, sporenlose, fakultativ anaerobe, invasive kurze Stäbchenbakterien Y. enterocolitica ist der häufigste Erreger der enteralen Yersiniose. Die Gattung Yersinia gehört zur Familie der Enterobacteriaceae, von der noch die Spezies Y. pseudotuberculosis und Y. pestis humanpathogene Bedeutung besitzen. Yeen kann je nach Patientenalter und Immunstatus u.a. akute Gastroenterititiden mit Fieber, Erbrechen und Durchfällen, eine Lymphadenitis mesenterialis, akute Arthritiden sowie M. Reiter verursachen. Das Vorkommen ist weltweit in tierischen Reservoiren. Eine Infektion erfolgt meist über den Genuss von nur ungenügend erhitzten tierischen Produkten sowie verunreinigtem Wasser. Yeen wurde als pathogenes, invasives gramnegatives Stäbchen für dieses Experiment ausgewählt (Schlegel, 2006). 


\subsubsection{HT29- und Caco2-Zellen mit Enterococcus faecium}

Enterococcus faecium bei HT29-Zellen: Die Exposition von HT29-Zellen gegenüber dem kommensalen Bakterium E. faecium führt zu einer deutlichen Suppression der Genexpression aller vier membranständigen Proteasen bei sehr ähnlichen Kurvenverläufen. Während MTSP-1 eine geringere Suppression erfährt, sind Hepsin, TMPRSS- 2 und -4 deutlich stärker erniedrigt. Alle zeigen bei $12 \mathrm{~h}$ das GenexpressionsMinimum (0,4-fach für MTSP-1, 0,1-fach für Hepsin und TMPRSS-4 sowie 0,08-fach für TMPRSS-2). (Abb. 3.17)

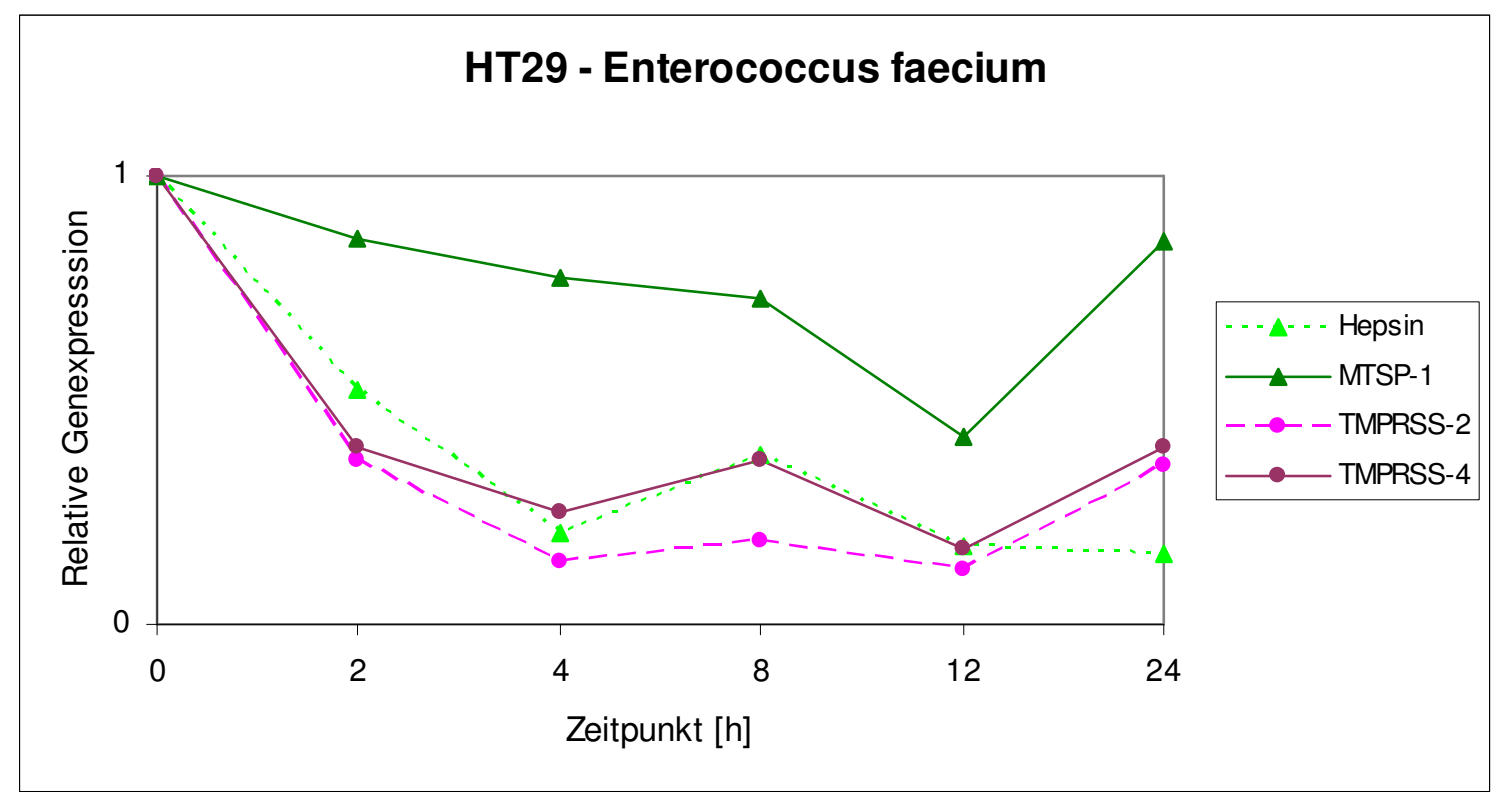

Abb. 3.17: Monolayers der Zelllinie HT29 wurden bei Subkonfluenz mit ca. $3 * 10^{8}$ Bakterien des Stammes Enterococcus faecium (grampositiv, nicht invasiv) für eine Stunde infiziert, abgesaugt und durch normales Medium ersetzt. Nach 0, 2, 4, 8, 12 und $24 \mathrm{~h}$ erfolgte die Isolierung der RNA. Unter Verwendung eines Transkriptionskits wurde cDNA hergestellt und im abschließenden Arbeitsschritt die Genexpression mittels real time quantitative PCR bestimmt. Die Werte wurden gegen 18sRNS normalisiert. 
Enterococcus faecium bei Caco2-Zellen: Caco2 reagiert auf die Infektion durch E. faecium mit einer Suppression aller vier membranständiger Proteasen. Alle TTSP zeigen ihre Minima der Genexpression nach 4 h (Hepsin 0,32-fach, MTSP-1 0,19-fach, TMPRSS-2 0,22-fach, TMPRSS-4 0,26-fach). Hepsin und TMPRSS-4 steigen im weiteren Zeitverlauf diskret an, während MTSP-1 und TMPRSS-2 weiterhin deutlich erniedrigt bleiben. Keine der membranständigen Proteasen steigt über den Ausgangswert hinaus an, alle Gene bleiben über den gesamten Zeitverlauf deutlich supprimiert. (Abb. 3.18)

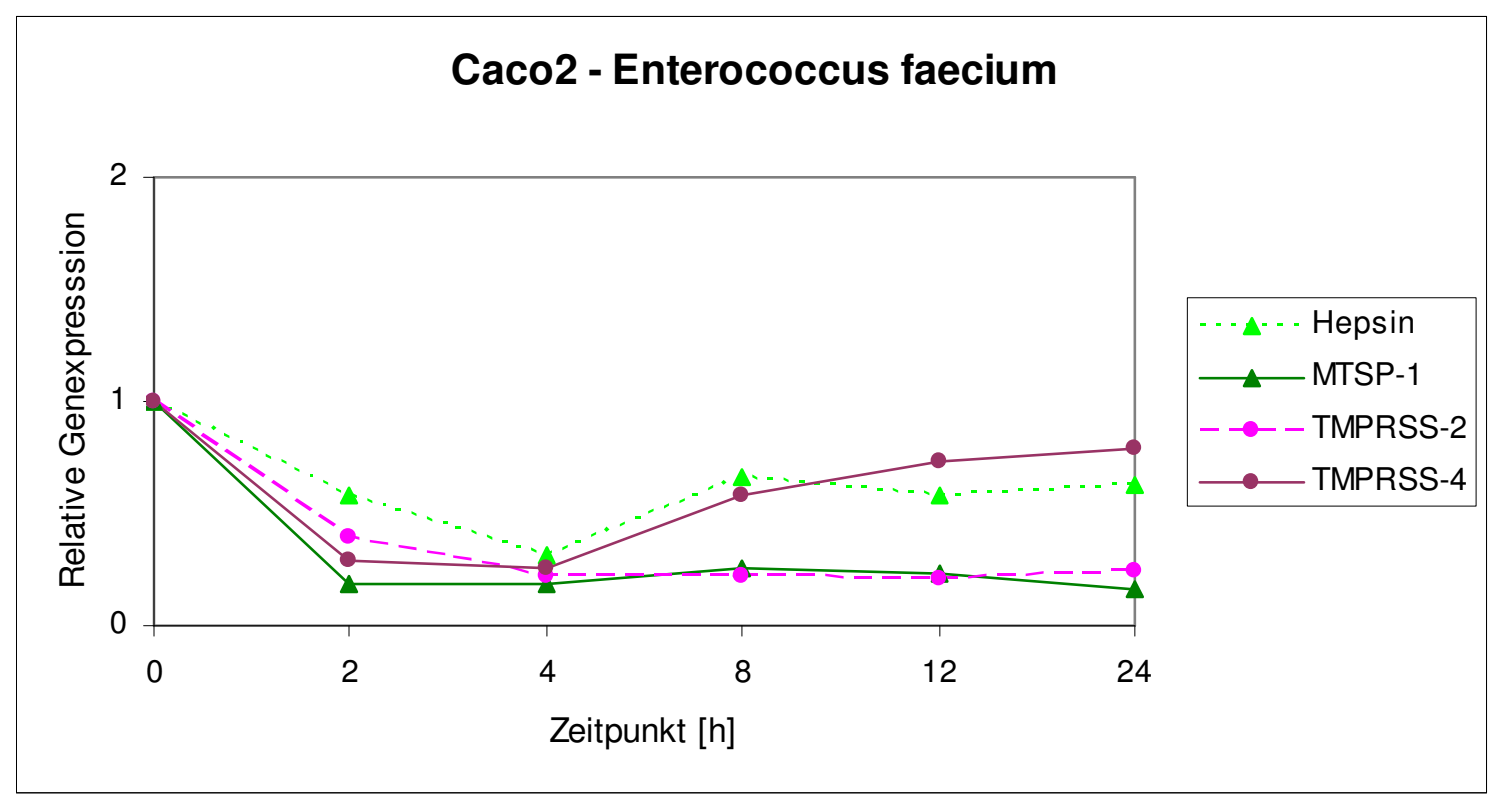

Abb. 3.18: Monolayers der Zelllinie Caco 2 wurden bei Subkonfluenz mit ca. $3 * 10^{8}$ Bakterien des Stammes Enterococcus faecium (grampositiv, nicht invasiv) für eine Stunde infiziert, abgesaugt und durch normales Medium ersetzt. Nach 0, 2, 4, 8, 12 und $24 \mathrm{~h}$ erfolgte die Isolierung der RNA. Unter Verwendung eines Transkriptionskits wurde cDNA hergestellt und im abschließenden Arbeitsschritt die Genexpression mittels real time quantitative PCR bestimmt. Die Werte wurden gegen 18sRNS normalisiert. 


\subsubsection{HT29- und Caco2-Zellen mit E. coli}

Escherichia coli bei HT29-Zellen: Alle TTSP zeigen als Reaktion auf E. coli eine zweigipflige Kurve. Hepsin, TMPRSS-2 und -4 haben ihr erstes Maximum nach 2 h, MTSP-1 nach 4 h. Bei Hepsin fällt dieses erste Maximum mit einer 4,8-fachen Induktion am deutlichsten aus. Das zweite Maximum tritt bei Hepsin, MTSP-1 und TMPRSS-4 nach $12 \mathrm{~h}$ auf, bei TMPRSS-2 zeigt sich ein Anstieg der Expression bis zum 24 h- Wert. Das zweite Maximum liegt für MTSP-1 (5,8-fach) und TMPRSS-4 (4,6-fach) höher als das erste Maximum, für Hepsin und TMPRSS-2 niedriger als das erste Maximum. (Abb. 3.19)

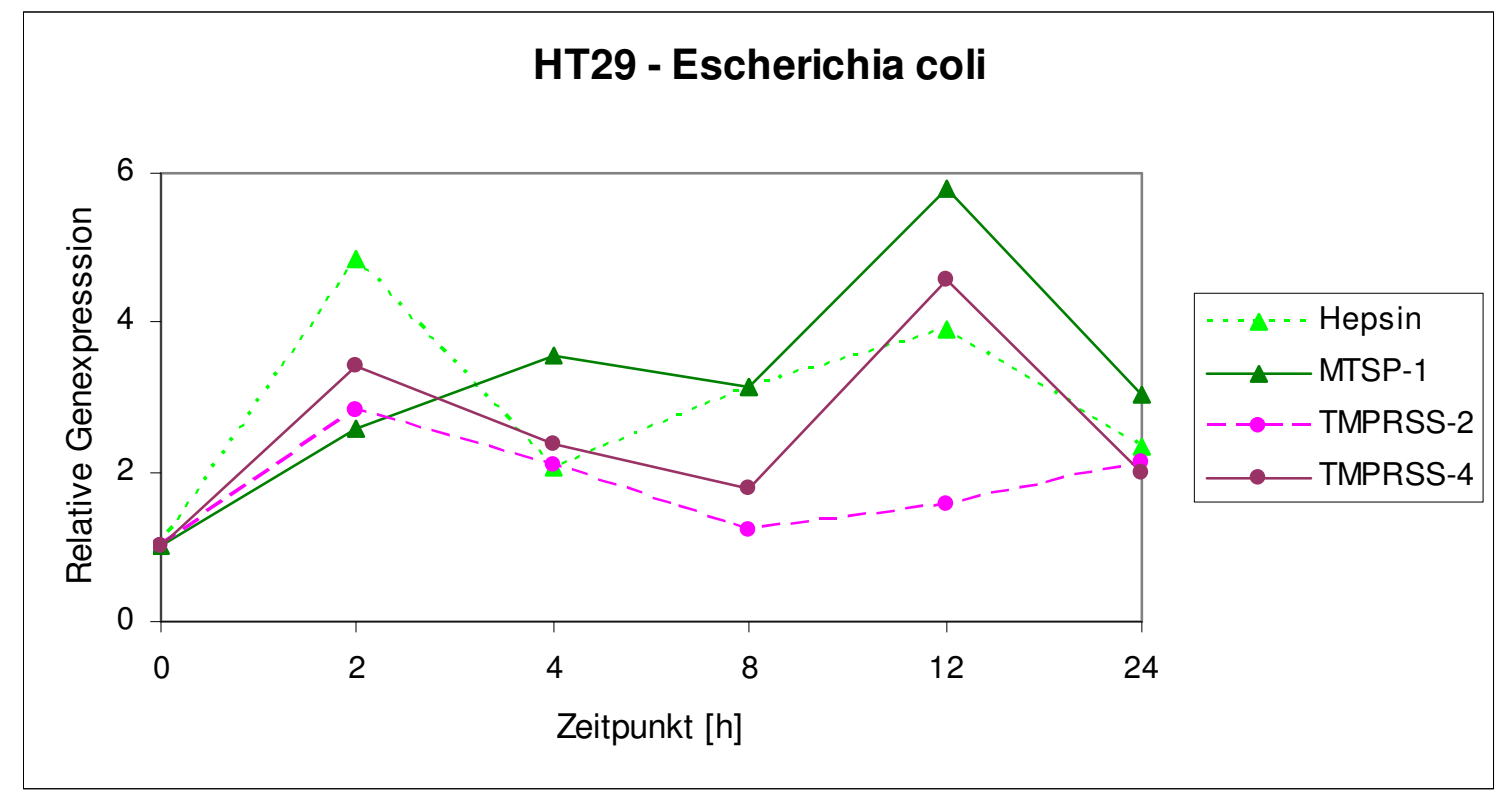

Abb. 3.19: Monolayers der Zelllinie HT29 wurden bei Subkonfluenz mit ca. $3 * 10^{8}$ Bakterien des Stammes Escherichia coli (gramnegativ, nicht invasiv) für eine Stunde infiziert, abgesaugt und durch normales Medium ersetzt. Nach 0, 2, 4, 8, 12 und $24 \mathrm{~h}$ erfolgte die Isolierung der RNA. Unter Verwendung eines Transkriptionskits wurde cDNA hergestellt und im abschließenden Arbeitsschritt die Genexpression mittels real time quantitative PCR bestimmt. Die Werte wurden gegen 18sRNS normalisiert. 
Escherichia coli bei Caco2-Zellen: TMPRSS-2 TMPRSS-4 und MTSP-1 zeigen einen ersten Peak nach $2 \mathrm{~h}$ mit einer 3,9-fachen Induktion für TMPRSS-2, 2,9-fachen Induktion für TMPRSS-4 und einer 1,5-fachen Induktion für MTSP-1. Hepsin zeigt ebenfalls einen ersten Peak mit 1,5-facher Induktion, allerdings erst nach 4 h. Alle Gene sinken intermittierend wieder ab und erreichen zwischen Zeitpunkt 4 und $12 \mathrm{~h}$ einen Tiefpunkt um dann zum Zeitpunkt $24 \mathrm{~h}$ wieder anzusteigen. Hepsin und MTSP-1 erreichen hier mit einer 3- und 2,4-fachen Induktion ihr Maximum. (Abb. 3.20)

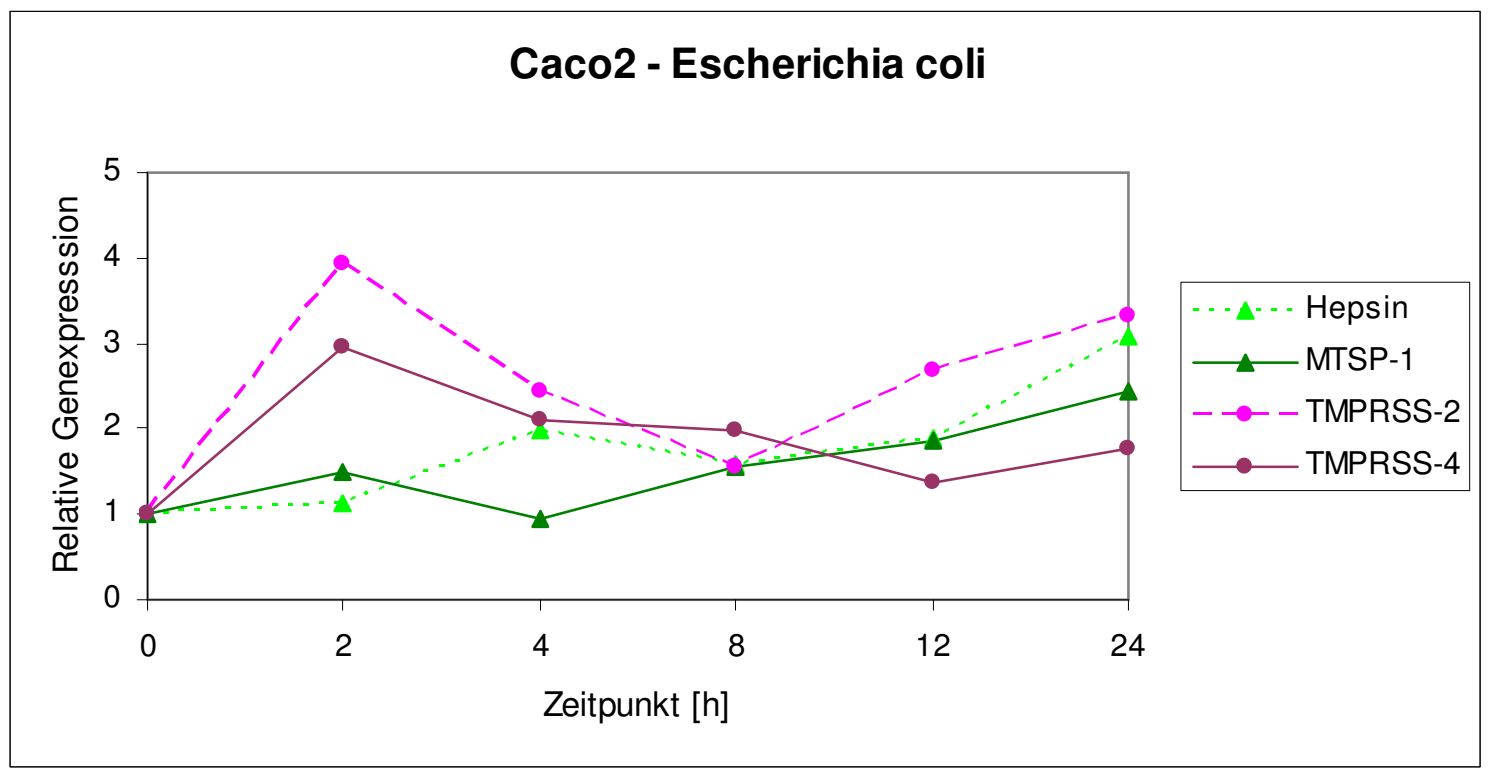

Abb. 3.20: Monolayers der Zelllinie Caco 2 wurden bei Subkonfluenz mit ca. $3 * 10^{8}$ Bakterien des Stammes Escherichia coli (gramnegativ, nicht invasiv) für eine Stunde infiziert, abgesaugt und durch normales Medium ersetzt. Nach 0, 2, 4, 8, 12 und $24 \mathrm{~h}$ erfolgte die Isolierung der RNA. Unter Verwendung eines Transkriptionskits wurde cDNA hergestellt und im abschließenden Arbeitsschritt die Genexpression mittels real time quantitative PCR bestimmt. Die Werte wurden gegen 18sRNS normalisiert. 


\subsubsection{HT29- und Caco2-Zellen mit Listeria monocytogenes}

Listeria monocytogenes bei HT29-Zellen: MTSP-1, Hepsin und TMPRSS-4 werden durch Exposition gegenüber Listeria monocytogenes induziert und erreichen ihr Expressionsmaximum nach $4 \mathrm{~h}$. Dieses beträgt für MTSP-1 2,6-fach, für Hepsin 1,8fach und für TMPRSS-4 1,4-fach. TMPRSS-2 weist zwischen 0 und $4 \mathrm{~h}$ keine signifikante Regulation auf. Alle Gene sinken zum Zeitpunkt 8 h auf ein Minimum ab (TMPRSS-4 0,7-fach, Hepsin 0,3-fach, TMPRSS-2 0,2-fach, MTSP-1 1,2-fach). MTSP-1 weist im Vergleich zu den anderen Proteasen über den gesamten Zeitverlauf eine Erhöhung seiner Genexpression auf. (Abb. 3.21)

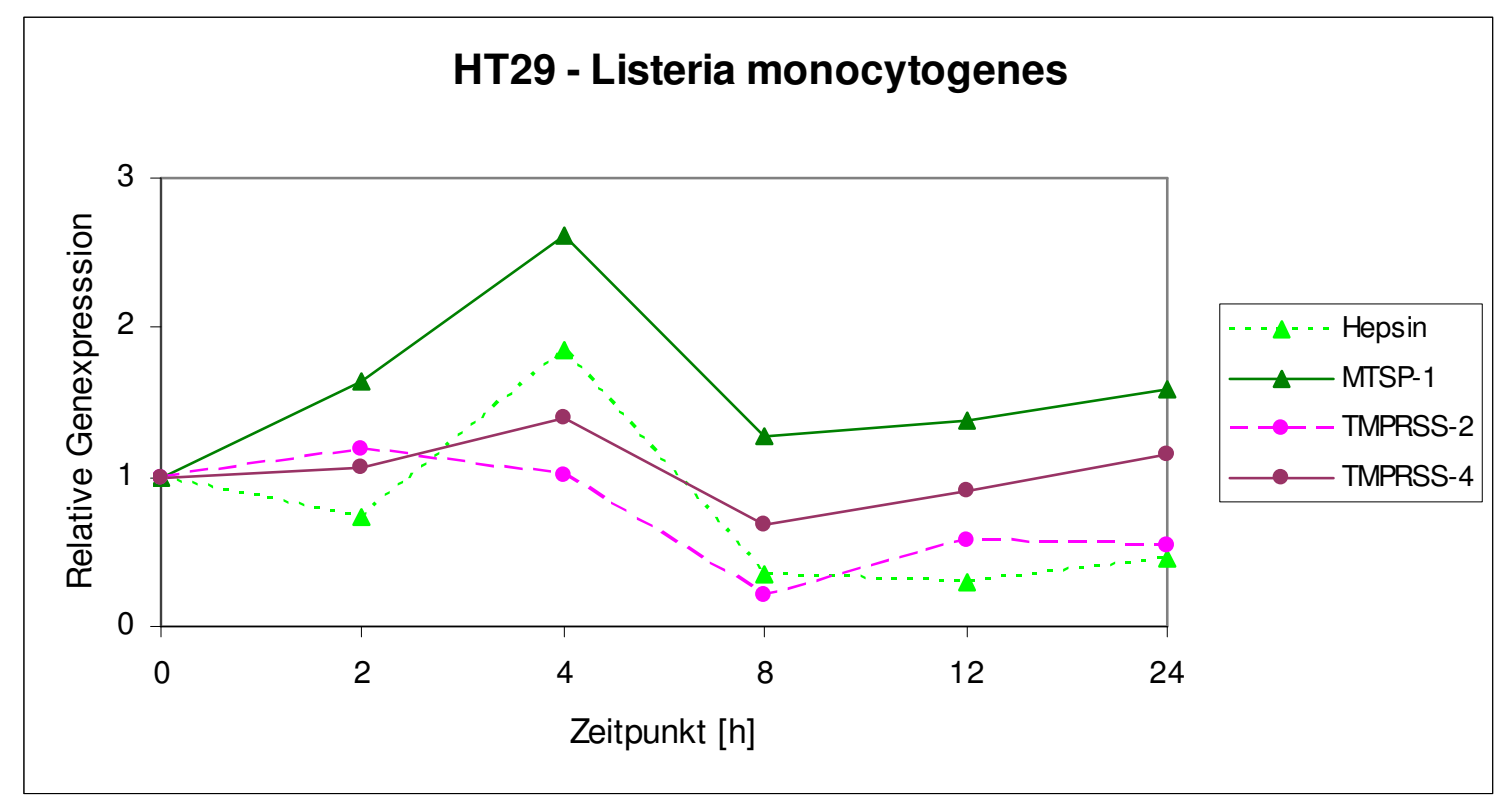

Abb. 3.21: Monolayers der Zelllinie HT29 wurden bei Subkonfluenz mit ca. $3 * 10^{8}$ Bakterien des Stammes Listeria monocytogenes (grampositiv, invasiv) für eine Stunde infiziert, abgesaugt und durch normales Medium ersetzt. Nach 0, 2, 4, 8, 12 und $24 \mathrm{~h}$ erfolgte die Isolierung der RNA. Unter Verwendung eines Transkriptionskits wurde cDNA hergestellt und im abschließenden Arbeitsschritt die Genexpression mittels real time quantitative PCR bestimmt. Die Werte wurden gegen 18sRNS normalisiert. 
Listeria monocytogenes bei Caco2-Zellen: Die TTSP zeigen im Kontext mit den Caco2-Zellen ein etwas inhomogenes Bild durch die Stimulation mit L. monocytogenes. TMPRSS-2 wird deutlich supprimiert mit dem Minimum bei $8 \mathrm{~h}$ mit 0,2-fach und erholt sich zum 24 h-Zeitpunkt auf einen noch subnormalen Wert. Hepsin und TMPRSS-4 werden zunächst leicht erhöht exprimiert (beide 1,4-fach nach 2 h) um dann nach $12 \mathrm{~h}$ ihre Minima zu zeigen (0,4- und 0,5-fach). Beide steigen zum 24 h-Zeitpunkt wieder auf Werte um den Ausgangspunkt an. MTSP-1 bleibt als einzige membranständige Protease über den gesamten Zeitverlauf in seiner Genexpression erhöht (Maximum nach 4 h: 1,8fach), fällt jedoch ebenfalls nach $24 \mathrm{~h}$ wieder in etwa auf den Ausgangswert. (Abb. 3.22)

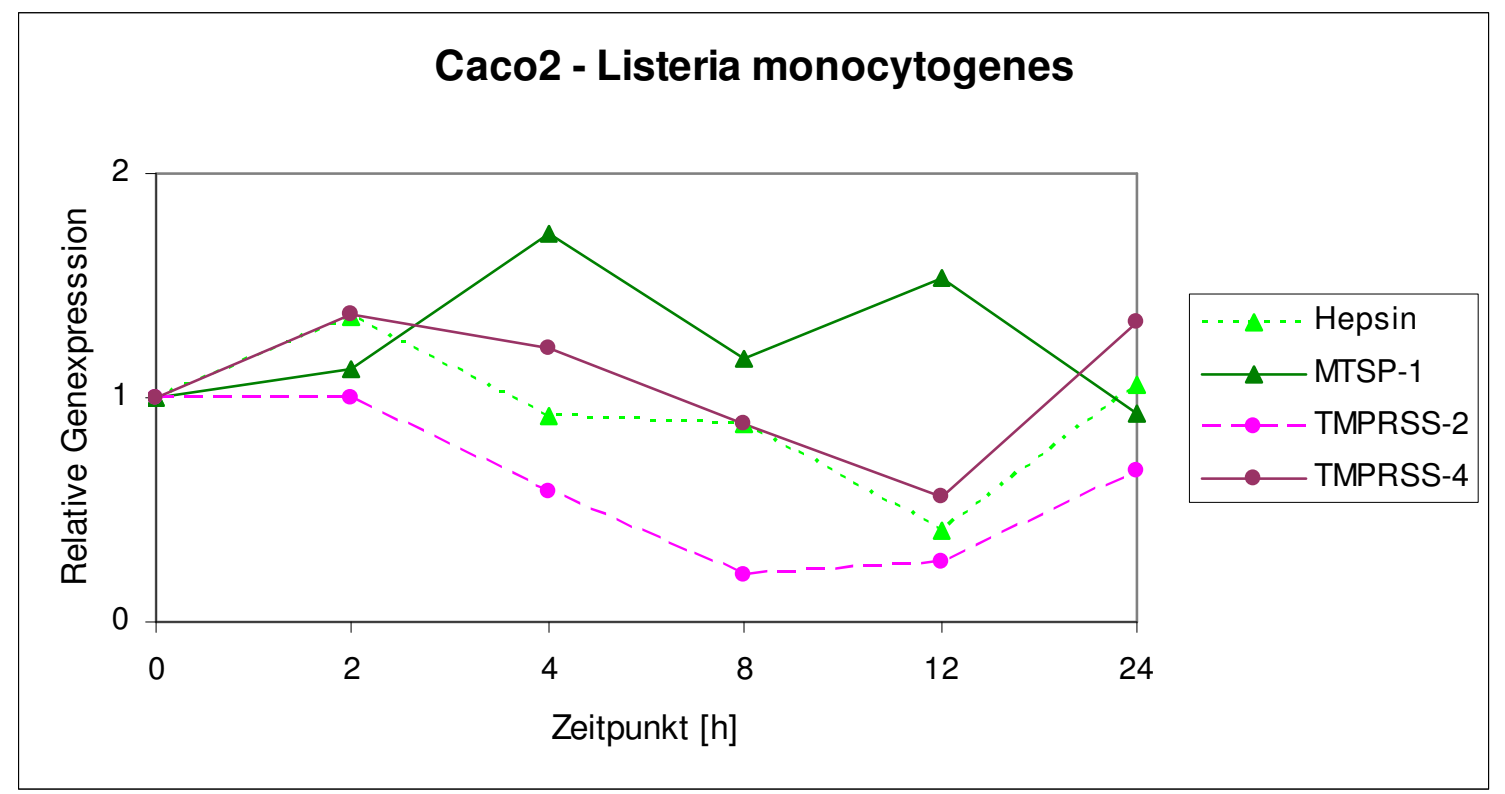

Abb. 3.22: Monolayers der Zelllinie Caco 2 wurden bei Subkonfluenz mit ca. $3 * 10^{8}$ Bakterien des Stammes Listeria monocytogenes (grampositiv, invasiv) für eine Stunde infiziert, abgesaugt und durch normales Medium ersetzt. Nach 0, 2, 4, 8, 12 und $24 \mathrm{~h}$ erfolgte die Isolierung der RNA. Unter Verwendung eines Transkriptionskits wurde cDNA hergestellt und im abschließenden Arbeitsschritt die Genexpression mittels real time quantitative PCR bestimmt. Die Werte wurden gegen 18sRNS normalisiert. 


\subsubsection{HT29- und Caco2-Zellen mit Salmonella typhi}

Salmonella typhi bei HT29-Zellen: Die Genexpression von MTSP-1 und Hepsin wird rasch (nach 2 h) durch Exposition gegenüber Salmonella typhi auf das 5,0- bzw. 3,4fache induziert. Die Hepsinexpression fällt danach rasch ab und findet sich nach $8 \mathrm{~h}$ auf das 0,35-fache supprimiert. Die Expression von MTSP-1 fällt zwar ebenfalls ab, bleibt jedoch bis zum 12 h-Zeitpunkt auf das 2,7-fache erhöht. TMPRSS-2 und -4 finden sich bereits zum 2 h-Zeitpunkt supprimiert und bleiben dies den gesamten Zeitverlauf mit einem Minimum von 0,2-fach für TMPRSS-2 (12 h) und 0,2-fach für TMPRSS-4 zum 8 h-Zeitpunkt. (Abb. 3.23)

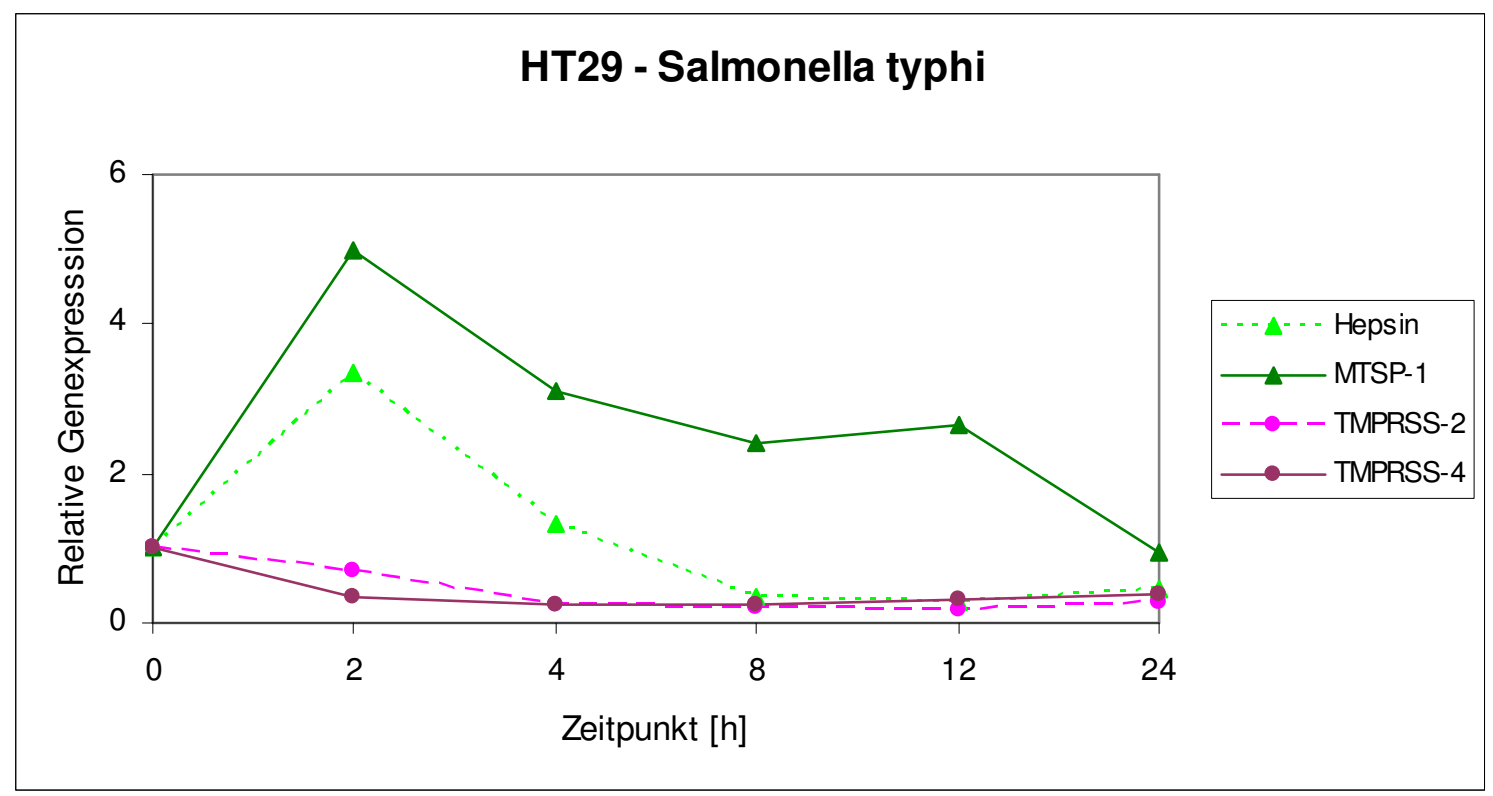

Abb. 3.23: Monolayers der Zelllinie HT29 wurden bei Subkonfluenz mit ca. $3 * 10^{8}$ Bakterien des Stammes Salmonella typhi (gramnegativ, invasiv) für eine Stunde infiziert, abgesaugt und durch normales Medium ersetzt. Nach 0, 2, 4, 8, 12 und $24 \mathrm{~h}$ erfolgte die Isolierung der RNA. Unter Verwendung eines Transkriptionskits wurde cDNA hergestellt und im abschließenden Arbeitsschritt die Genexpression mittels real time quantitative PCR bestimmt. Die Werte wurden gegen 18sRNS normalisiert. 
Salmonella typhi bei Caco2-Zellen: Auch die Antwort der vier TTSP auf Infektion der Caco2-Zellen mit Salmonella typhi verläuft uneinheitlich. Hepsin reagiert nach einem kurzen Peak bei $2 \mathrm{~h}(1,4-\mathrm{fach})$ mit einer schwachen Suppression im weiteren Zeitverlauf (Werte zwischen 0,7- und 0,9-fach). TMPRSS-2 zeigt ein Maximum nach 2 h (2,3-fach) um danach kontinuierlich auf ein Minimum von 0,6-fach bei $12 \mathrm{~h}$ abzufallen. TMPRSS-4 wird initial nach $2 \mathrm{~h}$ auf ein Minimum von 0,6-fach supprimiert, steigt dann aber stetig bis zum Maximum nach $12 \mathrm{~h}$ (2,2-fach) an. MTSP-1 bleibt über den gesamten Zeitverlauf in seiner relativen Genexpression, wenn auch gering, erhöht. Das Maximum liegt nach 8 h bei 2,1-fach. (Abb. 3.24)

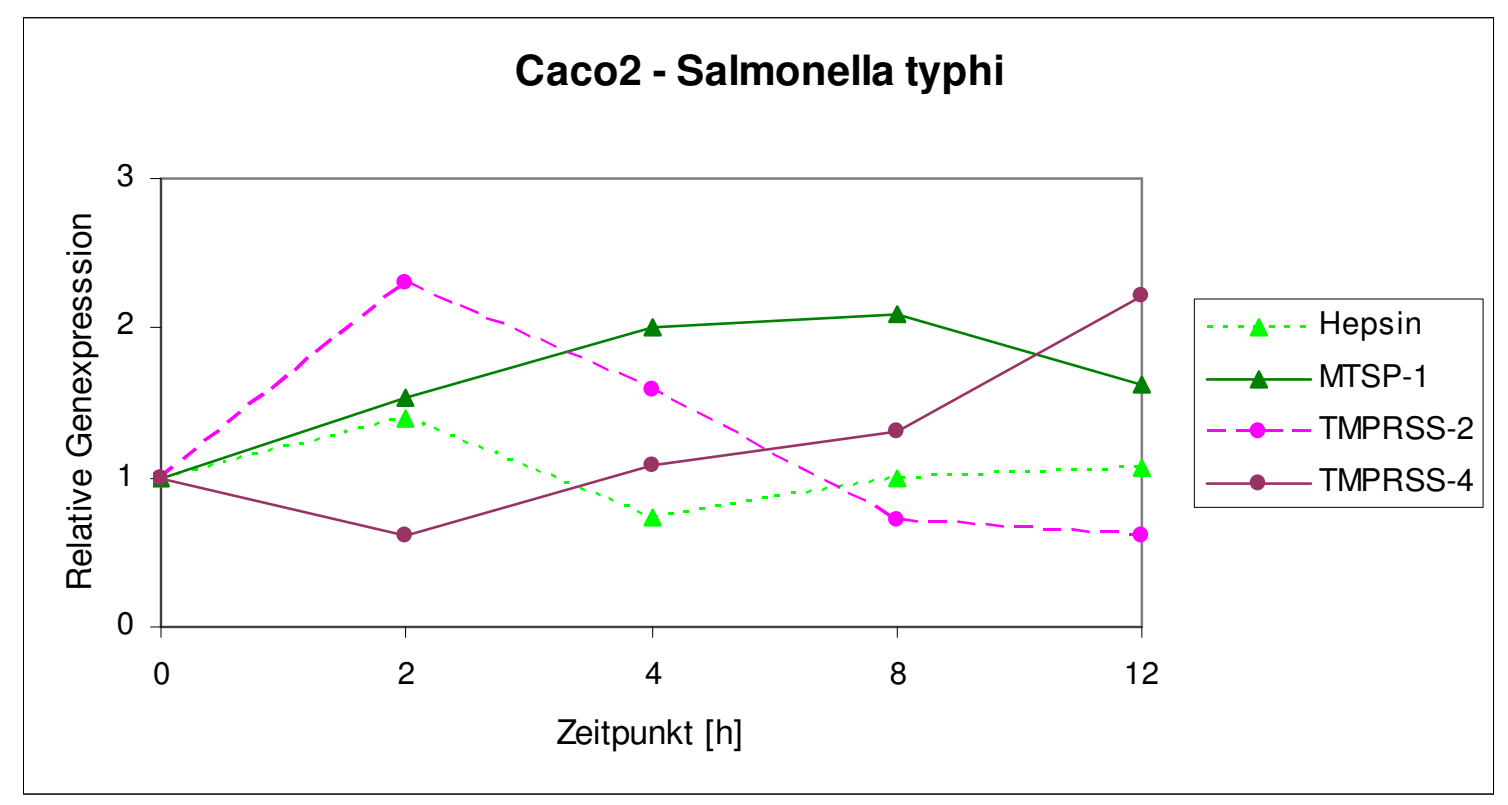

Abb. 3.24: Monolayers der Zelllinie Caco 2 wurden bei Subkonfluenz mit ca. $3 * 10^{8}$ Bakterien des Stammes Salmonella typhi (gramnegativ, invasiv) für eine Stunde infiziert, abgesaugt und durch normales Medium ersetzt. Die RNA wurde nach 0, 2, 4, 8 und bereits bei $12 \mathrm{~h}$ als Endpunkt isoliert, da sich im weiteren Zeitverlauf die Zellen vom Untergrund ablösten. Unter Verwendung eines Transkriptionskits wurde cDNA hergestellt und im abschließenden Arbeitsschritt die Genexpression mittels real time quantitative PCR bestimmt. Die Werte wurden gegen 18sRNS normalisiert. 


\subsubsection{HT29- und Caco2-Zellen mit Yersinia enterocolitica}

Yersinia enterocolitica bei HT29-Zellen: Die drei membranständigen Proteasen TMPRSS-2 /-4 und MTSP-1 reagieren auf die Stimulation durch Yersinia enterocolitica mit Maxima bei $4 \mathrm{~h}$ in ihren Kurvenverläufen. TMPRSS-2 zeigt dabei den höchsten Wert mit einer 10,4-fachen Erhöhung der Genexpression, MTSP-1 und TMPRSS-4 folgen mit einer 8,1-fachen und 5-fachen Induktion. Hepsin steigt ebenfalls bis $4 \mathrm{~h}$ leicht an, erreicht aber seinen Peak erst nach 24 h (4,8-fach). Insgesamt zeigen alle TTSP über den gesamten Zeitverlauf eine Erhöhung ihrer relativen Genexpression. (Abb. 3.25)

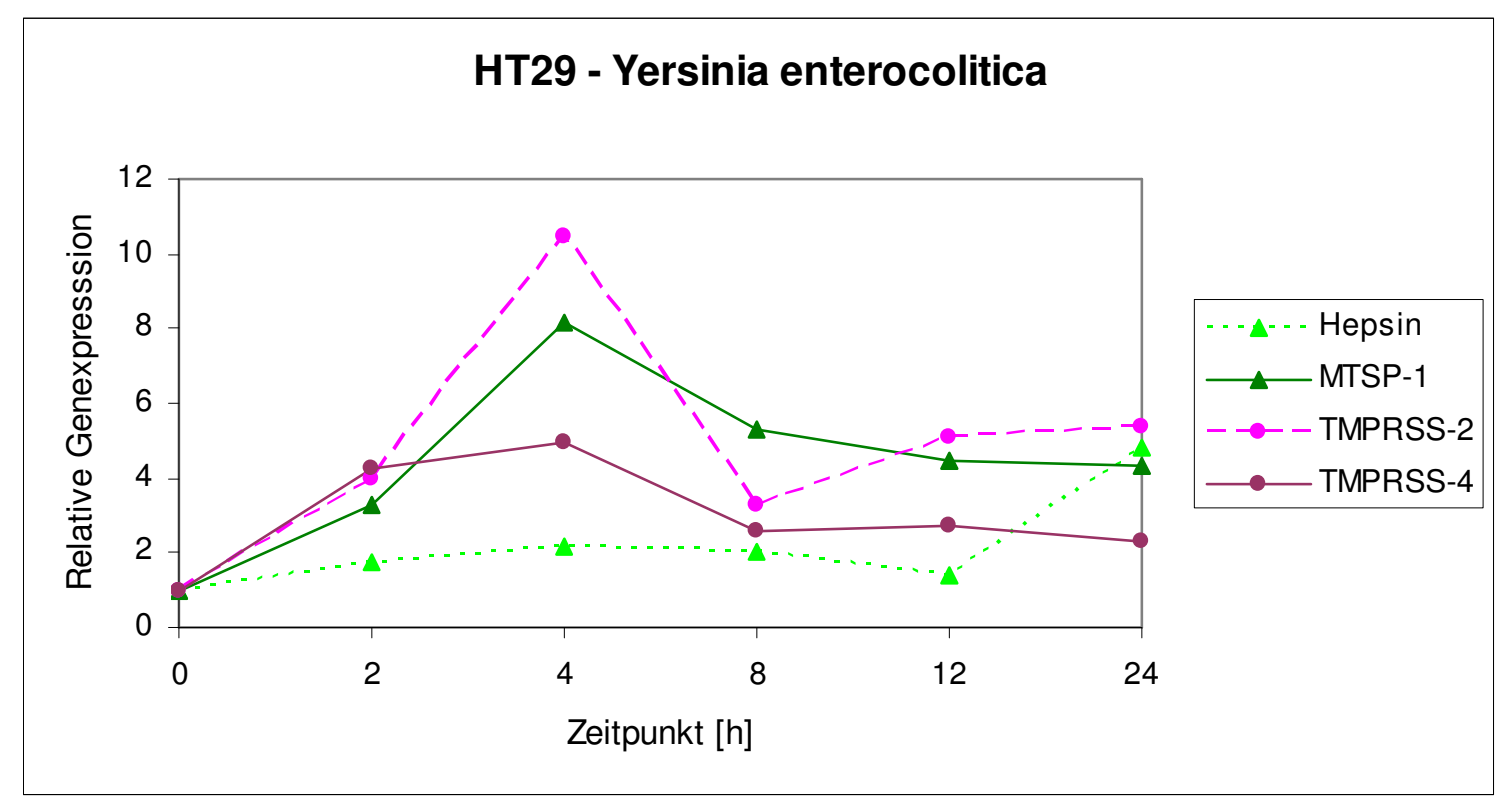

Abb. 3.25: Monolayers der Zelllinie HT29 wurden bei Subkonfluenz mit ca. $3 * 10^{8}$ Bakterien des Stammes Yersinia enterocolitica (gramnegativ, invasiv) für eine Stunde infiziert, abgesaugt und durch normales Medium ersetzt. Nach 0, 2, 4, 8, 12 und $24 \mathrm{~h}$ erfolgte die Isolierung der RNA. Unter Verwendung eines Transkriptionskits wurde cDNA hergestellt und im abschließenden Arbeitsschritt die Genexpression mittels real time quantitative PCR bestimmt. Die Werte wurden gegen 18sRNS normalisiert. 
Yersinia enterocolitica bei Caco2-Zellen: MTSP-1 wird nach Infektion von Caco2Zellen deutlich induziert und erreicht nach $12 \mathrm{~h}$ ein Maximum von 2,7-facher Expression. Hepsin zeigt sein Maximum schon nach 2 h mit einer 1,7-fachen Erhöhung der relativen Genexpression. Danach sinkt Hepsin kontinuierlich bis auf ein Minimum nach $24 \mathrm{~h}$ ab (0,2-fach). TMPRSS-2 und -4 zeigen einen ähnlichen Kurvenverlauf, wobei TMPRSS-4 in den ersten $12 \mathrm{~h}$ leicht oberhalb des Ausgangswertes und TMPRSS-2 leicht unterhalb des Ausgangswertes verläuft. Zum 24 h-Zeitpunkt steigen TMPRSS-2 und -4 auf ein Maximum von 1,5-fach und 1,8-fach an. (Abb. 3.26)

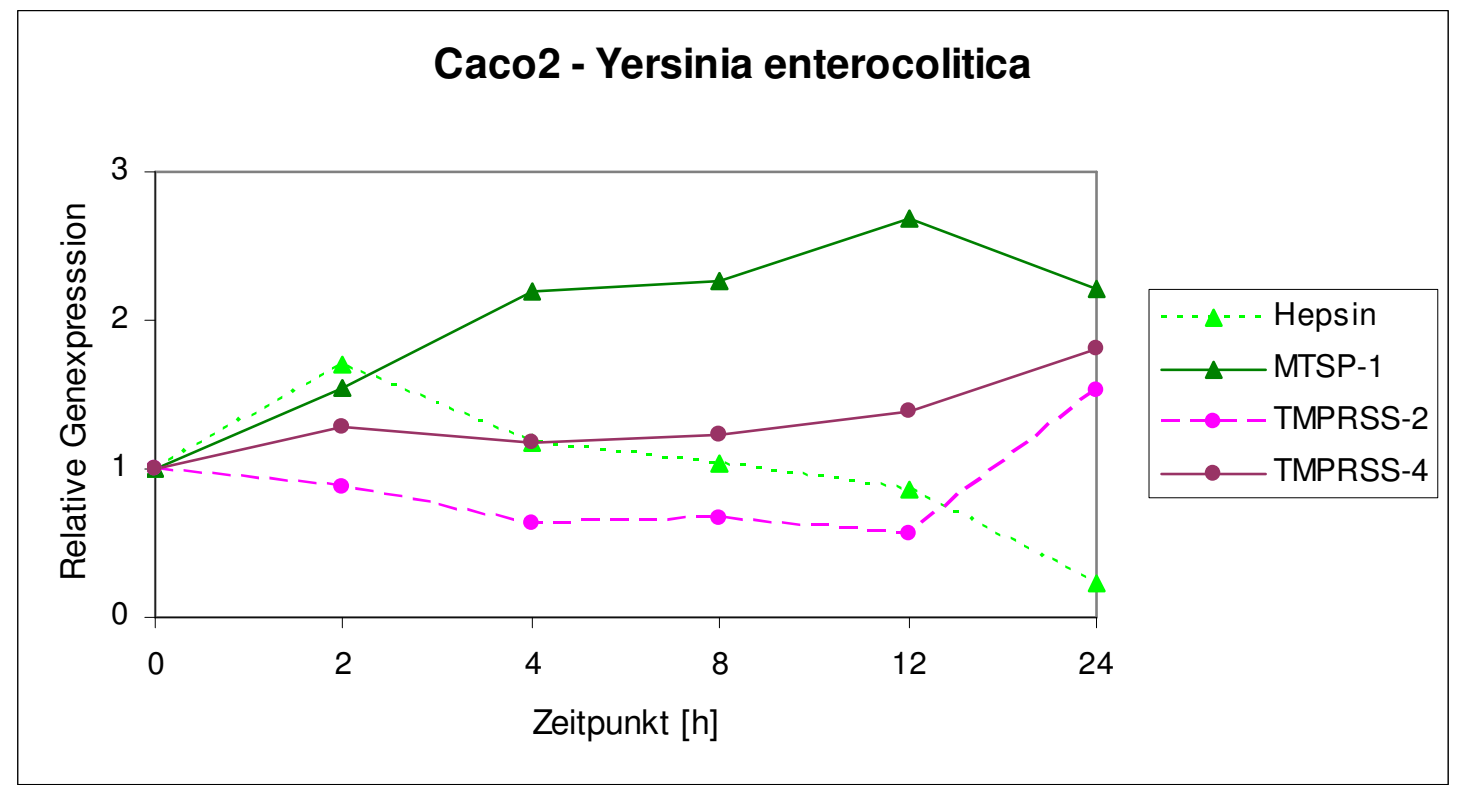

Abb. 3.26: Monolayers der Zelllinie Caco 2 wurden bei Subkonfluenz mit ca. $3 * 10^{8}$ Bakterien des Stammes Yersinia enterocolitica (gramnegativ, invasiv) für eine Stunde infiziert, abgesaugt und durch normales Medium ersetzt. Nach 0, 2, 4, 8, 12 und $24 \mathrm{~h}$ erfolgte die Isolierung der RNA. Unter Verwendung eines Transkriptionskits wurde cDNA hergestellt und im abschließenden Arbeitsschritt die Genexpression mittels real time quantitative PCR bestimmt. Die Werte wurden gegen 18sRNS normalisiert 


\subsubsection{Tabellarische Zusammenfassung}

\begin{tabular}{|l|c|c|c|c|c|c|c|c|c|c|}
\hline \multicolumn{1}{|c|}{ HT29 } & \multicolumn{2}{c|}{ Ecfc } & \multicolumn{2}{c|}{ Esco } & \multicolumn{2}{c|}{ Limo } & \multicolumn{2}{c|}{ Saty } & \multicolumn{2}{c|}{ Yeen } \\
\hline IL-8 & ++ & $4 \mathrm{~h}$ & +++ & $2 \mathrm{~h}$ & +++ & $2 \mathrm{~h}$ & ++ & $2 \mathrm{~h}$ & ++ & $12 \mathrm{~h}$ \\
\hline PAR-2 & + & $4 \mathrm{~h}$ & + & $24 \mathrm{~h}$ & + & $2 \mathrm{~h}$ & + & $2 \mathrm{~h}$ & + & $24 \mathrm{~h}$ \\
\hline Hepsin & -- & $2 \mathrm{~h}$ & + & $2 \mathrm{~h}$ & + & $4 \mathrm{~h}$ & + & $2 \mathrm{~h}$ & + & $24 \mathrm{~h}$ \\
\hline MTSP-1 & $0 /-$ & $2 \mathrm{~h}$ & + & $12 \mathrm{~h}$ & + & $4 \mathrm{~h}$ & + & $2 \mathrm{~h}$ & + & $4 \mathrm{~h}$ \\
\hline TMPRSS-2 & -- & $2 \mathrm{~h}$ & + & $2 \mathrm{~h}$ & 0 & $2 \mathrm{~h}$ & - & $2 \mathrm{~h}$ & ++ & $4 \mathrm{~h}$ \\
\hline TMPRSS-4 & -- & $2 \mathrm{~h}$ & + & $12 \mathrm{~h}$ & + & $4 \mathrm{~h}$ & -- & $2 \mathrm{~h}$ & + & $4 \mathrm{~h}$ \\
\hline
\end{tabular}

Tab. 3.4.1: Übersicht der Stimulationsexperimente mit Angabe der maximalen Höhe der Genexpression und dem korrespondierenden Zeitpunkt bei HT29-Zellen

\begin{tabular}{|l|c|c|c|c|c|c|c|c|c|c|}
\hline \multicolumn{1}{|c|}{ Caco2 } & \multicolumn{2}{|c|}{ Ecfc } & \multicolumn{2}{c|}{ Esco } & \multicolumn{2}{c|}{ Limo } & \multicolumn{2}{c|}{ Saty } & \multicolumn{2}{c|}{ Yeen } \\
\hline IL-8 & + & $4 \mathrm{~h}$ & +++ & $2 \mathrm{~h}$ & ++ & $2 \mathrm{~h}$ & +++ & $12 \mathrm{~h}$ & + & $8 \mathrm{~h}$ \\
\hline PAR-2 & + & $12 \mathrm{~h}$ & ++ & $4 \mathrm{~h}$ & ++ & $4 \mathrm{~h}$ & ++ & $12 \mathrm{~h}$ & + & $4 \mathrm{~h}$ \\
\hline Hepsin & - & $8 \mathrm{~h}$ & + & $24 \mathrm{~h}$ & + & $2 \mathrm{~h}$ & + & $2 \mathrm{~h}$ & + & $2 \mathrm{~h}$ \\
\hline MTSP-1 & -- & $8 \mathrm{~h}$ & + & $24 \mathrm{~h}$ & + & $4 \mathrm{~h}$ & + & $8 \mathrm{~h}$ & + & $12 \mathrm{~h}$ \\
\hline TMPRSS-2 & -- & $2 \mathrm{~h}$ & + & $2 \mathrm{~h}$ & 0 & $2 \mathrm{~h}$ & + & $2 \mathrm{~h}$ & + & $24 \mathrm{~h}$ \\
\hline TMPRSS-4 & - & $12 \mathrm{~h}$ & + & $2 \mathrm{~h}$ & + & $4 \mathrm{~h}$ & + & $12 \mathrm{~h}$ & + & $24 \mathrm{~h}$ \\
\hline
\end{tabular}

Tab. 3.4.2: Übersicht der Stimulationsexperimente mit Angabe der maximalen Höhe der Genexpression und dem korrespondierenden Zeitpunkt bei Caco2-Zellen

Tab. 3.4.1 und 3.4.2 fassen die vorangegangenen Daten für HT29- und Caco2-Zellen zusammen. Für die obige Darstellung der Daten wurden die jeweiligen absoluten Maximalwerte, unabhängig vom Zeitpunkt, verwendet.

\begin{tabular}{|llll|}
\hline++ & $=$ & $>100-$ & fache Erhöhung der Genexpression \\
++ & $=$ & $>10-$ & fache Erhöhung der Genexpression \\
+ & $=$ & $>1,25-$ & fache Erhöhung der Genexpression \\
0 & $=$ & Keine Veränderung der Genexpression \\
- & $=$ & $<0,75-$ & fache Suppression der Genexpression \\
- & $=$ & $<0,5-$ & fache Suppression der Genexpression \\
--- & $=$ & $<0,25-$ & fache Suppression der Genexpression
\end{tabular}


Anmerkungen:

1. IL-8 wird als Referenz für den proinflammatorischen Effekt der Infektionen aufgeführt. PAR-2 ist ein mögliches molekulares Target für die proteolytische Aktivität der Typ II transmembranäre Serinproteasen. Es ist daher von Interesse, ob dieser Rezeptor gleichsinnig oder gegensinnig durch die Infektion reguliert wird. Die Daten sind der Arbeit von Hr. M. Himpel entnommen und erscheinen mit dessen freundlicher Genehmigung.

2. Die Experimente wurden 2-bzw. 3-mal wiederholt, es wird für jede Kombination von Zelllinie und Bakterienstamm ein repräsentatives Ergebnis gezeigt.

\subsubsection{Textorische Zusammenfassung}

1. Das augenfälligste Ergebnis ist die deutliche Suppression aller vier untersuchten TTSP in beiden Zelllinien durch das kommensale Bakterium Enterococcus faecium.

2. Quantitativ die ausgeprägteste Geninduktion ist durch Yersinia enterocolitica in HT29-Zellen (10,4-fach TMPRSS-2), Salmonella typhi in HT29-Zellen (5-fach MTSP-1) und Escherichia coli in HT29-Zellen (5,8-fach MTSP-1) aber auch Caco2-Zellen (3,9-fach TMPRSS-2) zu beobachten. Insgesamt sind somit in HT29-Zellen stärkere Geninduktionen zu beobachten als in Caco2-Zellen.

3. Neben Enterococcus faecium führt Listeria monocytogenes noch $\mathrm{zu}$ sehr ähnlichen Reaktionen der TTSP in den beiden Zelllinien HT29 und Caco2 (dominanter Peak bei $4 \mathrm{~h}$ für MTSP-1, Suppression für Hepsin und TMPRSS-2, um den Ausgangspunkt undulierende Regulation für TMPRSS-4). Partielle Ähnlichkeiten in ihren Reaktionsmustern weisen die beiden Zelllinien in ihrer Reaktion auf Escherichia coli auf. So verlaufen die Kurven für TMPRSS-2 und 4 ähnlich, die für Hepsin und MTSP-1 jedoch vollkommen unterschiedlich in beiden Zelllinien.

4. Vollkommen zellspezifisch verlaufen die Reaktionen auf Salmonella typhi und Yersinia enterocolitica. Während Salmonella typhi in HT29-Zellen zur Induktion von MTSP-1 und Hepsin sowie zur Suppression von TMPRSS-2 und 4 führt, zeigen die beiden Proteasen in Caco2-Zellen eine frühe bzw. späte Reaktion. Hepsin wird dagegen in Caco2-Zellen kaum reguliert, MTSP-1 zeigt 
eine schwache, verzögerte Induktion. Yersinia enterocolitica führt in HT29Zellen zu ausgeprägten, frühen Peaks bei TMPRSS-2 und -4 sowie MTSP-1. Im Gegensatz hierzu findet sich in Caco2-Zellen bei diesen drei TTSP eine schwache späte Induktion. Hepsin wird sowohl in HT29 als auch in Caco2 in den ersten $12 \mathrm{~h}$ kaum reguliert, in HT29 jedoch spät stark induziert und in Caco2 deutlich supprimiert.

5. Fast ausnahmslos zeigen TMPRSS-2 und -4 weitgehend parallel verlaufende Kurven. Einzige Ausnahme ist die Infektion von Caco2 mit Salmonella typhi. Dies ist möglicherweise Ausdruck der starken Verwandtschaft der Gene. MTSP1 wird außer durch Enterococcus faecium immer induziert, während TMPRSS-2 und -4 häufiger supprimiert oder nur schwach reguliert werden.

\subsection{Expression von TTSP nach bakterieller Infektion intestinaler Epithelzellen (IEC) mit verschiedenen E. coli - Stämmen}

Monolayers der Zelllinien HT29 und Caco2 wurden über einen Zeitraum von 24 h mit drei verschiedenen Escherichia coli- (=Esco/ E. coli) Stämmen (ATCC 25922, 0157 EHEC, Nissle 1917) in drei unterschiedlichen Ansätzen vitales/ intaktes Bakterium, hitzeinaktiviertes Bakterium (= Hi), Überstand Bakterium (= Ü) beimpft.

E. coli ATCC 25922: Dieser E. coli-Referenzstamm wurde bereits in einem anderen Experiment (siehe unter 3.3.2) verwendet und ausführlich beschrieben (siehe unter 3.3). Zusammenfassend handelt es sich um ein gramnegatives, säurebildendes (Laktosepositiv), stäbchenförmiges, Oxidase-negatives und peritrich begeißeltes, nicht-invasives Bakterium, das im menschlichen und tierischen Verdauungstrakt vorkommt. Es gehört zur Familie der Enterobacteriaceae (Brock, 2003).

Der kommensale E. coli wurde für dieses Experiment als Normvariante der intestinalen Mikroflora ausgewählt.

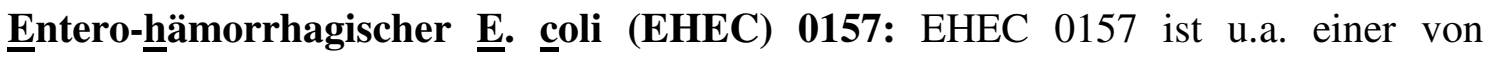
serologisch differenzierten E. coli-Stämmen (ETEC, EIEC, EPEC, EAEC) mit pathogener Potenz. Diesbezüglich weist EHEC mehrere Besonderheiten auf. Erstens besitzen sie ein spezielles Hüllenprotein (Adhäsin), mit welchem ein Anheften z.B. an Darmepithelzellen gelingt. Zweitens produzieren sie ein Toxin, welches Ähnlichkeit mit 
dem neurotoxischen und nekrotisierenden Toxin von Shigella dysenteriae hat und als Shiga-Toxin oder auch Vero-Toxin bezeichnet wird. Schließlich produzieren die EHECStämme auch noch ein plasmidkodiertes Hämolysin. Auf die 3 häufigsten Serogruppen O157, O103 und O26 verteilen sich fast 60\% der Erreger. Eine Infektion erfolgt über fäkal verunreinigtes Wasser, Lebensmittel sowie in direktem Kontakt mit Mensch oder Tier. Eine sehr geringe Infektionsdosis von nur 20-100 Bakterien reicht oftmals schon für eine Infektion aus. Diese kann inapparent verlaufen oder aber sich zu einer manifesten Gastroenteritis mit blutigen Diarrhoen i.S.e. enterohämorrhagischen Kolitis entwickeln. Als schwere Komplikation einer EHEC-Infektionen ist das enteropathische hämolytisch-urämische Syndrom (HUS) zu nennen. Die Infektion mit EHEC ist meldepflichtig (Brock et al., 2003).

EHEC wurde als pathogener Stamm von E. coli für dieses Experiment ausgesucht. Insbesondere unter Berücksichtigung seiner bakteriellen Besonderheiten soll die Geninduktion der TTSP untersucht werden.

E. coli Nissle $1917(\mathbf{E c N})$ : EcN gehört als apathogenes gramnegatives fakultativ anaerobes Stäbchen zur Gattung Escherichia, Familie der Enterobacteriaceae. Als einer der bestuntersuchtesten probiotischen Stämme wird er u.a. in der Behandlung von Darmerkrankungen eingesetzt. Von der WHO ist EcN vollständig typisiert als Serovar O6:K5:H1. In der Deutschen Sammlung für Mikroorganismen wird er unter dem Kürzel DSM-6601 geführt. EcN produziert keine hitzestabilen Enterotoxine und Zytotoxine sowie Shiga-like Toxine und verfügt auch nicht über das bei pathogenen E. coli für die Sekretion zuständige Typ-III Transportsystem. Der Stamm weist keine hochmolekularen Plasmide auf, welche häufig Träger von Virulenzfaktoren und Antibiotikaresistenzen sind. So zeigt sich $\mathrm{EcN}$ sensitiv gegenüber allen routinemäßig gegen Enterobacteriaceae eingesetzten Antibiotika (Grozdanov et al., 2002). Der Stamm ist genetisch stabil und besitzt weder in vivo noch in vitro eine Invasivität (LodinovaZadnikova et al., 1997). Neben EcN kommen z.B. auch Laktobazillen oder Bifidobakterien als so genannte Probiotika zum Einsatz. Sie besiedeln den Darm, können pathogene Mikroorganismen verdrängen und dabei gesundheitsfördernde Effekte hervorrufen. So ist EcN zur Remissionserhaltung bei Colitis ulcerosa ebenso effektiv und sicher wie Mesalazin und bietet damit eine therapeutische Alternative (Kruis et al., 2004). Probiotika können definiert werden als „Reinkultur oder Keimgemisch lebender Mikroorganismen, welche, eine ausreichende Zufuhr 
vorausgesetzt, die Eigenschaften der intestinalen Standortflora verbessern und dadurch die Gesundheit von Mensch und Tier positiv beeinflussen“ (Havenaar et al., 1992). Der Freiburger Arzt Dr. Alfred Nissle isolierte 1917 aus dem Stuhl eines „darmgesunden“ Soldaten einen apathogenen E. coli welcher nicht an einer in der Truppe ausgebrochen Enteritis erkrankt war. Bereits ein Jahr später setzte Nissle diesen nach ihm benannten E. coli aufgrund seines probiotischen Effekts als Therapeutikum zur Behandlung chronischer Darmerkrankungen ein (de Vrese, Schrezenmeir; 2008). Bis heute wird E. coli Nissle1917 als Probiotikum unter dem Präparatenamen Mutaflor® vertrieben. EcN wurde als apathogener probiotischer Stamm in dieses Experiment aufgenommen um seine möglichen protektiven Eigenschaften auf IEC unter Berücksichtigung der Regulation der TTSP zu untersuchen.

In dem Experiment wurden neben den o.g. verschiedenen Bakterienstämmen diese noch in drei unterschiedliche Präparationen (intaktes Bakterium, hitzeinaktiviert und Bakterien-Überstand) separiert. Dieser Versuchsaufbau sollte Rückschlüsse auf die einzelnen Bakterienbestandteile geben, welche eine mögliche Geninduktionen der TTSP auslösen.

Intaktes Bakterium: Der intakte, native E. coli- Stamm stellt die Ausgangsvariante dar. Hier sind alle Bakterienbestandteile wie Bakterienhülle mit LPS oder Flagellen noch vorhanden und aktiv.

Hitzeinaktiviertes Bakterium: Durch ein Erhitzen des jeweiligen BakterienStammes für $15 \mathrm{~min}$ bei $80^{\circ} \mathrm{C}$ mit nachfolgendem Abkühlen werden Proteinantigene der Erregeroberfläche wie zum Beispiel das Geißelprotein Flagellin denaturiert und letztlich das Bakterium inaktiviert. Lipopolysaccharid (LPS) als ein wesentlicher Zellwandbestandteil gramnegativer Bakterien bleibt dagegen immunologisch intakt.

Bakterien-Überstand: Durch Abtrennen der festen Bestandteile mittels Mikrofilter bleiben im Überstand nur noch vom Bakterium sezernierte Faktoren wie z.B. Toxine über. 


\subsubsection{HT29-Zellen mit E. coli (vital, hitzeinaktiviert und Überstand)}

E. coli: Alle TTSP zeigen als Reaktion auf E. coli eine zweigipflige Kurve. Hepsin, TMPRSS-2 und -4 haben ihr erstes Maximum nach 2 h, MTSP-1 nach 4 h. Bei Hepsin fällt dieses erste Maximum mit einer 5,8-fachen Induktion am deutlichsten aus. Das zweite Maximum tritt bei Hepsin, MTSP-1 und TMPRSS-4 nach $12 \mathrm{~h}$ auf, bei TMPRSS-2 zeigt sich ein Anstieg der Expression bis zum 24 h- Wert. Das zweite Maximum liegt für MTSP-1 (6,1-fach) und TMPRSS-4 (5,3-fach) höher als das erste Maximum, für Hepsin und TMPRSS-2 niedriger als das erste Maximum. (Abb. 3.27)

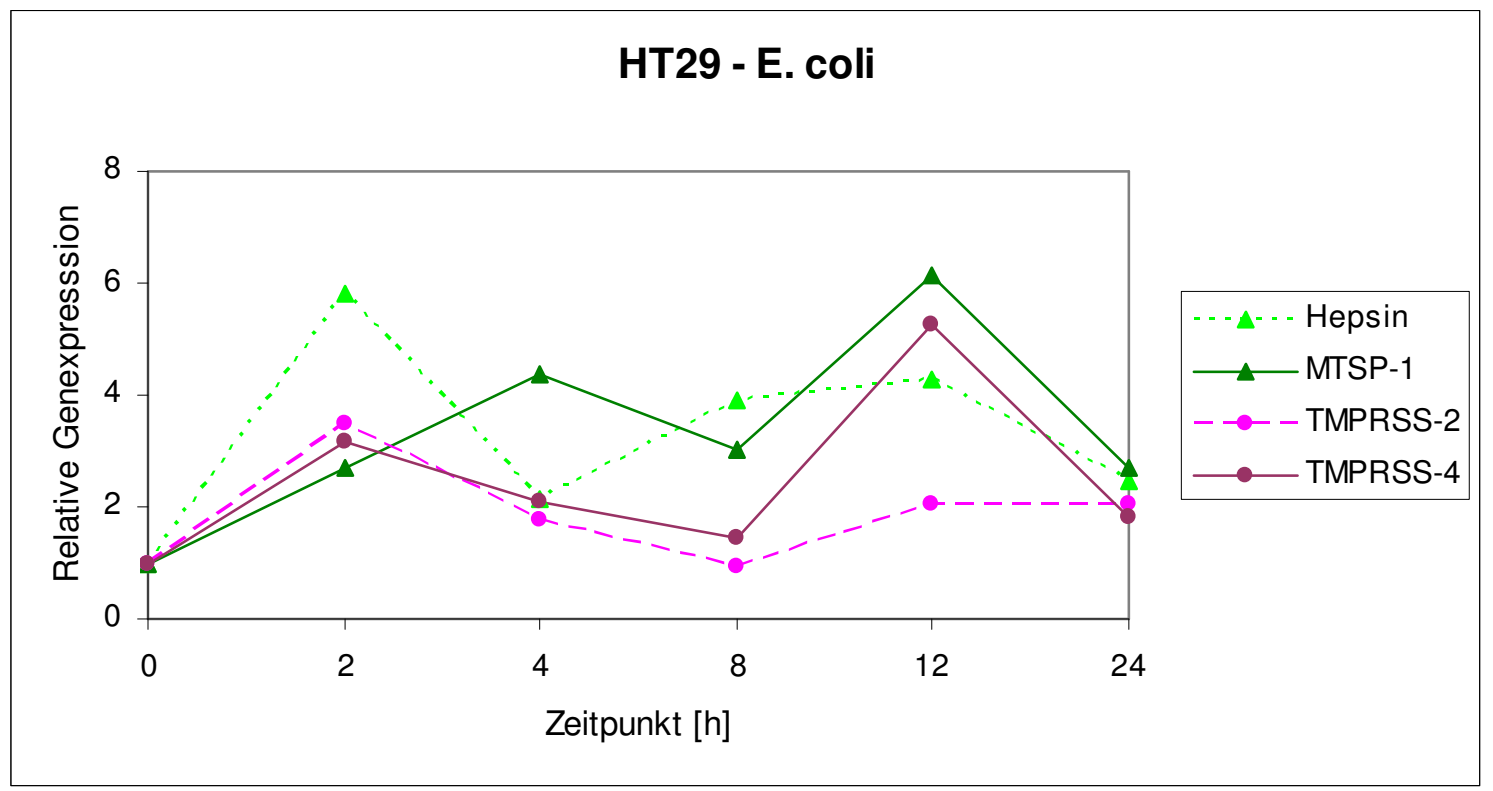

Abb. 3.27: Monolayers der Zelllinie HT29 wurden bei Subkonfluenz mit ca. $3 * 10^{8}$ Bakterien des Stammes E. coli für eine Stunde infiziert, abgesaugt und durch normales Medium ersetzt. Nach 0, 2, 4, 8, 12 und 24 h erfolgte die Isolierung der RNA. Unter Verwendung eines Transkriptionskits wurde cDNA hergestellt und im abschließenden Arbeitsschritt die Genexpression mittels real time quantitative PCR bestimmt. Die Werte wurden gegen 18sRNS normalisiert. 
E. coli-hitzeinaktiviert: TMPRSS-2 und Hepsin reagieren auf die lysierten und hitzedenaturierten Bakterien nach $2 \mathrm{~h}$ mit einer ausgeprägten Induktion ihrer Genexpression. Die Maxima liegen bei einer 40-fachen Erhöhung für TMPRSS-2 und 10-fachen Erhöhung für Hepsin. Beide fallen danach deutlich ab, Hepsin steigt nach 24 h nochmals auf das 8,5-fache an. TMPRSS-4 und MTSP-1 reagieren verhaltener und zeigen keine so ausgeprägte Regulation. Ihre Werte sind dennoch immer leicht erhöht und zeigen ihre Maximalwerte von 2,8-fach nach 2 h für TMPRSS-4 sowie 2,1-fach nach 24 h für MTSP-1. (Abb. 3. 28)

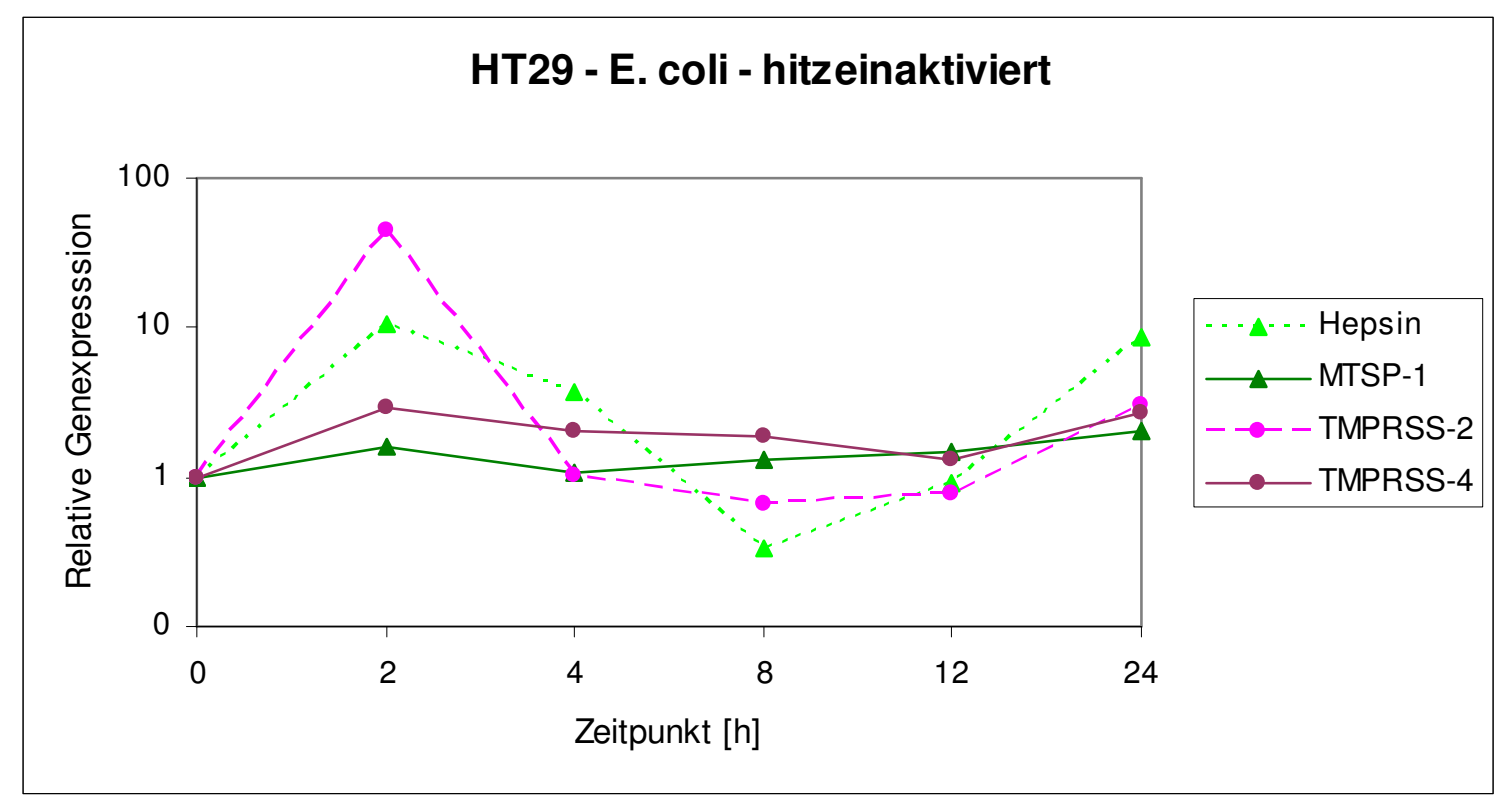

Abb. 3.28: Monolayers der Zelllinie HT29 wurden bei Subkonfluenz mit initial ca. $3^{*} 10^{8}$ Bakterien des hitzeinaktivierten E. coli-Stammes $\left(15 \mathrm{~min}\right.$ bei $\left.80^{\circ} \mathrm{C}\right)$ für eine Stunde exponiert, abgesaugt und durch normales Medium ersetzt. Nach 0, 2, 4, 8, 12 und $24 \mathrm{~h}$ erfolgte die Isolierung der RNA. Unter Verwendung eines Transkriptionskits wurde cDNA hergestellt und im abschließenden Arbeitsschritt die Genexpression mittels real time quantitative PCR bestimmt. Die Werte wurden gegen 18sRNS normalisiert. 
E. coli-Überstand: Die Exposition von HT29-Zellen gegenüber E. coli-Überstand führt zu einer biphasischen Reaktion von MTSP-1, TMPRSS-4 und Hepsin. Diese Proteasen weisen ein erstes Maximum nach 2 bzw. 4 Stunden mit einer 4-fachen, 3,5-fachen und 2,8-fachen Induktion auf. Nach einem Abfallen des Expressionslevels erreichen diese drei Proteasen nach 24 h noch ein zweites Maximum mit einer 4,8-fachen Induktion für Hepsin, einer 3,3-fachen Induktion für MTSP-1 und einer 2,2-fachen Induktion für TMPRSS-4. TMPRSS-2 wird hingegen bis zum 12 h-Wert bis auf die 0,4-fache Expression supprimiert um dann zum 24 h-Wert auf die 2,3-fache Expression anzusteigen. (Abb. 3.29)

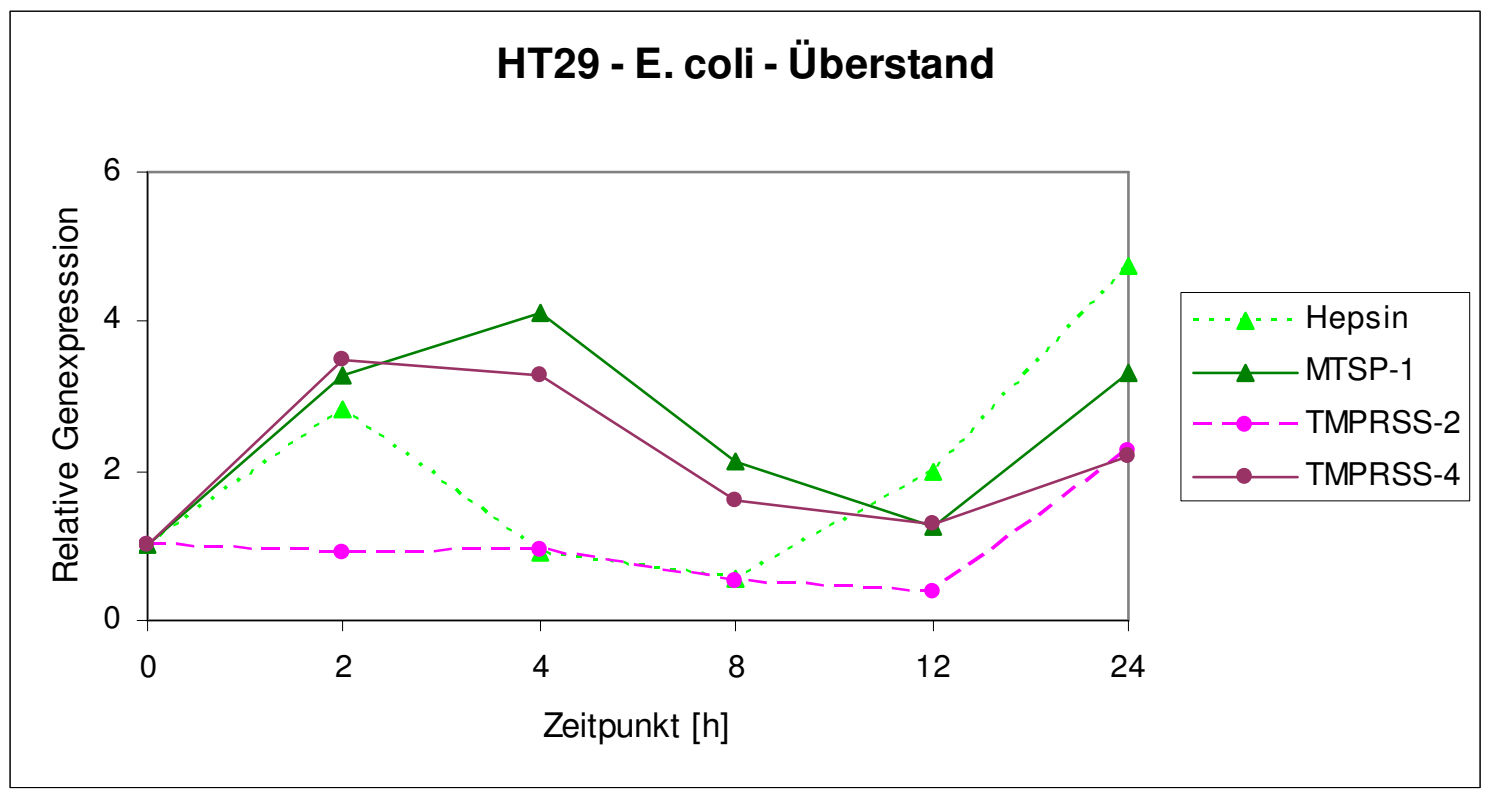

Abb. 3.29: Monolayers der Zelllinie HT29 wurden bei Subkonfluenz mit E. coliÜberstand (Abtrennen der Bakterien mittels Mikrofilter) für eine Stunde beimpft, abgesaugt und durch normales Medium ersetzt. Nach 0, 2, 4, 8, 12 und 24 h erfolgte die Isolierung der RNA. Unter Verwendung eines Transkriptionskits wurde cDNA hergestellt und im abschließenden Arbeitsschritt die Genexpression mittels real time quantitative PCR bestimmt. Die Werte wurden gegen 18sRNS normalisiert. 


\subsubsection{Textorische Zusammenfassung E. coli mit HT29}

1. Am augenfälligsten ist die starke Induktion von TMPRSS-2 durch die hitzeinaktivierte Präparation. Dieses starke Stimulans der TMPRSS-2Expression macht die gesamte durch das intakte Bakterium beobachtete Induktion aus, nachdem der Überstand, also von den Bakterien sezernierte Faktoren zu diesem Peak nach 2 h nichts beiträgt.

2. Der durch die intakten Bakterien nach $2 \mathrm{~h}$ ausgelöste Peak bei Hepsin setzt sich dagegen durch sezernierte Faktoren im Überstand und Faktoren aus der hitzeinaktivierten Fraktion zusammen.

3. $\mathrm{Zu}$ der biphasischen Induktion von MTSP-1 und TMPRSS-4 durch die intakten Bakterien trägt die hitzeinaktivierte Fraktion wenig bei. Das erste Maximum der intakten Bakterien wird durch den Überstand gut nachgezeichnet, der zweite Peak tritt im Überstand jedoch zeitverzögert auf. 


\subsubsection{HT29-Zellen mit EHEC (vital, hitzeinaktiviert und Überstand)}

EHEC: Auch der intakte enterohämorrhagische E. coli führt zu einer biphasischen Reaktion der TTSP-Expression in HT29-Zellen. Es kommt zu einer raschen Induktion nach $2 \mathrm{~h}$, wobei diese bei Hepsin mit einer 16,2-fachen Induktion am ausgeprägtesten ausfällt. TMPRSS-4, TMPRSS-2 und MTSP-1 weisen geringere frühe Maxima mit einer 4,9-fachen, 4,4-fachen und 1,9-fachen Induktion auf. Alle TTSP fallen dann rasch auf ein Minimum bei $4 \mathrm{~h}$ ab um dann wieder anzusteigen und bei $12 \mathrm{~h}$ oder $24 \mathrm{~h}$ ein weiteres Maximum zu erreichen. Diese liegen für TMPRSS-4 und MTSP-1 mit einer 4,5-fachen und einer 1,6-fachen Induktion in etwa auf gleichem Niveau wie das erste Maximum, für Hepsin und TMPRSS-2 mit einer 6,9-fachen und 1,7-fachen Induktion jedoch deutlich niedriger als der erste Peak. (Abb. 3.30)

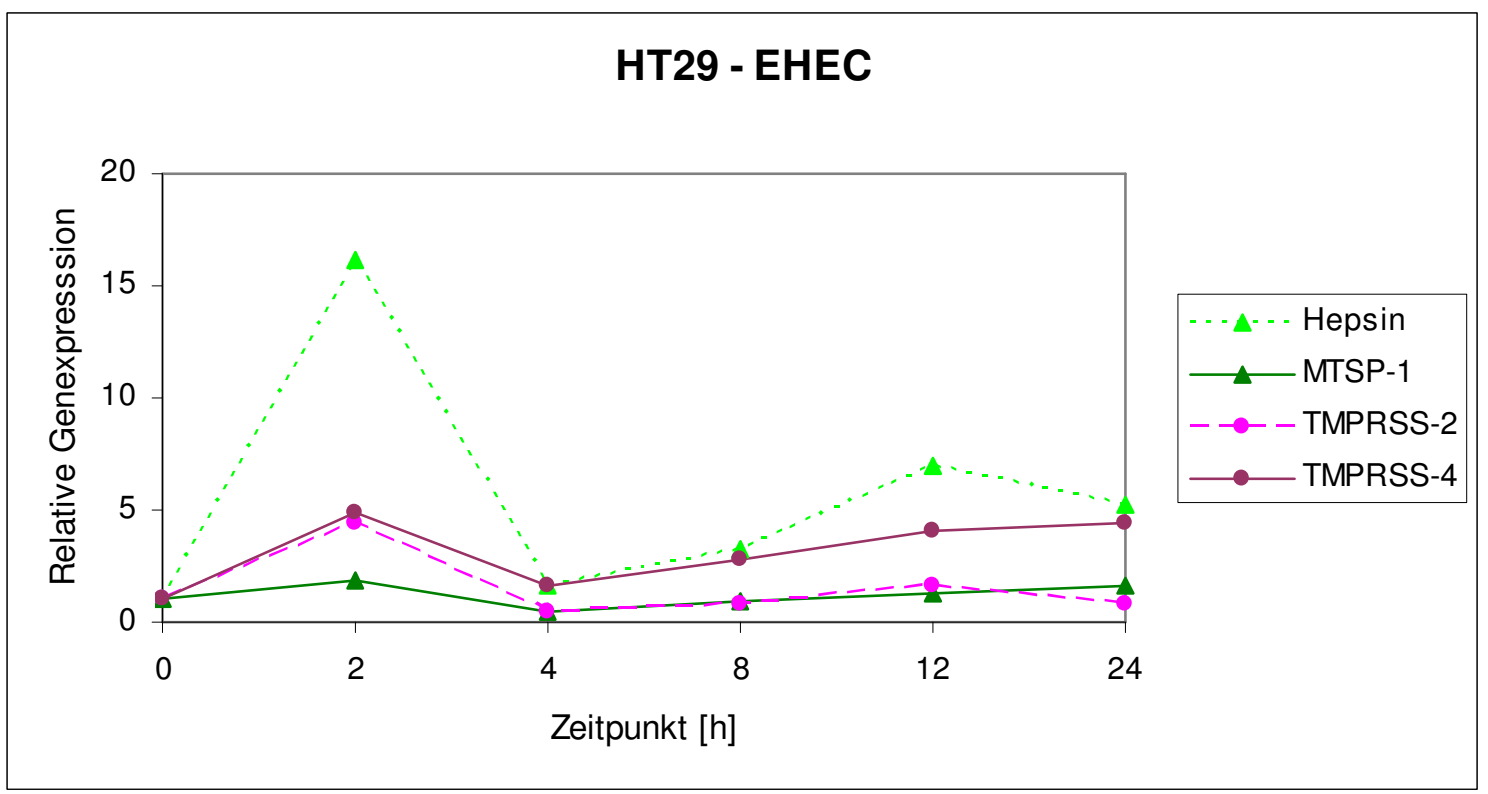

Abb. 3.30: Monolayers der Zelllinie HT29 wurden bei Subkonfluenz mit EHEC (ca. $3 * 10^{8}$ Bakterien) für eine Stunde infiziert, abgesaugt und durch normales Medium ersetzt. Nach 0, 2, 4, 8, 12 und 24 h erfolgte die Isolierung der RNA. Unter Verwendung eines Transkriptionskits wurde cDNA hergestellt und im abschließenden Arbeitsschritt die Genexpression mittels real time quantitative PCR bestimmt. Die Werte wurden gegen 18sRNS normalisiert. 
EHEC-hitzeinaktiviert: Die Exposition von HT29-Zellen gegenüber der hitzeinaktivierten Präparation des enterohämorrhagischen E. coli führt zur raschen Induktion von TMPRSS-2, TMPRSS-4 und MTSP-1 mit einer 8,9-fachen, 5,8-fachen und 3,8-fachen Induktion. Lediglich Hepsin reagiert bei $2 \mathrm{~h}$ kaum (0,9-fach). Alle membranständigen Proteasen haben ihr Minimum bei $8 \mathrm{~h}$ und steigen bis zum $24 \mathrm{~h}$ Wert wieder an. Hier zeigt Hepsin sein Maximum mit einer 6,4-fachen Erhöhung der Genexpression. (Abb. 3.31)

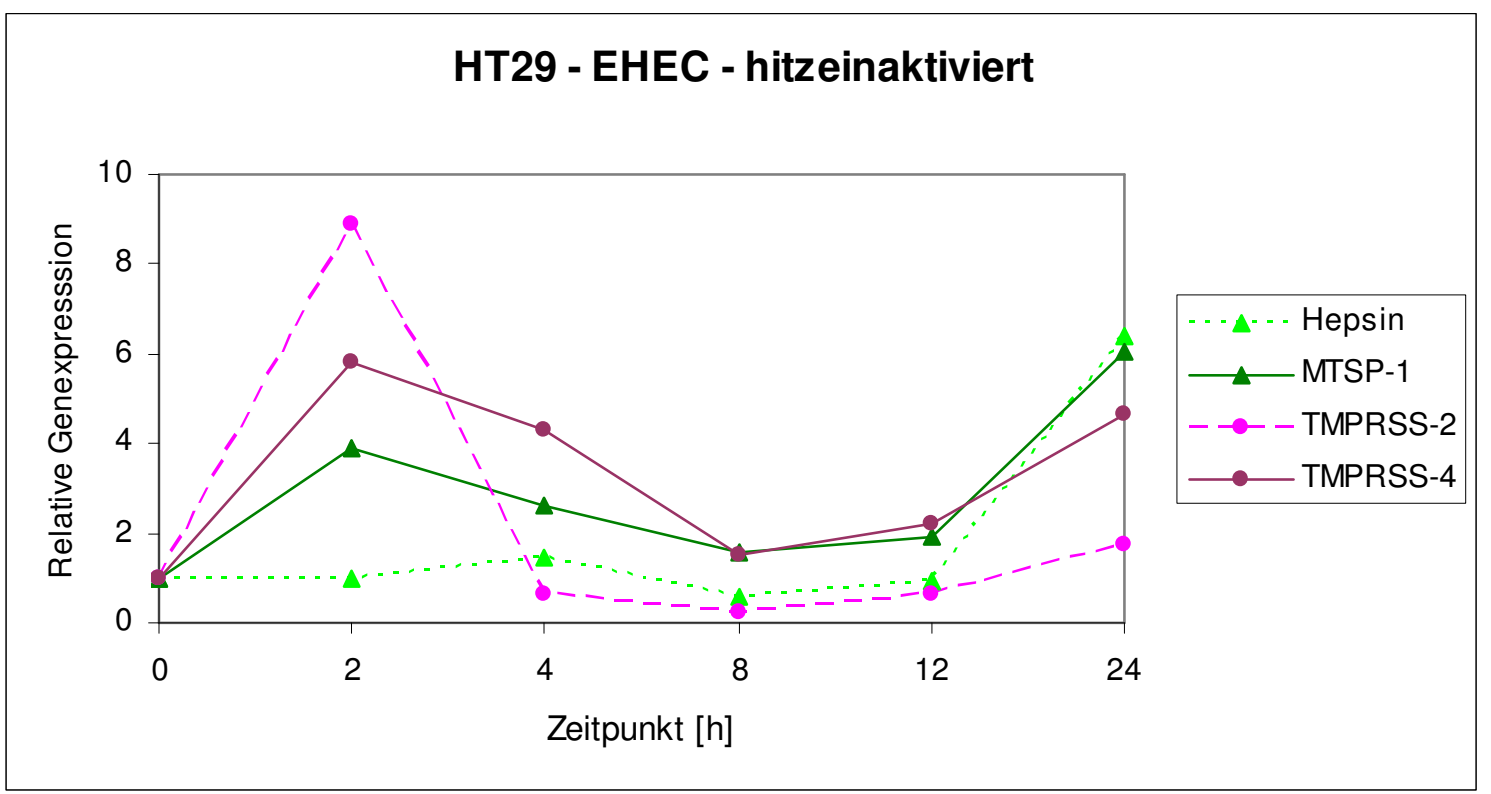

Abb. 3.31: Monolayers der Zelllinie HT29 wurden bei Subkonfluenz mit initial ca. $3^{*} 10^{8}$ Bakterien des hitzeinaktivierten EHEC-Stammes $\left(15 \mathrm{~min}\right.$ bei $\left.80^{\circ} \mathrm{C}\right)$ für eine Stunde exponiert, abgesaugt und durch normales Medium ersetzt. Nach 0, 2, 4, 8, 12 und $24 \mathrm{~h}$ erfolgte die Isolierung der RNA. Unter Verwendung eines Transkriptionskits wurde cDNA hergestellt und im abschließenden Arbeitsschritt die Genexpression mittels real time quantitative RT-PCR bestimmt. Die Werte wurden gegen 18sRNS normalisiert. 
EHEC-Überstand: Hepsin reagiert am deutlichsten auf die Stimulation und zeigt ein absolutes Maximum nach $2 \mathrm{~h}$ mit einer 20-fachen Erhöhung der Genexpression. Die Kurve fällt danach stark bis zu einem Minimum von 3,3-fach ab und steigt nochmals zum 24 h-Wert auf eine knapp 10-fache Erhöhung. TMPRSS-2 reagiert ähnlich, hat aber seinen ersten Peak mit einer 6,2-fachen Induktion bei $4 \mathrm{~h}$ und sein Maximum dann nach 24 h (6,6-fach). MTSP-1 und TMPSS-4 zeigen sich etwas verhaltener in ihrer Reaktion. Beide weisen einen ersten Peak nach $2 \mathrm{~h}$ mit einer 2,9-fachen und 2,4-fachen Induktion auf und steigen nach $24 \mathrm{~h}$ nochmals leicht an. (Abb. 3.32)

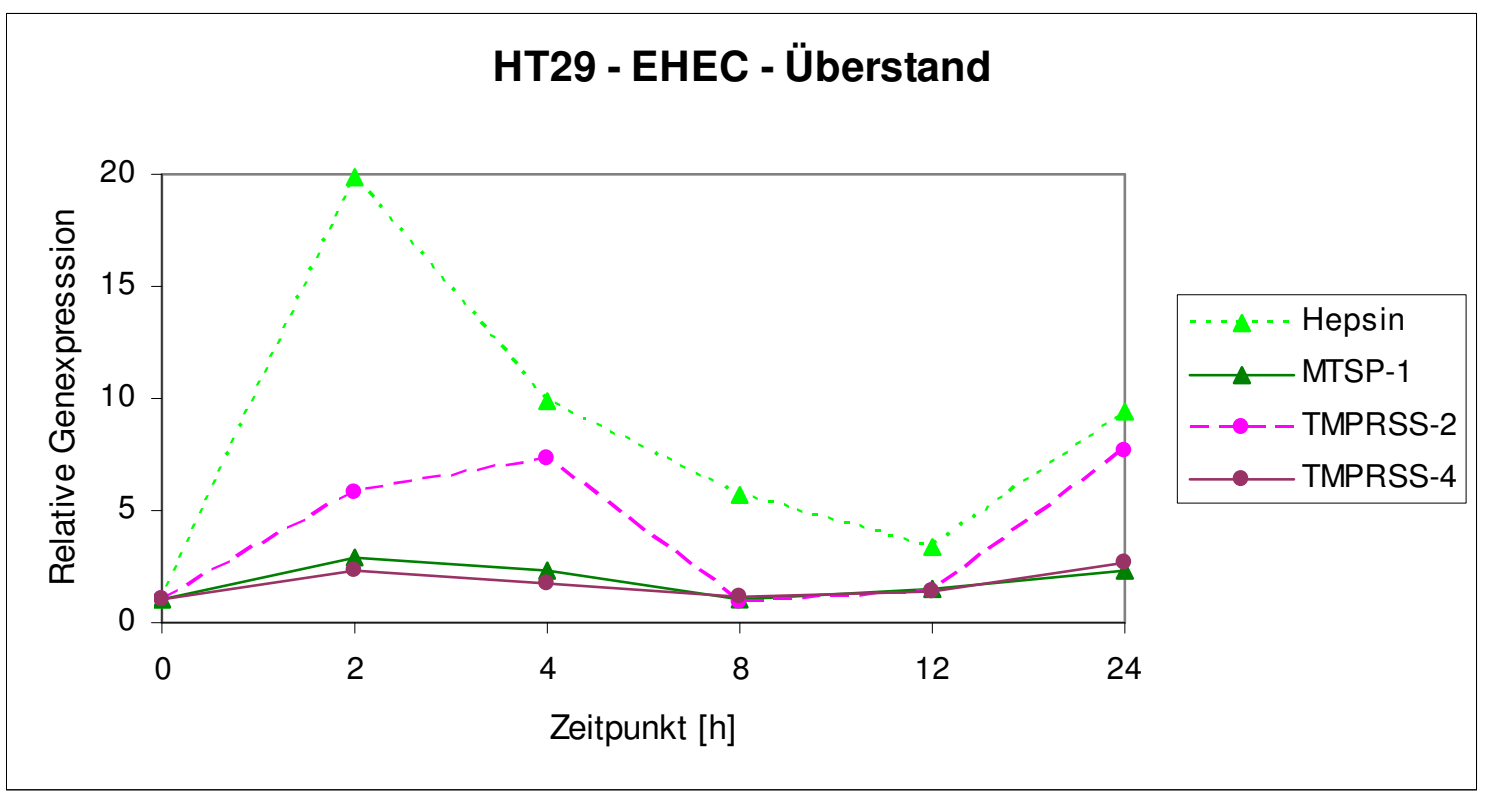

Abb. 3.32: Monolayers der Zelllinie HT29 wurden bei Subkonfluenz mit EHECÜberstand (Abtrennen der Bakterien mittels Mikrofilter) für eine Stunde beimpft, abgesaugt und durch normales Medium ersetzt. Nach 0, 2, 4, 8, 12 und 24 h erfolgte die Isolierung der RNA. Unter Verwendung eines Transkriptionskits wurde cDNA hergestellt und im abschließenden Arbeitsschritt die Genexpression mittels real time quantitative PCR bestimmt. Die Werte wurden gegen 18sRNS normalisiert. 


\subsubsection{Textorische Zusammenfassung EHEC mit HT29}

1. Als stärkstes Stimulans unter den verschiedenen Präparationen des enterohämorrhagischen E. coli zeigt sich die Fraktion des Überstands, also der sezernierten Faktoren des Bakteriums auf die Induktion von Hepsin mit einem ausgeprägten frühen Peak nach $2 \mathrm{~h}$. Eine beinahe analoge Reaktion für Hepsin induziert das aktive Bakterium mit einem 2 h- Maximum. Dagegen trägt die hitzeinaktivierte Präparation zu diesem frühen Peak nichts bei, erst nach $24 \mathrm{~h}$ steigt die Induktion für Hepsin auf ein Maximum an.

2. Der durch die intakten Bakterien induzierte erste frühe Peak für TMPSS-2 nach 2 bzw. $4 \mathrm{~h}$ setzt sich dagegen durch sezernierte Faktoren im Überstand und Faktoren aus der hitzeinaktivierten Präparation zusammen. Dabei zeigt die hitzeinaktivierte Fraktion die stärkste Induktion der Genexpression von TMPRSS-2.

3. MTSP-1 und TMPRSS-4 imponieren durch sehr ähnliche biphasische Kurvenverläufe. Das erste Maximum zeigen beide nach $2 \mathrm{~h}$ um danach abzufallen und nach $24 \mathrm{~h}$ ein zweites Maximum zu erreichen. Dabei zeigt TMPRSS-4 eine stärkere Induktion nach $2 \mathrm{~h}$ sowohl durch die intakten Bakterien als auch die Faktoren der hitzeinaktivierten Präparation. MTSP-1 wird am stärksten durch die hitzeinaktivierte Fraktion nach $24 \mathrm{~h}$ induziert. 


\subsubsection{HT29-Zellen mit E. coli Nissle (vital, hitzeinaktiviert und Überstand)}

E. coli Nissle: Der intakte E. coli Nissle führt bei allen membranständigen Proteasen zu einer biphasischen Reaktion der Genexpression in HT29-Zellen. Hepsin und MTSP-1 zeigen einen ersten Peak nach $2 \mathrm{~h}$ mit einer 4,8-fachen und 3,2-fachen Induktion. MTSP-1 reagiert im weiteren Verlauf am stärksten mit einer 19-fachen Erhöhung als zweites Maximum nach 12 h, Hepsin ebenfalls stärker mit einer 6-fachen Erhöhung im zweiten Peak nach $12 \mathrm{~h}$. TMPRSS-2 und -4 zeigen ihren ersten Peak nach $4 \mathrm{~h}$ mit einer 2,9-fachen und 3,7-fachen Erhöhung. Der zweite Peak fällt für TMPRSS-4 mit einer 11,5-fachen Induktion nach $12 \mathrm{~h}$ deutlich stärker im Vergleich zu TMPRSS-2 mit einer 2,4-fachen Induktion nach $24 \mathrm{~h}$ aus. (Abb. 3.33)

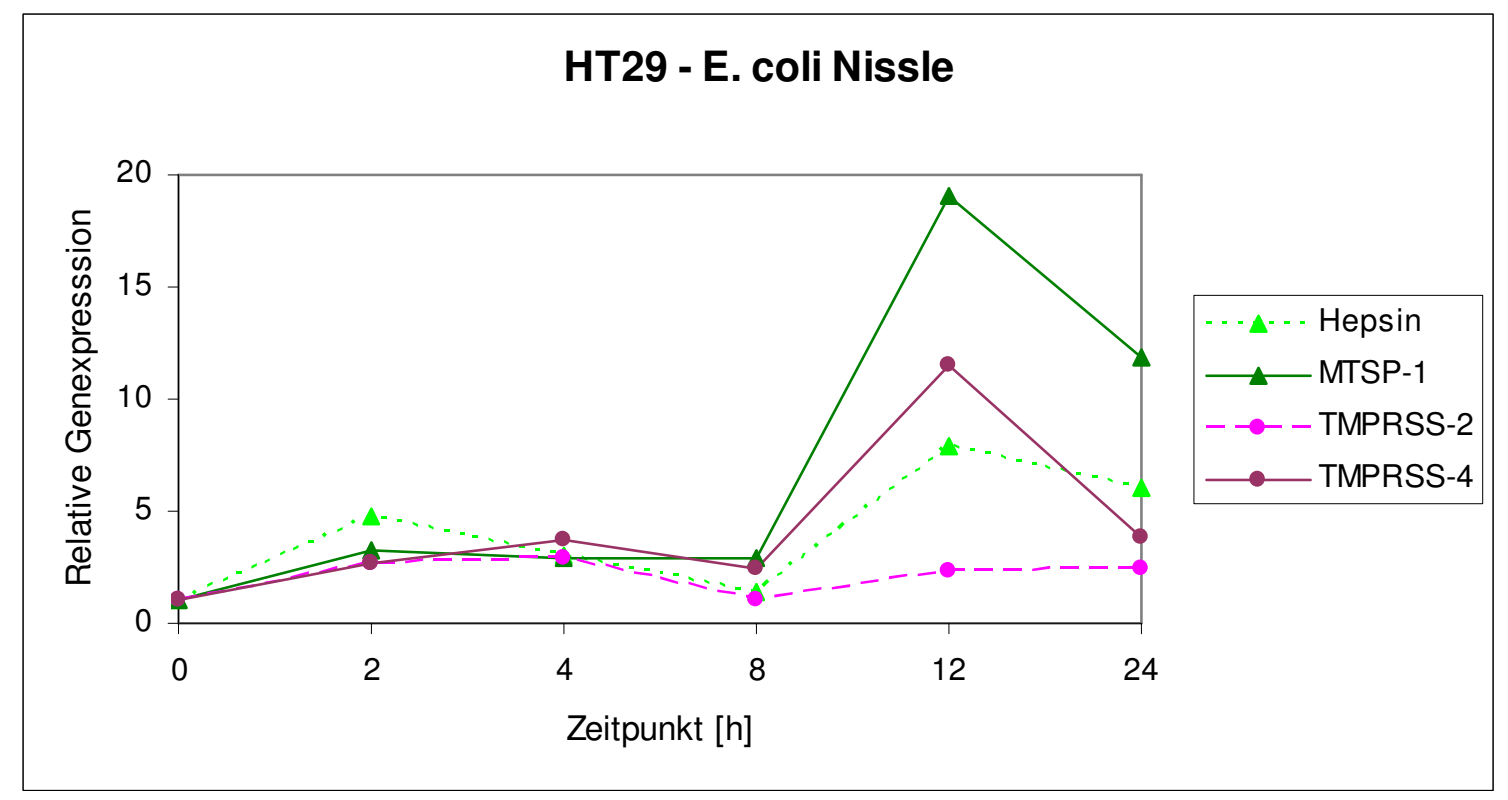

Abb. 3.33: Monolayers der Zelllinie HT29 wurden bei Subkonfluenz mit ca. $3 * 10^{8}$ Bakterien des Stammes E. coli Nissle für eine Stunde infiziert, abgesaugt und durch normales Medium ersetzt. Nach 0, 2, 4, 8, 12 und 24 h erfolgte die Isolierung der RNA. Unter Verwendung eines Transkriptionskits wurde cDNA hergestellt und im abschließenden Arbeitsschritt die Genexpression mittels real time quantitative PCR bestimmt. Die Werte wurden gegen 18sRNS normalisiert. 
E. coli Nissle-hitzeinaktiviert: Hepsin reagiert auf die Stimulation durch Faktoren des hitzeinaktivierten Nissle mit der deutlichsten Induktion seiner Genexpression. Die Maxima liegen nach $4 \mathrm{~h}$ bei einer 6,6-fachen und nach $24 \mathrm{~h}$ bei einer 14,7-fachen Erhöhung. Auch MTSP-1 zeigt seine Peaks nach 4 h und 24 h mit einer knapp 2-fachen und 1,5-fachen Induktion. TMPRSS-2 und TMPRSS-4 zeigen eine frühere Induktion mit einem Peak nach $2 \mathrm{~h}$ und einer 5,2-fachen sowie 2,8-fachen Erhöhung. TMPRSS-2 fällt danach deutlicher als TMPRSS-4 ab um nach $24 \mathrm{~h}$ wieder auf eine 2,4-fache bzw. 1,6-fache Erhöhung anzusteigen. MTSP-1 steigt auf eine knapp 2-fache Erhöhung nach $4 \mathrm{~h}$ an. Alle TTSP zeigen nach $12 \mathrm{~h}$ ihr Minimum um danach wieder anzusteigen. (Abb. 3.34)

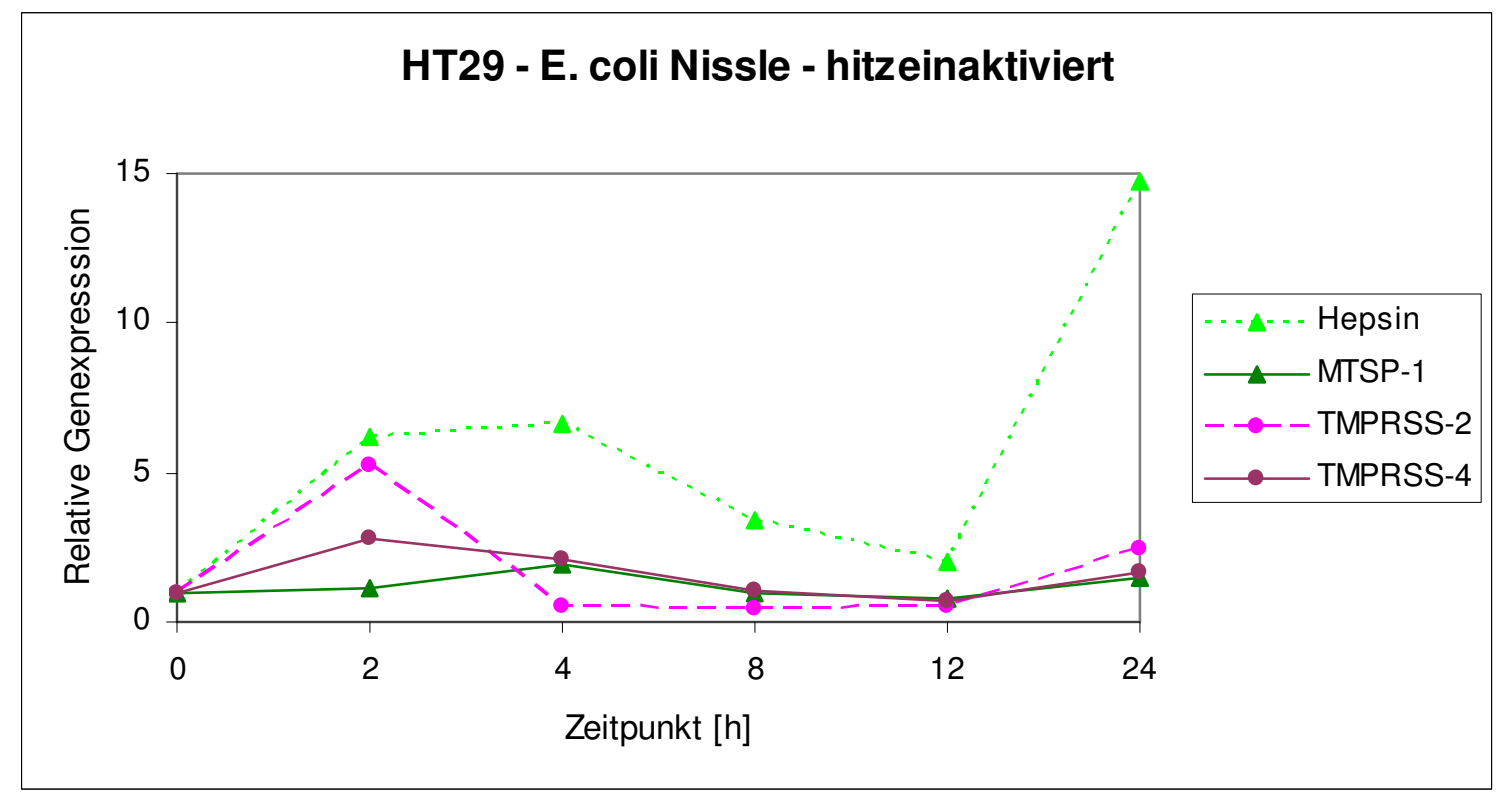

Abb. 3.34: Monolayers der Zelllinie HT29 wurden bei Subkonfluenz mit initial ca. $3 * 10^{8}$ Bakterien des hitzeinaktivierten Stammes E. coli Nissle $\left(15 \mathrm{~min}\right.$ bei $\left.80^{\circ} \mathrm{C}\right)$ für eine Stunde exponiert, abgesaugt und durch normales Medium ersetzt. Nach 0, 2, 4, 8, 12 und $24 \mathrm{~h}$ erfolgte die Isolierung der RNA. Unter Verwendung eines Transkriptionskits wurde cDNA hergestellt und im abschließenden Arbeitsschritt die Genexpression mittels real time quantitative PCR bestimmt. Die Werte wurden gegen 18sRNS normalisiert. 
E. coli Nissle-Überstand: Die Exposition von HT29-Zellen gegenüber E. coli NissleÜberstand führt zu einer biphasischen Reaktion aller TTSP. TMPRSS-4, TMPRSS-2 und Hepsin zeigen einen ersten Peak nach $2 \mathrm{~h}$ mit einer 8,5-fachen, 2,6-fachen und 2,7fachen Induktion. Nach Absinken des Expressionslevels steigen diese drei Proteasen nach $24 \mathrm{~h}$ auf ein zweites Maximum mit einer 6,6-fachen Induktion für TMPRSS-4, einer 4,8-fachen Induktion für Hepsin und einer 2,9-fachen Induktion für TMPRSS-2. Dagegen erfährt MTSP-1 die stärkste Induktion mit einer 13,6-fachen Erhöhung nach 4 $\mathrm{h}$ als ersten Peak um im weiteren Verlauf deutlich abzufallen und zum 24 h-Wert wieder auf ein zweites Maximum mit einer 9,9-fachen Induktion anzusteigen. (Abb. 3.35)

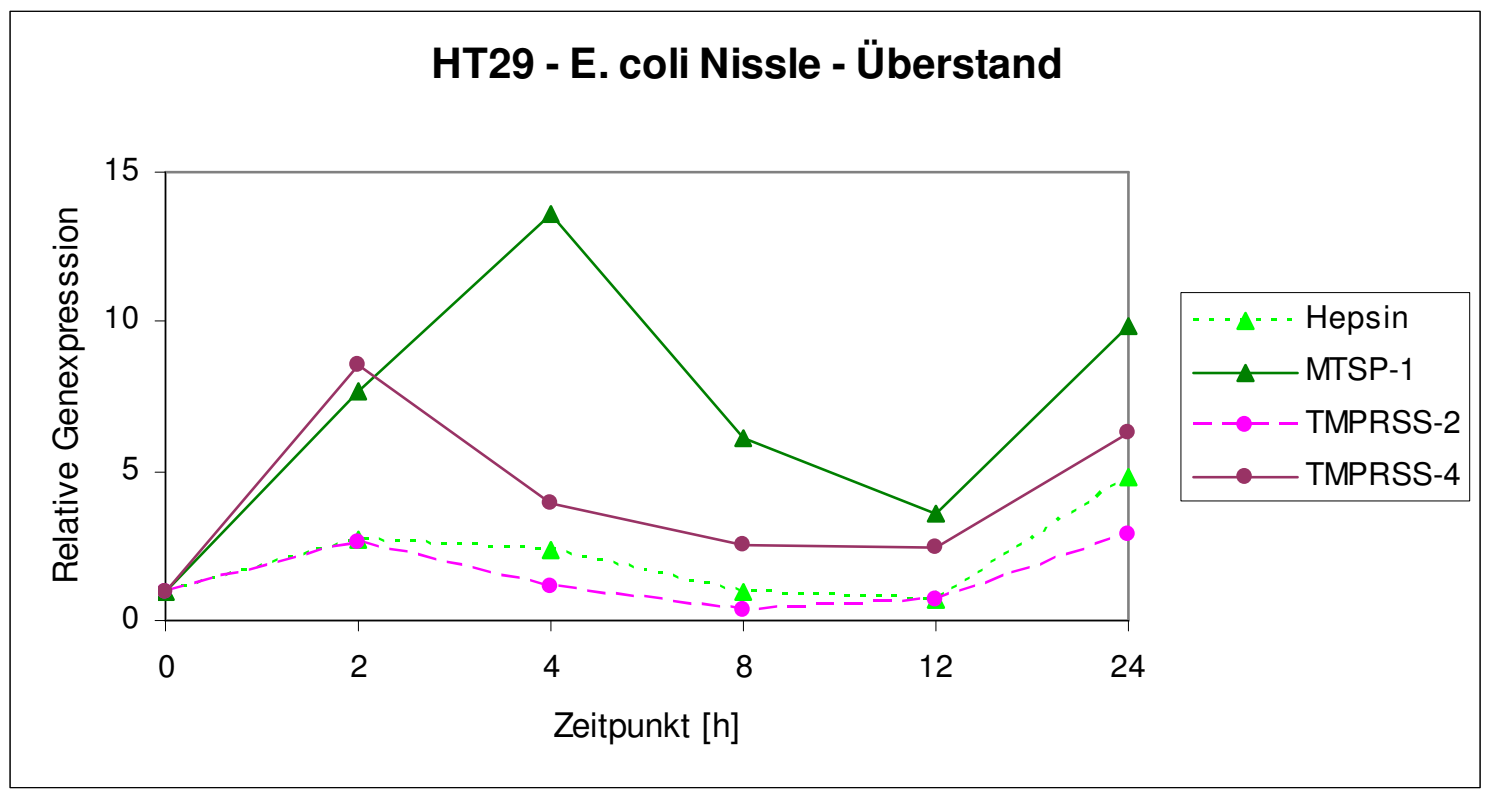

Abb. 3.35: Monolayers der Zelllinie HT29 wurden bei Subkonfluenz mit E. coli NissleÜberstand (Abtrennen der Bakterien mittels Mikrofilter) für eine Stunde beimpft, abgesaugt und durch normales Medium ersetzt. Nach 0, 2, 4, 8, 12 und 24 h erfolgte die Isolierung der RNA. Unter Verwendung eines Transkriptionskits wurde cDNA hergestellt und im abschließenden Arbeitsschritt die Genexpression mittels real time quantitative PCR bestimmt. Die Werte wurden gegen 18sRNS normalisiert. 


\subsubsection{Textorische Zusammenfassung E. coli Nissle mit HT29}

1. Bei E. coli Nissle imponiert die starke Induktion nach $12 \mathrm{~h}$ von MTSP-1 durch das vitale Bakterium. Dieser ausgeprägte Stimulus für MTSP-1 findet sich zeitlich verzögert bei 4 und $24 \mathrm{~h}$ auch in der Fraktion der sezernierten Faktoren im Überstand. Dagegen führt die hitzeinaktivierte Präparation zu keiner wesentlichen Induktion der Genexpression von MTSP-1.

2. Die hitzeinaktivierte Präparation des E. coli Nissle erweist sich auch als ein starker Stimulus für die Induktion von Hepsin. Der biphasische Kurvenverlauf zeigt sich, wenngleich weniger ausgeprägt, auch bei dem intakten Bakterium und der Fraktion des Überstands.

3. Der intakte E. coli Nissle führt bei TMPRSS-4 und TMPRSS-2 zu einer nur geringen Induktion mit Peaks nach $4 \mathrm{~h}$. Überstand und hitzeinaktivierte Präparation dagegen führen zu einer stärkeren Induktion bereits nach $2 \mathrm{~h}$ sowie einem zweiten Peak nach $24 \mathrm{~h}$. 


\subsubsection{Caco2-Zellen mit E. coli (vital, hitzeinaktiviert und Überstand)}

E. coli: Die vier membranständigen Proteasen reagieren in Caco2 auf die Stimulation durch E. coli relativ ähnlich. TMPRSS-2, TMPRSS-4 und MTSP-1 weisen einen ersten Peak nach $2 \mathrm{~h}$ mit einer 4,8-fachen, 3,7-fachen und 1,8-fachen Induktion auf. Hepsin zeigt seinen ersten Peak nach $4 \mathrm{~h}$ mit einer 2-fachen Erhöhung um danach nur leicht abzusinken und zum 24 h-Wert auf eine 3,5-fache Induktion anzusteigen. TMPRSS-2 und MTSP-1 zeigen einen zweiten Peak nach $24 \mathrm{~h}$ mit einer 4,2-fachen und 2,5-fachen Induktion. Dagegen fällt TMPRSS-4 nach dem ersten Maximum kontinuierlich bis zum 24 h- Wert ab. (Abb. 3.36)

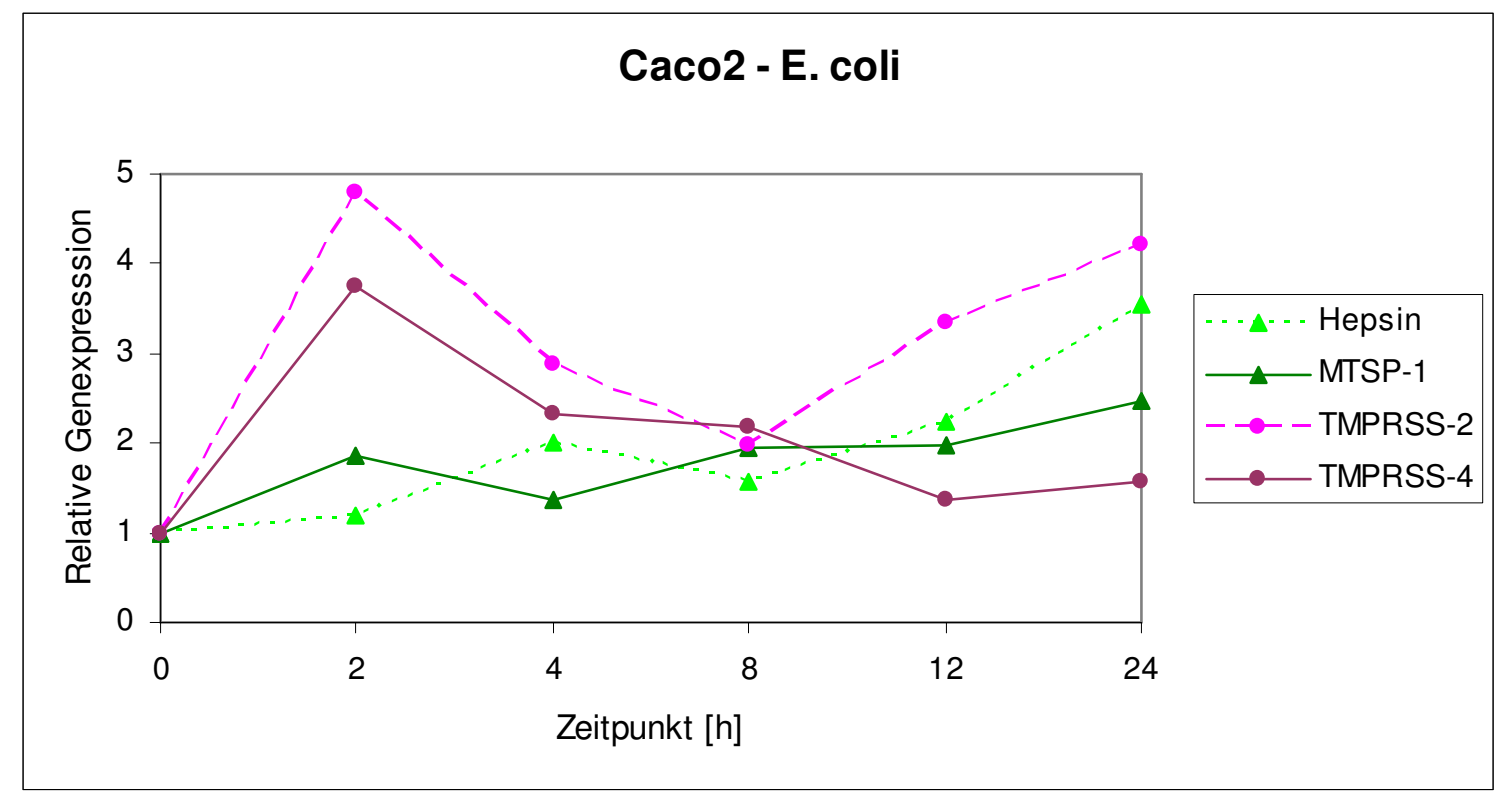

Abb. 3.36: Monolayers der Zelllinie Caco 2 wurden bei Subkonfluenz mit ca. $3 * 10^{8}$ Bakterien des Stammes E. coli für eine Stunde infiziert, abgesaugt und durch normales Medium ersetzt. Nach 0, 2, 4, 8, 12 und 24 h erfolgte die Isolierung der RNA. Unter Verwendung eines Transkriptionskits wurde cDNA hergestellt und im abschließenden Arbeitsschritt die Genexpression mittels real time quantitative PCR bestimmt. Die Werte wurden gegen 18sRNS normalisiert. 
E. coli-hitzeinaktiviert: Die Exposition der Caco2-Zellen gegenüber der hitzeinaktivierten Präparation des E. coli ATCC-Stammes führt zu einem biphasischen Kurvenverlauf aller TTSP. TMPRSS-2 und TMPRSS-4 reagieren mit einer raschen 11fachen und 5-fachen Induktion nach 2 h. Hepsin und MTSP-1 reagieren mit einem Peak nach $4 \mathrm{~h}$ und 5,7-facher und 4,5-facher Erhöhung der Genexpression. Alle TTSP haben ihr Minimum nach 8 h. Ein zweiter Peak schließt sich nach 24 h mit einer 11,5-fachen, 7,5-fachen und 4,1-fachen Induktion für TMPRSS-2, Hepsin und MTSP-1 an. Lediglich TMPRSS-4 zeigt sein zweites Maximum bereits nach $12 \mathrm{~h}$ mit einer 3,9-fachen Induktion. (Abb. 3.37)

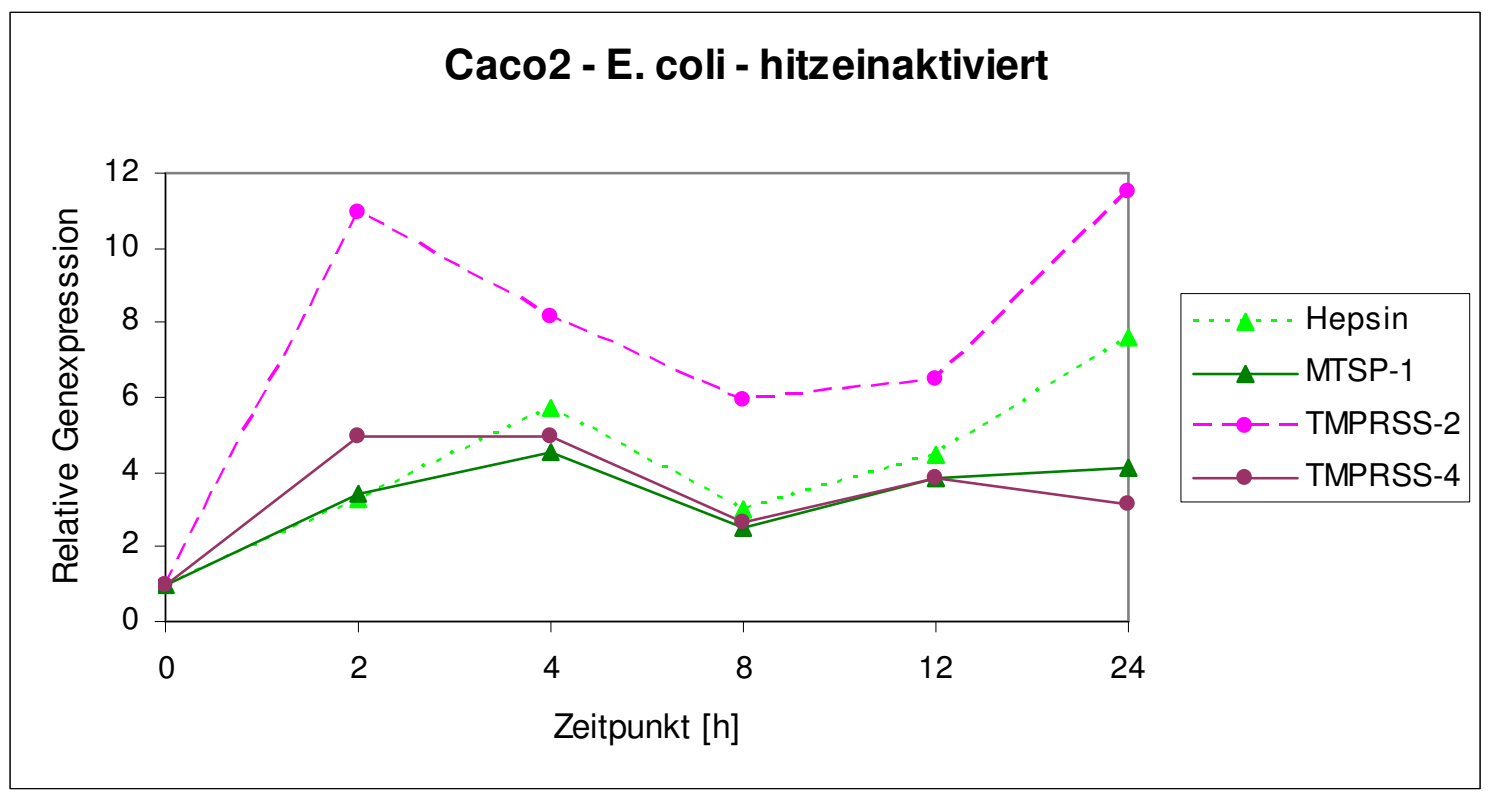

Abb. 3.37: Monolayers der Zelllinie Caco2 wurden bei Subkonfluenz mit initial ca. $3^{*} 10^{8}$ Bakterien des hitzeinaktivierten E. coli-Stammes $\left(15 \mathrm{~min}\right.$ bei $\left.80^{\circ} \mathrm{C}\right)$ für eine Stunde exponiert, abgesaugt und durch normales Medium ersetzt. Nach 0, 2, 4, 8, 12 und $24 \mathrm{~h}$ erfolgte die Isolierung der RNA. Unter Verwendung eines Transkriptionskits wurde cDNA hergestellt und im abschließenden Arbeitsschritt die Genexpression mittels real time quantitative PCR bestimmt. Die Werte wurden gegen 18sRNS normalisiert. 
E. coli-Überstand: Die Stimulation mit E. coli-Überstand führt zu einer dreigipfligen Induktion der Genexpression für TMPRSS-4, MTSP-1 und Hepsin mit einer 1,5-fachen, 1,4-fachen und 1,2-fachen Induktion nach $2 \mathrm{~h}$. Der zweite Peak zeigt sich nach $8 \mathrm{~h}$ mit einer 1,6-fachen Induktion für Hepsin, einer 1,5-fachen Induktion für MTSP-1 sowie einer 1,3-fachen Induktion für TMPRSS-4. Ein drittes Maximum weisen MTSP-1, Hepsin und TMPRSS-4 nach $24 \mathrm{~h}$ mit 1,9-facher und 1,7-facher Induktion sowie einer 0,7-fachen Suppression auf. TMPRSS-2 zeigt sich über den gesamten Zeitverlauf supprimiert. (Abb. 3.38)

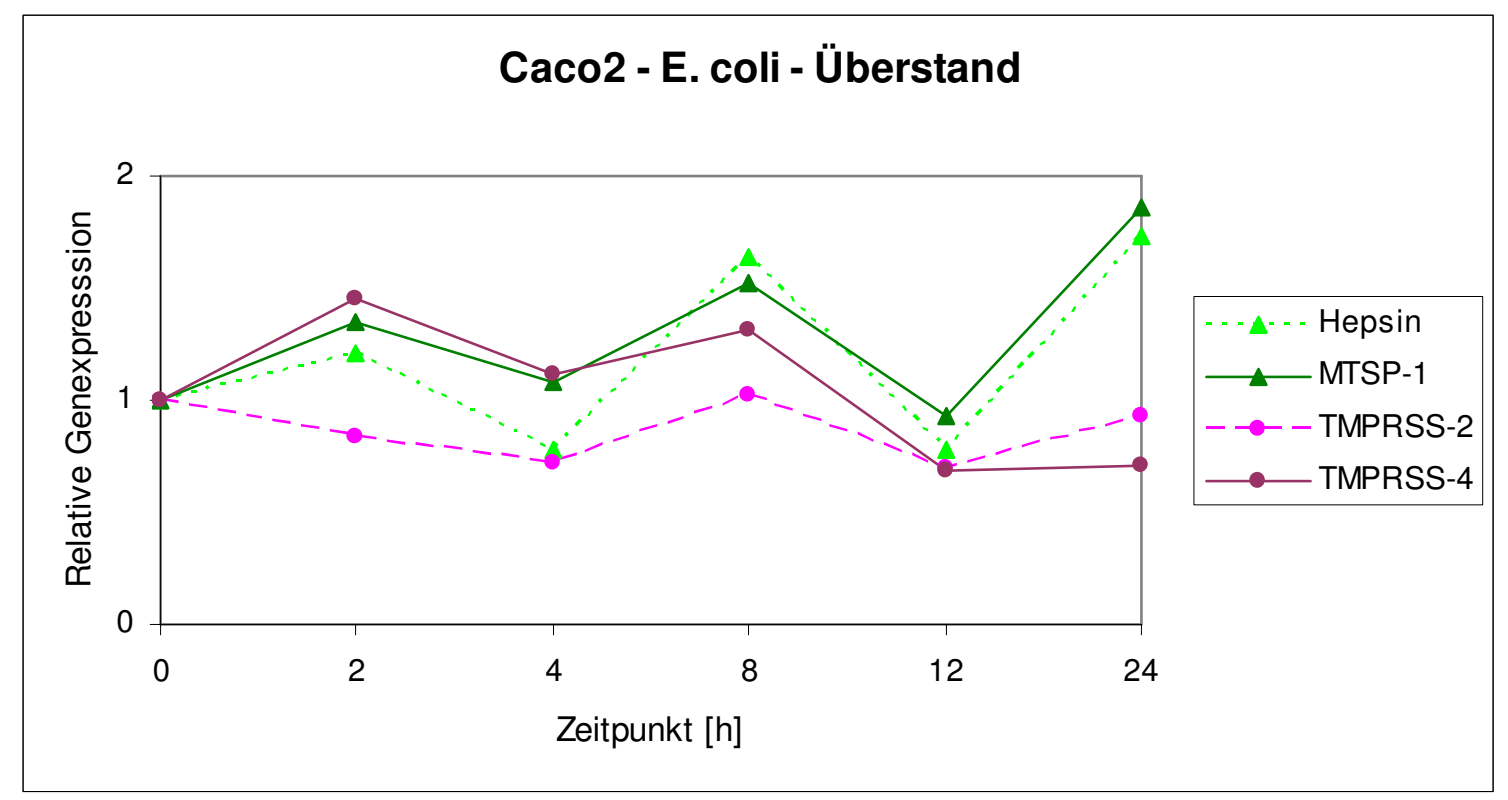

Abb. 3.38: Monolayers der Zelllinie Caco2 wurden bei Subkonfluenz mit E. coliÜberstand (Abtrennen der Bakterien mittels Mikrofilter) für eine Stunde beimpft, abgesaugt und durch normales Medium ersetzt. Nach 0, 2, 4, 8, 12 und 24 h erfolgte die Isolierung der RNA. Unter Verwendung eines Transkriptionskits wurde cDNA hergestellt und im abschließenden Arbeitsschritt die Genexpression mittels real time quantitative RT-PCR bestimmt. Die Werte wurden gegen 18sRNS normalisiert. 


\subsubsection{Textorische Zusammenfassung E. coli mit Caco2}

1. Wie schon bei HT29-Zellen ist auch bei Caco2 am augenfälligsten die starke Induktion von TMPRSS-2 durch die hitzeinaktivierte Präparation. Dieses starke Stimulans macht auch hier die gesamte durch das intakte Bakterium beobachtete biphasische Induktion aus. Dagegen tragen die sezernierten Faktoren aus der Fraktion des Überstands zu diesen Peaks nach 2 und 24 h nichts bei.

2. Interessant imponiert der durch den Überstand in allen TTSP induzierte „Zwischen-Peak“ bei 8 h. Dagegen verursachen das intakte Bakterium und die hitzeinaktivierte Präparation bei $8 \mathrm{~h}$ deutliche Minima in der Genexpression.

3. Der durch das intakte Bakterium nach $2 \mathrm{~h}$ ausgelöste Peak bei TMPRSS-4 setzt sich durch sezernierte Faktoren im Überstand und aus Faktoren aus der hitzeinaktivierten Fraktion zusammen.

4. Die triphasische Induktion von Hepsin und MTSP-1 durch die sezernierten Faktoren im Überstand lässt sich lediglich bei dem letzten Peak im Bereich des 24 h-Wertes durch das intakte Bakterium und die hitzeinaktivierte Präparation unterstützen. 


\subsubsection{Caco2-Zellen mit EHEC (vital, hitzeinaktiviert und Überstand)}

EHEC: Der intakte enterohämorrhagische E. coli führt zu einer biphasischen Reaktion von TMPRSS-2 und TMPRSS-4. Dabei zeigt TMPRSS-2 die insgesamt stärkste Induktion nach $4 \mathrm{~h}$ mit einer 3,4-fachen Erhöhung und einem zweiten Peak nach $12 \mathrm{~h}$ mit einer 4-fachen Erhöhung. TMPRSS-4 zeigt sich geringer reguliert mit Peaks nach 2 und $12 \mathrm{~h}$ und einer 1,8-fachen sowie 2,3-fachen Induktion. MTSP-1 weist zunächst keine Genregulation auf, um dann nach $12 \mathrm{~h}$ zu einem geringen Peak mit einer 1,9fachen Induktion anzusteigen. Hepsin zeigt keinen phasischen Verlauf. Es steigt dagegen kontinuierlich bis zu seinem Maximum mit einer 3,6-fachen Induktion nach 24 h an. (Abb. 3.39)

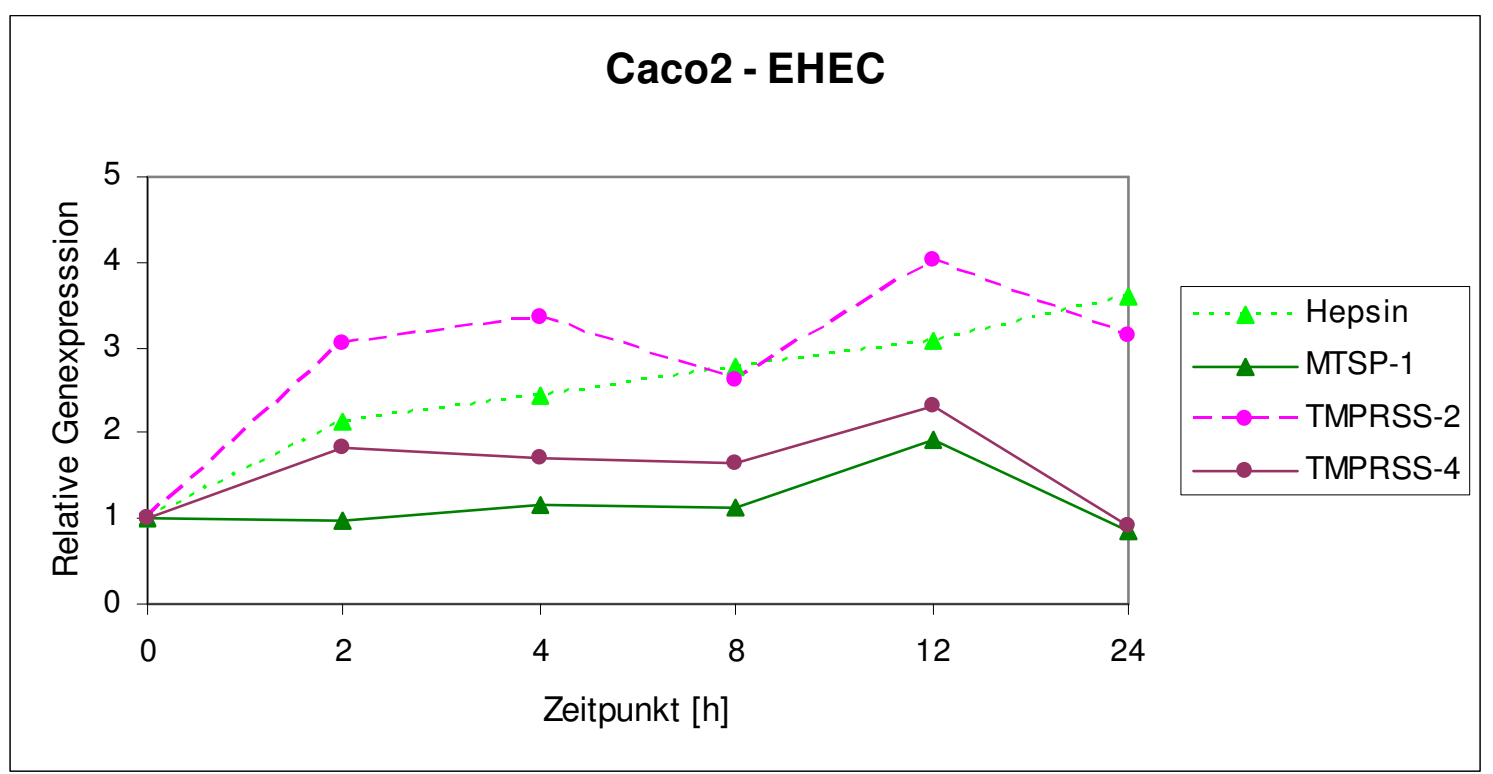

Abb. 3.39: Monolayers der Zelllinie Caco 2 wurden bei Subkonfluenz mit EHEC (ca. $3 * 10^{8}$ Bakterien) für eine Stunde infiziert, abgesaugt und durch normales Medium ersetzt. Nach 0, 2, 4, 8, 12 und $24 \mathrm{~h}$ erfolgte die Isolierung der RNA. Unter Verwendung eines Transkriptionskits wurde cDNA hergestellt und im abschließenden Arbeitsschritt die Genexpression mittels real time quantitative PCR bestimmt. Die Werte wurden gegen 18sRNS normalisiert. 
EHEC-hitzeinaktiviert: Die Exposition der Caco2-Zellen gegenüber der hitzeinaktivierten Präparation des enterohämorrhagischen E. coli führt zu einer raschen Induktion nach $2 \mathrm{~h}$ von TMPRSS-2, MTSP-1 und Hepsin mit einer 5,3-fachen, 4,3fachen und 3,5-fachen Induktion. TMPRSS-4 zeigt einen Peak nach $4 \mathrm{~h}$ mit einer 2,5fachen Erhöhung um danach abzusinken. Die biphasische Induktion von TMPRSS-2 und Hepsin mit einem frühen Peak nach 2 h führt zu einer 3,9-fachen und 4,2-fachen Erhöhung der Genexpression nach 24 h. Dagegen fällt MTSP-1 nach dem ersten Peak nach $2 \mathrm{~h}$ deutlich ab, ohne einen weiteren Peak aufzuweisen. (Abb. 3.40)

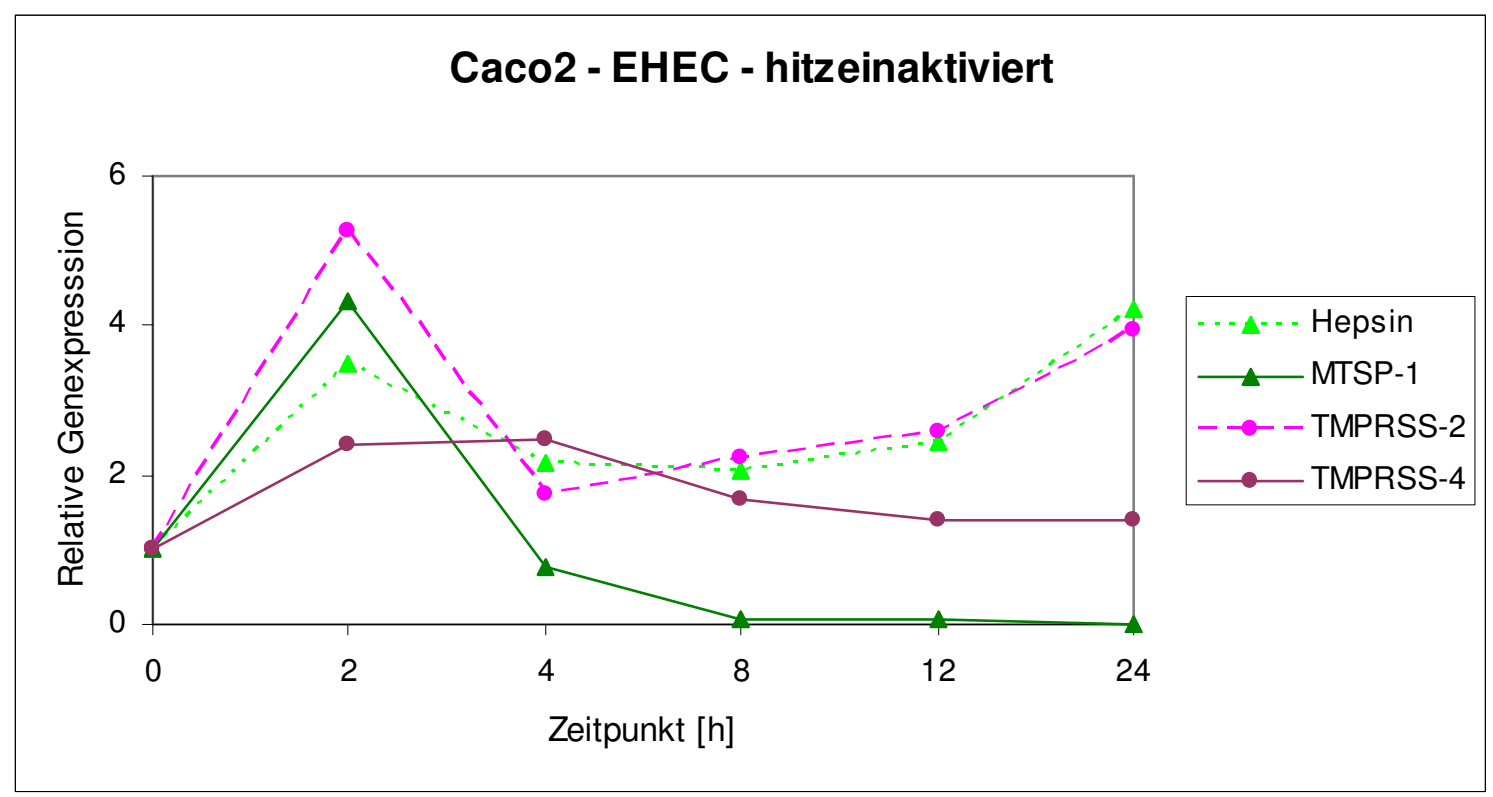

Abb. 3.40: Monolayers der Zelllinie Caco 2 wurden bei Subkonfluenz mit initial ca. $3^{*} 10^{8}$ Bakterien des hitzeinaktivierten EHEC-Stammes $\left(15 \mathrm{~min}\right.$ bei $\left.80^{\circ} \mathrm{C}\right)$ für eine Stunde exponiert, abgesaugt und durch normales Medium ersetzt. Nach 0, 2, 4, 8, 12 und $24 \mathrm{~h}$ erfolgte die Isolierung der RNA. Unter Verwendung eines Transkriptionskits wurde cDNA hergestellt und im abschließenden Arbeitsschritt die Genexpression mittels real time quantitative PCR bestimmt. Die Werte wurden gegen 18sRNS normalisiert. 
EHEC-Überstand: Die Stimulation durch sezernierte Faktoren des bakteriellen Überstandes führt bei TMPRSS-4 und MTSP-1 zu einer ersten frühen 2,3-fachen und 2,1-fachen Induktion nach 2 h. Der Verlauf der Erhöhung der Genexpression erweist sich als biphasisch mit einem zweiten Peak nach 12 h für MTSP-1 mit einer 2,6-fachen Induktion und nach $24 \mathrm{~h}$ für TMPRSS-4 mit einer 1,5-fachen Induktion. TMPRSS-2 zeigt initial keine Regulation der Genexpression, um dann auf ein Maximum nach $24 \mathrm{~h}$ mit einer 2,5-fachen Induktion anzusteigen. Hepsin erfährt einen kontinuierlichen Anstieg seiner Induktion bis hin zu einem Maximum nach $24 \mathrm{~h}$ mit einer 4,2-fachen Erhöhung. (Abb. 3.41)

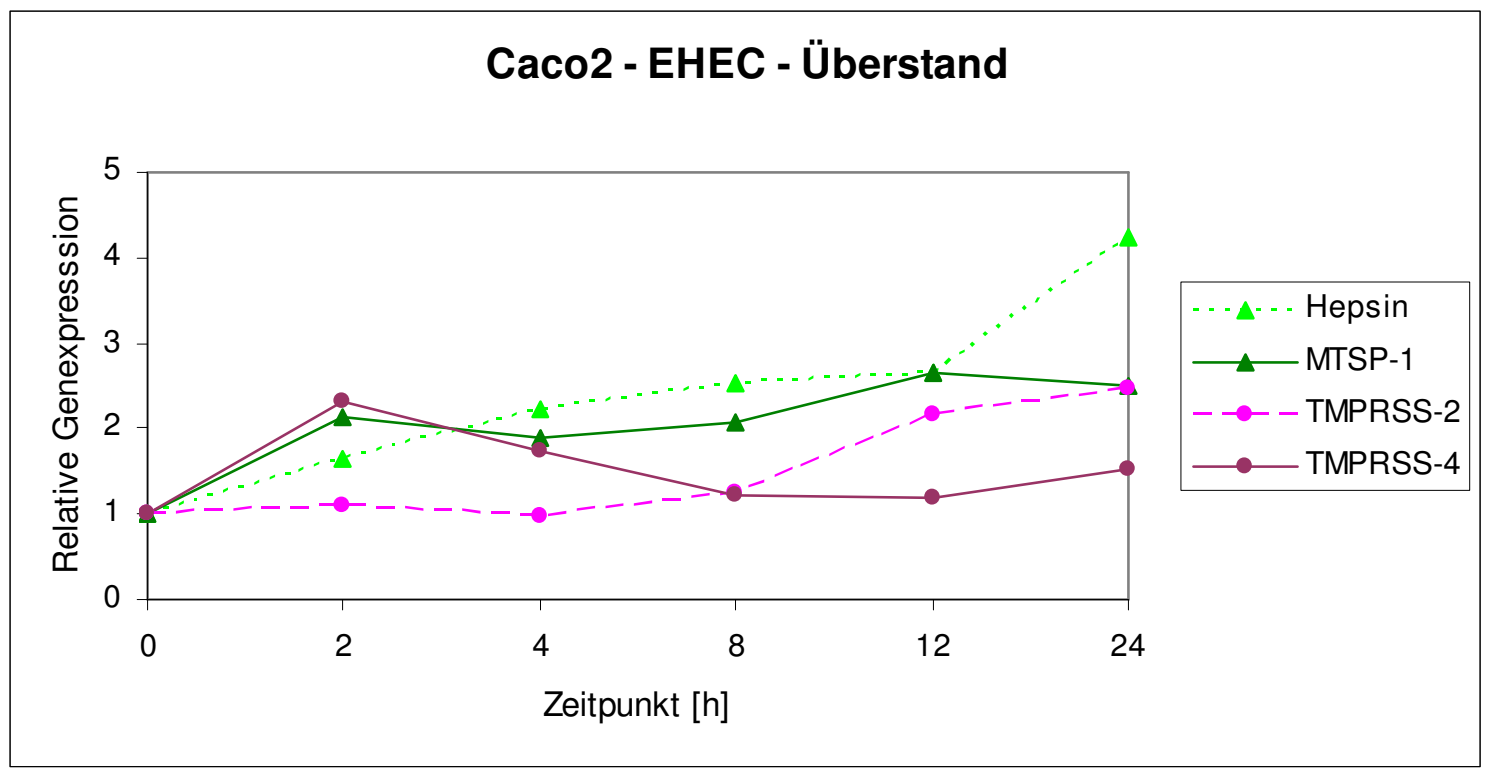

Abb. 3.41: Monolayers der Zelllinie Caco 2 wurden bei Subkonfluenz mit EHECÜberstand (Abtrennen der Bakterien mittels Mikrofilter) für eine Stunde beimpft, abgesaugt und durch normales Medium ersetzt. Nach 0, 2, 4, 8, 12 und 24-h erfolgte die Isolierung der RNA. Unter Verwendung eines Transkriptionskits wurde cDNA hergestellt und im abschließenden Arbeitsschritt die Genexpression mittels real time quantitative PCR bestimmt. Die Werte wurden gegen 18sRNS normalisiert. 


\subsubsection{Textorische Zusammenfassung EHEC mit Caco2}

1. Auch bei Caco2-Zellen zeigt sich am deutlichsten die frühe und robuste Induktion von TMPRSS-2 durch die hitzeinaktivierte Präparation. Dieser Stimulus der TMPRSS-2-Expression wird durch das intakte Bakterium, leicht zeitverzögert, unterstützt. Die sezernierten Faktoren des Bakterien-Überstandes tragen zu diesem frühen Peak nach $2 \mathrm{~h}$ nichts bei.

2. Der durch den intakten enterohämorrhagischen E. coli induzierten kontinuierlichen Anstieg der Genexpression von Hepsin wird durch die sezernierten Faktoren im Überstand gut nachgezeichnet. Dagegen führt die hitzeinaktivierte Präparation schon zu einer frühen Induktion mit einem Peak nach $2 \mathrm{~h}$.

3. Die Induktion von MTSP-1 imponiert durch einen ebenfalls raschen Anstieg mit einem Peak nach $2 \mathrm{~h}$ durch die hitzeinaktivierte Präparation. Auffallend ist die darauf folgende ausgeprägte Suppression bis einschließlich des $24 \mathrm{~h}$-Wertes. Dieses Induktionsmuster kann weder durch das intakte Bakterium noch durch die Faktoren des Überstands nachgezeichnet werden.

4. Der durch die intakten Bakterien nach $2 \mathrm{~h}$ ausgelöste Peak bei TMPRSS-4 setzt sich dagegen aus sezernierten Faktoren im Überstand und Faktoren aus der hitzeinaktivierten Fraktion zusammen. 


\subsubsection{Caco2-Zellen mit E. coli Nissle (vital, hitzeinaktiviert und Überstand)}

E. coli Nissle: Die Stimulation mit intaktem E. coli Nissle führt bei den vier membranständigen Proteasen zur Induktion von biphasischen Kurvenverläufen. So zeigen alle TTSP einen ersten Peak nach 2 h. TMPRSS-2 reagiert deutlichsten mit einer 11,5-fachen Induktion, gefolgt von Hepsin mit einer 4,4-fachen Induktion sowie MTSP1 und TMPRSS-4 mit 3,3- und 3,1-facher Induktion. Nach einem steilen Absinken von TMPRSS-2 wird eine 12,1-fache Induktion nach 24 h erreicht. Hepsin, MTSP-1 und TMPRSS-4 weisen ebenfalls ein zweites Maximum mit einer 6,9-fachen, 4,5-fachen und 3,3-fachen Erhöhung der Genexpression auf. (Abb. 3.42)

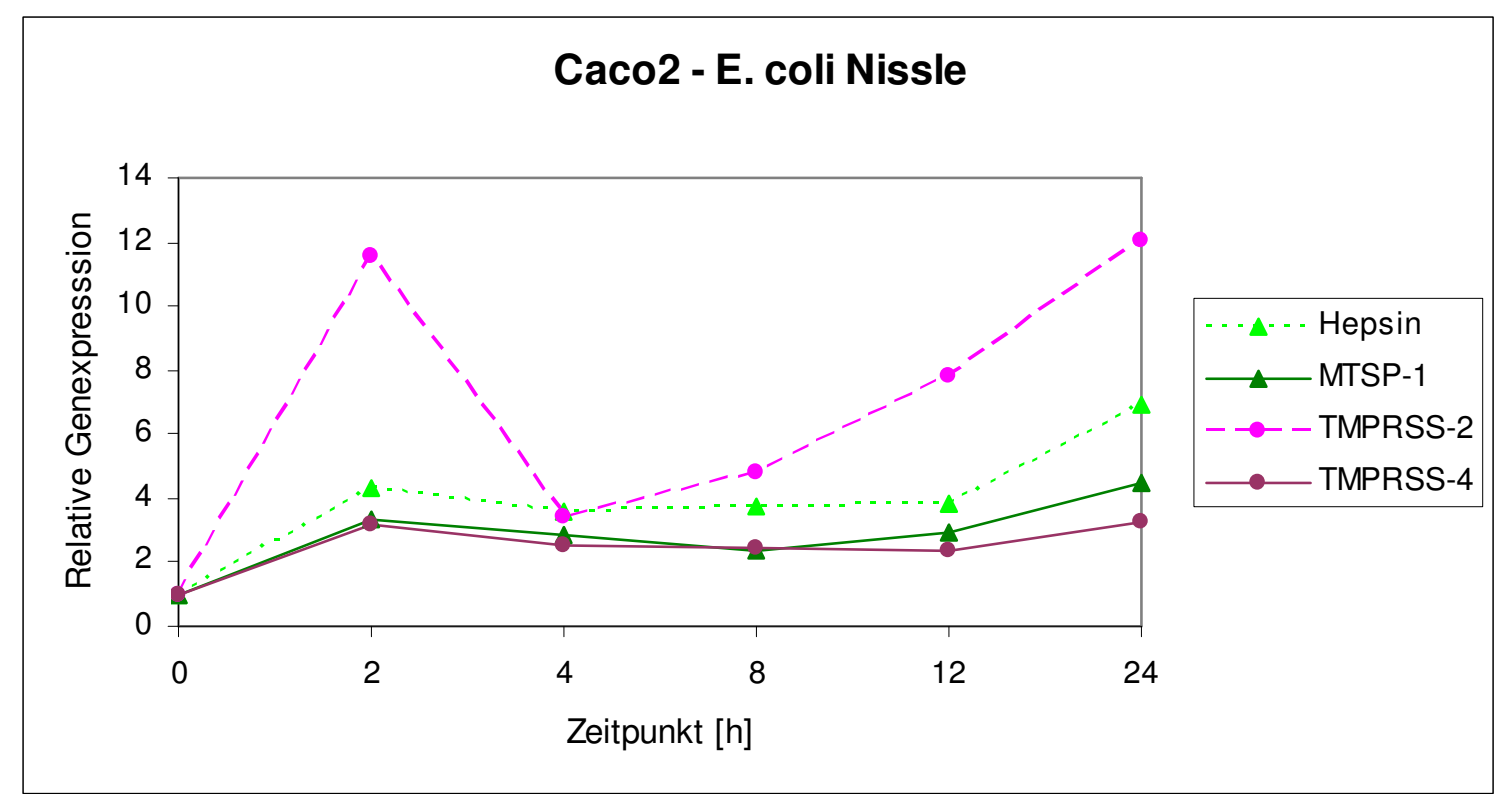

Abb. 3.42: Monolayers der Zelllinie Caco 2 wurden bei Subkonfluenz mit ca. $3^{*} 10^{8}$ Bakterien des Stammes E. coli Nissle für eine Stunde infiziert, abgesaugt und durch normales Medium ersetzt. Nach 0, 2, 4, 8, 12 und 24 h erfolgte die Isolierung der RNA. Unter Verwendung eines Transkriptionskits wurde cDNA hergestellt und im abschließenden Arbeitsschritt die Genexpression mittels real time quantitative PCR bestimmt. Die Werte wurden gegen 18sRNS normalisiert. 
E. coli Nissle-hitzeinaktiviert: Die Exposition von Caco2-Zellen gegenüber der hitzeinaktivierten Präparation von E. coli Nissle führt bei den TTSP nach $2 \mathrm{~h} \mathrm{zu}$ keiner wesentlichen Induktion. TMPRSS-4 zeigt einen ersten Peak nach $4 \mathrm{~h}$ mit einer 3-fachen Erhöhung der Genexpression sowie einem zweiten Peak nach 24 h und 2,3-facher Erhöhung. MTSP-1 und Hepsin steigen über einen angedeuteten Peak nach 8 h mit 2,9facher und 3,5-facher Induktion fast kontinuierlich auf ein Maximum nach $24 \mathrm{~h}$ mit einer 5,7-fachen und 5,3-fachen Induktion an. TMPRSS-2 zeigt einen stetigen Anstieg auf ein Maximum mit einer 3,2-fachen Erhöhung der Genexpression nach 24 h. (Abb.

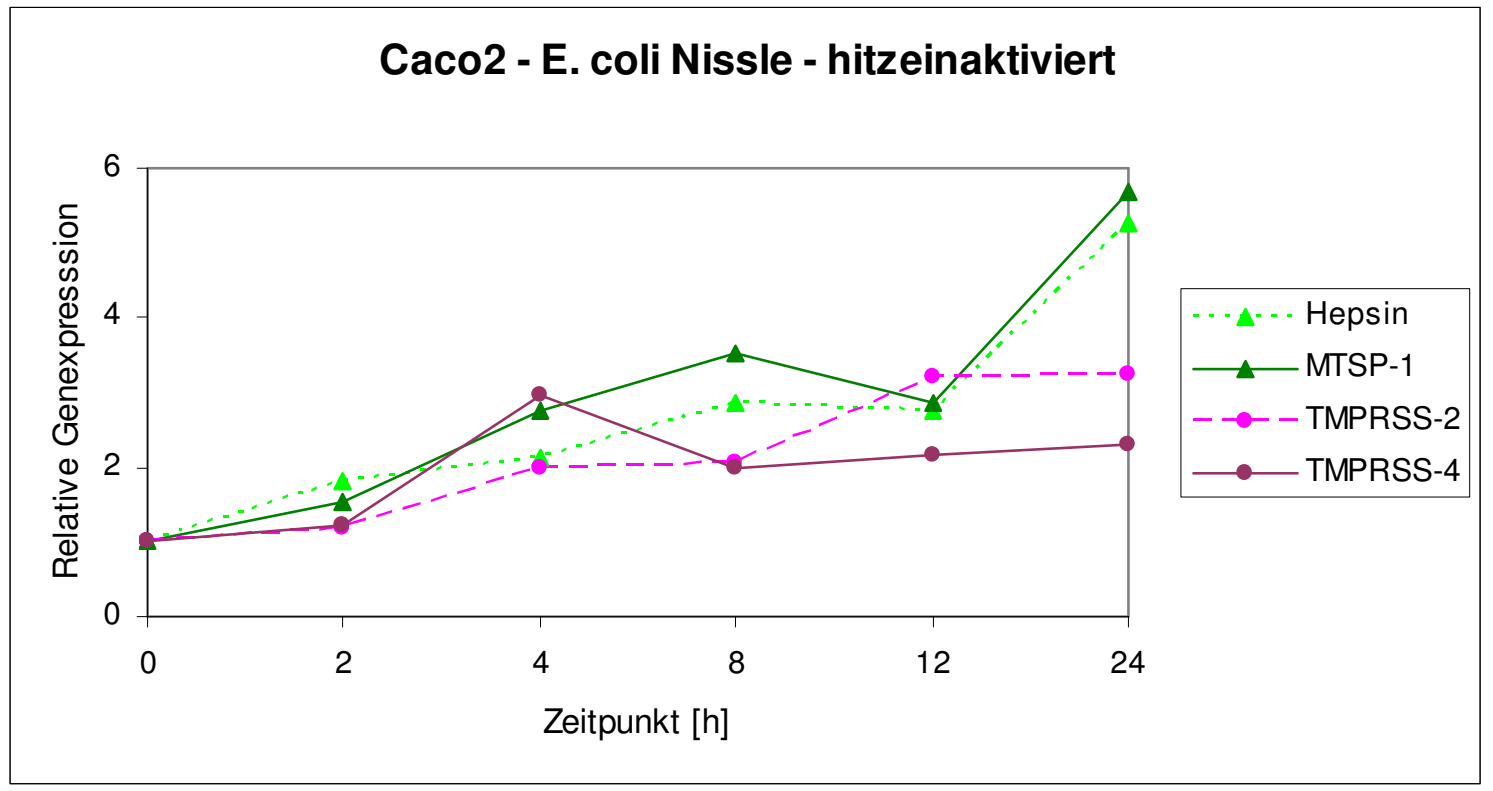

Abb. 3.43: Monolayers der Zelllinie Caco2 wurden bei Subkonfluenz mit initial ca. $3^{*} 10^{8}$ Bakterien des hitzeinaktivierten E. coli Nissle-Stammes $\left(15 \mathrm{~min}\right.$ bei $\left.80^{\circ} \mathrm{C}\right)$ für eine Stunde exponiert, abgesaugt und durch normales Medium ersetzt. Nach 0, 2, 4, 8, 12 und $24 \mathrm{~h}$ erfolgte die Isolierung der RNA. Unter Verwendung eines Transkriptionskits wurde cDNA hergestellt und im abschließenden Arbeitsschritt die Genexpression mittels real time quantitative PCR bestimmt. Die Werte wurden gegen 18sRNS normalisiert. 
E. coli Nissle-Überstand: Die Stimulation durch den bakteriellen Überstand von E. coli Nissle führt in Caco2 zu einem frühen Peak nach $2 \mathrm{~h}$ für TMPRSS-4 mit einer 2,1fachen Induktion. Danach sinkt TMPRSS-4 nach 24 h auf den Ausgangswert ab. Hepsin dagegen zeigt eine kontinuierliche Erhöhung auf ein Maximum mit 3-facher Induktion nach 24 h. TMPRSS-2 weist einen ersten diskreten Peak mit 1,5-facher Induktion nach $2 \mathrm{~h}$ auf um nach $24 \mathrm{~h}$ einen zweiten Peak mit 2,1-facher Erhöhung zu erreichen. Ebenfalls biphasisch verläuft MTSP-1 mit Peaks nach 4 und 24 h und 1,6-facher sowie 1,9-facher Induktion. (Abb. 3.44)

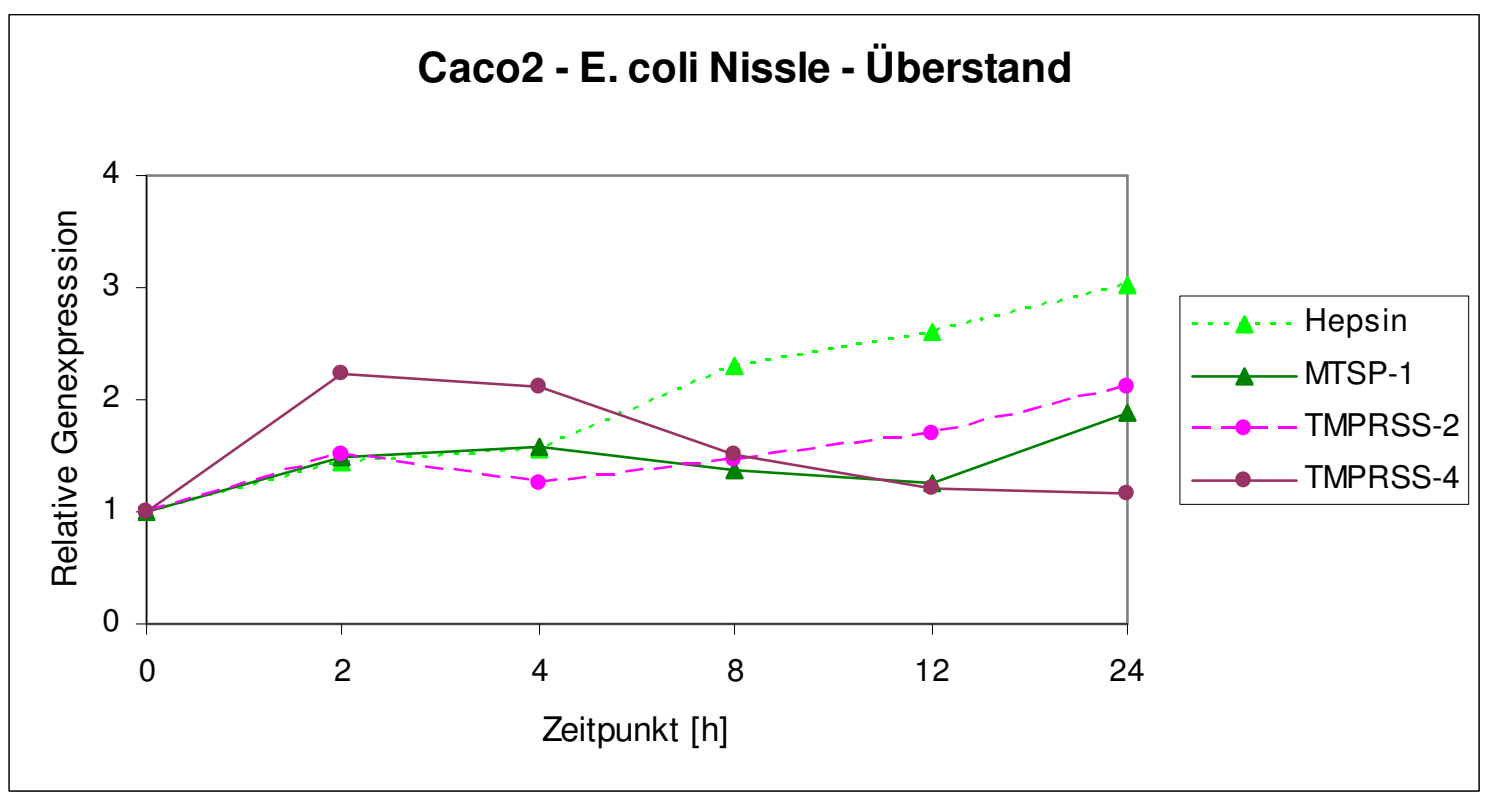

Abb. 3.44: Monolayers der Zelllinie Caco2 wurden bei Subkonfluenz mit E. coli Nissle-Überstand (Abtrennen der Bakterien mittels Mikrofilter) für eine Stunde beimpft, abgesaugt und durch normales Medium ersetzt. Nach 0, 2, 4, 8, 12 und 24 h erfolgte die Isolierung der RNA. Unter Verwendung eines Transkriptionskits wurde cDNA hergestellt und im abschließenden Arbeitsschritt die Genexpression mittels real time quantitative PCR bestimmt. Die Werte wurden gegen 18sRNS normalisiert. 


\subsubsection{Textorische Zusammenfassung E. coli Nissle mit Caco2}

1. Am augenfälligsten ist die rasche und starke Induktion von TMPRSS-2 durch das intakte Bakterium. Weder die Faktoren im Überstand noch die hitzeinaktivierte Fraktion können zu diesem starken Stimulus etwas beitragen.

2. Dagegen setzt sich die durch den intakten E. coli Nissle ausgelöste Induktion bei Hepsin mit einem Maximum nach $24 \mathrm{~h}$ durch Faktoren im Überstand und Faktoren aus der hitzeinaktivierten Präparation zusammen.

3. Für MTSP-1 und TMPRSS-4 zeigt sich eine biphasische Induktion durch den intakten E. coli Nissle. Diese wird für den ersten Peak nach $2 \mathrm{~h}$ durch die Faktoren im Überstand gut nachgezeichnet, dagegen trägt die hitzeinaktivierte Fraktion nur wenig bei. Im weiteren Verlauf jedoch zeigt sich für MTSP-1 durch die Faktoren in der hitzeinaktivierte Präparation noch eine starke Induktion nach 24 h. Diese ist, wenn gleich weniger stark ausgeprägt, auch durch das intakte Bakterium und den Überstand nachzuweisen. 
3.4.13 Tabellarische Zusammenfassung

\begin{tabular}{|c|c|c|c|c|c|c|c|c|c|c|c|c|c|c|c|c|c|c|}
\hline HT29 & \multicolumn{2}{|c|}{ E. coli } & \multicolumn{2}{|c|}{$\begin{array}{c}\text { E.coli- } \\
\text { Hi }\end{array}$} & \multicolumn{2}{|c|}{$\begin{array}{c}\text { E.coli- } \\
\ddot{\mathbf{U}}\end{array}$} & \multicolumn{2}{|c|}{ EHEC } & \multicolumn{2}{|c|}{$\begin{array}{c}\text { EHEC- } \\
\mathrm{Hi}\end{array}$} & \multicolumn{2}{|c|}{$\begin{array}{c}\text { EHEC- } \\
\ddot{\mathbf{U}}\end{array}$} & \multicolumn{2}{|c|}{$\begin{array}{l}\text { E. coli } \\
\text { Nissle }\end{array}$} & \multicolumn{2}{|c|}{$\begin{array}{c}\text { E. coli } \\
\text { Nissle- } \\
\text { Hi }\end{array}$} & \multicolumn{2}{|c|}{$\begin{array}{c}\text { E. coli } \\
\text { Nissle- } \\
\dot{\mathbf{U}}\end{array}$} \\
\hline IL-8 & $\begin{array}{l}++ \\
+ \\
\end{array}$ & $2 \mathrm{~h}$ & $\begin{array}{c}++ \\
+ \\
\end{array}$ & $2 \mathrm{~h}$ & ++ & $4 \mathrm{~h}$ & $\begin{array}{l}++ \\
+ \\
\end{array}$ & $24 \mathrm{~h}$ & $\begin{array}{l}++ \\
+ \\
\end{array}$ & $2 \mathrm{~h}$ & ++ & $2 \mathrm{~h}$ & $\begin{array}{c}++ \\
+ \\
\end{array}$ & $2 \mathrm{~h}$ & $\begin{array}{c}++ \\
+ \\
\end{array}$ & $2 \mathrm{~h}$ & $\begin{array}{c}++ \\
+ \\
\end{array}$ & $2 \mathrm{~h}$ \\
\hline PAR-2 & ++ & $12 \mathrm{~h}$ & + & $8 \mathrm{~h}$ & + & $2 \mathrm{~h}$ & + & $8 \mathrm{~h}$ & + & $8 \mathrm{~h}$ & + & $2 \mathrm{~h}$ & ++ & $4 \mathrm{~h}$ & + & $8 \mathrm{~h}$ & ++ & $2 \mathrm{~h}$ \\
\hline Hepsin & + & $2 \mathrm{~h}$ & ++ & $2 \mathrm{~h}$ & + & $24 \mathrm{~h}$ & ++ & $2 \mathrm{~h}$ & + & $24 \mathrm{~h}$ & ++ & $2 \mathrm{~h}$ & + & $24 \mathrm{~h}$ & ++ & $24 \mathrm{~h}$ & + & $24 \mathrm{~h}$ \\
\hline MTSP-1 & + & $12 \mathrm{~h}$ & + & $24 \mathrm{~h}$ & + & $4 \mathrm{~h}$ & + & $2 \mathrm{~h}$ & + & $24 \mathrm{~h}$ & + & $2 \mathrm{~h}$ & ++ & $12 \mathrm{~h}$ & + & $4 \mathrm{~h}$ & ++ & $4 \mathrm{~h}$ \\
\hline TMPRSS-2 & + & $2 \mathrm{~h}$ & ++ & $2 \mathrm{~h}$ & + & $24 \mathrm{~h}$ & + & $2 \mathrm{~h}$ & + & $2 \mathrm{~h}$ & + & $24 \mathrm{~h}$ & + & $4 \mathrm{~h}$ & + & $2 \mathrm{~h}$ & + & $24 \mathrm{~h}$ \\
\hline TMPRSS-4 & + & $12 \mathrm{~h}$ & + & $2 \mathrm{~h}$ & + & $2 \mathrm{~h}$ & + & $2 \mathrm{~h}$ & + & $2 \mathrm{~h}$ & + & $24 \mathrm{~h}$ & ++ & $12 \mathrm{~h}$ & + & $2 \mathrm{~h}$ & + & $2 \mathrm{~h}$ \\
\hline
\end{tabular}

Tab. 3.5.1: Übersicht der Stimulationsexperimente mit verschiedenen E. coli-Stämmen bzgl. der Höhe der Genexpression und des dazugehörigen Zeitpunkts bei HT29-Zellen

\begin{tabular}{|c|c|c|c|c|c|c|c|c|c|c|c|c|c|c|c|c|c|c|}
\hline Caco2 & \multicolumn{2}{|c|}{ E. coli } & \multicolumn{2}{|c|}{$\begin{array}{c}\text { E. coli- } \\
\text { Hi }\end{array}$} & \multicolumn{2}{|c|}{$\begin{array}{c}\text { E.coli- } \\
\ddot{\mathbf{U}}\end{array}$} & \multicolumn{2}{|c|}{ EHEC } & \multicolumn{2}{|c|}{$\begin{array}{c}\text { EHEC- } \\
\text { HI }\end{array}$} & \multicolumn{2}{|c|}{$\underset{\ddot{U}}{\text { EHEC- }}$} & \multicolumn{2}{|c|}{$\begin{array}{l}\text { E. coli } \\
\text { Nissle }\end{array}$} & \multicolumn{2}{|c|}{$\begin{array}{c}\text { E. coli } \\
\text { Nissle- } \\
\text { Hi }\end{array}$} & \multicolumn{2}{|c|}{$\begin{array}{c}\text { E. coli } \\
\text { Nissle- } \\
\text { Ü }\end{array}$} \\
\hline IL-8 & $\begin{array}{c}++ \\
+\end{array}$ & $2 \mathrm{~h}$ & $\begin{array}{c}++ \\
+\end{array}$ & $2 \mathrm{~h}$ & + & $12 \mathrm{~h}$ & $\begin{array}{c}++ \\
+\end{array}$ & $24 \mathrm{~h}$ & $\begin{array}{c}++ \\
+\end{array}$ & $2 \mathrm{~h}$ & + & $2 \mathrm{~h}$ & $\begin{array}{c}++ \\
+\end{array}$ & $2 \mathrm{~h}$ & $\begin{array}{c}++ \\
+\end{array}$ & $2 \mathrm{~h}$ & + & $2 \mathrm{~h}$ \\
\hline PAR-2 & ++ & $4 \mathrm{~h}$ & + & $24 \mathrm{~h}$ & + & $4 \mathrm{~h}$ & + & $4 \mathrm{~h}$ & + & $4 \mathrm{~h}$ & + & $2 \mathrm{~h}$ & + & $4 \mathrm{~h}$ & + & $4 \mathrm{~h}$ & + & $4 \mathrm{~h}$ \\
\hline Hepsin & + & $24 \mathrm{~h}$ & + & $24 \mathrm{~h}$ & + & $24 \mathrm{~h}$ & + & $24 \mathrm{~h}$ & + & $24 \mathrm{~h}$ & + & $24 \mathrm{~h}$ & + & $24 \mathrm{~h}$ & + & $24 \mathrm{~h}$ & + & $24 \mathrm{~h}$ \\
\hline MTSP-1 & + & $24 \mathrm{~h}$ & + & $4 \mathrm{~h}$ & + & $24 \mathrm{~h}$ & + & $12 \mathrm{~h}$ & + & $2 \mathrm{~h}$ & + & $12 \mathrm{~h}$ & + & $24 \mathrm{~h}$ & + & $24 \mathrm{~h}$ & + & $24 \mathrm{~h}$ \\
\hline TMPRSS-2 & + & $2 \mathrm{~h}$ & ++ & $24 \mathrm{~h}$ & 0 & $8 \mathrm{~h}$ & + & $12 \mathrm{~h}$ & + & $2 \mathrm{~h}$ & + & $24 \mathrm{~h}$ & ++ & $24 \mathrm{~h}$ & + & $24 \mathrm{~h}$ & + & $24 \mathrm{~h}$ \\
\hline TMPRSS-4 & + & $2 \mathrm{~h}$ & + & $2 \mathrm{~h}$ & + & $2 \mathrm{~h}$ & + & $12 \mathrm{~h}$ & + & $8 \mathrm{~h}$ & + & $2 \mathrm{~h}$ & + & $24 \mathrm{~h}$ & + & $4 \mathrm{~h}$ & + & $2 \mathrm{~h}$ \\
\hline
\end{tabular}

Tab. 3.5.2: Übersicht der Stimulationsexperimente mit verschiedenen E. coli-Stämmen bzgl. der Höhe der Genexpression und Zeitpunkts bei Caco2-Zellen

Tab. 3.5.1 und 3.5.2 fassen die vorangegangenen Daten für HT29- und Caco2-Zellen zusammen. Für die obige Darstellung der Daten wurden die jeweiligen absoluten Maximalwerte, unabhängig vom Zeitpunkt, verwendet.

\begin{tabular}{|llll|}
\hline+++ & $=$ & $>100-$ & fache Erhöhung der Genexpression \\
++ & $=$ & $>10-$ & fache Erhöhung der Genexpression \\
+ & $=$ & $>1,25-$ fache Erhöhung der Genexpression \\
0 & $=$ & Keine Veränderung der Genexpression \\
- & $=$ & $<0,75-$ fache Suppression der Genexpression \\
-- & $=$ & $<0,5-$ fache Suppression der Genexpression \\
-- & $=$ & $<0,25-$ fache Suppression der Genexpression
\end{tabular}


Anmerkungen:

1. IL-8 wird als Referenz für den proinflammatorischen Effekt der Infektionen aufgeführt. PAR-2 ist ein mögliches molekulares Target für die proteolytische Aktivität der Typ II transmembranären Serinproteasen. Es ist daher von Interesse, ob dieser Rezeptor gleichsinnig oder gegensinnig durch die Infektion reguliert wird. Die Daten sind der Arbeit von Hr. M. Himpel entnommen und erscheinen mit dessen freundlicher Genehmigung.

2. Die Experimente wurden 2- bzw. 3-mal wiederholt, es wird von den jeweiligen Experimenten ein repräsentatives Ergebnis gezeigt.

\subsubsection{Gesamtüberblick}

1. Quantitativ die mit Abstand ausgeprägteste Geninduktion ist durch die Faktoren der hitzeinaktivierten Präparation von E. coli in HT29-Zellen für TMPRSS-2 mit einer 40-fachen Induktion nach $2 \mathrm{~h}$ zu beobachten. Ebenso erfährt Hepsin durch diese Präparation nach $2 \mathrm{~h}$ einen starken Stimulus und reagiert mit einer 10fachen Induktion. Des Weiteren weist Hepsin in HT29 durch die hitzeinaktivierte E. coli Nissle Fraktion eine 14,7-fache Induktion, durch intakten EHEC eine 16,2-fache Induktion und durch EHEC Überstand eine 20fache Induktion auf. In HT29-Zellen findet sich unter den vier gemessenen TTSP 8-mal eine Erhöhung der Genexpression über das 10-fache hinaus, dagegen nur 2-mal in Caco2-Zellen. Insgesamt sind somit in HT29-Zellen stärkere Geninduktionen zu beobachten als in Caco2-Zellen.

2. Augenfällig ist die fast ausnahmslos biphasische Induktion der Proteasen. Einzige Ausnahme ist die Stimulation von Caco2 mit E. coli ATCC Überstand. Hier zeigt sich eine triphasische Induktion von Hepsin und MTSP-1, angedeutet auch von TMPRSS-4.

3. Alle vier Proteasen erfahren durch die verschiedenen Bakterien und deren unterschiedliche Präparation im Wesentlichen eine Erhöhung der Genexpression (siehe auch Übersicht Tab. 3.4.1 und 3.4.2). Lediglich E. coli Überstand in Caco2 führt zu einer kompletten Suppression bzw. keiner Regulation von TMPRSS-2. 
4. Bei HT29 bewirken die verschiedenen Stimuli eine starke Genexpression von Hepsin. Insgesamt 4-mal kann die Protease mit einer mehr als 10-fachen Induktion gemessen werden. Dagegen weist Hepsin bei Caco2-Zellen eine deutlich schwächere Induktion auf, die zudem ausnahmslos durch alle Stimuli erst nach $24 \mathrm{~h}$ auftritt.

5. Die TTSP erfahren in beiden Zelllinien durch Faktoren der hitzeinaktivierten und lysierten Präparationen der drei verschiedenen Bakterien durchgängig eine frühe und starke Induktion mit einem Peak nach $2 \mathrm{~h}$, welcher oftmals durch einen zweiten Peak nach $24 \mathrm{~h}$ ergänzt wird. Hervorzuheben ist hierbei TMPRSS-2, die durch die Faktoren der hitzeinaktivierten Fraktion die deutlichste Induktion erfährt.

6. Es zeigt sich kein stringentes einheitliches Muster der Geninduktion unter den drei verschiedenen Präparationen intaktes Bakterium, hitzeinaktivierte Fraktion und Überstand. So zeigt Hepsin bei HT29 mit E. coli einen frühen Peak, der sich aus allen Fraktionen zusammensetzt. Dagegen weist Hepsin bei Caco2 mit E. coli einen späten gemeinsamen Peak auf. Oftmals werden die durch das intakte Bakterium induzierten Peaks nur durch eine weitere Präparation nachgezeichnet (HT29 mit intaktem EHEC und einem starken Peak nach $2 \mathrm{~h}$, ergänzt durch EHEC Überstand; die hitzeinaktivierte Präparation trägt nichts bei). 


\section{Diskussion}

Die Expression von TTSP kann in einer Vielzahl von gesunden, entzündlich veränderten sowie malignen humanen Geweben nachgewiesen werden. Dabei stellen TTSP eine relativ junge Familie von Proteasen dar, deren physiologische wie auch pathophysiologische Funktion noch weitgehend ungeklärt ist.

Ziel dieser Arbeit war es daher, die Expression ausgewählter TTSP unter unterschiedlichen experimentellen Konditionen genauer $\mathrm{zu}$ untersuchen und $\mathrm{zu}$ versuchen daraus Rückschlüsse auf die Funktion zu ziehen. Das heißt:

1. Wie verhält sich die physiologische Expression von TTSP im humanen Gastrointestinaltrakt in Relation zur Expression von PAR-2?

2. Werden TTSP in IEC durch proinflammatorische Zytokine, LPS und Dexamethason induziert?

3. Welchen Effekt hat die Infektion von Monolayers intestinaler Epithelzellen mit Bakterien unterschiedlicher Pathogenität auf die Expression der TTSP?

4. Welche Bakterienbestandteile und -Faktoren verursachen eine Regulation der TTSP in IEC?

5. Werden TTSP durch bestimmte Stimuli gleich- oder gegensinnig exprimiert und korreliert dies mit der Expression von PAR-2?

\subsection{Genexpression von TTSP in humanen gastrointestinalen Geweben (3.1)}

Das eingehende Studium der zurückliegenden wie auch aktuellen wissenschaftlichen Veröffentlichungen zeigt interessanterweise bislang keine Daten im Hinblick auf die im Folgenden zu diskutierende Ergebnisse zur Expression von TTSP im longitudinalen Verlauf von humanen gastrointestinalen Gewebeproben. So wurde die relative Genexpression von fünf TTSP sowie PAR-2 über zehn Lokalisationen von cranial (Magenkorpus) nach caudal (Rektum) in humanen Gewebeproben ermittelt.

Hepsin konnte in den Gewebeproben nicht nachgewiesen werden (Daten im Hauptteil nicht gezeigt). Es zeigte sich keinerlei Expression im humanen GI-Trakt. Dies korreliert 
mit der aktuellen Datenlage, die ebenfalls keinen Hinweis auf die physiologische Expression von Hepsin im Verdauungstrakt liefert. Daten zur physiologischen Funktion von Hepsin im Menschen sind bisher nur spärlich vorhanden. So gibt es Hinweise, dass Hepsin eine bedeutende Rolle bei der Hämostase beim Menschen spielt (Kazama et al., 1995).

In malignen Neoplasien des humanen Verdaungsstrakts konnte eine Überexpression von Hepsin bisher nicht gezeigt werden. Dagegen wird Hepsin in Karzinomen außerhalb des GI-Traktes, hier vor allem der Prostata und Ovarien, beschrieben. So besteht eine Korrelation zwischen erhöhter Genexpression der Protease und verstärkter Progression und Metastasierung von Prostatakarzinomen beim Menschen (Klezovitch et al., 2004). Daraus resultiert die Möglichkeit der Verwendung von Hepsin als Biomarker (neben weiteren) zur molekularen Diagnostik des Prostatakarzinoms (Landers et al., 2005). In Ovarialkarzinomen des Menschen zeigt Hepsin ebenfalls eine deutliche Induktion der Genexpression (Tanimoto et al., 1997).

Weitere Hinweise zur Expression und Funktion von Hepsin finden sich in Studien mit anderen Säugetierzellen. So scheint Hepsin eine wichtige Rolle bei Wachstum und Entwicklung von Mäusen zu spielen (Torres-Rosado et al., 1993; Vu et al., 1997) und insbesondere zur Entwicklung und Regeneration von Leberzellen bei Mäusen beizutragen (Yu et al., 2000). In einem Prostatakarzinom-Mausmodell induziert HepsinÜberexpression eine deutlich verstärkte Tumorprogression und Metastasierung. Dagegen kann in vitro durch anti-Hepsin Antikörper eine Tumorprogression inhibiert werden (Wu, Parry, 2007). Neueste Untersuchungen beschreiben in einem Mausmodell mit Prostatakarzinomen Laminin-332 als ein spezifisches Substrat von Hepsin, welches durch direkte Spaltung zu einer Tumorprogression beitragen kann (Tripathi et al., 2008). Auch in einem Ovarialkarzinom- Mausmodell wurde dies belegt. Dabei konnte eine erhöhte Genexpression und Kolokalisation von Hepsin und seines vermutlichen proteolytischen Substrats HGF mit desmosomalen Zellverbindungen bei gesteigerter Tumorprogression und -expansion nachgewiesen werden (Miao et al., 2008).

Damit ergeben sich neue Erkenntnisse zur Funktion und Regulation von Hepsin in einzelnen Tumoren vor allem der Prostata und der Ovarien sowie deren Progression. Dagegen bleibt Hepsin im humanen Gatrointestinaltrakt nach unseren Ergebnissen und den bisherigen Veröffentlichungen physiologisch nicht expremiert.

Enterokinase konnte im Gesamtkollektiv der humanen Proben lediglich im Duodenum nachgewiesen werden. Dies entspricht den bisherigen Veröffentlichungen, die für 
Enterokinase ebenfalls nur eine physiologische Expression im proximalen humanen Dünndarm beschreiben (Yuan et al., 1998; Hermon-Taylor et al., 1977). Eine mögliche Begründung in der recht restriktiven Expression könnte die sehr spezifische Rolle und physiologische Funktion der Enterokinase sein. So ist das Vorkommen der so genannten Brunner-Drüsen auf das Duodenum beschränkt. Diese schleimproduzierenden, submukösen Drüsen sezernieren u.a. Enterokinase, welche als Aktivator von pankreatischem Trypsinogen zu Trypsin eine hohe Funktions- und Milieuspezifität besitzt. Trypsin aktiviert sodann die weiteren Proenzyme Chymotrypsinogen, Proelastase und Procarboxypeptidase. Mutationen des Proenterokinase-Gens verursachen einen kongenitale Enterokinase-Mangel, welcher nach der Geburt zu chronischer Diarrhoe, Anämie und durch Hypoproteinämie bedingten generalisierten Ödemen führt. Daraus resultieren schwere frühkindliche Wachstumsstörungen (Rutgeerts, Eggermont, 1976). Enterokinase ist durch ihre Rolle bei der TrypsinAktivierung indirekt an der Aktivierung von PAR-2 durch Trypsin auf der Zelloberfläche von Darmepithelzellen beteiligt (Cottrell et al., 2004). Die Aktivierung von PAR-2 auf intestinalen Epithelzellen wiederum führt in einigen Untersuchungen zur Suppression der Entzündung im TNBS-Kolitis-Modell (Fiorucci et al., 2001). Des Weiteren führt die Induktion von PAR-2 auf IEC durch Trypsin und andere trypsinähnliche Proteasen zu protektiven Effekten wie der Stimulation von Chlorid- und Wassersekretion (van der Merwe et al., 2008) sowie einer Induktion der MuzinSekretion (Kawabata et al., 2001; Jarry et al., 2007).

Zusammenfassend besitzt Enterokinase nur einen sehr eingeschränkten Aktionsradius, seit der Entdeckung von PARs wird aber klar, dass sie durch die Steuerung der Aktivierung von Proteinasen eine viel weitreichendere Rolle in der Homöostase des Darms spielen könnte.

TMPRSS-2 wird, wie in 3.1, Abb. 3.1 dargestellt, über den gesamten longitudinalen Verlauf der Gewebeproben des GI-Trakts exprimiert. Die Protease wird im proximalen Magen (Korpus) und im Kolon (Coecum) am höchsten exprimiert und weist dann zur distalen Organgrenze hin jeweils eine geringere Expression auf. Diese Daten zur Expression von TMPRSS-2 im humanen Gastrointestinaltrakt korrelieren mit bisherigen wissenschaftlichen Veröffentlichungen. TMPRSS-2 wird demnach in Geweben des humanen Verdauungstrakt, insbesondere des Magens und des Kolons exprimiert (Vaarala et al., 2001). Des Weiteren wird die Protease in humanen Geweben der 
Speicheldrüsen, des Pankreas, der Nieren, der Mammae sowie der Prostata exprimiert (Lucas et al., 2008). In Geweben der Maus konnte TMPRSS-2 weiterhin noch in Urogenital- und Respirationstrakt nachgewiesen werden (Vaarala et al., 2001). TMPRSS-2 kann in vitro die Funktion des epithelialen Natrium-Kanals (ENaC) regulieren, was eine mögliche Rolle bei der epithelialen Natrium-Homöostase spielen könnte (Donaldson et al., 2002). Dies könnte im GI-Trakt für einen ausgewogenen Natrium- und Wasserhaushalt von Bedeutung sein. In Kolon- und vor allem Prostatakarzinomen zeigt sich die Genexpression der Protease deutlich erhöht (Afar et al., 2001). In Prostatakarzinomzellen ist die Regulation der Expression von TMPRSS-2 dabei androgenabhängig (Lin, Ferguson et al., 1999). In einer weiteren Veröffentlichung konnte gezeigt werden, dass TMPRSS-2 in Prostatatumorzellen PAR-2 aktiviert und damit möglicherweise zu Tumorprogression und Metastasierung beiträgt (Wilson et al., 2005). Für normales Prostatagewebe konnte diese Aktivierung noch nicht nachgewiesen werden. Weitere bedeutende Erkenntnisse wurden in den letzten Jahren für TMPRSS-2 als diagnostisches und therapeutisches Target in Prostatakarzinomen beschrieben. So konnte eine Gen-Fusion zwischen androgen-reguliertem TMPRSS-2 und den Mitgliedern der ETS Transkriptionsfaktor-Familie (ERG, ETV1, ETV4) in Prostatakarzinomen nachgewiesen werden (Rubin, Chinnaiyan, 2006). Das TMPRSS2:ETS- Fusionsprodukt kann zur Diagnostik noninvasiv im Urin bestimmt werden und wird mit einem aggressiveren Phänotyp des Karzinoms in Verbindung gebracht (Tomlins et al., 2009). Insbesondere eine Duplikation des Fusionslokus bedingt eine deutlich geringere Patienten-Überlebensrate (Attard et al., 2008). Es ist zu vermuten, dass diese und noch folgende Erkenntnisse die Diagnostik, Einteilung und Therapie von Prostatakarzinomen maßgeblich verändern werden.

In dieser Arbeit wurde die Expression von TMPRSS-2 im humanen GI-Trakt bestätigt und detailliert beschrieben, die physiologische Funktion dieser Protease bleibt weiterhin unklar.

Für TMPRSS-4 besteht eine eher spärliche Datenlage mit nur wenigen wissenschaftlichen Veröffentlichungen. Während für die sehr ähnlich strukturierte membranständige Serin Protease TMPRSS-2 viele Daten über eine weit gefächerte Expression zur Verfügung stehen, finden sich zu TMPRSS-4 kaum Angaben zu seiner physiologischen Expression in humanen Geweben. Szabo und Bugge beschreiben in einem aktuellen Review die Expression von TMPRSS-4 in humanem Ösophagus, 
Magen, Dünndarm, Dickdarm, Nieren und Harnblase (Szabo, Bugge 2008). Dabei beziehen sie sich auf eine Veröffentlichung von Wallrapp et al. 2000, welche Expression und Regulation einer damals neuen Protease mit initialem Namen TMPRSS3 beschreibt. Diese Protease wurde später in TMPRSS-4 umbenannt. Eine mögliche physiologische Funktion von TMPRSS-4 wird in nur wenigen Studien beschrieben, wonach TMPRSS-4 an der Regulation des epithelialen Natrium-Kanals (ENaC) beteiligt sein könnte (Adachi et al., 2001; Donaldson et al., 2002). Wie in 3.1, Abb. 3.2 dargestellt, weist TMPRSS-4 die geringste relative wie absolute Erhöhung (Maximum: 3,7-fach im Colon descendens) der Genexpression im Vergleich mit TMPRSS-2, MTSP-1 und PAR-2 im GI-Trakt auf.

Wir beschreiben hiermit die Expression von TMPRSS-4 im Gastrointestinaltrakt. Eine mögliche Überexpression von TMPRSS-4 in Kolonkarzinomen analog zu TMPRSS-2 sollte Gegenstand weiterer Untersuchungen sein. In Pankreastumoren ist die Expression von TMPRSS-4 deutlich erhöht, während sie in normalen Pankreasgeweben nicht nachgewiesen werden konnte (Wallrapp et al., 2000). In einer weiteren Studie konnte die Überexpression von TMPRSS-4 in malignen gegenüber benignen Schilddrüsenneoplasien nachgewiesen werden (Kebebew et al., 2005). Zusammenfassend wurde in dieser Arbeit TMPRSS-4 im humanen Gastrointestinaltrakt nachgewiesen. Damit konnten wir die bisher einzige Veröffentlichung von Wallrapp et al. bestätigen. Über seine Expression in anderen normalen humanen Geweben existieren noch zu wenige Daten, während in Tumorgeweben eine Überexpression gezeigt werden konnte. Dies lässt über eine proteolytische Funktion bei Tumorprogression und Metastasierung auch mit Bezug auf seine enge strukturelle Verwandtschaft zu TMPRSS-2 spekulieren. Eine Aktivierung von PAR-2 in Karzinomzellen analog zu TMPRSS-2 wäre auch für TMPRSS-4 denkbar, wurde bislang aber noch nicht beschrieben. Die physiologische Funktion von TMPRSS-4 bleibt damit weiter unklar und sollte Gegenstand weiterer Forschung sein.

MTSP-1 zeigt die höchste relative Expression im humanen GI-Trakt (3.1, Abb. 3.3) mit einem absoluten Maximum im Caecum (11-fache Erhöhung der Genexpression). Dies korreliert mit der insgesamt guten Datenlage zu MTSP-1. So wird MTSP-1 in humanen gesunden Gewebeproben des Gastrointestinaltrakts an der basolateralen Seite von Enterozyten exprimiert (Tsuzuki et al., 2005). Des Weiteren findet sich die Genexpression der Protease im Dünndarm und Kolon von Ratten sowie eine Expression 
an der basolateralen Seite von Caco2-Zellen (Satomi et al., 2001). Darüber hinaus wird MTSP-1 im Respirationstrakt, Urogenitaltrakt, in der Epidermis, im Thymus, in isolierten Gewebe-Immunzellen, ZNS-Purkinjezellen, Neuronen der Grauen und Weißen Substanz, Rückenmarkneuronen, Monozyten und Granulozyten exprimiert (Oberst, Anders et al., 2001). MTSP-1 ist unter den TTSP eine der Bestuntersuchtesten, was sich an der Anzahl der Veröffentlichungen zur physiologischen Funktion ablesen läßt. Dies wurde in der Einleitung schon ausführlich dargelegt, hier werden nur noch einige wesentliche Punkte erwähnt.

Ein knock-out des MTSP-1-Gens bei Mäusen führte binnen 48 h nach Geburt zum Tod, bedingt durch unkontrollierbare Dehydratation und Hypothermie auf Grund einer stark aberranten Entwicklung der Haut. Zusammengenommen ergibt sich für MTSP-1 eine Schlüsselfunktion in der Entwicklung der Epidermis, der Haarfollikel und des zellulären Immunsystems (Bugge, List, Szabo, 2007). Interessant sind auch Ergebnisse über die ausschließliche Expression von MTSP-1 auf der basolateralen Seite von Nierenepithelzellen (COS-1) des Affen (Tsuzuki et al., 2005). Diese polare Expression könnte im GI-Trakt von besonderer Bedeutung sein, da intestinale Epithelzellen einem hohen Zell-Turnover unterliegen. Dieser beginnt im unteren Teil der Krypte mit der stetigen Proliferation von Stammzellen, führt über die kontinuierliche Wanderung dieser Zellen bis zur Villusspitze schließlich zur Abstoßung der alternden Zellen. MTSP-1 könnte bei der Steuerung des epithelialen Zell-Turnover durch die Regulation der Zell-Zell und/oder Zell-Substratum-Kontakte eine Schlüsselrolle einnehmen. Dies könnte seine ausgeprägte Expression im Colon wenigstens teilweise erklären.

IEC unterliegen nicht nur einer stetigen Wanderung von Kryptenbasis zur Villusspitze sondern dabei auch einem steigenden Differenzierungsgrad mit sich verändernden Eigenschaften. So konnten auf epithelialen Zelloberflächen als physiologische Aktivatoren von MTSP-1 Trypsin und Sphingosin 1-Phosphat beschrieben werden (Benaud et al., 2002; Jin et al., 2005). Vor allem Trypsin ist hier von Interesse. Durch Enterokinase, welche Trypsinogen zu Trypsin aktiviert, könnte sich damit über die Aktivierung von MTSP-1 eine Kaskade ausbilden, die den epithelialen Zell-Turnover mit steuert. In diese Aktivierungskaskade könnte noch der ursprünglich als MTSP-1Inhibitor beschriebene und hepatocyte growth factor activator inhibitor (HAI)-1 benannte Serinproteaseninhibitor einbezogen werden (Oberst et al., 2002).. Andere Ergebnisse sehen HAI-1 jedoch in einer Rolle der Protektion von Epithelzellen gegenüber unkontrollierter MTSP-1-Aktivierung, also eher als regulierenden Faktor 
(Oberst et al., 2005). Einen weiteren Aspekt einer vermutlich weit gefächerten Aktivierungskaskade zeigt die Möglichkeit der Aktivierung von PAR-2 auf XenopusOozyten durch eine lösliche MTSP-1 Proteasen Domäne (Takeuchi et al., 2000). Aktuellste Ergebnisse beschreiben eine Interaktion von PAR-2 mit MTSP-1 in nichtmelanomartigem Hautkrebs, wobei vermutet wird, dass PAR-2 ein Substrat für MTSP-1 in humaner Haut darstellt (Bocheva et al., 2009). MTSP-1 kann (neben Hepsin) auf Zelloberflächen autokatalytisch aktiviert werden, was einen eher ungewöhnlichen Mechanismus unter den Serin Proteasen darstellt (Qui et al., 2007). In mehreren aktuellen Studien konnten neue grundlegende Erkenntnisse zu MTSP-1 und seines Inhibitors HAI-1 vor allem in der postnatalen Gewebehomöostase beschrieben werden. So führt eine Mutation im Spint1-Gen, welches für HAI-1 kodiert, zu einem Verlust der MTSP-1 Suppression durch HAI-1 und daraus resultierend zu massiv gestörter Hautentwicklung und Gedeihstörungen bis hin zum Tod in Mäusen (Szabo, Kosa, List, Bugge, 2009). Damit wird die essentielle inhibitorische Funktion von HAI-1 immer deutlicher. In Ovarialkarzinomen geht eine geringe Expression von HAI-1 (sowie HAI-2) mit einer schlechteren Prognose einher (Nakamura et al., 2009) und in kolorektalen Karzinomen geht eine verminderte Expression von MTSP-1 und HAI-1 mit einer aggressiveren Tumorprogression einher (Zeng, Cao, Zhang, 2005).

Zusammenfassend spielt MTSP-1 in Kombination mit seinem Inhibitor HAI-1für die Entwicklung der Epidermis eine essentielle Rolle, seine Rolle in der Physiologie des Gastrointestinalstraktes ist bislang weniger gut verstanden.

PAR-2 zeigt, wie in 3.1, Abb. $3.4 \mathrm{zu}$ erkennen, eine deutliche Expression im gastrointestinalen Gewebe. Das Maximum mit einer fast 8-fachen Erhöhung konnte im Caecum ermittelt werden. Auch die weitere Verteilung der Genexpression verläuft sehr ähnlich im Vergleich zu den gemessenen membranständigen Proteasen. So haben alle ihr Maximum im Caecum (nur TMPRSS-4 im Colon descendens) und zeigen, wenn man alle Daten mittelt, dass der Schwerpunkt der Expression im Wesentlichen im Dickdarm zu finden ist. Inwieweit sich histomorphologisch ein Erklärungsansatz für dieses gleiche Expressionsmuster der TTSP postulieren lässt, ist bislang noch unklar. Festzuhalten ist diesbezüglich, dass im terminalen Ileum sowie Caecum die größte Anzahl von muzinsezernierenden Becherzellen existiert. Des Weiteren produzieren Panethzellen im Dünndarm (vor allem Jejunuum) sehr hohe Dosen an Defensinen und halten damit eine niedrige Bakterienzahl aufrecht. Dagegen ist im Dickdarm die 
Bildung antimikrobieller Peptide sehr gering, was sich in einer sehr hohen Bakterienzahl widerspiegelt (Wehkamp et al., 2007). Diese hohe Keimzahl der kommensalen Verdauungsflora könnte zur Induktion der TTSP und PAR-2 vor allem im proximalen Dickdarm, wie in diesen Untersuchungen dargestellt, führen.

PAR-2 wird eindeutig im humanen GI-Trakt mit TMPRSS-2, TMPRSS-4 und MTSP-1 koexprimiert. Hier stellt sich die Frage nach der Bedeutung dieser Koexpression und der physiologischen Funktion von PAR-2 im Kontext der membranständigen Proteasen. Die aktuelle wissenschaftliche Literatur beschreibt ebenfalls die Expression von PAR-2 im Verdauungstrakt (insbesondere in intestinalen und Kolonepithelzellen), in neuronalen Strukturen und in Myozyten (Foirucci et al., 2001). Damit korrelieren die Daten dieser Arbeit mit denen bisheriger Veröffentlichungen. Die physiologische Funktion von PAR-2 ist noch weitgehend unverstanden. Es wurden sowohl proinflammatorische als auch protektive, antiinflammatorische Effekte beschrieben. So führt eine PAR-2Aktivierung in nativen Mäusen zu proinflammatorischen Effekten, unter anderem zu erhöhter mukosaler Permeabilität und bakterieller Translokation in peritoneale Organe (Cenac et al., 2002). Dagegen konnte in einem TNBS-Kolitis-Model der Maus über PAR-2 Aktivierung eine antiinflammatorische Reaktion beschrieben werden (Foirucci et al., 2001). Wie bereits oben erläutert, können MTSP-1 und TMPRSS-2 sowie Trypsin und Sphingosin 1-Phosphat PAR-2 auf unterschiedliche Art aktivieren. In diesem Zusammenhang soll im Folgenden untersucht werden, wie sich die Expression von TTSP in verschiedenen Entzündungsmodellen in Relation zu PAR-2 verändert.

\section{Resümierend kann gesagt werden:}

TTSP werden in humanen Gewebeproben des Gastrointestinaltraktes exprimiert Vergleichend zeigt sich ein sehr ähnliches Expressionsmuster der TTSP Das quantitative Expressionsmaximum liegt wesentlich im Bereich des Caecum TTSP werden eindeutig mit PAR-2 koexprimiert 


\subsection{Expression von TTSP in IEC in Abhängigkeit von proinflammatorischen Zytokinen, LPS und Dexamethason (3.2)}

Intestinale Epithelzellen (IEC) bilden eine erste strukturelle und auch funktionelle Barriere gegenüber dem intestinalen Lumen und seinen darin befindlichen Substanzen. Dieser immensen Vielfalt der luminalen Agentien und daraus resultierender Stimuli begegnen IEC mit multiplen physiologischen und ggf. pathophysiologischen Reaktionen. So können IEC auf bestimmte Stimuli unter anderem mit der Produktion verschiedenster inflammatorischer Mediatoren reagieren sowie Genexpression und regulation verändern.

Monolayers der intestinalen Epithelzelllinien HT29 und Caco2 wurden mit den Zytokinen IFN- $\gamma$, IL-1 $\beta$, TNF- $\alpha$ sowie LPS, Dexamethason und Dexamethason plus IL$1 \beta$ über einen Zeitrahmen von bis zu $96 \mathrm{~h}$ stimuliert und die relative Genexpression der membranständigen Proteasen Hepsin, MTSP-1, TMPRRS-2 und TMPRSS-4 sowie PAR-2 und IL-8 gemessen. Beide Zelllinien exprimierten die vier TTSP, PAR-2 und IL-8.

$I F N-\gamma$ ist ein interzellulärer Botenstoff, der ausschließlich von T-Lymphozyten gebildet wird und virustatische, antiproliferative und immunmodulierende Eigenschaften besitzt. HT29 und Caco2 antworten auf die Stimulation durch IFN- $\gamma$ mit einer mäßigen Regulation der TTSP-Genexpression. MTSP-1, TMPRSS-2 und TMPRSS-4 werden in beiden Zelllinien eher supprimiert. So weisen TMPRSS-2 und TMPRSS-4 besonders deutlich in HT29 eine über den gesamten Zeitverlauf vorhandene Suppression auf. Lediglich Hepsin zeigt eine bis zu 3-fache Erhöhung seiner Genexpression um den 4 hWert bei HT29 und Caco2. IFN- $\gamma$ induziert von allen Zytokinen die geringste IL-8Erhöhung. Nach 2 h findet sich ein schwacher Peak mit nur 1,5-facher Induktion, auch ein zweiter Peak nach $72 \mathrm{~h}$ erreicht nur eine 3,7-fache Induktion. PAR-2 zeigt ein Maximum nach $2 \mathrm{~h}$ mit 2,5-facher Induktion (beide Zelllinien ähnlich).

8-tägige Stimulation von HT29-Zellen durch IFN- $\gamma$ induziert eine gesteigerte Zellproliferation und verminderten Zelltod (Seidelin et al., 2004). Ein ähnliches Muster des gesteigerten Zell-Turnovers findet man in Patienten mit Colitis ulcerosa. In dieser Arbeit konnte gezeigt werden, dass IFN- $\gamma$ in HT29- und Caco2-Zellen zu teilweise ausgeprägter Suppression der Proteasen MTSP-1, TMPRSS-2 und TMPRSS-4 führt. Inwieweit dies eine indirekte Auswirkung der oben beschriebenen gesteigerten 
Zellproliferation oder eine direkte Wirkung von IFN- $\gamma$ auf die Expression der Proteasen oder beides ist, sollte Gegenstand weiterer Untersuchungen sein.

Hepsin wird dagegen durch IFN- $\gamma$ vor allem in HT29-Zellen deutlich induziert. Das lässt auf unterschiedliche Regulationsmechanismen $\mathrm{zu}$ MTSP-1, TMPRSS-2 und TMPRSS-4 schließen.

$I L-1 \beta$ stellt ein äußerst potentes Zytokin dar, das starke proinflammatorische Reaktionen in verschiedensten Geweben hervorrufen kann. Deshalb wird IL-1 $\beta$ in vielen Studien mit IEC zur Induktion einer Entzündungsreaktion verwendet. Auch in dieser Studie induziert IL-1 $\beta$ in beiden Zelllinien eine massive Erhöhung der IL-8-Genexpression. Das Maximum zeigt sich bei HT29 schon nach 2 h mit einer 320-fachen Erhöhung. Caco2 verhalten sich ähnlich. IL-1 $\beta$ verursacht damit die deutlichste Erhöhung der IL8-Genexpression unter allen verwendeten Zytokinen (gefolgt von TNF- $\alpha$, siehe unten). Die PAR-2 Expression wird durch dieses Zytokin supprimiert mit einem Minimum von 0,4-fach nach $24 \mathrm{~h}$. Die TTSP reagieren ebenfalls mit einer Suppression über den gesamten Zeitverlauf, in HT29-Zellen ausgeprägter als Caco2-Zellen. Ausnahme ist wiederum Hepsin mit einer späten Induktion der Genexpression vor allem in HT29Zellen (9-fach nach 72 h), schwächer auch in Caco2-Zellen (2,9-fach nach 2 h). Das lässt darauf schließen, dass die vier untersuchten membranständigen Proteasen unterschiedlichen regulatorischen Mechanismen unterliegen.

$L P S$ als ein bakterielles Lipopolysaccharid gramnegativer Keime induziert zu einem wesentlichen Anteil durch Bakterien verursachte Entzündungsreaktionen und damit auch die Expression von verschiedensten Zytokinen. LPS führt bei HT29 und Caco2 zu ähnlichen Induktionen der IL-8-Genexpression. LPS induziert in HT29 nach $2 \mathrm{~h}$ ein Maximum mit einer 16-fachen Erhöhung. PAR-2 wird dagegen zum Zeitpunkt $2 \mathrm{~h}$ supprimiert. In einer Studie konnte gezeigt werden, dass die LPS-induzierte IL-8Sekretion zur Muzin-Sekretion in HT29-MTX-Zellen führt. Diese Muzinsekretion von Becherzellen stellt einen wichtigen Faktor in der unspezifischen mucosalen Immunität von IEC dar (Smirnova et al., 2003). In beiden Zelllinien erfahren die TTSP durch die Stimulation mit LPS insgesamt eine mäßige Erhöhung ihrer Genexpression und zeigen nach 2-4 h erste Peaks mit einer ca. 2-fachen Erhöhung. TMPRSS-4 bildet in Caco2Zellen eine Ausnahme und zeigt sich über den gesamten Zeitverlauf supprimiert. 
Zusammenfassend scheinen TTSP gemessen an ihrer Expression auch nach Stimulation mit Wandbestandteilen gramnegativer Bakterien keine bedeutende Rolle in der Vermittlung der Immunität zu spielen.

$T N F-\alpha$ spielt eine zentrale Rolle in der Initiierung und Verstärkung von inflammatorischen Reaktionen und ist unter anderem auch in die Pathogenese von (chronisch) entzündlichen Darmerkrankungen (CED) verwickelt. In vielen Studien ist die Induktion von diversen Zytokinen, insbesondere aber IL-8, durch Stimulation mit TNF- $\alpha$ beschrieben.

HT29- und Caco2-Zellen reagieren auf die Stimulation mit TNF- $\alpha$ mit einer massiven Erhöhung der relativen Genexpression von IL-8. HT29-Zellen zeigen mit einem absoluten Maximum von 200-facher Erhöhung nach $2 \mathrm{~h}$ die deutlichste Antwort.

Diese TNF- $\alpha$ induzierte starke IL-8-Expression kann durch Vorbehandlung von HT29Zellen mit Probiotika deutlich abgemildert werden. In einer Studie weisen HT29-Zellen, die mit Bifidobakterien oder Lactobazillen kultiviert werden nach einer Stimulation mit TNF- $\alpha$ wesentlich geringere IL-8-Sekretionslevel auf (Bai et al., 2004).

PAR-2 wird über den gesamten Zeitverlauf eher supprimiert. In einer Studie wurden HT29 bis zu 20 Tage gegenüber TNF exponiert. Dabei sank die Rate der Proliferationen ohne wesentliche morphologische Veränderung der Zellen. Diverse proinflammatorische Gene, u.a. IL-8 wurden deutlich induziert (Bruno, Kaetzel, 2005). Diesbezüglich konnte in einer weiteren Studie bei HT29-Zellen mit TNF- $\alpha$ gezeigt werden, dass antiproliferative und proapoptotische Effekte entscheidend vom Status der Zelldifferenzierung von HT29 abhängig sind und vor allem mit Natriumbutyrat behandelte, differenzierte HT29-Zellen oben genannte Effekte unter Behandlung mit TNF- $\alpha$ aufweisen (Kovarikova et al., 2004). Ein ähnlicher Effekt unter TNF konnte auch bei den im Vergleich zu HT29 ohnehin stärker differenzierten Caco2-Zellen nachgewiesen werden. Demnach zeigen Caco2-Zellen unter TNF eine erhöhte Apoptoserate und parazelluläre Permeabilität (Diebel et al., 2005)

Alle membranständigen Proteasen zeigen eine robuste Induktion ihrer Genexpression in beiden Zelllinien, wobei diese bei Caco2-Zellen noch ein wenig deutlicher ausfällt als bei HT29-Zellen. So sind Hepsin, MTSP-1 und TMPRSS-2 zu den frühen Zeitpunkten bei Caco2-Zellen auf das 4 bis 5-fache erhöht, bei HT29-Zellen immerhin noch um das 2- bis 4-fache. Damit führt TNF- $\alpha$ im Gegensatz zu IFN- $\gamma$, IL-1 $\beta$ und LPS zu einer deutlichen Stimulation der TTSP-Expression. In diesem Kontext sollte ein möglicher 
Zusammenhang der TTSP-Induktion mit der gesicherten TNF- $\alpha$ induzierten Apoptoserate bei HT29- und Caco2-Zellen Gegenstand weiterer Untersuchungen sein.

Kortikosteroide haben eine antiinflammatorische Wirkung. Sie werden zur Therapie verschiedener entzündlicher Erkrankungen, z.B. der chronisch entzündlichen Darmerkrankungen eingesetzt. Das potenteste der Kortikosteroide mit einer relativen Wirkstärke von 40 gegenüber Hydrocortison ist Dexamethason.

Dexamethason induziert in HT29-Zellen in den ersten 24 h eine Suppression der IL-8Genexpression, um danach auf ein gut 6-faches Maximum anzusteigen. PAR-2 zeigt einen sehr ähnlichen Kurvenverlauf mit einem Maximum nach 48 h (7,1-fach erhöht). Dagegen führt Dexamethason in Caco2-Zellen zu einer ausgeprägten IL-8-Induktion mit 300-facher Erhöhung nach 72 h. PAR-2 wird in Caco2-Zellen über den gesamten Zeitverlauf supprimiert. Die membranständigen Proteasen zeigen unterschiedliche Reaktionen durch die Stimulation mit Dexamethason. Hepsin erfährt eine ausgeprägte Erhöhung seiner Genexpression, in HT29-Zellen noch deutlicher mit einer 14-fachen Erhöhung nach $48 \mathrm{~h}$ im Vergleich zu einer knapp 3-fachen Erhöhung in Caco2-Zellen. MTSP-1 wird insgesamt in beiden Zelllinien supprimiert. In Caco2-Zellen induziert Dexamethason eine komplette Suppression von TMPRSS-4 über den gesamten Zeitverlauf. Damit beeinflußt Dexamethason die Genexpression von membranständigen Proteasen in unterschiedlicher Weise.

Zusammenfassend führt Dexamethason in Caco2-Zellen überraschender weise zu einer starken Induktion des proinflammatorischen Zytokins IL-8. Die membranständigen Proteasen werden durch Dexamethason differentiell reguliert.

Die Kombination von Dexamethason und dem eine Stunde später gegebenen $I L-1 \beta$ führt in HT29- und Caco2-Zellen nicht zu einem additiven Effekt der IL-8-Induktion, sondern Dexamethason führt in erster Linie zu einer Inhibition des weit stärker ausgeprägten Effekts von IL-1 $\beta$. Sowohl die frühe ( 2 h) als auch die späte (48 h) starke Induktion der IL-8-Genexpression wird durch die Vorbehandlung mit Dexamethason in beiden Zelllinien, wenngleich differentiell, unterdrückt. So wird bei Caco2-Zellen in der Kombination der beiden Substanzen die starke späte IL-8 Induktionen fast vollständig inhibiert. Dagegen zeigt sich in HT29-Zellen in der frühen Phase eine deutliche Inhibition der IL-8-Genexpression durch Dexamethason. 
Die PAR-2 Expression wird von IL-1 $\beta$ in HT29-Zellen supprimiert, in Caco2-Zellen jedoch zu einem frühen Zeitpunkt stimuliert (3-fache Erhöhung nach $2 \mathrm{~h}$ ). Dexamethason führt bei HT29-Zellen zu einer späten Induktion der PAR-2 Expression (6,7-fach nach 48 h), in Caco2-Zellen jedoch zu einer Suppression der Expression über den gesamten Beobachtungszeitraum. Die kombinierte Gabe von Dexamethason und IL-1 $\beta$ führt zu einer Unterdrückung der Dexamethason induzierten späten PAR-2 Induktion in HT29-Zellen und zu einer Suppression der IL-1 $\beta$ induzierten frühen PAR-2 Induktion. Somit ist auch bezüglich der PAR-2 Expression zu beobachten, dass sich das proinflammatorische Zytokin IL-1 $\beta$ und das entzündungshemmende Glukokortikoid Dexamethason gegenseitig antagonisieren.

Glukokortikoide können nach einem durch Buttgereit et al. erstmals postulierten modularen Funktionsprinzip auf unterschiedlicher molekularer Ebene eine Wirkung erzielen. Zum einen durch genomische Effekte (über die DNS des Zellkerns, transkriptions- und translationsabhängig), zum anderen über spezifisch nichtgenomische Effekte. Dieser Wirkungsmechanismus ist rezeptorspezifisch, aber transkriptions- und translationsunabhängig. Die Wirkung des nicht-genomischen Effekts tritt bereits nach Sekunden bis Minuten ein, die des genomischen Effekts dagegen mit einer zeitlichen Latenz von einigen Stunden. Des Weiteren gibt es Hinweise auf unspezifisch nichtgenomisch vermittelte Effekte, die nicht durch Transkriptionsinduktion oder repression spezifischer Gene erklärbar sind (Buttgereit et al., 1996). Als allgemein anerkannt gilt, dass der molekulare Wirkungsmechanismus der Glukokortikoide im Wesentlichen auf die Beeinflussung transkriptioneller Prozesse zurückzuführen ist und dadurch die meisten immunmodulatorischen und antientzündlichen Effekte bedingt. So wirkt nach der Aktivierung des Glucocorticoidrezeptors durch den Liganden der Rezeptor zum einen als Transkriptionsfaktor und kontrolliert die Transkription bestimmter Gene, zum anderen wirkt er als direkter Inhibitor proinflammatorischer Transkriptionsfaktoren wie NF- $\kappa \mathrm{B}$ oder AP-1.

Des Weiteren wird als nicht-transkriptioneller Wirkungsmechanismus der der Mitogenactivated-protein-Kinase-Phosphatase-1 (MKP-1) beschrieben. Diese aktiviert, ohne direkte Beeinflussung der Transkription spezifische intrazelluläre Signalwege. So konnte gezeigt werden, dass MKP-1 in humanen Endothelzellen durch Dexamethason in niedriger Konzentration (1-100nM) hochreguliert wird und direkt eine antientzündliche Wirkung ausübt (Fürst et al., 2007). 
Glukokortikoide, insbesondere Dexamethason finden im klinischen Alltag in Akutsituationen wie auch in der Behandlung chronischer Krankheiten ein weitreichendes Indikationsspektrum. Hierzu zählen zum Beispiel die Therapie von toxischem Lungenödem, Contusio spinalis, anaphylaktischem Schock, Hirnödem, Status asthmaticus, rheumatoider Arthritis, Arthrose, Neurodermitis, Lupus erythematodes und nicht zuletzt chronisch entzündliche Darmerkrankungen, etc.

$I L-1 \beta$ ist ein hochwirksames Zytokin, welches vorwiegend von Monozyten produziert und dessen Synthese über Toll-like Rezeptoren-Agonisten stimuliert wird. Das Interleukin fungiert als zentraler Botenstoff in der Antwort des Organismus auf eine Reihe von Fremdeinflüssen (wie zum Beispiel Lipopolysaccharide). Dabei triggert es über den aktivierten Interleukin-1-Rezeptor Typ 1 in Endothelzellen über NFкB die Transduktion von Cyclooxygenase-2 (COX-2) und führt darüber zu einer vermehrten

Bildung von Prostaglandin- $E_{2}$. Des Weiteren stimuliert IL-1 $\beta$ bei Entzündungsprozessen im Hypothalamus die Ausschüttung von Corticotropin Releasing Hormone $(\mathrm{CRH})$ und führt darüber $\mathrm{zu}$ einer Stimulation von adrenocorticotropem Hormon (ACTH). IL-1 $\beta$ induziert die Bildung von CD 14-Zellen, triggert die IL-6Freisetzung sowie die vermehrte Bildung von neutrophilen Granulozyten im Knochenmark (Dinarello, 5/2005, 12/2005).

Die TTSP zeigen sich unterschiedlich in der Induktion der Genexpression durch die Kombination des Glukokortikoids Dexamethason und dem eine Stunde später gegebenen Zytokin IL-1 $\beta$. So zeigt sich in HT29-Zellen ein relevanter Effekt sowohl bei IL-1 $\beta$ als auch bei Dexamethason nur für die Protease Hepsin. Dexamethason und IL-1 $\beta$ scheinen einen additiven Effekt zu haben. Es findet sich sowohl die nur unter IL$1 \beta$ beobachtete frühe Suppression als auch die Induktion, die sowohl nach Dexamethason als auch nach IL-1 $\beta$ beobachtet wird. TMPRSS-2, TMPRSS-4 und MTSP-1 zeigen keine wesentliche Regulation der Genexpression in dieser kombinierten Versuchsanordnung.

In Caco2-Zellen wird die frühe Induktion von Hepsin durch IL-1 $\beta$ durch Dexamethason inhibiert, es zeigt sich sogar eine Suppression unter dem Glukokortikoid. Eine Induktion ab $24 \mathrm{~h}$ tritt mit beiden Einzelsubstanzen auf, in Kombination wirken sie jedoch nicht additiv. Eine frühe Induktion von MTSP-1 nach $4 \mathrm{~h}$ durch IL-1 $\beta$ wird durch Dexamethason verzögert und tritt erst nach $72 \mathrm{~h}$ auf. TMPRSS-2 wird durch IL-1 $\beta$ insbesondere nach $24 \mathrm{~h}$ inhibiert, durch Dexamethason nach diesem Zeitpunkt jedoch induziert, die Kombination der beiden Substanzen führt zu der Reduktion der durch 
Dexamethason ausgelösten Induktion auf das 1,5-fache. TMPRSS-4 wird weder durch IL-1 $\beta$ noch durch Dexamethason wesentlich reguliert, in Folge dessen ist auch in der Kombination keine wesentliche Regulation zu erkennen.

Am augenfälligsten imponiert die ausgeprägte Induktion der Protease Hepsin in beiden Zelllinien. Hepsin wird nach bisheriger Studienlage nicht in IEC exprimiert. Somit beschreiben wir erstmals deren Expression in HT29- und Caco2-Zellen. Dabei wird Hepsin in HT29-Zellen in der Versuchskombination additiv induziert, während in Caco2-Zellen Hepsin eher supprimiert wird. Daraus resultierend lässt sich für die Regulation von Hepsin im Vergleich zu TMPRSS-2, TMPRSS-4 und MTSP-1 in IEC durch pro- und antiinflammatorische Stimuli ein differentieller Mechanismus vermuten. Dies sollte Gegenstand weiterer Untersuchungen sein.

Bezüglich der entzündlichen Effekte ist zusammenfassend festzustellen, dass Dexamethason eine durch IL-1 $\beta$ in HT29- und Caco2-Zellen induzierte proinflammatorische Reaktion, also IL-8-Induktion, deutlich inhibieren kann. Dies bestätigt eine Studie mit IEC nur teilweise. So konnte eine Inhibition von IL-1 $\beta$ durch Dexamethason in IEC-6-Zellen, jedoch nicht in Caco2-Zellen nachgewiesen werden (Raddatz et al., 2001). Des Weiteren wurde eine IL-8-Inhibition in HT29-Zellen durch Ciclosporin A, nicht jedoch durch Dexamethason durch Saitoh et al. 1997 beschrieben. Unter Berücksichtigung der oben genannten molekularen Grundlagen bestätigt sich hiermit die klinische Evidenz und Relevanz einer Glucocorticoidbehandlung als wichtige immunmodulatorische Therapieoption. Die kombinierte Gabe der Einzelsubstanzen Dexamethason und IL-1 $\beta$ bewirkt in IEC eine Antagonisierung bezüglich der PAR-2 Induktion. Damit könnte PAR-2 in Zukunft im klinischen Alltag als mögliches molekulares Target einer antiinflammatorischen Therapie bei (chronisch) entzündlichen Darmerkrankungen in Frage kommen.

Diese Ergebnisse zeigen, dass membranständige Serin Proteasen auf HT29- und Caco2Zellen exprimiert werden und einer Regulation durch pro- und antiinflammatorische Stimuli unterliegen. Daraus resultierend könnten sie einen wichtigen Beitrag zur Homöostase im Verdauungstrakt leisten. 


\subsection{Expression von TTSP nach bakterieller Infektion intestinaler Epithelzellen (3.3)}

Eine enorme Anzahl von Bakterien bevölkert den humanen Gastrointestinaltrakt und bildet unter physiologischen Bedingungen ein perfekt ausbalanciertes Miniaturökosystem. Es erscheint umso erstaunlicher, dass das bei einer Dichte von ca. $10^{12}$ Organismen pro Gramm Faeces auch wirklich funktioniert. Denn die kommensale Mikroflora besteht aus etwa 400 Spezies, die in diffiziler Harmonie im Intestinum miteinander existieren und interagieren. Diese Interaktionen finden sich sowohl untereinander, also im Lumen des Verdauungstraktes, wie auch mit den umgebenden Strukturen, den intestinalen Epithelzellen. Diese bilden eine erste morphologische Barriere gegenüber dem Wirtsorganismus, zunächst für alle mikrobiellen Organismen, insbesondere aber für die pathogenen Keime. Um diese pathogene bakterielle Bedrohung identifizieren und schnell darauf reagieren zu können, besitzen intestinale Epithelzellen (IEC) eine Vielfalt von Mechanismen, die eine erste und entscheidende Rolle in der mukosalen Immunantwort spielen. Um dies eingehender zu beleuchten, wurden Monolayers von HT29- und Caco2-Zellen mit verschiedenen Bakterienstämmen über einen Zeitraum von $24 \mathrm{~h}$ infiziert und die relative Genexpression von Hepsin, MTSP-1, TMPRSS-2, TMPRSS-4 sowie PAR-2 und IL-8 gemessen.

Enterococcus faecium (Ecfc) ist ein nicht invasives, gramnegatives Bakterium, welches zur Normalflora des menschlichen Verdauungstraktes gehört. Ecfc findet unter der Vielzahl von Lactobacillus-Stämmen Verwendung in Probiotika, welche zur Stimulation der intestinalen Mikroflora dienen sollen (Rolfe, 2000; Marteau et al., 2001; Canani et al., 2007). Im Gegensatz dazu stellen Vancomycin-resistente Stämme von Enterococcus faecium in zunehmendem Maße bei nosokomialen Infektionen von immunsupprimierten Patienten ein bedeutendes Problem der antibiotischen Therapiemöglichkeiten dar (Werner et al., 2008).

In unseren Experimenten induziert Ecfc die geringste Erhöhung der Genexpression von IL-8 unter allen untersuchten Bakterien. Dabei reagieren beide Zelllinien ähnlich (HT29 deutlicher) mit einer im Mittel 8-fachen IL-8-Erhöhung nach 2 h. Dies korreliert mit Veröffentlichungen, die unter der Stimulation mit apathogenen, nichtinvasiven Bakterien keine bis minimale Induktion der IL-8 Genexpression beschreiben (Jung et 
al., 2001; Eckmann, Kagnoff, Fierer, 1993). PAR-2 wird durch die Stimulation mit Ecfc in beiden Zelllinien kaum reguliert (Caco2: 2-fach nach 12 h). IL-8 und PAR-2 werden somit durch Ecfc in HT29- und Caco2-Zellen nur sehr gering induziert. Dies könnte bedeuten, dass PAR-2 unter physiologischen Bedingungen, also dem Kontakt des in normaler Darmflora vorhandenen kommensalen Keims Ecfc keiner wesentlichen Induktion seiner Genexpression unterliegt.

Dagegen zeigen die TTSP in beiden Zelllinien ein noch auffälligeres Ergebnis gegenüber einer Exposition mit Ecfc. TMPRSS-2, TMPRSS-4, Hepsin und MTSP-1 reagieren mit einer starken Suppression der Genexpression über den gesamten Zeitrahmen und weisen starke Ähnlichkeiten in ihrem Kurvenverlauf auf. So zeigen die TTSP in HT29 nach $12 \mathrm{~h}$ ihr Minimum mit einer im Mittel 0,2-fachen Suppression, in Caco2 schon nach $4 \mathrm{~h}$ (ebenfalls auf das 0,2-fache erniedrigt). In der aktuellen Literatur finden sich weder Hinweise auf die Expression noch einer möglichen Funktion der TTSP in IEC unter einer Behandlung mit dem kommensalen Bakterium. Wir beschreiben in dieser Arbeit somit erstmals die ausgeprägte und einheitliche Suppression der Genexpression der Proteasen MTSP-1, Hepsin, TMPRSS-2 und TMPRSS-4 in HT29- und Caco2-Zellen unter Exposition von Enterococcus faecium. Diese Ergebnisse lassen vermuten, dass TTSP unter physiologischen Bedingungen bei Kontakt mit der Normalflora des Verdauungstrakts kaum aktiv sind.

Escherichia coli (Esco, E. coli) kommt als kommensales Bakterium in großer Anzahl im menschlichen Intestinuum vor. Es ist ein gramnegatives, fakultativ anaerobes, begeißeltes Bakterium ohne wesentliche Pathogenität. Diese zeigt sich vor allem außerhalb des Verdauungstrakts, u.a. als häufigster Erreger von Harnwegsinfekten. Der in diesem Experiment verwendete E. coli (Referenzstamm ATCC 25922) führt zu einer deutlichen IL-8-Induktion mit einer fast 100-fachen Erhöhung nach 2 h in HT29-Zellen und einer 275-fachen Erhöhung nach $2 \mathrm{~h}$ in Caco2-Zellen. Eine deutliche Induktion zeigt sich ebenfalls für PAR-2 mit einer 10,5-fachen Erhöhung nach $4 \mathrm{~h}$ in Caco2- und einer 5-fachen Erhöhung nach $24 \mathrm{~h}$ in HT29-Zellen. Diese Ergebnisse werden durch bisherigen Veröffentlichungen bestätigt, in denen ebenfalls eine IL-8-Induktion in IEC durch apathogene E. coli-Stämme beschrieben wird (Bambou et al., 2004). Dagegen existieren keine Daten zur Induktion von PAR-2 in IEC durch E. coli. Wir beschreiben hiermit die deutliche Induktion der Genexpression von IL-8 und PAR-2 vor allem in Caco2-Zellen, weniger deutlich auch in HT29-Zellen. Das könnte bedeuten, dass IEC 
auch in vivo das kommensale Bakterium E. coli wahrnehmen und mit einer kontinuierlichen Immunantwort zur Aufrechterhaltung der mucosalen Integrität beitragen.

Die untersuchten TTSP reagieren auf die Exposition gegenüber E. coli vor allem in HT29-Zellen und weniger in Caco2-Zellen mit einem zweigipfligen Kurvenverlauf. Quantitativ am stärksten wird MTSP-1 nach $12 \mathrm{~h}$ und Hepsin nach $2 \mathrm{~h}$ in HT29-Zellen mit einer 5,8-fachen und 4,8-fachen Erhöhung induziert. In Caco2-Zellen zeigt sich TMPRSS-2 mit einer knapp 4-fachen Induktion am stärksten erhöht. Insgesamt kann gesagt werden, dass der apathogene E. coli in IEC eine deutliche Induktion der TTSPExpression hervorruft. Diese Ergebnisse sind unseres Wissens bislang noch nicht publiziert. Wir beschreiben hiermit erstmals die deutliche Induktion von MTSP-1, Hepsin, TMPRSS-2 und TMPRSS-4 in HT29- und Caco2-Zellen durch das kommensale Bakterium Escherichia coli. TTSP zeigen sich durch die physiologische Exposition gegenüber E. coli aktiviert und induziert. Es lässt sich vermuten, dass sie direkt an einer angeborenen Immunmodulation zur Aufrechterhaltung der intestinalen Homöostase auf mucosaler Ebene beteiligt sind.

Als äußerst wichtig erscheint dabei die unterschiedliche Reaktion der TTSP auf gramnegative und grampositive bakterielle Stimuli. Wie bereits oben beschrieben, zeigen sich TTSP durch Enterococcus faecium als grampositives, kommensales Bakterium deutlich supprimiert, dagegen unter dem gramnegativen E. coli mittelstark induziert. Damit werden TTSP durch gramnegative und grampositive apathogene Bakterien unterschiedlich induziert. Dabei könnten spezifische, gramnegative bakterieneigene Bestandteile wie zum Beispiel Flagellin oder LPS eine Rolle spielen. Dieser Fragestellung sind wir im letzten Experiment nachgegangen (siehe 4.4).

Listeria monocytogenes (Limo) stellt ein invasives, grampositives Bakterium dar. Listerien müssen als opportunistisch pathogene Erreger eingestuft werden, die sich fakultativ intrazellulär vermehren. Limo führt zu einer 130-fachen Induktion von IL-8 in HT29 und einer 60-fachen Induktion von IL-8 in Caco2 nach 2 h. Diese durch Limo deutliche IL-8 Induktion in HT29- und Caco2-Zellen wurde bereits in anderen Publikationen beschrieben (Jung et al., 1995; Kampik et al., 2000). Darüber hinaus wurde gezeigt, dass Limo in IEC über eine Nod1-abhängige Aktivierung von p38 MAPK und NF-кB zu einer Induktion von IL-8 führt (Opitz et al., 2006). Dies zeigt nur eine der vielfältigen Möglichkeiten der mucosalen Immunantwort. So beschreibt eine 
weitere Studie eine durch das von Listeria monocytogenes produzierte Exotoxin Listeriolysin O (LLO) in HT29-MTX-Zellen ausgelöste Induktion von MUC-Genen mit gesteigerter Mucinexozytose, wodurch eine Invasion der Wirtszelle durch Limo inhibiert wird (Liévin-Le Moal et al., 2005). PAR-2 wird durch das invasive Bakterium in beiden Zelllinien erhöht exprimiert, in Caco2-Zellen deutlicher mit einer 14-fachen Erhöhung der Genexpression nach $4 \mathrm{~h}$. Diesbezüglich existieren keine veröffentlichten Daten. Wir beschreiben hiermit die starke Induktion von PAR-2 in Caco2-Zellen (weniger deutlich in HT29-Zellen) durch das grampositive invasive Bakterium Listeria monocytogenes.

TTSP werden durch Listeria monocytogenes in HT29- und Caco2-Zellen differentiell induziert. Es finden sich $\mathrm{zu}$ diesem Experiment keine vergleichbaren Veröffentlichungen. Wir beschreiben hiermit die Induktion von MTSP-1, Hepsin, TMPRSS-2 und TMPRSS-4 in HT29- und Caco2-Zellen. Dabei zeigen TTSP sehr ähnliche Reaktionen in den beiden Zelllinien. MTSP-1 weist einen dominanten Peak bei $4 \mathrm{~h}$ auf (in HT29 stärker ausgeprägt mit einer 2,6-fachen Erhöhung). Eine deutliche Suppression durch Limo erfährt TMPRSS-2 in beiden Zelllinien. Dagegen zeigen TMPRSS-4 und Hepsin eine um den Ausgangspunkt undulierende Regulation der Genexpression.

Zusammenfassend bleibt festzuhalten, dass TTSP in IEC nach Exposition gegenüber Listeria monocytogenes differentiell induziert werden. Am auffälligsten erscheint dabei die Suppression von TMPRSS-2 in beiden Zelllinien. Die untersuchten membranständigen Proteasen reagieren somit sehr unterschiedlich auf die Infektion durch ein invasives grampositives Bakterium.

Salmonella typhi (Saty) ist ein invasives, gramnegatives Bakterium mit hoher Pathogenität. Schon kleinste Mengen oral aufgenommener Keime (100-1000), zum Beispiel durch kontaminierte Nahrungsmittel oder Trinkwasser, genügen zur Infektion. Saty induziert in Caco2-Zellen mit einer gut 800-fachen Erhöhung von IL-8 nach 12 h die stärkste quantitative Genexpression im gesamten Bakterienexperiment. In HT29 zeigt sich eine schwächere Induktion mit einer 93-fachen Erhöhung nach 2 h. Bisherige Veröffentlichungen bestätigen diese deutlichen IL-8 Induktionen. So wird eine IL-8 Induktion durch das weniger pathogene Bakterium Salmonella enterica Serovar Typhimurium in T84-Zellen beschrieben (Huang et al., 2004). Dabei stellt u.a. Flagellin einen bedeutenden Reiz für eine erste zelluläre immunmodulatorische Antwort durch 
eine IL-8-Induktion dar (Winter et al., 2008). Anzumerken ist der vorzeitige experimentelle Endpunkt nach 12 h in Caco2, da sich die Zellen zum 24 h-Zeitpunkt vollständig vom Untergrund abgelöst hatten. Als Erklärung mag diesbezüglich der in einer Übersichtsarbeit beschriebene Pathomechanismus bei Infektion mit Salmonella typhi dienen. Saty induziert dabei über spezifische Virulenzmechanismen Apoptose und Nekrose in den infizierten Wirtszellen (Guiney, 2005). In unserem Experiment ist davon vor allem die gut differenzierte Caco2-Zelllinie betroffen.

PAR-2 wird in Caco2-Zellen mit einer 35-fachen Erhöhung nach $12 \mathrm{~h}$ stärker als in HT29-Zellen mit einer 4,3-fachen Erhöhung nach $2 \mathrm{~h}$ induziert. Diese ausgeprägte Induktion von PAR-2 durch das invasive Bakterium wird hiermit erstmals beschrieben. Es finden sich keine Veröffentlichungen zu diesem Thema. Dagegen bestätigt sich die IL-8-Induktion in IEC durch Saty in den vorhandenen Publikationen (Huang et al., 2004). Die membranständigen Serin Proteasen zeigen sich uneinheitlich durch Saty induziert. Lediglich MTSP-1 wird in beiden Zelllinien erhöht exprimiert. So zeigt MTSP-1 nach $2 \mathrm{~h}$ in HT29-Zellen ein frühes 5-fach erhöhtes Maximum, in Caco2Zellen ein späteres 2,1-fach erhöhtes Maximum nach 8 h. TMPRSS-2 und -4 zeigen ähnliche Kurvenverläufe in HT29-Zellen und weisen vor allem in dieser Zelllinie eine Suppression ihrer Genexpression auf. Dagegen zeigen sich die beiden Proteasen in Caco2-Zellen gegenläufig reguliert. Die aktuelle Literaturrecherche ergibt keine Veröffentlichungen zur Induktion von TTSP nach Infektion mit Saty in IEC.

Zusammenfassend kann gesagt werden, dass Saty als invasives gramnegatives Bakterium hoher Pathogenität die ingesamt stärkste IL-8- und PAR-2- Erhöhung in Caco2-Zellen in diesem Experiment induziert. Die TTSP zeigen in IEC durch die Infektion mit Saty eine uneinheitliche Regulation. Am auffälligsten erscheint dabei der ähnliche Kurvenverlauf sowie die deutliche Suppression von TMPRSS-2 und TMPRSS4 in HT29-Zellen.

Yersinia enterocolitica (Yeen) ist ein invasives, gramnegatives Bakterium. Klinisch imponiert eine Infektion mit Yeen vor allem durch eine akute Enteritis mit dünnflüssigen Stühlen und kolikartigen abdominellen Schmerzen. Die Infektion ist in der Regel bei immunkompetenten Personen nach wenigen Tagen selbstlimitierend. In diesem Experiment verursacht Yeen sowohl in HT29- als auch in Caco2-Zellen eine robuste Induktion der IL-8 Genexpression. Diese zeigt sich in HT29 deutlicher mit einer fast 20-fachen Erhöhung nach $12 \mathrm{~h}$. In bisherigen Veröffentlichungen findet sich dieser 
Sachverhalt einer Induktion von IL-8 in IEC nach Infektion mit Yeen wieder (Schulte et al., 2000; Kampik et al., 2000). Des Weiteren konnte gezeigt werden, dass es in IEC unter Vorbehandlung mit dem kommensalen Keim Lactobacillus fermentum und nachfolgender Infektion mit Yeen zu einer Inhibition der IL-8-Induktion kommt (Frick et al., 2007). PAR-2 wird in HT29-Zellen gut 2-fach nach 24 h, in Caco2-Zellen knapp 2-fach nach $4 \mathrm{~h}$ induziert. Veröffentlichungen zu einer PAR-2 Induktion nach Infektion von IEC mit Yeen sind nicht vorhanden. Wir beschreiben hiermit die schwache PAR-2 Induktion in HT29- und Caco2-Zellen durch das gramnegative, invasive Bakterium Yersinia enterocolitica.

Die TTSP reagieren deutlich auf die Stimulation mit Yeen. Quantitativ am ausgeprägtesten zeigt sich dies in HT29-Zellen mit einer 10,4-fachen Induktion der Genexpression für TMPRSS-2 sowie für MTSP-1 mit einer 8-fachen Erhöhung nach 4h. Weniger deutlich verläuft die Induktion der TTSP in Caco2-Zellen. MTSP-1 wird 2,7fach erhöht nach $12 \mathrm{~h}$ exprimiert, die anderen Proteasen schwanken in ihrer Genexpression um den Ausgangswert. Die Reaktion der TTSP in HT29- und Caco2Zellen zeigt sich nach Infektion mit Yeen somit vollkommen zellspezifisch. Die aktuelle Literatur verzeichnet keine Veröffentlichungen. Wir beschreiben hiermit erstmals die starke Induktion von TMPRSS-2 und MTSP-1 in HT29-Zellen durch die Infektion mit Yeen.

Vergleicht man die Reaktion mit dem ebenfalls invasiven gramnegativen Bakterium Saty, so zeigen sich einige Auffälligkeiten. Sowohl Yeen als auch etwas schwächer Saty verursachen in HT29-Zellen die höchste quantitative Geninduktion einzelner TTSP. Dagegen weisen die gut differenzierten Caco2-Zellen eine geringere TTSP-Induktion auf. Saty induziert im Vergleich mit Yeen stärker IL-8 und PAR-2 in beiden Zelllinien. Während Yeen in HT29-Zellen sehr deutlich TMPRSS-2 und TMPRSS-4 induziert, werden diese beiden Proteasen durch Saty über den gesamten Zeitverlauf supprimiert. Es ist $\mathrm{zu}$ vermuten, dass neben Gramzugehörigkeit und invasivem/ nichtinvasivem Verhalten weitere bakterielle Faktoren existieren, welche die Induktion der Genexpression der TTSP in IEC bedingen. 


\subsection{Expression von TTSP nach bakterieller Infektion intestinaler Epithelzellen (IEC) mit verschiedenen E. coli - Stämmen (3.4)}

Unter Berücksichtigung der ersten Bakterienexperimente sollte in diesem abschließenden Versuchsaufbau untersucht werden wie TTSP und PAR-2 sowie IL-8 als proinflammatorischer Entzündungsmarker in IEC auf verschiedenen E. coli- Stämme und deren unterschiedliche Präparationen reagieren. Dazu wurden HT29- und Caco2Zellen gegenüber E. coli ATCC 25922, EHEC 0157 sowie E. coli Nissle 1917 als vitale Bakterien, hitzeinaktivierte Bakterien sowie bakteriellen Überstand exponiert und über einen Zeitraum von $24 \mathrm{~h}$ monitoriert.

\subsubsection{HT29- und Caco2-Zellen mit E. coli ATCC 25922- Präparationen}

Escherichia coli (E. coli, Esco) als ATCC 25922-Stamm wurde erneut als nichtinvasives, gramnegatives, apathogenes Bakterium verwendet (siehe auch analog zum Versuch 3.3). Der Stamm ATCC 25922 wird zu wissenschaftlichen Zwecken in vielen Experimenten als einer der Referenzstämme von E. coli verwendet. In diesem Versuch wurden IEC gegenüber den jeweiligen Präparation in Form von vitalen Bakterien, einer hitzeinaktivierten Form sowie filtriertem Überstand exponiert.

Vital: Analog des Experiments unter 3.3 führt der vitale E. coli ATCC 25922 in IEC zu einer deutlichen Induktion von IL-8 mit einer 109-fachen (vs. 97-fach unter 3.3) nach 2 $\mathrm{h}$ in HT29-Zellen und einer mehr als 250-fachen Erhöhung nach $2 \mathrm{~h}$ in Caco2-Zellen in beiden Experimenten. Diese IL-8 Induktion durch E. coli korreliert mit bisherigen Veröffentlichungen (Bambou et al., 2004). Eine deutliche Induktion zeigt sich ebenfalls für PAR-2 mit einer 6,5-fachen (vs. 10,5-fach unter 3.3) Erhöhung nach $4 \mathrm{~h}$ in Caco2 und einer jeweils mehr als 10-fachen Erhöhung nach 24 h in HT29-Zellen. Intestinale Epithelzellen nehmen somit kommensale bakterielle Stimuli wahr und reagieren mit einer frühen Immunmodulation via IL-8-Induktion. Des Weiteren vermag die vitale E. coli- Präparation in HT29- und Caco2-Zellen eine deutliche Erhöhung der PAR-2 Genexpression zu induzieren. Diesbezüglich finden sich keine Veröffentlichungen. PAR-2 reagiert somit auf vitale nichtinvasive, gramnegative Bakterien. Seine genaue physiologische Funktion in IEC bleibt jedoch weiterhin unklar. 
TTSP reagieren auf die Exposition gegenüber der Präparation des vitalen E. coli vor allem in HT29-Zellen und weniger in Caco2-Zellen mit einem zweigipfligen Kurvenverlauf. So wird MTSP-1 nach 12 h und Hepsin nach 2 h in HT29 mit einer 6,1fachen und 5,8-fachen Erhöhung induziert. TMPRSS-2 und TMPRSS-4 weisen dagegen in Caco2 einen frühen ersten Peak nach $2 \mathrm{~h}$ mit einer 4,8-fachen und 3,7-fachen Erhöhung auf. Dieser frühe erste Peak der beiden Proteasen findet sich auch in HT29Zellen, jedoch weniger deutlich mit einer 3,1-fachen und 3,5-fachen Induktion nach $2 \mathrm{~h}$. Damit wird quantitativ am stärksten TMPRSS-2 mit einer 4,8-fachen Erhöhung nach 2 $\mathrm{h}$ in Caco2-Zellen und MTSP-1 in HT29-Zellen mit einer 6,1-fachen Erhöhung nach 12 $\mathrm{h}$ induziert. Somit führt der apathogene E. coli in IEC zu einer deutlichen Induktion der TTSP-Genregulation. Wir beschreiben hiermit die starke Genexpression von MTSP-1, Hepsin, TMPRSS-2 und TMPRSS-4 in HT29- und Caco2-Zellen durch das vitale kommensale Bakterium Escherichia coli.

Hitzeinaktivierung: In dieser Präparation wurde E. coli ATCC 25922 zunächst in Flüssigmedium kultiviert, dann für 15 min bei $80^{\circ} \mathrm{C}$ hitzeinaktiviert und nach Abkühlen auf Raumtemperatur auf Monolayers von IEC aufgebracht. Dabei zeigt die hitzeinaktivierte Fraktion eine massive IL-8 Induktion vor allem in Caco2-Zellen mit einer 1900-fachen Erhöhung sowie einer 540-fachen Erhöhung in HT29-Zellen nach jeweils 2 h. Damit stellt die Präparation des hitzeinaktivierten E. coli den stärksten Stimulus der IL-8 Geninduktion in Caco2-Zellen im gesamten Experiment dar. PAR-2 wird weit weniger ausgeprägt mit einer 3,5-fachen Erhöhung in HT29 nach 8 h sowie einer 7,9-fachen Erhöhung in Caco2 nach $2 \mathrm{~h}$ induziert. Die Tatsache, dass vitaler E. coli in IEC eine IL-8 Induktion hervorrufen kann, ist bekannt und publiziert (Bambou et al., 2004). Über eine so deutliche Induktion der IL-8 Genexpression durch Hitzeinaktivierung und Denaturierung von E. coli wird dagegen keine grundlegende Aussage in den bisherigen Veröffentlichungen gemacht.

Die TTSP erfahren ebenfalls eine sehr ausgeprägte Induktion der Genexpression durch die hitzeinaktivierte Präparation. Am auffälligsten imponiert die starke Induktion von TMPRSS-2 in beiden Zelllinien. Das quantitative Maximum zeigt sich mit einer 40fachen Erhöhung in HT29-Zellen nach 2 h. In Caco2 zeigt sich TMPRSS-2 nach 2 h mit 11-facher und nach $24 \mathrm{~h}$ mit 11,5-facher Induktion stark erhöht exprimiert. Auch die restlichen Proteasen TMPRSS-4, MTSP-1 und Hepsin werden ebenfalls erhöht exprimiert, jedoch weniger stark ausgeprägt. Dabei verlaufen die Kurven der TTSP in beiden Zelllinien sehr ähnlich. 
Überstand: Der bakterielle Überstand, also die von E. coli sezernierten Faktoren, fungiert im Vergleich zu vitalem Bakterium und hitzeinaktivierter Präparation als schwacher Stimulus. So induziert die Fraktion des Überstands eine 24-fache IL-8 Induktion in HT29 nach $4 \mathrm{~h}$ und eine 4-fache IL-8 Induktion nach $4 \mathrm{~h}$ in Caco2-Zellen. PAR-2 wird 5,4-fach nach $2 \mathrm{~h}$ in HT29 und 3,1-fach nach $4 \mathrm{~h}$ in Caco2-Zellen induziert. Auch die TTSP werden durch den bakteriellen Überstand weit weniger stark reguliert, und dies mit unterschiedlichen Reaktionen in den beiden Zelllinien. Die Proteasen reagieren in Caco2 auf die Stimulation kaum, dagegen in HT29 etwas deutlicher. MTSP-1, TMPRSS-4 und Hepsin werden in HT29 biphasisch und in Caco2 triphasisch induziert. Insgesamt zeigt Hepsin die stärkste quantitative Induktion in HT29-Zellen mit einer 4,8-fachen Erhöhung nach 24 h. Dagegen zeigt TMPRSS-2 gleichsinnig in beiden Zelllinien eher eine Suppression bzw. keine wesentliche Regulation der Genexpression.

\subsubsection{Zusammenfassung und Diskussion E. coli ATCC 25922}

Die TTSP werden durch die verschiedenen Präparationen differentiell reguliert. TMPRSS-2 zeigt die augenfälligste Reaktion mit der quantitativ stärksten Stimulation im gesamten Versuch in HT29-Zellen durch die hitzeinaktivierte Präparation. Dieser starke Stimulus macht die gesamte durch die intakten Bakterien beobachte Induktion aus, während die Faktoren im Überstand zu diesem Peak nichts beitragen.

Die Hitzeinaktivierung führt einerseits zur Zerstörungen/ Denaturierung von Proteinen sowie andererseits zu einem Aufbrechen der Bakterien mit Freisetzung neuer Antigene. Diese vermehrte Exposition der HT29- und Caco2-Zellen gegenüber nicht-Protein hitzeresistenten Faktoren, also vermutlich Kohlenhydratstrukturen, führt zu einer starken Induktion der TTSP und IL-8.

Auch in Caco2 zeigt sich eine ähnliche Reaktion für die Induktion von TMPRSS-2. Dagegen setzt sich die Induktion von Hepsin mit frühen und späten Peaks in HT29 und Caco2 aus vitalem Bakterium, hitzeinaktivierter Präparation und Überstand zusammen. MTSP-1 und TMPRSS-4 werden in HT29-Zellen durch den vitalen E. coli biphasisch induziert, wobei die hitzeinaktivierte Fraktion wenig beiträgt und der Überstand den zweiten Peak zeitverzögert nachzeichnet.

TTSP reagieren auf die unterschiedlichen Präparationen des E. coli ATCC 25922 zum Teil deutlich. Diesbezüglich finden sich in der vorhandenen Literatur bislang keine Angaben zu einer Regulation von TTSP in IEC nach bakterieller Stimulation. 
Für die im Experiment am deutlichsten induzierte Protease TMPRSS-2 bleibt festzuhalten, dass sie gut im Epithel des Gastrointestinal-, Respirations- und Urogenitaltrakts exprimiert wird (Afar et al., 2001). Dabei ist die TMPRSS-2 Expression stark durch Androgene induzierbar und zeigt sich vor allem in Prostatakarzinomen stark erhöht exprimiert (Vaarala et al., 2001). Bedeutend sind die aktuellen Erkenntnisse einer TMPRSS-2:ETS-Genfusion beim Prostatakarzinom als diagnostisches und therapeutisches Target (Tomlins et al., 2009). In unserem Experiment wird TMPRSS-2 am stärksten durch die hitzeinaktivierte Präparation induziert, gefolgt von vitalem E. coli. Der Überstand führt in beiden Zelllinien für TMPRSS-2 kaum zu einer Regulation. Dies veranschaulicht umso deutlicher die differentielle Reaktion der Proteasen, insbesondere hier TMPRSS-2 auf die verschiedenen E. coli- Präparationen.

Es bleibt festzuhalten, dass die Hitzeinaktivierung von E. coli ATCC 25922 dessen Proteinantigene der Erregeroberfläche zerstört, während Kohlenhydratstrukturen, hier vermutlich LPS, immunologisch intakt bleiben. Damit imponiert LPS vor allem für TMPRSS-2 als ein starkes Stimulans und sollte Gegenstand weiterer Untersuchungen im Hinblick auf die physiologische Funktion der TTSP im GI-Trakt sein.

\subsubsection{HT29- und Caco2-Zellen mit EHEC - Präparationen}

Escherichia coli als enterohämorrhagischer Subtyp (EHEC) ist ein pathogener, verotoxinproduzierender E. coli. Dieses Verotoxin besitzt Ähnlichkeiten (shiga-toxinlike) mit dem, welches Shigella dysenteriae produziert. Eine sehr geringe Dosis von ca. 100 Bakterien ist oftmals ausreichend für eine Infektion, welche in ungünstigen Fällen bei vor allem immunsupprimierten Menschen eine hämorrhagische Kolitis sowie ein hämolytisch-urämisches-Syndrom (HUS) verursachen kann.

Vital: Der native EHEC induziert in beiden Zelllinien eine mittelstarke IL-8 Erhöhung. So zeigt sich in HT29-Zellen eine 140-fache Erhöhung und in Caco2-Zellen eine 120fache Erhöhung nach 24 h. PAR-2 wird in HT29 nach 8 h 6,9-fach und in Caco2 weniger deutlich 2,8-fach erhöht expremiert.

Unter den Proteasen zeigt Hepsin durch den nativen EHEC die augenfälligste Reaktion und zugleich die quantitativ stärkste Erhöhung der Genexpression. So wird Hepsin 16- 
fach in HT29-Zellen nach $2 \mathrm{~h}$ induziert und in Caco2-Zellen dagegen nur 3,6-fach nach $24 \mathrm{~h}$ und damit deutlich schwächer.

Hitzeinaktivierung: Der hitzeinaktivierte EHEC induziert in beiden Zelllinien eine annähernd identische, starke IL-8 Genexpression mit einer rund 800-fachen Erhöhung nach 2 h. PAR-2 wird in HT29 8,5-fach nach $4 \mathrm{~h}$ und in Caco2 5-fach nach $4 \mathrm{~h}$ induziert.

Die TTSP werden durch die hitzeinaktivierte Präparation von EHEC deutlich induziert. In beiden Zelllinien zeigen die TTSP, bis auf Hepsin in HT29, einen frühen ersten Peak nach $2 \mathrm{~h}$ und bis auf MTSP-1 und TMPRSS-2 in Caco2 auch einen zweiten späten Peak nach $24 \mathrm{~h}$. Dabei markiert das quantitative Maximum der Genexpression jeweils TMPRSS-2 in HT29- und Caco2-Zellen mit einer 8,9-fachen und 5,3-fachen Induktion nach 2 h. Einen auffälligen Kurvenverlauf zeigt MTSP-1 in Caco2 sowie Hepsin in HT29. So wird MTSP-1 nach 2 h mit einer 4,3-fachen Erhöhung gut induziert. Im weiteren Zeitverlauf imponiert dagegen eine deutliche Suppression. Hepsin wird in HT29-Zellen, entgegen der robusten frühen Peaks der anderen Proteasen, nach $2 \mathrm{~h}$ nicht reguliert.

Überstand: Der Überstand von EHEC, also die sezernierten Faktoren der Bakterien, induzieren in beiden Zelllinien eine eher geringe Erhöhung von IL-8. Das proinflammatorische Interleukin wird in HT29-Zellen nach $2 \mathrm{~h}$ 52-fach erhöht exprimiert und in Caco2-Zellen knapp 4-fach nach 2 h. PAR-2 wird ebenfalls in HT29und Caco2-Zellen nach jeweils $2 \mathrm{~h}$ mit einer 4,5-fachen und 3,2-fachen Induktion leicht erhöht exprimiert.

Die TTSP weisen einen eher differentielles Induktionsmuster durch den Überstand von EHEC auf. Dabei zeigt Hepsin in beiden Zelllinien das quantitative Maximum der Genexpression: in HT29-Zellen mit einer starken 20-fachen Induktion als früher Peak nach $2 \mathrm{~h}$ sowie in Caco2-Zellen mit einem späten Peak nach $24 \mathrm{~h}$ und einer weniger deutlichen Induktion mit 4,2-facher Erhöhung. Des Weiteren wird TMPRSS-2 in HT29 mit zwei Peaks nach 4 und 24 h und dabei 6,2-fachen sowie 6,6-fachen Erhöhung ebenfalls deutlich induziert.

\subsubsection{Zusammenfassung und Diskussion EHEC}

Die TTSP reagieren auf die Exposition gegenüber den verschiedenen Präparationen des EHEC unterschiedlich. Am stärksten imponiert in HT29-Zellen die deutliche frühe 
Induktion von Hepsin durch vitalen EHEC. Dies wird durch die Präparation des Überstands gut nachgezeichnet, der hitzeinaktivierte EHEC trägt nichts bei. In Caco2Zellen dagegen zeigt Hepsin einen späten und schwächeren Peak, der sich aus allen drei Präparationen zusammensetzt. TMPRSS-2 reagiert mit jeweils frühen Peaks in beiden Zelllinien deutlich auf die hitzeinaktivierte Fraktion, was durch vitalen EHEC und zeitverzögert in HT29 durch den Überstand unterstützt wird. Das stärkste Stimulans ist auch in HT29-Zellen für TMPRSS-4 die hitzeinaktivierte Präparation. Dieses Stimulans macht die gesamte durch die intakten Bakterien beobachtete Induktion aus, der Überstand trägt dazu kaum etwas bei. Dagegen wird TMPRSS-4 in Caco2-Zellen schwächer induziert, jedoch setzt sich der erste Peak aus allen drei Präparationen zusammen. MTSP-1 wird in beiden Zelllinien am stärksten durch die hitzeinaktivierte Fraktion induziert, der vitale EHEC trägt zu dieser Induktion nichts bei.

Als proinflammatorischer Marker wird IL-8 in HT29- und Caco2-Zellen durch die hitzeinaktivierte Präparation mit Abstand am stärksten induziert. Durch die Hitzeinaktivierung werden Proteinantigene der Erregeroberfläche, hier insbesondere das Flagellin, zerstört. Dagegen bleibt LPS intakt und wird, neben vermutlich weiteren Kohlenhydratstrukturen, durch die Erhitzung noch stärker immunmodulatorisch für die Induktion von IL-8 und PAR-2 sowie einzelner TTSP wirksam. Der Überstand des potentiellen Verotoxin-II-Bildners EHEC führt dagegen zu einer nur sehr geringen IL-8 Induktion. Dies bestätigen Veröffentlichungen, die das EHEC H7 Flagellin im Vergleich zum sezernierten Verotoxin-II als den Stimulus für eine erste proinflammatorische Zellantwort mit u.a. einer IL-8 Induktion beschreiben (Miyamoto et al., 2006; Berin et al., 2002). Flagellin wurde auch als der Faktor des Probiotikums E. coli Nissle $(\mathrm{EcN})$ charakterisiert, der in IEC von humanem Beta-Defensin 2 (hBD-2), einem antimikrobiellen Peptid zur Abwehr bakterieller Adhäsion und Invasion, hauptsächlich zur Induktion führt (Schlee et al., 2007). Im Gegensatz dazu existieren bisher keine Veröffentlichungen zur Regulation von TTSP auf IEC nach Exposition gegenüber verschiedenen EHEC-Präparationen. In einer Studie mit Caco2-Zellen konnte gezeigt werden, dass eine Exposition gegenüber EHEC-Überstand die Zell-ZellVerbindungen, insbesondere die tight junctions, zerstört. Wurden die Zellen zuvor mit dem Überstand von vier probiotischen Stämmen behandelt, zeigte sich ein protektiver Effekt, die interzellulären tight junctions wurden nicht geschädigt (Putaala et al., 2008). In einer weiteren Veröffentlichung mit EHEC konnte in T84-Zellen ein protektiver Effekt auf die epitheliale Barrierefunktion durch Vorbehandlung mit vitalem 
Lactobacillus rhamnosus GG (LGG) beschrieben werden. Die hitzeinaktivierte Präparation des probiotischen Lactobacillus hatte dagegen keinen schützenden Effekt auf morphologische Veränderungen der interzellulären tight junctions sowie Adhäsionsläsionen durch EHEC (Johnson-Henry et al., 2008). Somit können zellfreier Überstand, Hitzeinaktivierung und vitale Bakterien von probiotischen oder pathogenen Bakterienstämmen vielfältige Effekte auf IEC und deren Rezeptoren, insbesondere TTSP, ausüben. Dabei sind die auslösenden Faktoren der unterschiedlichen Bakterienstämme und -präparationen in ihrem Wirkungsmechanismus auf IEC noch weitgehend unklar. In diesem Experiment ist diesbezüglich festzuhalten, dass TTSP, insbesondere die Proteasen Hepsin und TMPRSS-2, mit einer deutlichen Induktion ihrer Genexpression auf die Exposition gegenüber der hitzeinaktivierten wie auch vitalen EHEC-Präparation reagieren, während die bakteriell sezernierten Faktoren im Überstand kaum zu dieser Regulation beitragen.

\subsubsection{HT29- und Caco2-Zellen mit E. coli Nissle 1917 - Präparationen}

Escherichia coli Nissle $1917(\mathrm{EcN})$ ist ein apathogener E. coli- Stamm, welcher als Probiotikum seit vielen Jahrzehnten u.a. zur Behandlung verschiedener insbesondere gastroenterologischer Erkrankungen Verwendung findet.

Vital: In diesem Experiment induziert der native EcN in HT29- und Caco2-Zellen eine starke IL-8 Expression. So reagieren HT29 deutlich mit einer gut 800-fachen Erhöhung nach $2 \mathrm{~h}$ und Caco2 weniger ausgeprägt mit einer 220-fachen Erhöhung nach $2 \mathrm{~h}$. Auch PAR-2 wird in HT29- und Caco2-Zellen gut exprimiert und zeigt frühe Peaks nach jeweils 4 h mit knapp 11-facher und 7-facher Induktion.

Die TTSP reagieren zum Teil sehr deutlich auf die Infektion mit vitalem EcN. Am augenfälligsten ist die deutliche Induktion von MTSP-1 in HT29-Zellen mit einer 19fachen Erhöhung nach 12 h. MTSP-1 markiert damit die stärkste quantitative Induktion der Genexpression unter den TTSP. Dagegen wird TMPRSS-2 in Caco2 mit einem frühen ersten Peak nach $2 \mathrm{~h}$ und einer 11,5-fachen Erhöhung sowie einem zweiten späten Peak nach 24 h mit einer 12-fachen Erhöhung am stärksten induziert. Insgesamt verlaufen die Kurven der TTSP in beiden Zelllinien nach Exposition mit EcN sehr ähnlich. In HT29 zeigen sich biphasische Verläufe mit frühen Peaks nach 2 bzw. 4 h sowie späten Peaks nach 12 h. In Caco2-Zellen werden diese Peaks nach 2 und 24 h erreicht. 
Hitzeinaktivierung: Die hitzeinaktivierte Präparation führt ähnlich dem nativen $\mathrm{EcN} z u$ einer deutlichen Induktion von IL-8. So zeigt sich in HT29-Zellen eine 700-fache Erhöhung sowie in Caco2-Zellen eine gut 900-fache Erhöhung der Genexpression als früher Peak jeweils nach $2 \mathrm{~h}$. Ebenfalls in Caco2 wird PAR-2 mit einer knapp 10-fachen Erhöhung nach 4 h stärker induziert als in HT29 mit einer 3,6-fachen Induktion.

Auch die TTSP werden durch die denaturierte Präparation von $\mathrm{EcN}$ deutlich induziert. Hepsin reagiert quantitativ am stärksten mit einer 14,7-fachen Erhöhung nach $24 \mathrm{~h}$ in HT29-Zellen. Ein später, wenn gleich schwächerer Peak nach 24 h zeigt sich für Hepsin auch in Caco2-Zellen mit einer 5,3-fachen Erhöhung. MTSP-1 wird in Caco2 am stärksten mit einer 5,7-fachen Erhöhung nach 24 h exprimiert. Im Vergleich der beiden Zelllinien reagieren die TTSP in HT29-Zellen insgesamt mit einer deutlicheren Induktion der Genexpression.

Überstand: Der Überstand, also die von EcN sezernierten Faktoren, induzieren ein sehr unterschiedliches IL-8- und PAR-2 Expressionsmuster in beiden Zelllinien. In HT29Zellen wird IL-8 deutlich mit einer 450-fachen Erhöhung nach 2 h induziert. Dagegen reagiert in Caco2-Zellen IL-8 mit einer knapp 10-fachen Induktion nach $2 \mathrm{~h}$ nur unwesentlich. PAR-2 zeigt sich in HT29 nach 2h deutlich erhöht mit einer 40-fachen Induktion, während in $\mathrm{Caco} 2$ eine nur geringe Regulation mit einer 2,6-fachen Induktion nach $4 \mathrm{~h}$ zu beobachten ist.

Die TTSP reagieren auf die Exposition gegenüber dem EcN- Überstand zelllinienspezifisch. In HT29-Zellen zeigen die Proteasen eine stärkere Induktion als in Caco2-Zellen. Der Kurvenverlauf ist in HT29 biphasisch mit der stärksten Induktion von MTSP-1 nach 4 h und einer 13,6-fachen Erhöhung. In Caco2 zeigt sich MTSP-1 dagegen kaum reguliert. Das quantitative Maximum in Caco2-Zellen weist Hepsin mit einer 3-fachen Erhöhung nach 24 h auf.

\subsubsection{Zusammenfassung und Diskussion E. coli Nissle 1917}

EcN als einer der bestuntersuchtesten probiotischen Stämme zeigt eine deutliche IL-8 Induktion. Diese wird in HT29 neben hitzeinaktivierter und vitaler Fraktion auch durch den Überstand induziert, wogegen in Caco2 eine nur sehr geringe IL-8 Induktion durch den Überstand hervorgerufen wird. Die Tatsache, dass ein probiotischer Bakterienstamm eine solche IL-8 Antwort induziert, konnte in mehreren Veröffentlichungen bestätigt werden (Otte, Podolsky, 2004; Lammers et al., 2002; 
Schultz, 2008). Des Weiteren konnte gezeigt werden, dass E. coli Nissle 1917 in einem dosisabhängigen Verhältnis in HT29-Zellen eine IL-8 Induktion hervorruft. Probiotische grampositive Bakterien wie Lactobacillus GG und VSL\#3 induzieren dagegen keine IL-8 Erhöhung. Vermutlich resultieren die Benefits des gramnegativen E. coli Nissle und grampositiven probiotischen Stämmen aus unterschiedlichen Mechanismen in Bezug auf IEC (Lammers et al., 2002). Des Weiteren konnte als ein wesentlicher Unterschied von $\mathrm{EcN}$ zu anderen gramnegativen apathogenen E. coliStämmen dessen veränderte LPS-Struktur beschrieben werden. Diese beruht auf einer Punktmutation im Gen für die O-Antigen-Polymerase (Grozdanov et al., 2004). Das könnte neben anderen stammspezifischen Eigenschaften von $\mathrm{EcN}$ sein spezielles Wirkungsspektrum im Vergleich zu anderen E. coli spp. ausmachen. EcN kann die Invasion von pathogenen Bakterien, insbesondere Salmonella typhimurium in INT407Zellen um bis zu 2/3 reduzieren, wobei dieser Effekt sehr wahrscheinlich durch sezernierte Faktoren von EcN hervorgerufen wird. Dabei bleibt der genaue Mechanismus unbekannt, beruht jedoch nicht auf direktem Kontakt von EcN mit invasiven Bakterien oder Epithelzellen (Altenhoefer et al., 2004).

PAR-2 wird durch die unterschiedlichen Präparationen zum Teil stark induziert. Dies könnte Ausdruck einer protektiven Immunmodulation durch $\mathrm{EcN}$ über eine Induktion von PAR-2 in IEC sein. Diesbezüglich fehlen eingehende Veröffentlichungen. Weitere Untersuchungen sollten hierzu folgen.

Die TTSP werden durch die verschiedenen EcN-Präparationen ebenfalls deutlich induziert. So erfahren die Proteasen allein in HT29 vier Mal eine über 10-fache Induktion ihrer Genexpression. Der vitale EcN induziert in HT29-Zellen die quantitativ stärkste Genexpression der TTSP für MTSP-1, wobei Überstand und hitzeinaktivierte Präparation zu diesem Peak nichts beitragen. Ein früher Peak mit Induktion von MTSP1 durch den EcN-Überstand wird durch die beiden anderen Fraktionen nicht unterstützt. Dagegen setzen sich die späten Peaks in Caco2-Zellen für MTSP-1 und Hepsin, wenngleich schwächer ausgeprägt, aus allen drei Fraktionen zusammen. Die Präparation des vitalen EcN induziert eine starke frühe Erhöhung der TMPRSS-2 Expression in Caco2, Hitzeinaktivierung und Überstand tragen nichts bei. Somit zeigen die TTSP ein eher uneinheitliches Bild in der Induktion ihrer Genexpression durch die verschiedenen Präparationen von EcN. Des Weiteren existieren bisher keine Publikationen zu dieser Thematik. Untersuchungen mit anderen probiotischen Stämmen in verschiedenen Präparationen bestätigen jedoch ein differentielles Bild in Bezug auf Wirkungsweise 
und Effekt. So reduziert vitaler Lactobacillus rhammnosus GG (LGG) die TNF-alpha induzierte IL-8 Produktion wesentlich stärker als hitzeinaktivierter LGG (Zhang et al., 2005). Dagegen verhindert eine hitzeinaktivierte Präparation von mehreren Lactobacillus-Stämmen die Invasion von Salmonella typhimurium in Mäusen deutlich im Vergleich zu einem einzelnen vitalen Stamm (Lin et al., 2007). In unterschiedlichen Colitis-Modellen in der Maus konnten deutliche protektive Effekte durch E. coli Nissle bei akuter und chronischer intestinaler Inflammation gezeigt werden (Schultz et al., 2004). Eine aktuelle Studie konnte in Mukosaproben von M. Crohn-Patienten durch Vorbehandlung mit vitalem Lactobacillus casei eine signifikante Reduktion der proinflammatorischen Genexpression (u.a. IL-8, TNF-alpha, IFN-gamma) von kommensalem E. coli ATCC 35345 nachweisen (Llopis et al., 2009). Diesbezüglich konnte innerhalb der chronisch entzündlichen Darmerkrankungen (CED) für Colitis ulcerosa-Patienten in mehreren Studien festgestellt werden, dass eine Therapie mit E. coli Nissle 1917 für die Remissionserhaltung genauso effektiv ist wie der bisherige Goldstandard Mesalazin (5-ASA) (Kruis et al., 2004). In aktuellen Untersuchungen konnte diese Remissionserhaltung durch probiotischen $\mathrm{EcN}$ auch für Kinder und Jugendliche mit Colitis ulcerosa beschrieben werden (Henker et al., 2008). Damit bietet $\mathrm{EcN}$ eine wichtige therapeutische Alternative in der Remissionserhaltung der Colitis ulcerosa von jungen wie auch älteren Patienten.

TTSP und PAR-2 werden durch die verschiedenen Präparationen des EcN deutlich induziert. Dabei reagieren die Proteasen stärker auf die Stimulation in der HT29Zelllinie. IEC nehmen somit die verschiedenen Präparationen des probiotischen EcN wahr und reagieren mit einer deutlichen Induktion der TTSP- wie auch PAR-2 Genexpression. Inwieweit dies als erste Reaktion einer protektiven, antiinflammatorischen Immunmodulation in IEC $\mathrm{zu}$ werten ist, bleibt zunächst Spekulation. Die physiologische Funktion der TTSP und PAR-2 in der Reaktion auf die Exposition gegenüber verschiedenen Präparationen des probiotischen Bakterienstammes EcN bleibt im Detail weiter unklar. 


\section{$5 \quad$ Resümee}

Die Entdeckung und Untersuchung der Typ II transmembranären Serin Proteasen (TTSP) befindet sich noch immer in den Anfängen und obwohl erste Schritte schon gemacht wurden, bleibt noch ein weiter Weg, bis alle Fragen beantwortet sind. Dabei verschafft ihnen gerade die Lokalisation an der Zelloberfläche exzellente Voraussetzungen für die Kommunikation zwischen einzelnen Zellen und ihrer extrazellulären Umgebung. TTSP besitzen damit die Möglichkeit, entscheidungsrelevant in die Regulation von Zellantwort und Zellfunktion einzugreifen. Unter diesem Aspekt konnten neue Ergebnisse zu Expression und Regulation von TTSP auf humanen intestinalen Epithelzellen (IEC) in dieser Arbeit präsentiert werden. So wurde die Genexpression von MTSP-1, TMPRSS-2 und TMPRSS-4 sowie PAR-2 in humanen intestinalen Gewebeproben vor allem stark erhöht im Bereich des Caecums nachgewiesen. Hier könnte ein möglicher Zusammenhang mit der hohen Bakteriendichte im Dickdarm bestehen, die zur Induktion der TTSP führt. Vergleichend weisen die Proteasen ein sehr ähnliches Expressionsmuster auf. Insbesondere zeigte sich eine deutliche Koexpression der TTSP mit PAR-2 im GI-Trakt. Dies erscheint interessant, da PAR-2 durch MTSP-1 und TMPRSS-2 aktiviert werden kann und wirft die Frage nach der Existenz einer physiologischen Aktivierungskaskade zur Immunmodulation im humanen Intestinum auf.

Weitergehend untersuchten wir die Regulation der TTSP in IEC nach direkter Exposition mit gramnegativen und grampositiven sowie invasiven und nicht-invasiven vitalen Bakterien unterschiedlicher Pathogenität. Am augenfälligsten imponierte hierbei die deutliche Suppression aller TTSP in beiden Zelllinien durch das kommensale Bakterium Enterococcus faecium. Dagegen werden TTSP durch weitere Bakterien differentiell induziert, wobei sich die Genexpression stärker in gering differenzierten HT29-Zellen als in gut differenzierten Caco2-Zellen zeigte. Neben Gramzugehörigkeit und invasivem/nichtinvasivem Verhalten bedingen somit weitere bakterielle Faktoren die Regulation der Genexpression der TTSP in IEC.

Darauf basierend wurden IEC mit verschiedenen Bakterienpräparationen unterschiedlicher E. coli-Stämme exponiert. TTSP wurden erneut am deutlichsten in HT29-Zellen induziert, dies unter anderem durch die verschiedenen Präparationen des probiotischen E. coli Nissle 1917. Die Proteasen und PAR-2 werden differentiell durch einzelne Präparationen oder auch alle drei Präparationen induziert. Stärkster 
proinflammatorischer Stimulus ist dabei die hitzeinaktivierte Fraktion, welche zum Teil auch die deutlichste Induktion der TTSP hervorruft. Somit scheinen vor allem nichtProtein hitzeresistente Faktoren, vermutlich Kohlenhydratstrukturen wie LPS zu einer starken Induktion von IL-8 und TTSP zu führen. Dagegen zeigt sich der bakterielle Überstand, also die von den Bakterien sezernierten Faktoren, in beiden Zelllinien als schwächerer Stimulus der TTSP-Induktion. Insbesondere induziert der Überstand eine nur sehr geringe proinflammatorische IL-8 Expression.

Diesbezüglich zeigten weitere Experimente mit Zytokinen, LPS und Dexamethason, dass TTSP in IEC einer Regulation durch pro- und antiinflammatorische Stimuli unterliegen. So können proinflammatorische Zytokine TTSP und PAR-2 gleichsinnig induzieren. Dabei wirkt Dexamethason (immun-) modulatorisch auf die TTSP- und PAR-2 Expression und führt zur Suppression der durch proinflammatorische Zytokine induzierten TTSP-Expression.

Die Ergebnisse dieser Arbeit zeigen, dass TTSP in humanen Gewebeproben des GITrakts expremiert werden. Sie unterliegen in IEC einer Regulation durch pro- und antiinflammatorische Stimuli und werden durch Bakterien unterschiedlicher Gramzugehörigkeit, Pathogenität und Präparation differentiell induziert. Damit scheinen TTSP im humanen Gastrointestinaltrakt einen wichtigen Beitrag innerhalb der angeborenen Immunmodulation auf mucosaler Ebene zu leisten. 


\section{Literaturverzeichnis}

1. Adachi M, Kitamura K, Miyoshi T, Narikiyo T, Iwashita K, Shiraishi N, Nonoguchi H, Tomita K: Activation of epithelial sodium channels by prostasin in Xenopus oocytes. J Am Soc Nephrol 12: 1114-1121, 2001

2. Afar DE, Vivanco I, Hubert RS, Kuo J, Chen E, Saffran DC, Raitano AB, Jakobovits A: Catalytic cleavage of the androgen-regulated TMPRSS2 protease results in its secretion by prostate and prostate cancer epithelia. Cancer Res 61: $1686-1692,2001$

3. Aimes RT, Zijlstra A, Hooper JD, Ogbourne SM, Sit M-L, Fuchs S, Gotley DC, Quigley JP, Antalis TM: Endothelial cell serine proteases expressed during vascular morphogenesis and angiogenesis. Thromb Haemost 89: 569-572, 2003

4. Altenhoefer A, Oswald S, Sonnenborn U, Enders C, Schulze J, Hacker J, Oelschlaeger TA: The probiotic Escherichia coli strain Nissle 1917 interferes with invasion of human intestinal epithelial cells by different enteroinvasive bacterial pathogens. FEMS Immunol Med Microbiol. 9;40(3):223-9, 2004

5. Attard G, Clark J, Ambroisine L, Fisher G, Kovacs G, Flohr P, Berney D, Foster CS, Fletcher A, Gerald WL, Moller H, Reuter V, De Bono JS, Scardino P, Cuzick J, Cooper CS; Transatlantic Prostate Group: Duplication of the fusion of TMPRSS2 to ERG sequences identifies fatal human prostate cancer. Oncogene. 10;27(3):253-63, 2008

6. Bai AP, Ouyang Q, Zhang W, Wang CH, Li SF: Probiotics inhibit TNF-alphainduced interleukin-8 secretion of HT29 cells. World J Gastroenterol. $1 ; 10(3): 455-7,2004$

7. Bambou JC, Giraud A, Menard S, Begue B, Rakotobe S, Heyman M, Taddei F, Cerf-Bensussan N, Gaboriau-Routhiau V: In vitro and ex vivo activation of the TLR5 signaling pathway in intestinal epithelial cells by a commensal Escherichia coli strain. J Biol Chem. 279(41):42984-92, 2004

8. Benaud C, Oberst M, Hobson JP, Spiegel S, Dickson RB, Lin CY: Sphingosine 1-phosphate, present in serum derived lipoproteins, activates matriptase. J Biol Chem 277: 10539-10546, 2002 
9. Berin MC, Darfeuille-Michaud A, Egan LJ, Miyamoto Y, Kagnoff MF: Role of EHEC O157:H7 virulence factors in the activation of intestinal epithelial cell NF-kappaB and MAP kinase pathways and the upregulated expression of interleukin 8. Cell Microbiol. 4(10):635-48, 2002

10. Birkedal-Hansen H, Moore WG, Bodden MK, Windsor LJ, Birkedal-Hansen B, DeCarlo A, et al.: Matrix metalloproteinases : a review. Crit Rev Oral Biol Med. 4: 197-250, 1993

11. Bocheva G, Rattenholl A, Kempkes C, Goerge T, Lin CY, D'Andrea MR, Ständer S, Steinhoff M: Role of Matriptase and Proteinase-Activated Receptor-2 in Nonmelanoma Skin Cancer. J Invest Dermatol. Epub, Feb 2009

12. Böhm SK, Kong W, Bromme D, Smeekens SP, Anderson DC, Connolly A, Kahn M, Nelken NA, Coughlin SR, Payan DG, Bunnett NW: Molecular cloning, expression and potential functions of the human proteinase-activated receptor-2. Biochem J. 314 ( Pt 3):1009-16, 1996

13. Böhm SK, McConalogue K, Kong W, Bunnett NW: Proteinase-Activated Receptors: New Functions for Old Enzymes. News Physiol Sci. 13:231-240, 1998

14. Bork P, Beckmann G: The CUB domain. A widespread module in developmentally regulated proteins. J Mol Biol 231: 539-545, 1993

15. Bork P, Patthy L: The SEA module: A new extracellular domain associated with O-glycosylation. Protein Sci 4: 1421-1425, 1995

16. Brock TD, Parker J, Martinko JM, Madigan MT: Mikrobiologie, 11. Auflage, Spektrum Akademischer Verlag, 2003

17. Bruno ME, Kaetzel CS: Long-term exposure of the HT-29 human intestinal epithelial cell line to TNF causes sustained up-regulation of the polymeric Ig receptor and proinflammatory genes through transcriptional and posttranscriptional mechanisms. J Immunol. 1;174(11):7278-84, 2005

18. Bugge TH, List K, Szabo R: Matriptase-dependent cell surface proteolysis in epithelial development and pathogenesis. Front Biosci. 1;12:5060-70, 2007

19. Buttgereit F, Dimmeler S, Neugebauer E, Burmester GR: Mechanisms of action of high-dosage glucocorticoid therapy. Dtsch Med Wochenschr. 23;121(8):24852,1996 
20. Canani RB, Cirillo P, Terrin G, Cesarano L, Spagnuolo MI, De Vincenzo A, Albano F, Passariello A, De Marco G, Manguso F, Guarino A: Probiotics for treatment of acute diarrhoea in children: randomised clinical trial of five different preparations. BMJ. 18;335(7615):340, 2007

21. Cenac N, Chin AC, Garcia-Villar R, Salvador-Cartier C, Ferrier L, Vergnolle N, Buret AG, Fioramonti J, Bueno L: PAR2 activation alters colonic paracellular permeability in mice via IFN-gamma-dependent and -independent pathways. J Physiol. 1;558(Pt 3):913-25, 2004

22. Cottrell GS, Amadesi S, Grady EF, Bunnett NW: Trypsin IV, a novel agonist of protease-activated receptors 2 and 4. J Biol Chem. 2;279(14):13532-9, 2004

23. de Vrese M, Schrezenmeir J: Probiotics, prebiotics, and synbiotics. Adv Biochem Eng Biotechnol. 2008;111:1-66

24. Dhanasekaran SM, Barrette TR, Ghosh D, Shah R, Varambally S, Kurachi K, Pienta KJ, Rubin MA, Chinnaiyan AM: Delineation of prognostic biomarkers in prostate cancer. Nature 412: 822-826, 2001

25. Diebel LN, Liberati DM, Baylor AE 3rd, Brown WJ, Diglio CA: The pivotal role of tumor necrosis factor-alpha in signaling apoptosis in intestinal epithelial cells under shock conditions. J Trauma. 58(5):995-1001, 2005

26. Dinarello CA. Blocking IL-1 in systemic inflammation. J Exp Med. 2;201(9):1355-9, May 2005

27. Dinarello CA. Interleukin-1 beta. Crit Care Med. 33(12 Suppl):S460-2, Dec 2005

28. Donaldson SH, Hirsh A, Li DC, Holloway G, Chao J, Boucher RC, Gabriel SE: Regulation of the epithelial sodium channel by serine proteases in human airways. J Biol Chem 277: 8338-8345, 2002

29. Eckmann L, Kagnoff MF, Fierer J: Epithelial cells secrete the chemokine interleukin-8 in response to bacterial entry. Infect Immun. 61(11):4569-74, 1993

30. Fiorucci S, Mencarelli A, Palazetti B, Distrutti E, Vergnolle N, Hollenberg MD, Wallace JL, Morelli A, Cirino G: Proteinase-activated receptor 2 is an antiinflammatory signal for colonic lamina propria lymphocytes in a mouse model of colitis. PNAS 98(24):13936-41, 2001

31. Fogh et al., J: Natl. Cancer Inst. 58: 209-214,1977

32. Fogh J, Trempe G: Human Tumor Cells in Vitro, Plenum Press, New York, , pp. $115-159,1975$ 
33. Fonseca P, Light A: The purification and characterization of bovine enterokinase from membrane fragments in the duodenal mucosal fluid. J Biol Chem 258: 14516-14520, 1983

34. Frick JS, Fink K, Kahl F, Niemiec MJ, Quitadamo M, Schenk K, Autenrieth IB: Identification of commensal bacterial strains that modulate Yersinia enterocolitica and dextran sodium sulfate-induced inflammatory responses: implications for the development of probiotics. Infect Immun. 75(7):3490-7, 2007

35. Fürst R, Schroeder T, Eilken HM, Bubik MF, Kiemer AK, Zahler S, Vollmar AM: MAPK phosphatase-1 represents a novel anti-inflammatory target of glucocorticoids in the human endothelium. FASEB J. 21(1):74-80, 2007

36. Grozdanov L, Raasch C, Schulze J, Sonnenborn U, Gottschalk G, Hacker J, Dobrindt U: Analysis of the genome structure of the nonpathogenic probiotic Escherichia coli strain Nissle 1917. J Bacteriol.186(16):5432-41, 2004

37. Guiney DG: The role of host cell death in Salmonella infections. Curr Top Microbiol Immunol. 289:131-50, 2005

38. Guipponi M, Tan J, Cannon PZ, Donley L, Crewther P, Clarke M, Wu Q, Shepherd RK, Scott HS: Mice deficient for the type II transmembrane serine protease, TMPRSS1/hepsin, exhibit profound hearing loss. Am J Pathol. 171(2):608-16, 2007

39. Havenaar R et al.: Probiotics, Chapman \& Hall, New York, 1992

40. Henker J, Müller S, Laass MW, Schreiner A, Schulze J: Probiotic Escherichia coli Nissle $1917(\mathrm{EcN})$ for successful remission maintenance of ulcerative colitis in children and adolescents: an open-label pilot study. Z Gastroenterol. 46(9):874-5, 2008

41. Hermon-Taylor J, Perrin J, Grant DA, Appleyard A, Bubel M, Magee AI: Immunofluorescent localisation of enterokinase in human small intestine. Gut 18: $259-65,1977$

42. Hooper JD, Clements JA, Quigley JP, Antalis TM: Type II transmembrane serine proteases. Insights into an emerging class of cell surface proteolytic enzymes. J Biol Chem 276: 857-860, 2001 
43. Huang FC, Werne A, Li Q, Galyov EE, Walker WA, Cherayil BJ: Cooperative interactions between flagellin and SopE2 in the epithelial interleukin-8 response to Salmonella enterica serovar typhimurium infection. Infect Immun. 72(9):5052-62, 2004

44. Jarry A, Dorso L, Gratio V, Forgue-Lafitte ME, Laburthe M, Laboisse CL, Darmoul D: PAR-2 activation increases human intestinal mucin secretion through EGFR transactivation. Biochem Biophys Res Commun. 21;364(3):68994, 2007

45. Jin X, Hirosaki T, Lin CY, Dickson RB, Higashi S, Kitamura H, Miyazaki K: Production of soluble matriptase by human cancer cell lines and cell surface activation of its zymogen by trypsin. J Cell Biochem. 1;95(3): 632-47, 2005

46. Johnson-Henry KC, Donato KA, Shen-Tu G, Gordanpour M, Sherman PM. Lactobacillus rhamnosus strain GG prevents enterohemorrhagic Escherichia coli O157:H7-induced changes in epithelial barrier function. Infect Immun. 76(4):1340-8, 2008

47. Jung HC, Eckmann L, Yang SK, Panja A, Fierer J, Morzycka-Wroblewska E, Kagnoff MF: A distinct array of proinflammatory cytokines is expressed in human colon epithelial cells in response to bacterial invasion. J Clin Invest. 95(1):55-6, 1995

48. Kampik D, Schulte R, Autenrieth IB: Yersinia enterocolitica invasin protein triggers differential production of interleukin-1, interleukin-8, monocyte chemoattractant protein 1, granulocyte-macrophage colony-stimulating factor, and tumor necrosis factor alpha in epithelial cells: implications for understanding the early cytokine network in Yersinia infections. Infect Immun. 68(5):2484-92, 2000

49. Kang JY, Dolled-Filhart M, Ocal IT, Singh B, Lin CY, Dickson RB, Rimm DL, Camp RL: Tissue microarray analysis of hepatocyte growth factor/Met pathway components reveals a role for Met, matriptase, and hepatocyte growth factor activator inhibitor 1 in the progression of node-negative breast cancer. Cancer Res.1;63(5):1101-5, 2003

50. Kawabata A, Kinoshita M, Nishikawa H, Kuroda R, Nishida M, Araki H, Arizono N, Oda Y, Kakehi K: The protease-activated receptor-2 agonist induces gastric mucus secretion and mucosal cytoprotection. J Clin Invest. Jun;107(11):1443-50, 2001 
51. Kazama Y, Hamamoto T, Foster DC, Kisiel W: Hepsin, a putative membraneassociated serine protease, activates human factor VII and initiates a pathway of blood coagulation on the cell surface leading to thrombin formation. J Biol Chem 270: 66-72, 1995

52. Kebebew E, Peng M, Reiff E, Duh QY, Clark OH, McMillan A: ECM1 and TMPRSS4 are diagnostic markers of malignant thyroid neoplasms and improve the accuracy of fine needle aspiration biopsy. Ann Surg. 242(3): 353-61; discussion 361-3, 2005

53. Kim MG, Chen C, Lyu MS, Cho EG, Park D, Kozak C, et al.: Cloning and chromosomal mapping of a gene isolated from thymic stroma cells encoding a new mouse type II membrane serine protease, epithin, containing four LDL receptor modules and two CUB domains. Immunogenetics 49: 420-8, 1999

54. Kitamoto Y, Veile RA, Donis-Keller H, Sadler JE: cDNA sequence and chromosomal localization of human enterokinase, the proteolytic activator of trypsinogen. Biochemistry 34: 4562-4568, 1995

55. Kitamoto Y, Yuan X, Wu Q, McCourt DW, Sadler JE: Enterokinase, the initiator of intestinal digestion, is a mosaic protease composed of a distinctive assortment of domains. Proc Natl Acad Sci USA 91: 7588-7592, 1994

56. Klezovitch O, Chevillet J, Mirosevich J, Roberts RL, Matusik RJ, Vasioukhin V: Hepsin promotes prostate cancer progression and metastasis. Cancer Cell. 6(2): 185-95, 2004

57. Kovaríková M, Hofmanová J, Soucek K, Kozubík A: The effects of TNF-alpha and inhibitors of arachidonic acid metabolism on human colon HT-29 cells depend on differentiation status. Differentiation. 72(1):23-31, 2004

58. Kruis W, Fric P, Pokrotnieks J, Lukás M, Fixa B, Kascák M, Kamm MA, Weismueller J, Beglinger C, Stolte M, Wolff C, Schulze J: Maintaining remission of ulcerative colitis with the probiotic Escherichia coli Nissle 1917 is as effective as with standard mesalazine. Gut. 53(11):1617-23, 2004

59. Lammers KM, Helwig U, Swennen E, Rizzello F, Venturi A, Caramelli E, Kamm MA, Brigidi P, Gionchetti P, Campieri M: Effect of probiotic strains on interleukin 8 production by HT29/19A cells. Am J Gastroenterol. 97(5): 1182-6, 2002 
60. Landers KA, Burger MJ, Tebay MA, Purdie DM, Scells B, Samaratunga H, Lavin MF, Gardiner RA: Use of biomarkers for a molekular diagnosis of prostate cancer. Int J Cancer. 10;114(6): 950-6, 2005

61. Lee SL, Dickson RB, Lin CY: Activation of hepatocyte growth factor and urokinase/plasminogen activator by matriptase, an epithelial membrane serine protease. J Biol Chem 275: 36720-36725, 2000

62. Leytus SP, Loeb KR, Hagen FS, Kurachi K, Davie EW: A novel trypsin-like serine protease (hepsin) with a putative transmembrane domain expressed by human liver and hepatoma cells. Biochemistry 27: 1067-1074, 1988

63. Liévin-Le Moal V, Servin AL, Coconnier-Polter MH: The increase in mucin exocytosis and the upregulation of MUC genes encoding for membrane-bound mucins induced by the thiol-activated exotoxin listeriolysin $\mathrm{O}$ is a host cell defence response that inhibits the cell-entry of Listeria monocytogenes. Cell Microbiol. 7(7):1035-48, 2005

64. Lin B, Ferguson C, White JT, Wang S, Vessella R, True LD, HoodL, Nelson PS: Prostate-localized and androgen-regulated expression of the membrane-bound serine protease TMPRSS2. Cancer Res 59: 4180-4184, 1999

65. Lin CY, Anders J, Johnson M, Sang QA, Dickson RB: Molecular cloning of cDNA for matriptase, a matrixdegrading serine protease with trypsin-like activity. J Biol Chem 274: 18231-18236, 1999

66. Lin WH, Yu B, Lin CK, Hwang WZ, Tsen HY: Immune effect of heat-killed multistrain of Lactobacillus acidophilus against Salmonella typhimurium invasion to mice. J Appl Microbiol. 102(1):22-31, 2007

67. List K, Haudenschild CC, Szabo R, Chen W, Wahl SM, Swain W, et al.: Matriptase/MT-SP1 is required for postnatal survival, epidermal barrier function, hair follicle development, and thymic homeostasis. Oncogene 21: 3765-79, 2002

68. Llopis M, Antolin M, Carol M, Borruel N, Casellas F, Martinez C, EspínBasany E, Guarner F, Malagelada JR: Lactobacillus casei downregulates commensals' inflammatory signals in Crohn's disease mucosa. Inflamm Bowel Dis. 15(2):275-83, 2009

69. Lodinová-Zádniková R, Sonnenborn U: Effect of preventive administration of a nonpathogenic Escherichia coli strain on the colonization of the intestine with microbial pathogens in newborn infants. Biol Neonate. 71(4):224-32, 1997 
70. Louvard D, Maroux S, Baratti J, Desnuelle P: On the distribution of enterokinase in porcine intestine and on its subcellular localization. Biochim Biophys Acta 309: 127- 137, 1973

71. Lucas JM, True L, Hawley S, Matsumura M, Morrissey C, Vessella R, Nelson PS: The androgen-regulated type II serine protease TMPRSS2 is differentially expressed and mislocalized in prostate adenocarcinoma. J Pathol. 215(2):118-25, 2008

72. Luo J, Duggan DJ, Chen Y, Sauvageot J, Ewing CM, Bittner ML, Trent JM, Isaacs WB: Human prostate cancer and benign prostatic hyperplasia: Molecular dissection by gene expression profiling. Cancer Res 61: 4683-4688, 2001

73. Magee JA, Araki T, Patil S, Ehrig T, True L, Humphrey PA, Catalona WJ, Watson MA, Milbrandt J: Expression profiling reveals hepsin overexpression in prostate cancer. Cancer Res 61: 5692-5696, 2001

74. Mann NS, Mann SK: Enterokinase. Proc Soc Exp Biol Med 206: 114-8, 1994

75. Marteau PR, de Vrese M, Cellier CJ, Schrezenmeir J : Protection from gastrointestinal diseases with the use of probiotics. Am J Clin Nutr. 73(2 Suppl):430S-436S, 2001

76. Miao J, Mu D, Ergel B, Singavarapu R, Duan Z, Powers S, Oliva E, Orsulic S: Hepsin colocalizes with desmosomes and induces progression of ovarian cancer in a mouse model. Int J Cancer. 1;123(9):2041-7, 2008

77. Miyamoto Y, limura M, Kaper JB, Torres AG, Kagnoff MF: Role of Shiga toxin versus $\mathrm{H} 7$ flagellin in enterohaemorrhagic Escherichia coli signalling of human colon epithelium in vivo. Cell Microbiol. 8(5):869-79, 2006

78. Nakamura K, Abarzua F, Kodama J, Hongo A, Nasu Y, Kumon H, Hiramatsu Y: Expression of hepatocyte growth factor activator inhibitors (HAI-1 and HAI2) in ovarian cancer. Int J Oncol. 34(2):345-53, 2009

79. Netzel-Arnett S, Hooper JD, Szabo R, Madison EL, Quigley JP, Bugge TH, Antalis TM: Membrane anchored serine proteases: A rapidly expanding group of cell surface proteolytic enzymes with potential roles in cancer. Cancer Metast Rev 22: 237-58, 2003

80. Oberst M, Anders J, Xie B, Singh B, Ossandon M, Johnson M, et al.: Matriptase and HAI-1 are expressed by normal and malignant epithelial cells in vitro and in vivo. Am J Pathol 158: 1301-11, 2001 
81. Oberst MD, Chen LY, Kiyomiya K, Williams CA, Lee MS, Johnson MD, Dickson RB, Lin CY: HAI-1 regulates activation and expression of matriptase, a membrane-bound serine protease. Am J Physiol Cell Physiol. 289(2): C462-70. Epub, 2005

82. Oberst MD, Johnson MD, Dickson RB, Lin CY, Singh B, Stewart M, et al.: Expression of the serine protease matriptase and its inhibitor HAI-1 in epithelial ovarian cancer: correlation with clinical outcome and tumor clinicopathological parameters. Clin Cancer Res 8: 1101-7, 2002

83. Opitz B, Püschel A, Beermann W, Hocke AC, Förster S, Schmeck B, van Laak V, Chakraborty T, Suttorp N, Hippenstiel S: Listeria monocytogenes activated p38 MAPK and induced IL-8 secretion in a nucleotide-binding oligomerization domain 1-dependent manner in endothelial cells. J Immunol. 1;176(1):484-90, 2006

84. Otte JM, Podolsky DK: Functional modulation of enterocytes by gram-positive and gram-negative microorganisms. Am J Physiol Gastrointest Liver Physiol. 286(4):G613-26, 2004

85. Paoloni-Giacobino A, Chen H, Peitsch MC, Rossier C, Antonarakis SE: Cloning of the TMPRSS2 gene, which encodes a novel serine protease with transmembrane, LDLRA, andSRCR domains and maps to 21q22.3. Genomics 44: 309-320, 1997

86. Putaala H, Salusjärvi T, Nordström M, Saarinen M, Ouwehand AC, Bech Hansen E, Rautonen N: Effect of four probiotic strains and Escherichia coli O157:H7 on tight junction integrity and cyclo-oxygenase expression. Res Microbiol. 159(9-10):692-8, 2008

87. Qui D, Owen K, Gray K, Bass R, Ellis V: Roles and regulation of membraneassociated serine proteases. Biochem Soc Trans. 35(Pt 3):538-7, 2007

88. Raddatz D, Toth S, Schwörer H, Ramadori G: Glucocorticoid receptor signaling in the intestinal epithelial cell lines IEC-6 and Caco-2: evidence of inhibition by interleukin-1beta. Int J Colorectal Dis. 16(6):377-83, 2001

89. Rolfe RD: The role of probiotic cultures in the control of gastrointestinal health. J Nutr. 130(2S Suppl):396S-402S, 2000

90. Rousset M: The human colon carcinoma cell lines HT-29 and Caco-2: two in vitro models for the study of intestinal differentiation. Biochimie 68(9):1035-40, 1986 
91. Rubin MA, Chinnaiyan AM: Bioinformatics approach leads to the discovery of the TMPRSS2:ETS gene fusion in prostate cancer. Lab Invest. 86(11):1099-102, 2006

92. Rutgeerts L, Eggermont E: Human enterokinase. Tijdschr Gastroenterol. 19:23146, 1976

93. Saitoh O, Matsuse R, Sugi K, Nakagawa K, Uchida K, Maemura K, Kojima K, Hirata I, Katsu K: Cyclosporine A inhibits interleukin-8 production in a human colon epithelial cell line (HT-29). J Gastroenterol. 32(5):605-10, 1997

94. Satomi S, Yamasaki Y, Tsuzuki S, Hitomi Y, Iwanaga T, Fushiki T: A role for membrane-type serine protease (MT-SP1) in intestinal epithelial turnover. Biochem Biophys Res Commun 287: 995-1002, 2001

95. Schlee M, Wehkamp J, Altenhoefer A, Oelschlaeger TA, Stange EF, Fellermann $\mathrm{K}$ : Induction of human beta-defensin 2 by the probiotic Escherichia coli Nissle 1917 is mediated through flagellin. Infect Immun. 75(5):2399-407, 2007

96. Schlegel HG, Fuchs G: Allgemeine Mikrobiologie, 8. Auflage, Thieme, Stuttgart, 2006

97. Schulte R, Grassl GA, Preger S, Fessele S, Jacobi CA, Schaller M, Nelson PJ, Autenrieth IB: Yersinia enterocolitica invasin protein triggers IL-8 production in epithelial cells via activation of Rel p65-p65 homodimers. FASEB J. 14(11):1471-84, 2000

98. Schultz M, Strauch UG, Linde HJ, Watzl S, Obermeier F, Göttl C, Dunger N, Grunwald N, Schölmerich J, Rath HC: Preventive effects of Escherichia coli strain Nissle 1917 on acute and chronic intestinal inflammation in two different murine models of colitis. Clin Diagn Lab Immunol. 11(2):372-8, 2004

99. Schultz M: Clinical use of E. coli Nissle 1917 in inflammatory bowel disease. Inflamm Bowel Dis. 14(7):1012-8, 2008

100. Seidelin JB, Jaattela M, Nielsen OH: Continuous IFN- $\gamma$ or TNF- $\alpha$ exposure of enterocytes attenuates cell death response. Cytokine.7; 27(4-5): 113119,2004

101. Smirnova MG, Guo L, Birchall JP, Pearson JP: LPS-upregulates mucin and cytokine mRNA expression and stimulates mucin and cytokine secretion in goblet cells. Cell Immunol. 221(1):42-49, 2003

102. Szabo R, Bugge TH: Type II transmembrane serine proteases in development and disease. Int J Biochem Cell Biol. 40(6-7): 1297-316, 2008 
103. Szabo R, Kosa P, List K, Bugge TH: Loss of Matriptase Suppression Underlies Spint1 Mutation-Associated Ichthyosis and Postnatal Lethality. Am J Pathol. 2009 Apr 23. [Epub ahead of print]

104. Szabo R, Wu Q, Dickson RB, Netzel-Arnett S, Antalis MA, Bugge TH:

Type II transmembrane serine proteases. Thromb Haemost 90: 185-93, 2003

105. Takeuchi T, Harris JL, Huang W, Yan KW, Coughlin SR, Craik CS: Cellular localization of membrane-type serine protease 1 and identification of protease-activated receptor-2 and single-chain urokinase-type plasminogen activator as substrates. J Biol Chem 275: 26333-26342, 2000

106. Tang BL: ADAMTS: a novel familiy of extracellular matrix proteases. Int J Biochem Cell Biol. 33: 33-44, 2001

107. Tanimoto H, Yan Y, Clarke J, Korourian S, Shigemasa K, Parmley TH, Parham GP, O’Brien TJ: Hepsin, a cell surface serine protease identified in hepatoma cells, is Membrane anchored serine proteases 257 overexpressed in ovarian cancer. Cancer Res 57: 2884-2887, 1997

108. Tomlins SA, Bjartell A, Chinnaiyan AM, Jenster G, Nam RK, Rubin MA, Schalken JA: ETS Gene Fusions in Prostate Cancer: From Discovery to Daily Clinical Practice. Eur Urol. Apr 24, 2009

109. Torres-Rosado A, O’Shea KS, Tsuji A, Chou SH, Kurachi K: Hepsin, a putative cell-surface serine protease, is required for mammalian cell growth. Proc Natl Acad Sci USA 90: 7181-7185, 1993

110. Tripathi M, Nandana S, Yamashita H, Ganesan R, Kirchhofer D, Quaranta V: Laminin-332 is a substrate for hepsin, a protease associated with prostate cancer progression. J Biol Chem. 7;283(45):30576-84, 2008

111. Tsuji A, Torres-Rosado A, Arai T, Le Beau MM, Lemons RS, Chou SH, Kurachi K: Hepsin, a cell membrane associated protease. Characterization, tissue distribution, and gene localization. J Biol Chem 266: 16948-16953, 1991

112. Tsuzuki S, Murai N, Miyake Y, Inouye K, Hirayasu H, Iwanaga T, Fushiki T: Evidence for the occurrence of membrane-type serine protease 1/matriptase on the basolateral sides of enterocytes. Biochem J. 388(Pt2): 67987,2005 
113. Vaarala MH, Porvari K, Kyllonen A, Lukkarinen O, Vihko P: The TMPRSS2 gene encoding transmembrane serine protease is overexpressed in a majority of prostate cancer patients: Detection of mutated TMPRSS2 form in a case of aggressive disease. Int J Cancer 94: 705-710, 2001

114. Vaarala MH, Porvari KS, Kellokumpu S, Kyllonen AP, Vihko PT: Expression of transmembrane serine protease TMPRSS2 in mouse and human tissues. J Pathol 193: 134-140, 2001

115. van der Merwe JQ, Hollenberg MD, MacNaughton WK: EGF receptor transactivation and MAP kinase mediate proteinase-activated receptor-2-induced chloride secretion in intestinal epithelial cells. Am J Physiol Gastrointest Liver Physiol. Feb;294(2):G441-51, 2008

116. Vogel LK, Saebø M, Skjelbred CF, Abell K, Pedersen ED, Vogel U, Kure EH: The ratio of Matriptase/HAI-1 mRNA is higher in colorectal cancer adenomas and carcinomas than corresponding tissue from control individuals. BMC Cancer. Jul 4;6:176, 2006

117. Vu TK, Liu RW, Haaksma CJ, Tomasek JJ, HowardEW: Identification and cloning of the membrane-associated serine protease, hepsin, from mouse preimplantation embryos. J Biol Chem 272: 31315-31320, 1997

118. Wallrapp C, Hahnel S, Muller-Pillasch F, Burghardt B, Iwamura T, Ruthenburger M, Lerch MM, Adler G, Gress TM: A novel transmembrane serine protease (TMPRSS3) overexpressed in pancreatic cancer. Cancer Res 60: 2602-2606, 2000

119. Wehkamp J, Bals R, Kreft B, Schröder JM, Stange EF: Angeborene Immunabwehr. Dtsch Ärtztebl. 104(5): A 257-62, 2007

120. Welsh JB, Sapinoso LM, Su AI, Kern SG, Wang-Rodriguez J, Moskaluk CA, Frierson HF, Jr., Hampton GM: Analysis of gene expression identifies candidate markers and pharmacological targets in prostate cancer. Cancer Res 61: 5974-5978, 2001

121. Werner G, Coque TM, Hammerum AM, Hope R, Hryniewicz W, Johnson A, Klare I, Kristinsson KG, Leclercq R, Lester CH, Lillie M, Novais C, Olsson-Liljequist B, Peixe LV, Sadowy E, Simonsen GS, Top J, Vuopio-Varkila J, Willems RJ, Witte W, Woodford N: Emergence and spread of vancomycin resistance among enterococci in Europe. Euro Surveill. 20;13(47), 2008 
122. Wilson S, Greer B, Hooper J, Zijlstra A, Walker B, Quigley J, Hawthorne S: The membrane-anchored serine protease, TMPRSS-2, activates PAR-2 in prostate cancer cells. Biochem J. 15;388(PT 3): 967-72, 2005

123. Winter SE, Raffatellu M, Wilson RP, Rüssmann H, Bäumler AJ: The Salmonella enterica serotype Typhi regulator TviA reduces interleukin-8 production in intestinal epithelial cells by repressing flagellin secretion. Cell Microbiol. 10(1):247-61, 2008

124. Wu Q, Parry G: Hepsin and prostate cancer. Front Biosci. 1;12:5052-9, 2007

125. Wu Q, Yu D, Post J, Halks-Miller M, Sadler JE, Morser J: Generation and characterization of mice deficient in hepsin, a hepatic transmembrane serine protease. J Clin Invest 101: 321-6, 1998

126. Yamada K, Takabatake T, Takeshima K: Isolation and characterization of three novel serine protease genes from Xenopus laevis. Gene 252: 209-216, 2000

127. Yu IS, Chen HJ, Lee YS, Huang PH, Lin SR, Tsai TW, et al.: Mice deficient in hepsin, a serine protease, exhibit normal embryogenesis and unchanged hepatocyte regeneration ability. Thromb Haemost 84: 865-70, 2000

128. Yuan X, Zheng X, Lu D, Rubin DC, Pung CY, Sadler JE: Structure of murine enterokinase (enteropeptidase) and expression in small intestine during development. Am J Physiol 274: G342-G349, 1998

129. Yun Kim, Park D, Oh M, Sellamuthu S, Park WJ: Detection of sitespecific proteolysis in secretory pathways. Biochem Biophys Res Commun 296: 419-424, 2002

130. Zacharski LR, Ornstein DL, Memoli VA, Rousseau SM, Kisiel W: Expression of factor VII activating protease, hepsin, in situ in renal cell carcinoma. Thromb Haemost 79: 876-7, 1998

131. Zamolodchikova TS, Sokolova EA, Lu D, Sadler JE: Activation of recombinant proenteropeptidase by duodenase. FEBS Lett 466: 295-299, 2000

132. Zeeuwen PL: Epidermal differentiation: the role of proteases and their inhibitors. Eur J Cell Biol. 83(11-12):761-73, 2004 
133. Zeng L, Cao J, Zhang X: Expression of serine protease SNC19/matriptase and its inhibitor hepatocyte growth factor activator inhibitor type 1 in normal and malignant tissues of gastrointestinal tract. World $\mathbf{J}$ Gastroenterol. 21;11(39):6202-7, 2005

134. Zhang L, Li N, Caicedo R, Neu J: Alive and dead Lactobacillus rhamnosus GG decrease tumor necrosis factor-alpha-induced interleukin-8 production in Caco-2 cells. J Nutr. 135(7):1752-6, 2005 


\section{Abbildungsverzeichnis}

Abb. 1.1 Schematischer Aufbau der Matriptase- und Corin-Subfamilie............................ 3

Abb. 1.2 Schematische Proteinstruktur der 20 bekannten humanen TTSP ........................5

Abb. 2.1 Exemplarisches Ergebnisprotokoll einer real-time quantitativen

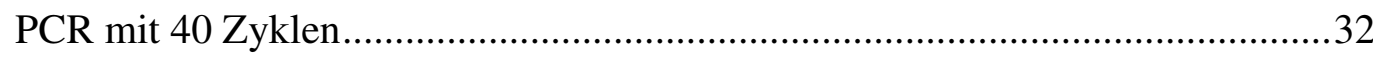

Abb. 2.2 Exemplarisches Beispiel eines Pipettierschemas mit Primer-Probe-Matrix.........34

Abb. 2.3 Exemplarisches Beispiel eines Pipettierschemas mit Verdünnungsreihe

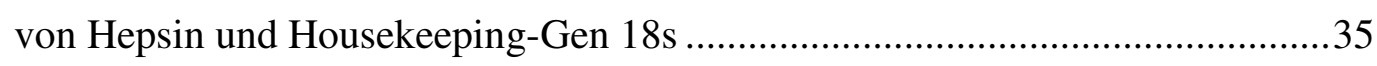

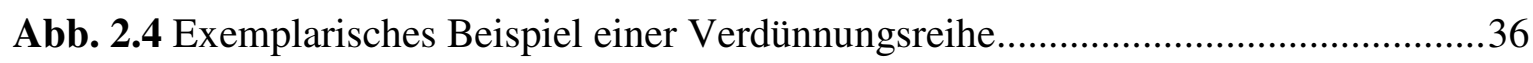

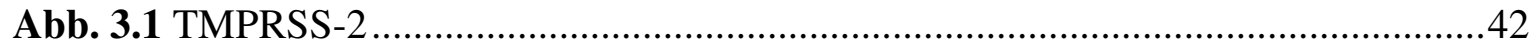

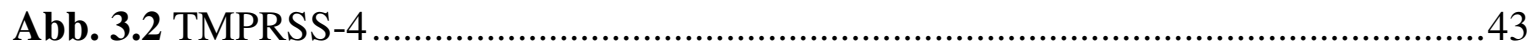

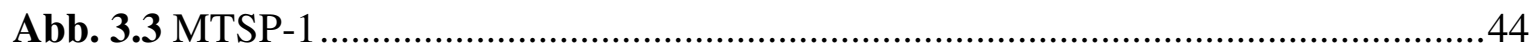

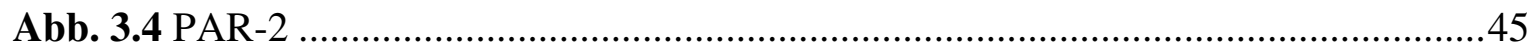

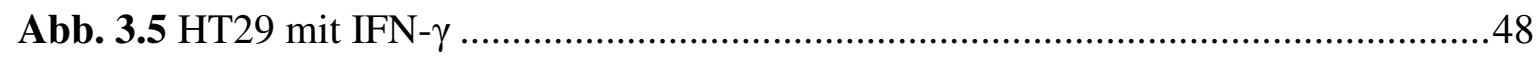

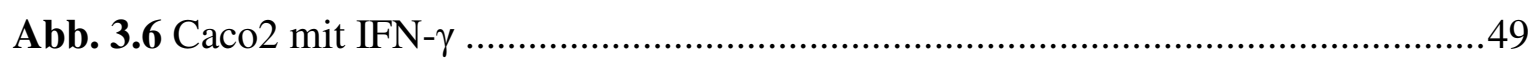

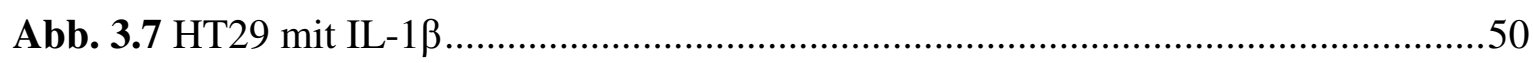

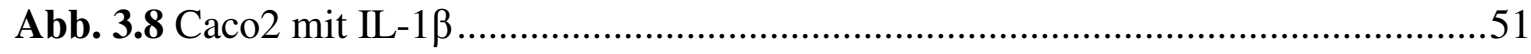

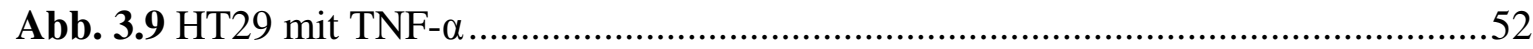

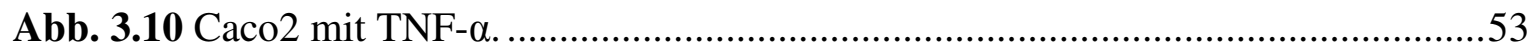

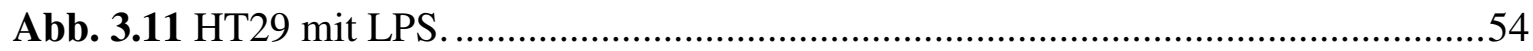

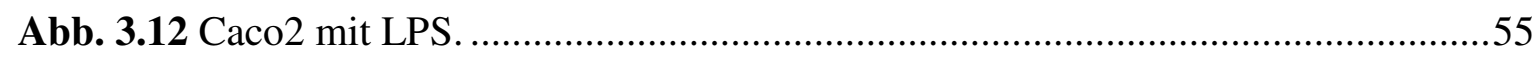

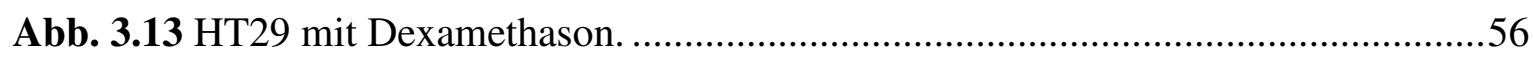

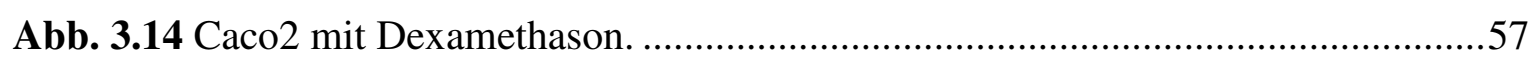

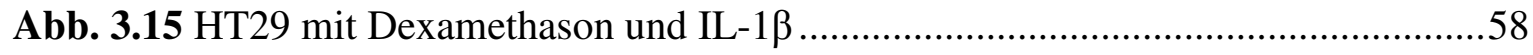

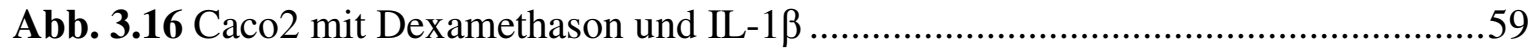

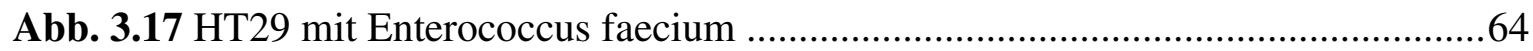

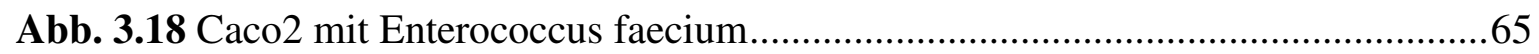

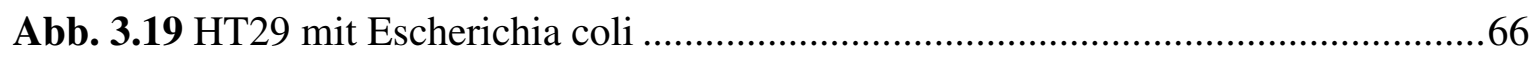

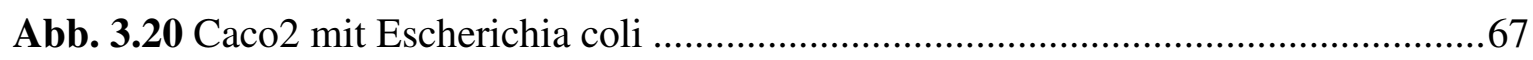

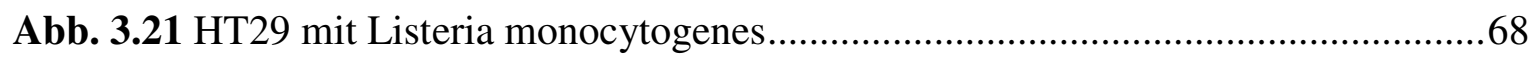

Abb. 3.22 Caco2 mit Listeria monocytogenes..................................................................69

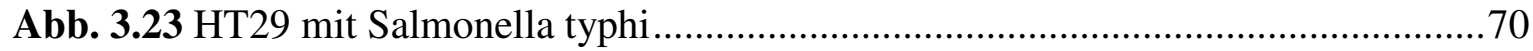

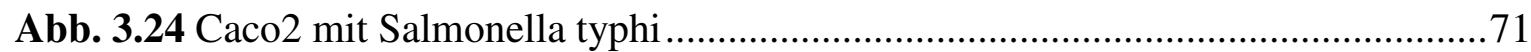




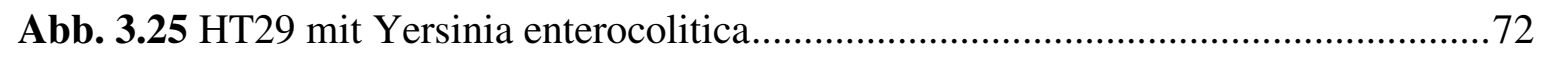

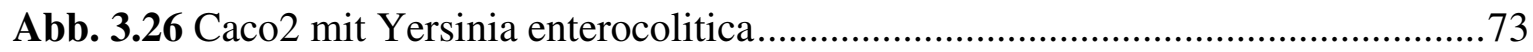

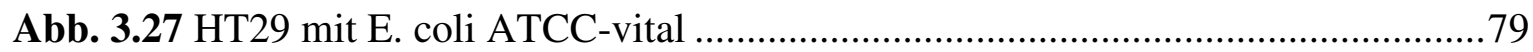

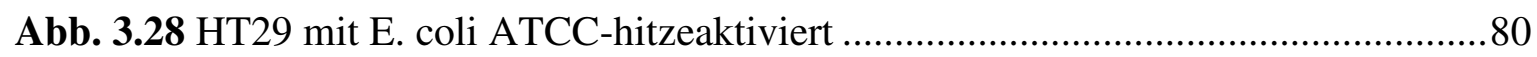

Abb. 3.29 HT29 mit E. coli ATCC-Überstand ................................................................ 81

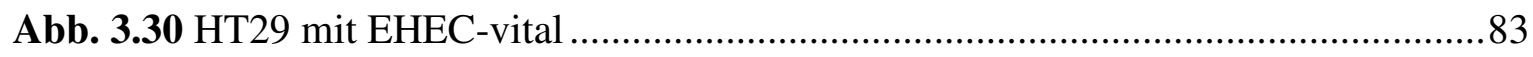

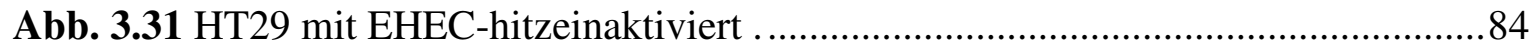

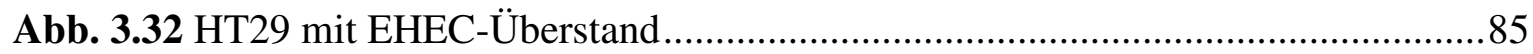

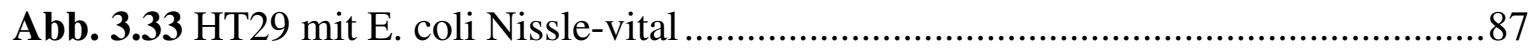

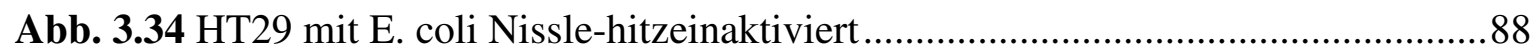

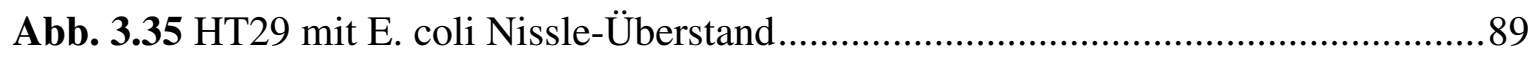

Abb. 3.36 Caco2 mit E. coli ATCC-vital. ....................................................................... 91

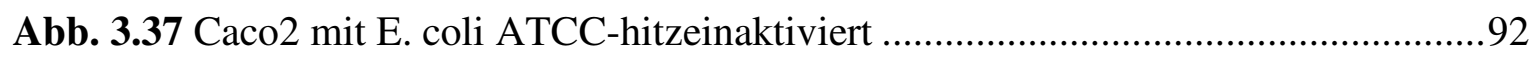

Abb. 3.38 Caco2 mit E. coli ATCC-Überstand. ............................................................... 93

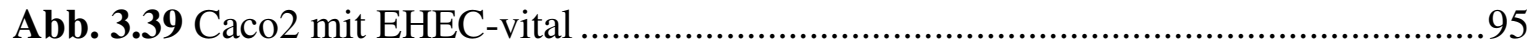

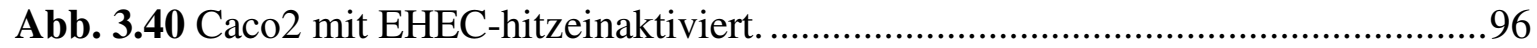

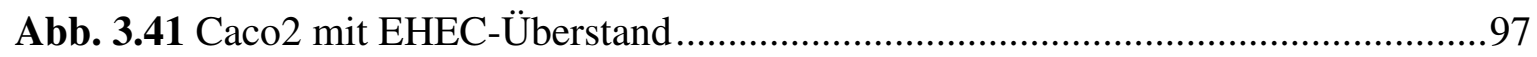

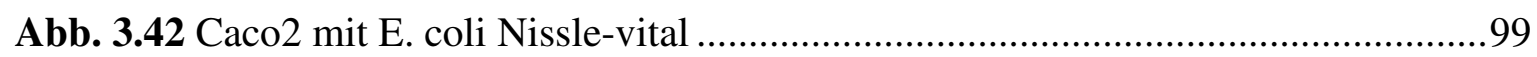

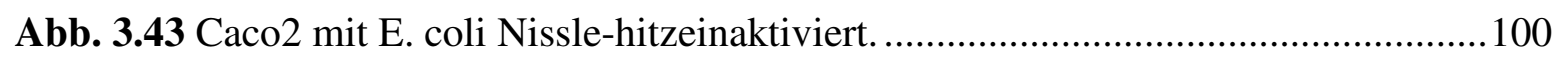

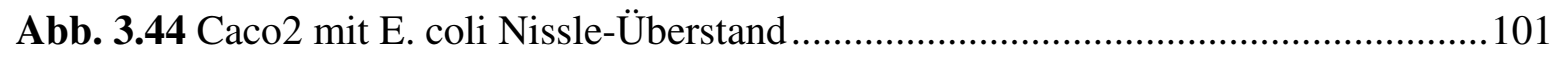




\section{Tabellenverzeichnis}

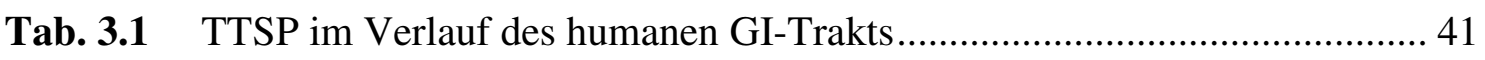

Tab. 3.2 Ergebnisse der nonparametrischen Paarvergleiche mittels

Wilcoxon-Tests .46

Tab. 3.3.1 TTSP mit HT29 in Abhängigkeit von proinflammatorischen Zytokinen, LPS und Dexamethason 60

Tab. 3.3.2 TTSP mit Caco2 in Abhängigkeit von proinflammatorischen Zytokinen, LPS und Dexamethason 60

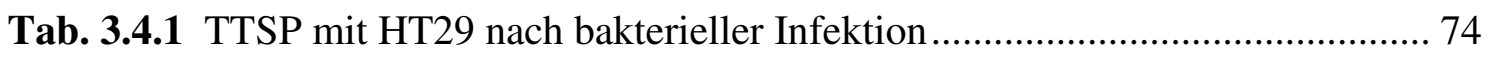

Tab. 3.4.2 TTSP mit Caco2 nach bakterieller Infektion ............................................ 74

Tab. 3.5.1 TTSP mit HT29 und verschiedenen E. coli-Stämmen............................... 103

Tab. 3.5.2 TTSP mit Caco2 und verschiedenen E. coli-Stämmen............................... 103 


\section{Verzeichnis der akademischen Lehrer}

Meine akademischen Lehrer waren Damen/ Herren in Marburg:

- Arnold, R., Prof. Dr., Zentrum für Innere Medizin, SP Verdauungs- und Stoffwechselkrankheiten

- Aumüller, G., Prof. Dr., Mikroskopische Anatomie, Anatomisches Institut

- Bach, T., Prof. Dr., Fachbereich Chemie

- Basler, H.-D., Prof. Dr. Dr., Institut für Medizinische Psychologie

- Baum, E., Prof. Dr., Abteilung für Allgemeinmedizin, Präventive- und Rehabilitative Medizin

- Becker, H., PD Dr., Zentrum für Innere Medizin, SP Pneumonologie

- Christiansen, H., PD Dr., Zentrum für Kinder- und Jugendmedizin

- Czubayko, F., Prof. Dr., Institut für Pharmakologie und Toxikologie

- Daut, J., Prof. Dr. Dr., Einführung in die Klinische Medizin, Fachbereich Humanmedizin

- Eilers, M., Prof. Dr., Institut für Molekularbiologie und Tumorforschung

- Feuser, B., PD. Dr., Fachbereich Physik

- Geus, A., Prof. Dr., Fachbereich Geschichte der Medizin

- Gotzen, L., Prof. Dr., Klinik für Unfallchirurgie

- Griss, P., Prof. Dr., Klinik für Orthopädie und Rheumatologie

- Gudermann, T., Prof. Dr., Institut für Pharmakologie und Toxikologie

- Happle, R., Prof. Dr., Klinik für Dermatologie und Allergologie

- Hellinger, A., PD Dr., Klinik für Visceral-, Thorax- und Gefäßchirurgie

- Hoffmann, R., Prof. Dr., Klinik für Urologie und Kinderurologie

- Jungclas, H., Prof. Dr., Radiologie und Strahlenschutz

- Kern, H. F., Prof. Dr., Institut für Zytobiologie und Zytopathologie

- Klenk, H.-D., Prof. Dr., Medizinisches Zentrum für Hygiene und Med. Mikrobiologie

- Koolmann, J., Prof. Dr., Institut für Physiologische Chemie

- Krieg, J.-C., Prof. Dr., Klinik für Psychatrie und Psychotherapie

- Kroll, P., Prof. Dr., MZ für Augenheilkunde

- Lammel, E., Prof. Dr., Institut für Normale und Pathologische Physiologie 
- Lang, R.E., Prof. Dr., Institut für Normale und Pathologische Physiologie

- Moll, R., Prof. Dr., Institut für Pathologie

- Mutters, R., Prof. Dr., Institut für Med. Mikrobiologie und Krankenhaushygiene

- Oertel, W. H., Prof. Dr., Klinik für Neurologie

- Remschmidt, H., Prof. Dr. Dr., Klinik für Psychatrie und Psychotherapie des Kindes- und Jugendalters

- Renz, H., Prof. Dr., Klinische Chemie und Hämatologie

- Rothmund, M., Prof. Dr., Klinik für Visceral-, Thorax- und Gefäßchirurgie

- Schäfer, H., Prof. Dr., Institut für Medizinische Biometrie und Epidemiologie

- Schmidt, S., Prof. Dr., Zentrum für Frauenheilkunde und Geburtshilfe

- Suske, G., Prof. Dr., Institut für Molekularbiologie und Tumorforschung

- Weihe, E., Prof. Dr., Makroskopische Anatomie, Anatomisches Institut

- Werner, J. A., Prof. Dr., Klinik für Hals-, Nasen und Ohrenheilkunde

- Westermann, R., PD Dr., Anatomische Seminare, Anatomisches Institut

- Wulf, H., Prof. Dr., Klinik für Anästhesie und Intensivtherapie 


\section{Danksagung}

An dieser Stelle möchte ich mich bei all den Personen bedanken, die zum gelingen dieser Arbeit auf vielfältige Weise beigetragen haben:

- bei Herrn Prof. Dr. R. Arnold als ehemaligen Direktor und Herrn Prof. Dr. T. M. Gress als derzeitigen Direktor der Klinik für Innere Medizin, SP Gastroenterologie, Endokrinologie und Stoffwechsel

- bei meinem Doktorvater Herrn PD Dr. Stephan Böhm

- bei Herrn Dr. Zimmermann, Mikrobiologisches Institut

- bei den ehemaligen MitarbeiterInnen des Forschungsbereichs Ebene -3, insbesondere Anne Bosshammer

- bei Lars Gerken und Michael Himpel, meinen beiden besten Freunden, Kommilitonen, Mitarbeitern und Doktoranden der Arbeitsgruppe

Ein besonderer Dank gilt meinen Eltern und meiner Schwester, welche mich immer unterstützt haben. Nicht zuletzt meinen Freunden, die mir mit Rat und Tat bei Seite standen. Darin fand ich immer wieder Kraft und Sicherheit, die mich bei der Erstellung dieser Arbeit geleitet haben.

Danke Michaela, ohne dich wäre diese Arbeit nicht vollendet worden. 


\section{Ehrenwörtliche Erklärung}

Ich erkläre ehrenwörtlich, dass ich die dem Fachbereich Medizin Marburg zur Promotionsprüfung eingereichte Arbeit mit dem Titel

\section{Expression und Regulation von Typ II transmembranären Serin Proteasen (TTSP) auf humanen intestinalen Epithelzellen}

im Forschungsbereich und Institut der Klinik für Innere Medizin, SP Gastroenterologie und Endokrinologie des Fachbereiches Medizin der Philipps-Universität Marburg und des Universitätsklinikums Gießen und Marburg, Standort Marburg, unter Leitung von PD Dr. Stephan Böhm ohne sonstige Hilfe selbst durchgeführt und bei der Abfassung der Arbeit keine anderen als die in der Dissertation angeführten Hilfsmittel benutzt habe.

Ich habe bisher an keinem in- und ausländischen Medizinischen Fachbereich ein Gesuch um Zulassung zur Promotion eingereicht noch die vorliegende oder eine andere Arbeit als Dissertation vorgelegt.

Teile der vorliegenden Arbeit wurden als Posterpräsentation bei der 59. Tagung der Deutschen Gesellschaft für Verdauungs- und Stoffwechselkrankheiten in Leipzig vom 01.-04.09.2004 unter oben genanntem Titel veröffentlicht. 